\title{
OPERATION AND PERFORMANCE OF A BIPHASE TURBINE POWER PLANT \\ AT THE CERRO PRIETO GEOTHERMAL FIELD
}

\author{
Final Report To \\ CALIFORNIA ENERGY COMMISSION \\ Agreements 912-93-001 \\ And 912-93-001 A.1 \\ U.S. DEPARTMENT OF ENERGY \\ Cooperative Agreement Number DE-PS02-92-CH10516
}

Progress Report To

COMISIÓN FEDERAL DE ELECTRICIDAD

And

E\&CO.

Submitted by

Douglas Energy Company

Placentia, California

September 1, 2000 


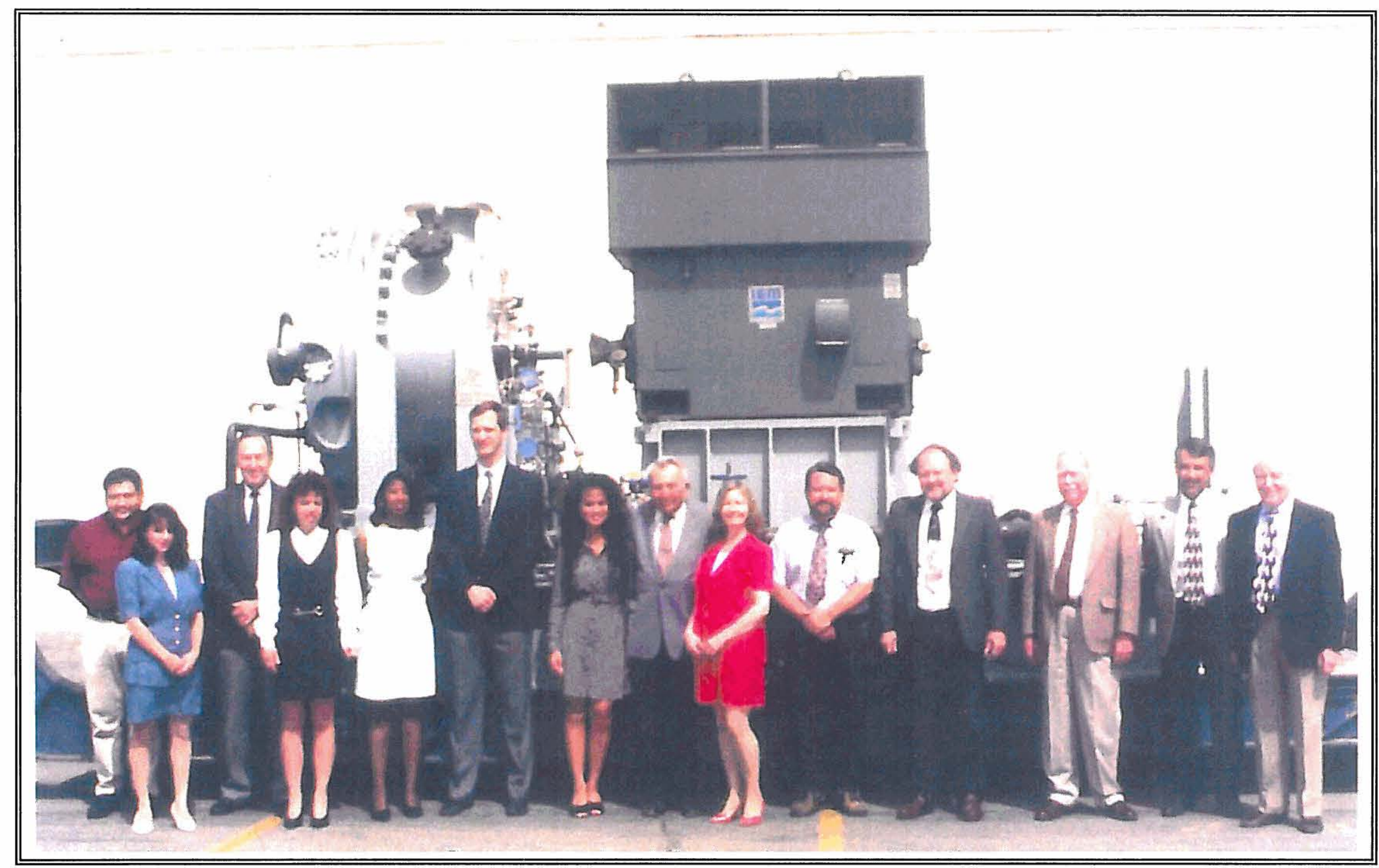

Frontispiece 1 Biphase Geothermal Turbine and Douglas Energy Company Staff 


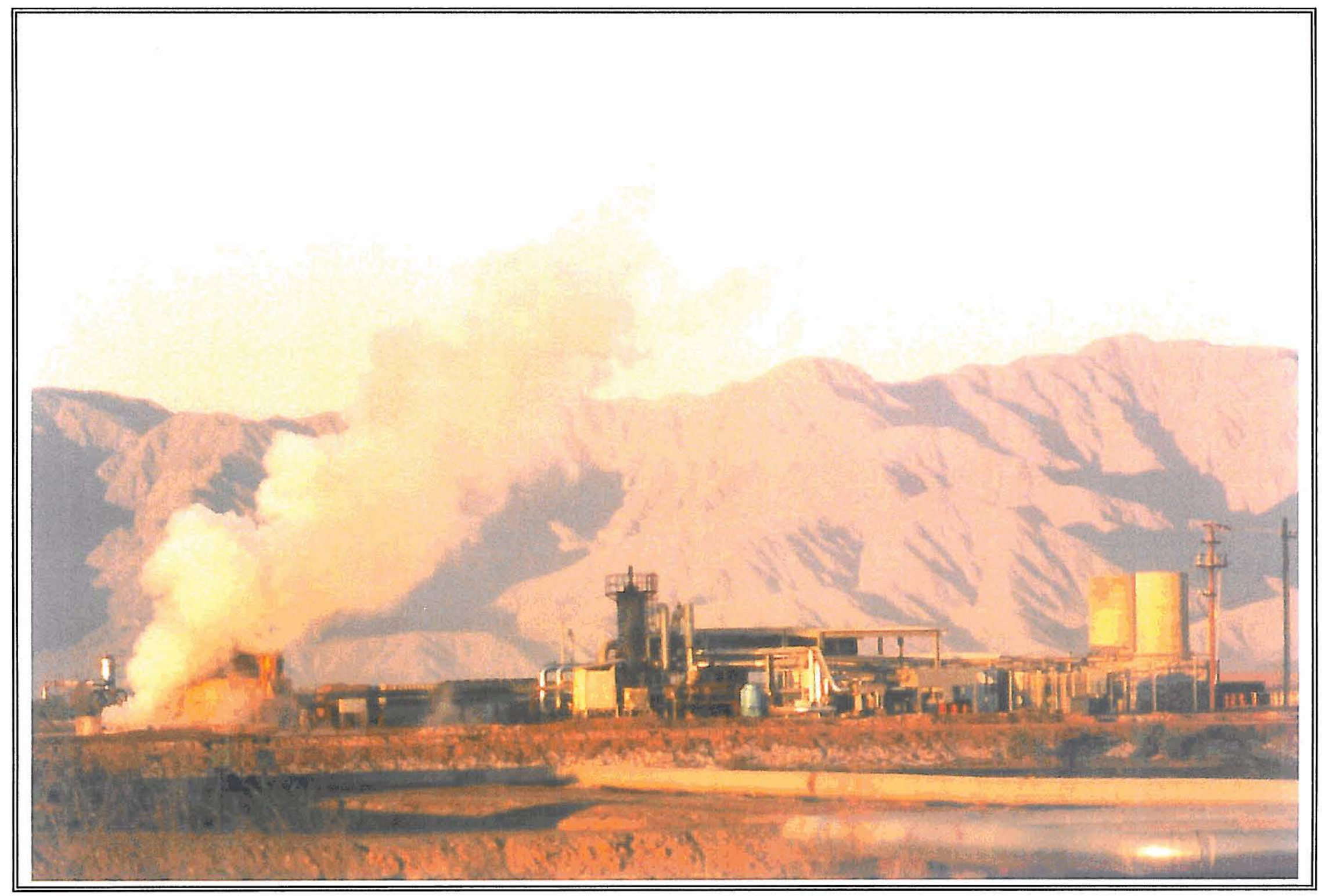

Frontispiece 2

Biphase Power Plant Operating at Cerro Prieto 
Abstract - -

Acknowledgement - -

1. Introduction -

1.1 Background -

1.2 Objectives - -

1.3 Design Philosophy -

1.4 General Description of Project - 10

2. Improvement of Geothermal Power Production - 14

3. Biphase Turbine Theory - 21

3.1 Two-Phase Nozzle - - 21

3.2 Rotary Separator---

3.3 Gas Blading -

3.4 Diffuser --_- 27

3.5 Euler Turbine Passage -

3.6 Turbine Code Output - 29

4. Project Experience - 30

4.1 Financing - 30

4.2 Design-- 30

4.2.1 Process Design - 30

4.2.1.1 Background -- 30

4.2.1.2 Biphase Turbine Plant Process Design - 31

4.2.2 Balance of Plant Design - 33

4.2.2.1 Steam Turbine - 33

4.2.2.2 Biphase Turbine Lubrication System - 33

4.2.2.3 Process Control and Instrumentation System - 33

4.2.2.4 High-Pressure Water-Jet Rotor Wash System - - 34

4.2.2.5 Chemical Feed System - 34

4.3 Construction - - 35

4.3.1 Biphase Turbine Generator - 35

4.3.2 Balance of Plant -- 38

4.4 Tests - - 40

4.4.1 Hydrostatic Test - 40

4.4.2 Bypass Valve Test - 40

4.4.3 Pre-Operational Tests -

4.4.3.1 Electrical System Pre-Operational Tests - - 41

4.4.3.2 Biphase Turbine Preheat and Steam Startup Tests - -

4.4.3.3 Biphase Turbine Over-Speed Protection Tests - 
4.4.4 Synchronization Tests - 45

4.4.5 Switch-On Test -

4.4.6 Production Test --- 45

4.4.7 Availability Test -- 46

4.5 Operational Experience -

4.5.1 Biphase Turbine -- 46

4.5.1.1 Startup - 46

4.5.1.2 Performance - - 46

4.5.1.3 Solids -- 47

4.5.1.4 Bearings - - 48

4.5.1.5 Seals - - 49

4.5.2 Balance of Plant - 49

4.5.2.1 Startup - 49

4.5.2.2 Performance - - 49

4.5.2.3 Chemical System - 50

4.5.2.4 Instrumentation - 50

4.5.2.5 Lubrication System - --- 51

4.5.2.6 Valves - 53

4.5.2.7 Control System - - 53

4.5.2.8 Well Pressure and Enthalpy Decline -

4.5.2.9 Project Subcontractors - 54

5. Electrical Generation Delivered to CFE - 55

6. Comparison of Predicted and Measured Performance -

7. Availability - 57

7.1 Biphase Turbine--- 57

7.2 Balance of Plant -

8. Improvements in the Biphase Turbine - 58

8.1 Dual Pressure Rotor Design -

8.2 Performance of Dual Pressure Rotor for Well 103

8.3 Design of Dual Pressure Rotor to Retrofit Existing Turbine -

9. Impact of Biphase Technology on Geothermal Power Production--a- 64

9.1 Cost of Power -

9.2 Increased Resource Utilization - 65

9.4 Reduction in Greenhouse Emissions - 68

9.5 Predicted Market - 68

10. Conclusions and Recommendations for Project and Technology - 70 
A. Updated Economics and Application Report

B. Operation Summary and Chronology

C. Chemical Analysis of Solids Deposits

D. Chemical Analysis of Steam and Brine Samples

E. As Built Mechanical Drawings and Electrical Drawings

F. Piping Proof Test Reports and Piping Lists

G. Bypass Valve Test Report

H. Protective Relay Test Report

I. Biphase Turbine Startup Analysis

J. Biphase Turbine Loss of Load Analysis

K. Summary Test Reports for Tests 1 thru 35

L. Maximum Power Test Report

M. Power Plant Operating Modes

N. Production Test

O. Steam Turbine Steam Seal Schematic

P. As Built Steam Turbine Electrical and Control Drawings

Q. Data System Input-Output Listing

R. Biphase Turbine Lubrication System

S. Valve List

T. Index of Contractors

U. Final Report on 12 RSB Tests

V. Final Payment Request Form (for State of California

W. Data Plots for Biphase Tests 1 thru 35

X. Raw Data Sheets for Biphase Tests 1 thru 35

Y. Code Output for Comparison of Measured with Predicted Power 


\begin{abstract}
A full scale, wellhead Biphase turbine was manufactured and installed with the balance of plant at Well 103 of the Cerro Prieto geothermal resource in Baja California. The Biphase turbine was first synchronized with the electrical grid of Comisión Federal de Electricidad on August 20, 1997. The Biphase power plant was operated from that time until May 23, 2000, a period of 2 years and 9 months. A total of $77,549 \mathrm{kWh}$ were delivered to the grid. The power plant was subsequently placed in a standby condition pending replacement of the rotor with a newly designed, higher power rotor and replacement of the bearings and seals.

The maximum measured power output of the Biphase turbine, $808 \mathrm{kWe}$ at 640 psig wellhead pressure, agreed closely with the predicted output, $840 \mathrm{kWe}$. When combined with the backpressure steam turbine the total output power from that flow would be increased by $40 \%$ above the power derived only from the flow by the present flash steam plant. The design relations used to predict performance and design the turbine were verified by these tests. The performance and durability of the Biphase turbine support the conclusions of the Economics and Application Report previously published, (Appendix A). The newly designed rotor (the Dual Pressure Rotor) was analyzed for the above power condition. The Dual Pressure Rotor would increase the power output to $2064 \mathrm{kWe}$ by incorporating two pressure letdown stages in the Biphase rotor, eliminating the requirement for a backpressure steam turbine.
\end{abstract}

The power plant availability was low due to deposition of solids from the well on the Biphase rotor and balance of plant problems. A great deal of plant down time resulted from the requirement to develop methods to handle the solids and from testing the apparatus in the Biphase turbine. Finally an online, washing method using the high pressure two-phase flow was developed which completely eliminated the solids problem. The availability of the Biphase turbine itself was $100 \%$ after implementation of this method in March 2000. However, failures of instrumentation and control system components led to additional plant down time and damage to the bearings and seals.

The enthalpy and pressure of well 103 declined substantially from the inception of the project. When the project was started the wellhead pressure and enthalpy were $760 \mathrm{psig}$ and $882 \mathrm{Btu} / \mathrm{lb}$, respectively. At the time the plant was placed in standby the corresponding values were only 525 psig and $658 \mathrm{Btu} / \mathrm{lb}$. This reduced the available plant power to only $400 \mathrm{kWe}$ making the project economically unfeasible.

However, replacement of the existing rotor with the Dual Pressure Rotor and replacement of the bearings and seals will enable the existing Biphase turbine to produce $1190 \mathrm{kWe}$ at the present well conditions without the backpressure steam turbine. Operation with the present staff can then be sustained by selling power under the existing Agreement with CFE. Implementation of this option is recommended with operation of the facility to continue as a demonstration plant.

Biphase turbine theory, design and performance are reported herein. The construction of the Biphase turbine and power plant and operational experience are detailed. Improvements in the Biphase turbine are indicated and analyzed. The impact of Biphase technology on geothermal power production is discussed and recommendations made. 


\section{Acknowledgement}

The present project was an ambitious undertaking by Douglas Energy Company, a small business concern. As is the case for many new technologies, conventional sources of financing could not be accessed. Support for the project was found from the following organizations:

- $\quad$ The U.S. Department of Energy - grant

- $\quad$ California Energy Company - test well at Coso Hot Springs

- The California Energy Commission - loan grant

- Calpine Corporation - engineering studies at Cerro Prieto

- $\quad$ Comisión Federal de Electricidad - project well, site and transmission line

- $\quad$ E \& Co - project loan

- $\quad$ ARB Inc - construction loan

- Multiphase Power and Processing Technologies - supplemental funding

We gratefully acknowledge this support without which the project could not have been completed.

In addition personal gratitude is extended to the people at these organizations who had the vision and courage to advocate advancement of this new technology - Jeff Hahn, Alicia Noyola, Dr. Gerardo Hiriart le Bert, Valentine Tiangco, Brad Goode, Christine Eibs-Singer and Ted Bond.

Finally, the project could not have been achieved without the dedication and sacrifices of the staff at Douglas Energy Company. Our thanks are signified by their inclusion in Frontispiece 1. 


\section{Introduction}

\subsection{Background}

The Biphase turbine was invented to improve the power production efficiency for geothermal resources and other two-phase processes. After developmental testing, a full size Biphase turbine unit was demonstrated with full flow from a geothermal well at Roosevelt Hot Springs, Utah, reference 1. This unit is shown during installation in figure 1 . The unit generated $1600 \mathrm{~kW}$ and demonstrated a $20 \%$ increase in power output above a single flash steam turbine. As a result of this 4,000-hour demonstration, the Electric Power Research Institute evaluated the Biphase turbine to be a "viable commercial technology", ibid.

The original Biphase turbine, although efficient in the generation of power from the separated brine, had two major limitations:

Three rotors were required to separate, generate power and pressurize the separated brine. This design feature increased the cost. The complexity of maintaining the speed of the three rotors at separate values increased the cost and difficulty of operation.

Only the brine kinetic energy was converted to shaft power. No method was provided to convert the kinetic energy of the separated steam to shaft power. For high enthalpy wells the benefit of the Biphase turbine was limited by the lack of a means to generate power from the steam phase.

In order to overcome these limitations an advanced Biphase turbine with a single rotor and steam blading was developed. This unit was successfully demonstrated with clean water and steam mixtures.

To demonstrate the applicability of the single rotor Biphase turbine to geothermal power production, a program was proposed to test the sub-scale unit, previously tested with clean water and steam, on a geothermal well. This demonstration was proposed to be followed by demonstration of a full size commercial unit for a two-year period in a commercial geothermal flash steam power plant.

The proposal was accepted by the U.S. Department of Energy, reference 2. The project was joined by the California Energy Commission, in response to a geothermal loan grant application, reference 3. The sub-scale site was provided by California Energy Company at Coso Hot Springs.

The sub-scale tests were successful. Over 700 hours were logged on the turbine, shown in figures 2 and 3. The specific power was increased from $4 \mathrm{~kW} / \mathrm{lb} / \mathrm{s}$ to $7 \mathrm{~kW} / \mathrm{lb} / \mathrm{s}$ by the addition of the steam blading. The measured power and efficiency agreed with predictions, reference 4 .

The project well and site for the full size demonstration were provided by Comision Federal de Electricidad at the Cerro Prieto geothermal field, reference 5. An Agreement was concluded with $\mathrm{CFE}$ to sell the project power in order to offset the operating expenses. 
The project well. Number 103, at the time of the Agreement had an enthalpy and pressure which were too large to take the full expansion in the Biphase turbine alone. The loan grant with the California Energy Commission was expanded to include the purchase and installation of a backpressure steam turbine, reference 6 .

Delays in funding and construction required supplemental funding, which was provided by E\&Co. and a construction loan from the contractor $\mathrm{ARB}$, Inc.

The Biphase turbine installation was completed first and that unit operated alone. Later the steam turbine installation was completed and operated, first with CFE steam and subsequently with separated steam directly from the Biphase turbine.

\subsection{Objectives}

The initial objectives of the present project were:

- Design and manufacture a full size Biphase turbine suitable for commercial operation with two-phase, high pressure, high enthalpy geothermal wellhead flow

- Design and install a geothermal topping power plant using the Biphase turbine and a backpressure steam turbine

- Demonstrate the performance, reliability and endurance of the Biphase turbine

- Determine the performance, reliability and endurance of the geothermal topping power plant

- Utilize the above data on performance and cost to evaluate the economics and predicted market of Biphase turbine systems

These objectives were predicated upon operation with a solids free two-phase well flow. Solids free flow was one of the criteria for the selection of well 103 for the project by CFE. However, after installation and startup extensive solids were found to occur which caused extensive additional research and testing before a satisfactory method was developed to handle the solids. A later objective that must be added to the list is:

- Demonstration of the ability of the Biphase turbine to operate with two-phase wellhead flow with solids

As will be detailed in the report all of the above objectives were met. 


\subsection{Design Philosophy}

The design philosophy for the project in descending order of importance was:

- Startup, operation and shutdown of the Biphase power plant must not affect operation of the geothermal well

- The Biphase turbine and balance of plant design must be reliable and suitable for the high pressure, high temperature brine and steam mixture

- The control system should be designed for fail safe operation in the event of power loss, equipment failures and instrumentation and control system failures

- The design was to be based on Well 103 operating conditions as provided by CFE

- The Biphase turbine design should be based on existing performance codes and on the subscale design

- Operation of the plant on a 24 hour basis should be possible with minimum staffing on site

- The use of reconditioned equipment to reduce cost was permissible as long as safety is not compromised

As will be discussed in the report, the first two criteria were completely satisfied, as was the Biphase turbine design and the plant operability. However, the control system that was supplied and programmed by a major company suffered failures, which caused damage to the Biphase turbine seals and bearings. As discussed above the decline in wellhead enthalpy and pressure and the presence of solids caused extensive harm to the project schedule and economic viability. Finally, unsatisfactory performance by several of the reconditioned valves used required their replacement with new valves, adding cost and further schedule delays to the project. For future projects testing of the well before plant design is recommended, as is exclusion of reconditioned equipment from the plant.

\subsection{General Description of Project Experience}

The Biphase turbine project at Cerro Prieto was formally initiated in August 1994 with the execution of a Research Agreement with Comisión Federal de Electricidad (CFE).

The first operation of the Biphase turbine, figure 4, was June 26, 1997. The first synchronization with the CFE grid was August 20,1997. Severe solids problems were encountered which produced unacceptably high vibrations and damage to the brine outlet structure (diffuser).

An online washing system was designed and installed. It enabled operation of the Biphase turbine with full well flow and at full power on November 20, 1997. The maximum power generated for the CFE grid was $808 \mathrm{kWe}$ with a wellhead pressure of 640 psig. However, the online washing system was only partially effective and the turbine was shut down to implement an improved system.

Research and intermittent testing and operation in 1998 resulted in a successful high-pressure water, online washing system that was demonstrated in August of 1998. Maximum power of $750 \mathrm{kWe}$ was generated for the CFE grid with a two-phase inlet pressure of $606 \mathrm{psig}$. Problems with the reconditioned valves prevented further operation. 
The proceeds from the sale of the Biphase technology to Dresser-Rand, in October of 1998, were used to improve the power plant, adding new valves, and to complete the installation of the backpressure steam turbine. During the construction period the Biphase turbine was again operated. During June of 1999 a maximum power of $560 \mathrm{kWe}$ was generated for the CFE grid at an inlet pressure of $540 \mathrm{psig}$. This operation was terminated by the failure of the lubrication system that caused damage to the bearings. New bearings were ordered and the lubrication system was redesigned and a new lubrication system built.

The backpressure steam turbine, figure 5, was commissioned in December of 1999 with CFE steam. Power of $600 \mathrm{kWe}$ was generated and fed into the CFE grid.

Completion of the new lubrication system and the installation of new bearings and seals enabled operation of the Biphase turbine to resume in March 2000. The wellhead pressure and enthalpy had declined such that the maximum inlet pressure at this time was only 475 psig and the maximum power was $395 \mathrm{kWe}$ (The generator efficiency was so low at the extreme part load condition that the actual shaft power was $620 \mathrm{~kW}$ ). A continuous run of 50 hours was accomplished. Solids were controlled with an improved online washing system that used the two-phase flow from the well instead of a secondary water pump. The test was voluntarily terminated to repair a leaking seal.

The unit was re-started on April 6, 2000. Operation was stable but was terminated by a CFE power outage. The emergency shutdown system worked well. However, a gasoline engine driven pump was added to enable water to be provided to the bearings in the event of a power outage.

On April 26 the Biphase turbine was restarted. Once again stable operation was demonstrated. The unit generated a maximum of $310 \mathrm{kWe}$ with partial flow from the well. Partial flow was required because at the then low wellhead pressure, 525 psig, the existing Biphase turbine nozzles could not swallow the entire flow. The unit was operated continuously for 170 hours and shut down when an Annubar flow meter failed, leaking brine and steam to the surroundings.

During this period of operation the steam turbine was operated with the Biphase turbine. Due to the low wellhead pressure and enthalpy the maximum steam turbine power that could be generated was $170 \mathrm{kWe}$. The total of the Biphase turbine plus steam turbine at this condition was only marginally better than the Biphase alone so the decision was made to operate the Biphase turbine by itself. Also during this operation period a well upset occurred which produced a massive amount of solids into the turbine. High vibrations resulted. However, repetitive operation of the online washing system eventually cleaned the rotor and reduced the vibrations to normal levels.

The leaking flow meter was isolated from the system, seals were inspected and re-built and the Biphase turbine re-started on May $23^{\text {rd }}$. Operation was extremely stable for 70 hours when failure of an ABB "modcell" in the control system occurred. The particular modcell that failed controlled the lubrication system causing damage to the bearings and seals. The power plant was shutdown and placed in a standby condition.

A summary of the three (3) years of power plant operations is provided in Appendix B, Operation Chronology and Summary. A total of 35 periods of operation and data sheets are summarized. 
The Biphase turbine achieved several milestones:

- Over 430 hours of operation at the full wellhead pressure and nozzle velocity of over 1000 feet/second has been demonstrated with no measurable erosion or corrosion from the twophase flow.

- The measured power - $808 \mathrm{kWe}$ - at the highest wellhead pressures tested - $640 \mathrm{psig}$ - agreed closely with the predictions of the Biphase turbine design code.

- Off-design power measured - as the wellhead pressure declined to $525 \mathrm{psig}$ - agreed to within $19 \%$ with the turbine code predictions.

- An online washing system for solids removal that uses the two-phase well flow was successfully demonstrated. Steady state operation with low vibration levels at 2-4 mils was routinely achieved.

- The water lubricated, silicon carbide bearings were resistant to high vibration levels $-10-12$ mils - resulting from high solids episodes.

- Startup, speed control and synchronization with two-phase well flow were routinely performed.

- A new rotor design was identified which enables two pressure expansions in a single rotor thereby producing more power and eliminating the need for a back pressure steam turbine. This rotor, the Dual Pressure Rotor (DPR) is described in Section 8 and results of application to well 103 are given.

The complete power plant also demonstrated stable operation:

- The Biphase turbine and backpressure steam turbine were operated together with the Biphase turbine feeding steam directly to the steam turbine. The pressure split between the two turbines was varied by the controls and the total power variation measured. Power from both turbines was fed into the grid simultaneously.

- Automatic control of the wellhead pressure was routinely accomplished by the use of a bypass valve. During trips the bypass valve opened quickly enough to maintain the flowing wellhead pressure within the limits set by CFE.

The operation was automated such that the power plant could and was operated by skilled local operators. Remote monitoring and control of the power plant via modem was demonstrated.

Overall the project results were very positive. The single rotor Biphase turbine performance was verified at full size on an operating high pressure, high enthalpy well. The durability and solids handling capability demonstrated during this project as well as the durability demonstrated by previous full size three-rotor Biphase turbines at Roosevelt Hot Springs and Desert Peak enable confidence in the application to commercial geothermal power generation. The improved rotor design identified, when demonstrated, can have a major impact on the market for the Biphase turbine.

The balance of plant problems, while having major impact on the project schedule and cost, are all readily correctable. Impact of the most serious problem - the decline in wellhead pressure and 
enthalpy - can be substantially lessened by the Dual Pressure Rotor which enables more power generation from declining wells and which, by eliminating the backpressure steam turbine, reduces the capital cost and enables the power plant to be readily moved. 


\section{Improvement of Geothermal Power Production}

The rotary separator turbine was invented in 1975, reference 7 . This turbine, the Biphase turbine generates power from mixtures of gas and liquid. For geothermal flash steam power plants, application of the Biphase turbine to the wellhead flow can generate power from the available twophase energy otherwise dissipated in frictional heating in the flash process. To illustrate the improvement in efficiency possible, the power derived from a representative well at Cerro Prieto with and without Biphase turbines is analyzed below.

Conventional flash steam power plants are shown in figures 6 and 7. The first has one flash stage and the second two flash stages. The flash across an orifice or valve occurs at constant enthalpy for a single flash system. The pressure drop across the flash doesn't produce any useful work. Instead the frictional heat makes additional steam for the power plant. The thermodynamic processes for a single stage flash system is illustrated in figure 8.

For an example of the power derived from the resource by geothermal plants we will use a well from Cerro Prieto that feeds a dual flash system. Consider well number E-54. The current conditions are:

$$
\begin{array}{ll}
\text { Wellhead Pressure, po } & 614 \text { psia } \\
\text { Wellhead Flow rate, mo } & 298,336 \mathrm{lb} / \mathrm{h} \\
\text { Wellhead Enthalpy, ho } & 637.39 \mathrm{~B} / \mathrm{lb} \\
\text { First Flash Pressure, p1 } & 200 \mathrm{psia} \\
\text { Second Flash Pressure, p2 } & 67 \text { psia } \\
\text { Condensing Pressure, p3 } & 3 \text { psia (assumed) }
\end{array}
$$

For these analyses we will neglect piping losses, assuming the steam turbine inlet pressures are equal to the separator pressures. For the actual case the piping losses result in lower steam turbine inlet pressure and steam flow. This results in lower power produced by conventional flash systems and increases the effectiveness of topping turbines or bottoming plants, since they are not affected by the gathering system losses.

The ideal power that could be generated from the well is:

$$
\begin{aligned}
& \mathrm{Pi}=\mathrm{m}_{0}\left(\mathrm{~h}_{0}-\mathrm{h}_{3 \mathrm{i}}\right) \\
& \text { Where: } \mathrm{h}_{3 \mathrm{i}}=\text { isentropic enthalpy at condensing pressure }
\end{aligned}
$$

For the well conditions and the condensing pressure of 3 psia:

$$
\mathrm{s}_{\mathrm{o}}=0.846776 \mathrm{~B} / \mathrm{lb} \mathrm{F}
$$

And $\quad \mathrm{h}_{3 \mathrm{i}}=497.706 \mathrm{~B} / \mathrm{lb}$ 
Therefore the ideal power is:

$$
\begin{aligned}
P_{i} & =(298,336)(637.39-497.706) /(3413) \\
& =\mathbf{1 2}, \mathbf{2 1 0} \mathbf{k W}
\end{aligned}
$$

The heat input is:

$$
\mathrm{Q}_{\mathrm{i}}=\mathrm{m}_{\mathrm{o}}\left(\mathrm{h}_{\mathrm{o}}-\mathrm{h}_{\mathrm{a}}\right)
$$

Where: $h_{a}=$ enthalpy of condensed liquid at ambient temperature

For an ambient temperature of $100 \mathrm{~F}, \mathrm{~h}_{\mathrm{a}}=67.759 \mathrm{~B} / \mathrm{lb}$

And $Q_{i}$ is:

$$
\begin{aligned}
Q_{i} & =(298,336)(637.39-67.759) \\
& =169,941,434 \mathrm{~B} / \mathrm{h}
\end{aligned}
$$

The ideal heat rate is:

$$
\begin{aligned}
\mathrm{HR}_{\mathbf{i}} & =169,941,434 / 12,210 \\
& =\mathbf{1 3 , 9 1 8} \mathbf{B} / \mathbf{k W h}
\end{aligned}
$$

The ideal efficiency is:

$$
\begin{aligned}
\eta_{\mathrm{i}} & =3413 / 13,918 \\
& =.245
\end{aligned}
$$

If the wellhead flow were flashed in a single stage flash the existing single flash pressure is approximately $100 \mathrm{psig}$. The flash conditions are isenthalpic, i.e. ho $=\mathrm{h}_{\mathrm{i}}$

Therefore the steam resulting from the flash can be determined from the pressure, $\mathrm{p}_{1}$ and enthalpy $\mathrm{h}_{0}$ :

$$
\mathrm{p}_{1}=115 \text { psia }
$$

The quality is:

$$
\begin{aligned}
\mathrm{x}_{1} & =\mathrm{x}\left(\mathrm{p} 1, \mathrm{~h}_{0}\right) \\
& =.3724
\end{aligned}
$$

The steam flow is: 


$$
\begin{aligned}
m_{\text {IV }} & =(.3724)(298,336) \\
& =111,100 \mathrm{lb} / \mathrm{h}
\end{aligned}
$$

For a $75 \%$ central turbine efficiency the power generated by the central steam turbine from this flow is:

$$
\begin{aligned}
& \mathrm{P}_{\text {cst }}=(.75)\left(\mathrm{m}_{1 \mathrm{v}}\right)\left(\mathrm{h}_{1 \mathrm{v}}-\mathrm{h}_{3 \mathrm{i}}\right) \\
& \text { Where: } \mathrm{h}_{1 \mathrm{v}}=\text { enthalpy of steam at pressure } \mathrm{p}_{\mathrm{l}} \\
& \mathrm{h}_{3 \mathrm{i}}=\text { isentropic enthalpy of steam exit flow from turbine at condenser } \\
& \text { pressure }
\end{aligned}
$$

For the conditions above:

$$
\begin{aligned}
& \mathrm{h}_{1 \mathrm{v}}=1190.52 \mathrm{~B} / \mathrm{lb} \\
& \mathrm{s}_{1 \mathrm{v}}=1.59221 \mathrm{~B} / \mathrm{lbF} \\
& \mathrm{h}_{3 \mathrm{i}}=945.795 \mathrm{~B} / \mathrm{lb}
\end{aligned}
$$

and the power is:

$$
\begin{aligned}
P_{\text {cst }} & =(.75)(111,100)(1190.52-945.795) / 3413 \\
& =\mathbf{5 9 7 5} \mathbf{~ k W}
\end{aligned}
$$

The heat rate for a single flash would therefore be

$$
\begin{aligned}
\mathrm{HR} & =(169,941,434) / 5975 \\
& =\mathbf{2 8 , 4 4 2} \mathbf{B} / \mathbf{k W h}
\end{aligned}
$$

And the efficiency is:

$$
\begin{aligned}
\eta & =3413 / 28,442 \\
& =.120
\end{aligned}
$$

For the present double flash configuration:

The steam flow produced in the high-pressure separator is given by:

$$
\begin{aligned}
& \mathrm{m}_{\mathrm{lv}}=\left(\mathrm{x}_{1}\right)\left(\mathrm{m}_{0}\right) \\
& \text { Where } \mathrm{x}_{\mathrm{I}}=\mathrm{x}\left(\mathrm{h}_{0}, \mathrm{p}_{1}\right)
\end{aligned}
$$


For the parameters of well E-54:

$$
\mathrm{x}_{1}=.3341
$$

and:

$$
\begin{aligned}
m_{1 v} & =(.3341)(298,336) \\
& =99,674 \mathrm{lb} / \mathrm{h}
\end{aligned}
$$

Following the single flash procedure, the power generated by this steam is:

$$
\begin{aligned}
\mathrm{P}_{\text {lv }} & =(.75)(99,674)(1198.28-918.22) / 3413 \\
& =6134 \mathrm{~kW}
\end{aligned}
$$

The separated brine is flashed in the second separator and flows through the steam turbine also. The amount of steam is:

$$
m_{2 v}=\left(x_{2}\right)\left(m_{0}-m_{1 v}\right)
$$

And:

$$
\mathrm{x}_{2}=\mathrm{x}\left(\mathrm{p}_{2}, \mathrm{~h}_{11}\right)
$$

Where: $h_{11}=$ the enthalpy of the separated liquid in the first separator

Following the procedures above:

$$
\begin{aligned}
\mathrm{x}_{2} & =.0943 \\
\mathrm{~m}_{2 \mathrm{v}} & =(.0943)(198,662) \\
& =18,734 \mathrm{lb} / \mathrm{h} \\
\mathrm{P}_{2 \mathrm{v}} & =(.75)(18,734)(1180.50-972.052) / 3413 \\
& =858 \mathrm{~kW}
\end{aligned}
$$

The total power is therefore:

$$
\begin{aligned}
P_{c s t} & =6134+858 \\
& =\mathbf{6 , 9 9 2} \mathbf{k W}
\end{aligned}
$$

The heat rate is:

$$
\text { HRt }=(169,941,434) / 6,992
$$


and the efficiency is:

$$
\begin{aligned}
\eta & =3,413 / 24,305 \\
& =\mathbf{. 1 4 0}
\end{aligned}
$$

As can be seen the heat rate and efficiency are low compared to modern steam plants for both the single flash and double flash plants. Because of the high initial steam fraction the single flash plant would optimize at a higher flash pressure than the average temperature rule.

The sources of energy loss for the example are the loss of available energy in the flash process and the inefficiencies in the gathering system and steam turbine. The efficiency of the steam turbine is fixed by the available manufacturers and won't be discussed further. However the loss of available energy in the flash process can be improved.

Two sources of lost energy occur in the flash process:

- The isenthalpic flash dissipates available energy in the throttling process. The heat energy generated, $\Delta Q$, results in an increase in entropy, $s=\Delta Q / T$. If an expander were used to reduce the pressure (topping turbine) additional power could be generated.

- The separated brine flowing from the separator has energy remaining that could be converted by a heat engine (bottoming system).

In the example above suppose a two-phase topping turbine of $50 \%$ efficiency were applied to the single flash cycle. This is illustrated in figure 9 . The power generation in the flash would be:

$$
\mathrm{P}_{1 \mathrm{f}}=(.5)\left(\mathrm{m}_{\mathrm{o}}\right)\left(\mathrm{h}_{0}-\mathrm{h}_{1 \mathrm{i}}\right)
$$

Where: $h_{1 i}=$ isentropic enthalpy at pressure, $p_{1}$

For the conditions above:

$$
\mathrm{p}_{1}=115 \mathrm{psia}
$$

And:

$$
\mathrm{h}_{1 \mathrm{i}}=595.815 \mathrm{~B} / \mathrm{lb}
$$

The power generated would be:

$$
\begin{aligned}
P_{\text {If }}= & (.5)(298,336)(637.39-595.815) / 3413 \\
& =\mathbf{1 8 1 7} \mathbf{k W}
\end{aligned}
$$


The power generated means there is less frictional dissipation to make steam at the flash pressure. The lost steam is equal to the power divided by the latent heat of vaporization:

$$
\begin{aligned}
\Delta \mathrm{m}_{\text {lv }} & =\mathrm{P}_{1 \mathrm{f}} / \mathrm{Lv} \\
& =(1817)(3413) / 881.318 \\
& =7,037 \mathrm{lb} / \mathrm{h}
\end{aligned}
$$

Thus the steam turbine power is determined by the new steam turbine flow rate:

$$
\begin{aligned}
\mathrm{P}_{\mathrm{cst}} & =(.75)(111,100-7,037)(1190.52-945.795) / 3413 \\
& =5,599 \mathrm{~kW}
\end{aligned}
$$

The total power with the topping turbine is therefore:

$$
\begin{aligned}
\mathrm{P}_{\mathrm{T}} & =1,817+5,599 \\
& =7,416 \mathbf{k W}
\end{aligned}
$$

This is an increase of $24 \%$ above the conventional single flash system and $6 \%$ above the double flash system. Higher topping turbine efficiency would of course result in greater advantages. A $70 \%$ efficient two-phase topping turbine would increase the total power to $7,988 \mathrm{~kW}$.

As will be shown later a two-phase turbine can also be applied to the second flash in a double flash plant to gain a further increase in power, however the added gain will be marginal.

The second source of loss, the heat in the separated brine can be recovered by a heat engine operating with the brine heat as the heat source and cooling water or ambient air as the heat sink. This option is illustrated in figures 10 and 11. Current options that will be discussed later are the binary power plant, the two-phase binary power plant and a low pressure steam power plant.

The power generated from the separated brine is:

$$
\begin{aligned}
& \mathrm{P}_{\mathrm{b}}=\left(\eta_{\mathrm{b}}\right)\left(\mathrm{m}_{11}\right)\left(\mathrm{h}_{11}-\mathrm{h}_{\mathrm{cl}}\right) \\
& \begin{aligned}
\text { Where: } \eta_{\mathrm{b}} & =\text { bottoming cycle efficiency } \\
\mathrm{m}_{11} & =\text { separated brine flow rate } \\
\mathrm{h}_{11} & =\text { enthalpy of separated brine } \\
\mathrm{h}_{\mathrm{cl}} & =\text { enthalpy of separated brine at rejection temperature }
\end{aligned}
\end{aligned}
$$

For a $10 \%$ bottoming cycle efficiency and a rejection temperature of $150 \mathrm{~F}$ the conditions for the single flash system with a $50 \%$ topping turbine give: 


$$
\begin{aligned}
P_{b} & =(.10)(194,273)(309.202-117.740) / 3413 \\
& =1090 \mathbf{k W}
\end{aligned}
$$

Thus the total power could be $8506 \mathbf{k W}$ with a $50 \%$ efficient two-phase topping turbine and $\mathbf{9 0 7 8}$ with a $70 \%$ efficient topping turbine. As will be discussed below, $50 \%$ is about the efficiency level demonstrated with the current single pressure Biphase turbine and $70 \%$ is the efficiency level calculated for the dual pressure Biphase turbine.

The options analyzed thus far are summarized below for well E-54:

\section{Plant Configuration}

\section{Power Heat Rate Efficiency \%of Ideal \\ $\mathrm{kW} \quad \mathrm{B} / \mathrm{kWh}$}

$\begin{array}{lllll}\text { Single Flash } & 5,972 & 28,442 & .12 & 50 \\ \text { Double Flash } & 6,992 & 24,305 & .14 & 57 \\ \text { Single Flash w 50\% Topping Turbine } & 7,412 & 22,928 & .149 & 61 \\ \text { Single Flash w 70\% Topping Turbine } & 7,988 & 21,274 & .160 & 65 \\ \begin{array}{l}\text { Single Flash w 50\% Topping } \\ \quad \text { And 10\% Bottoming System }\end{array} & 8,724 & 19,978 & .171 & 69 \\ \begin{array}{l}\text { Single Flash w 70\% Topping } \\ \quad \text { And 10\% Bottoming System }\end{array} & 9,078 & 18,720 & .182 & 74\end{array}$

Thus, by the use of two-phase topping turbines and/or bottoming plants the efficiency of power production for the example well can be increased from $12 \%$ to $18.2 \%$ with increasingly expensive added equipment. The capital cost must be evaluated in terms of the added power. For example the $1437 \mathrm{~kW}$ added by the $50 \%$ topping turbine can be obtained for about $\$ 400 / \mathrm{kW}$ whereas the 1,090 $\mathrm{kW}$ added by the bottoming system typically costs about $\$ 2,000 / \mathrm{kW}$.

The example above was for a specific set of conditions. The efficiency improvements by adding a two-phase topping turbine will be greater for higher wellhead pressures and enthalpies. The efficiency improvement will be less for the bottoming plant as the wellhead pressure and enthalpy increases since there will be less separated liquid to drive a heat engine. Mixing the flow from wells results in additional thermodynamic losses, which will be discussed later. 


\section{Biphase Turbine Theory}

The Biphase turbine is illustrated in Figure 12. Two-phase flow from the well enters the turbine and is split into several internal passages. Each passage feeds a two-phase nozzle inserted in the end plate. The flow is expanded in the nozzles producing high velocity two-phase jets.

The two-phase jets impinge tangentially on the straddle-mounted rotor. The high centrifugal force produces a clean separation of the steam from the brine.

The brine transfers kinetic energy to the rotor by drag forces. After slowing to the rotor velocity it flows through transfer holes to the opposite side of the rotor where it is collected by an Inconel scoop (diffuser). The diffuser can be used to recover the kinetic energy as outlet brine pressure. The brine flows back to the CFE separator.

The separated steam flows through steam blades, generating additional power. It leaves the turbine through a port and flows either to a steam turbine or to the CFE separator.

\subsection{Two-Phase Nozzle}

The initial part of the two-phase turbine is the two-phase nozzle. The purpose of the two-phase nozzle is to efficiently transfer thermal and pressure energy in the two-phase flow into directed kinetic energy. An example of a two-phase nozzle operating with air and water is given in figure 13.

The pressure decrease in the nozzle causes the steam to evolve and the steam specific volume to increase. The steam phase accelerates due to the increase in specific volume, dragging the liquid brine droplets along.

The two-phase nozzle design approach is to utilize the initial pressure gradient in the nozzle to break up the liquid phase into small droplets. The small droplets are subsequently accelerated by the gaseous phase via the shear forces occurring between the two phases.

The starting point for two-phase nozzle design is the inlet. The flow must be distributed fairly uniformly to multiple two-phase nozzles around the periphery of the turbine. If gas is present in the inlet flow, turning the flow in a manifold or in an elbow, for example, will cause separation of the gas from the liquid phase that in turn leads to non-uniform flow distribution to the nozzles.

This problem is eliminated if a homogeneous flow is established just prior to entering the turbine and then introduced to the turbine through a splitter, which is a device with knife-edged plates oriented perpendicular to the two-phase flow that captures a segment of the two-phase flow.

After capturing uniform segments of the two-phase flow, the flow must be ducted individually to each nozzle. Internal ducting with passages machined into the plate holding the nozzles was used in the design of the geothermal turbine.

Flow into the passages distributing two-phase flow to the individual nozzles will be separated if the path to the nozzle is not straight. If the flow does separate then it must be re-homogenized upon 
entering the two-phase turbine in order for the acceleration process to be efficient. To achieve this result an annular ring is provided to direct or sling the liquid on the duct wall into the core of the inlet of the two-phase nozzle. This is shown in figure 14, a cross section of the geothermal nozzle.

Design of the internal flow passage in the nozzle has been fully documented in the JPL nozzle report. The equations described have been programmed into a nozzle design code to design the nozzle contour and determine the nozzle exit velocity, diameter and efficiency. Inlet and exit conditions are input to the computer code. The computer code then generates the nozzle profile as well as the nozzle exit conditions. The code uses the so-called JPL Standard Pressure Profile, which has been found to offer the best performance for smoothly varying wall contours.

The length of the nozzle is a design trade-off. Shorter nozzles result in a smaller structure, but on the other hand, performance is lower because of the higher pressure gradient. The optimum nozzle length for a particular set of fluid conditions is determined by trial and error.

Off design performance of the nozzles is handled by calculating the velocity which would result from the off design pressure ratio as though it were a design pressure case. The off-design flow rate is then adjusted by multiplying the input flow rate times the ratio of the design throat area to the offdesign throat area (the nozzle throat area controls the mass flow rate for supersonic flow).

The exit velocity for the off-design conditions can be corrected by the ratio of the actual area ratio to the calculated area ratio for cases where calculated area ratio is greater - or by the ratio of the calculated area ratio to the actual area ratio for cases where the calculated area ratio is less than the actual area ratio. These methods of treating off-design conditions are approximations only, since no exact theory or correlation exists.

The output of the nozzle code for the wellhead conditions at the start of the project are provided in Table 1. As can be seen the design output velocity of 1000 feet per second occurs at a nozzle exit pressure of 440 psia. This was the basis for the nozzle design and the estimation of the backpressure steam turbine power.

Table 2, on the other hand, provides the calculated nozzle exit conditions at the current well conditions. The flow must be expanded to an exit pressure of only 172 psia to achieve the operating velocity of 1138 feet per second. The lower pressure and lower steam flow rate leaving the nozzle drastically reduces the energy available in the steam which can be converted to power in the backpressure steam turbine. The lower flowrate also results in less power that can be generated in the Biphase turbine.

For Table 1 the isentropic velocity is 1060 feet per second giving a nozzle efficiency of $90 \%$. For the conditions of table 2 the isentropic velocity is 1080 feet per second giving a nozzle efficiency of $85 \%$.

Table 3 provides the nozzle conditions at the maximum power point during the project. Once again the low exhaust pressure, 244 psia, required to generate the maximum power reduces the available energy in the steam flow. 


\subsection{Rotary Separator}

The rotary separator type of two-phase turbine is based on impingement of the nozzle flow tangentially onto a rotating separation surface. A cross section of the turbine and rotary separator is given in figure 15.

The impingement of the two-phase flow onto a surface at an angle necessarily results in a momentum loss. The ratio of the final velocity to the nozzle velocity is simply the cosine of the impingement angle. In practice we define two separate impingement angles. The first angle is the angle of the nozzle with the plane perpendicular to the axis of the separator. The second angle is the angle made by the two-phase flow as is impinges on the cylindrical separation surface. The second angle can also be expressed as the arccosine of the ratio of the nozzle centerline radius to the impingement-point radius.

In order to minimize the impingement losses, the nozzle should be inclined at as small an angle as is practical to the plane perpendicular to the axis of the turbine. Typically, fabrication considerations and packaging limit this nozzle to the range of 15 to 20 degrees.

The impingement losses are also minimized if the nozzles can be located at the largest radius possible relative to the surface of the separator. This implies that the ratio of the separator radius to the nozzle radius should be as large as possible.

Increasing the size of the rotating separator, however, produces more windage. In addition, for a given nozzle spouting velocity, increasing the separator radius, results in a higher rotational speed which may eventually lead to excessive stresses in the rotor disk itself. Therefore, a tradeoff analysis must conducted for each case. The rotor windage losses and speed are balanced against the reduction in impact losses. These losses are programmed into the rotary separator turbine code (RSR Code).

A lip is provided in the rotating cylinder to contain liquid that is separated onto the cylindrical surface. It is been found that considerable wave action occurs in the liquid on the separating surface. In particular, the large axial-flow component of the two-phase jet results in an axial reverse flow that is dominated by waves. In order to contain this flow within the separator, it has been found necessary to provide an inner lip to break the wave action of the axial reverse flow. This is illustrated in figure 16.

This construction is illustrated in the designs of the Biphase geothermal turbine demonstrated at Roosevelt Hot Springs and the two Biphase geothermal turbines operated on this project. Omission of this lip from the Biphase geothermal turbine operated at Desert Peak resulted in excessive liquid carryover due to the liquid waves breaching the primary lip.

For the typical size droplet emanating from a two-phase nozzle (25 - 100 microns), a width of the separator equal to three geometric impingement widths of the nozzle has been found to offer virtually complete separation. The width of the separator can be increased to provide a margin of safety. While increasing the width will result in better separation, the windage loss for the separator drum also increases. Once again a tradeoff is indicated, depending upon the primary requirements for the turbine. 
The height of the lip is an important factor in the momentum losses because the greater the lip height, the further the nozzle is from the separator surface resulting in higher impingement losses. On the other hand, greater lip heights will result in greater retention of liquid on the separator rim.

Particular attention must be placed on the possibility of liquid trapped between the rotating separator surface and either the casing or the nozzle structure. If trapped liquid is present, extremely large windage losses will result. The possibility also exists for material damage due to cavitation-type erosion. Therefore, the minimum distance between the rotating separator surface and the casing is $1 / 16$ inch. The minimum distance between the nozzle structure and the rotating lip of the separator is $1 / 32$ inch.

When a diffuser scoop is used to remove liquid from a rotary separator, the scoop can be located either on the nozzle side or on the opposite side of the rotor hub. The conventional approach as used for this design has been to locate it on the opposite side of the membrane from the nozzles. In this case, transfer holes are provided so the separated liquid flows under the influence of the centrifugal head from one side of the rotor to the other. The transfer holes are typically sized for an axial velocity of a few feet per second. Although in some cases an axial velocity as high as 20 feet/second has been used. The change in level required to accelerate the liquid to the axial flow velocity can be calculated and is quite small.

The use of transfer holes can result in localized axial velocity jets that can produce a fluctuating force field on an object immersed in a flow such as a diffuser scoop. A barrier can be provided to absorb the axial flow component of the velocity downstream of each transfer hole. This structure is illustrated in figure 17.

When the diffuser is located on the side of the hub opposite the nozzles the double-lip construction for wave breaking is used.

The liquid level on the separator is determined by the radial location of the diffuser scoop. If the diffuser scoop is located at a radial position outboard of the first impingement surface, the liquid will drain off of the liquid surface until it finds the level dictated by applying the conservation of mass to the diffuser inlet. It is desirable to drain the liquid off of the initial impingement surface to minimize wave action and to avoid rotating liquid layer instability. However, the further outboard the diffuser is located, the greater the loss is that is required to add energy to the liquid to accelerate it to the liquid velocity at the outboard position.

It is assumed that liquid solid body rotation occurs for all calculations in the liquid region. That is, the liquid is locked into the speed of the structure. This assumption leads to two very important effects that can result in significant losses.

In general, the diffuser is placed radially outboard of the separator surface to limit the depth of liquid on the separator. Since the liquid velocity is proportional to the radius, energy must be supplied to pump the liquid radially outward because of the increase in the liquid kinetic energy. The liquid entering the diffuser is leaving the control volume of the turbine itself, thus the added energy must be supplied by the rotor at the expense of the power transfer into the rotor from the two-phase jet. 
The second loss that occurs in the liquid layer is due to the centrifugal pressure increase provided by the rotating structure to the liquid. The centrifugal pressure gradient is caused by the centrifugal acceleration of the liquid due to the rotation of the liquid. Additional energy must be added to the liquid from the rotor to sustain this pressure gradient. This centrifugal pressure head exists in the flow leaving through the diffuser scoop and is dissipated as the liquid flow path becomes straight, and there is no longer any centrifugal force to sustain the pressure gradient.

Both of these losses are included in the RSR Turbine Code. The design process consists of trial and error location of the diffuser and calculation of the losses incurred at the various positions.

Windage losses are calculated for the rotating separator using equations by Sternlicht. The separator surfaces are a series of cylinders, disks and annuli. Thus the windage calculations are made from the equations for a cylinder and a disk.

The cylindrical surfaces are:

- Radial exterior surface of reaction-jet body.

- Radial exterior surfaces of separator and counterbalance.

- Interior surfaces of separator and counterbalance.

- Lip radial interior surfaces

The disc surfaces are:

- Two sides of the rotor face.

The annuli faces are:

- Two sides of each lip (end lips and wave-breaking lips).

- Two sides of the exterior reaction-jet body.

In general the separator surface is sloped radially outwards towards the rotor hub to facilitate the handling of solids in the incoming liquid flow. In the initial impingement region, solids will be fluidized and scrubbed and carried on out with the bulk liquid flow. This region can have a relatively mild slope.

For the reaction-jet version (c.f. below) when the liquid flow is out of the influence of the two-phase jets, the surface must be sloped at a larger angle to avoid collection of the solids.

Because of the requirements to intercept and separate the two-phase flow, the rotor in a rotary separator is typically larger and has more surface area than a typical turbine operating at the same pressure. Thus, windage is higher than for a typical turbine. This dictates that attention must be paid to selection of the optimum diameter and speed to minimize the windage. 
The higher the nozzle-exit pressure, the smaller the diameter, and hence, the higher the rotational speed. Conversely, if the diameter is fixed, windage considerations favor optimization of the operating speed at a lower rotational speed. In attempting to minimize the windage loss however, consideration must be given to the momentum impingement loss which becomes greater for a given nozzle diameter as the diameter of the rotor is decreased. The RSR turbine code contains all these factors and a typical design process would involve iterating through the design several times. By varying these parameters one can determine the optimum rotor efficiency within constraints placed by generator, speed requirements, gear requirements or other load characteristics.

A limiting impingement angle to achieve good separation has not been found. However, because of momentum losses and concern about splashing, the maximum impingement angle that has been used in the past is about 35 degrees.

\subsection{Gas Blading}

Gas blades can be applied to the rotary separator to recover the kinetic energy in the separated steam. Figures 18 and 19 are photographs of the blading in the 30 RSB geothermal turbine.

We assume in calculations that the two-phase jets drive a free gas vortex in the separator cavity. The initial value for the vortex is assumed to be the nozzle spouting velocity at the nozzle centerline. The velocity is then assumed to be proportional to $1 / r$. The vortex is assumed to extend to the bottom point of entry of any blading or gas passage ducting gas out of the cavity region.

These assumptions were also adopted by Mechanical Technology Inc. in the steam blade design for the geothermal steam turbines under a subcontract from Douglas Energy Company. Their calculations are summarized in the MTI design report on the steam blading provided as a part of the Douglas Energy Company report to the project sponsors.

To determine the losses in the cavity region between the impingement area and the rotor hub, we assume the axial flow velocity is same as the axial flow component leaving the nozzle. The effective velocity of the gas on the separator surface is determined and the gas friction losses are calculated. This results in a velocity at the blade row entrance which is less than the velocity at the inlet to the cavity region.

The axial component of velocity is assumed lost and a new axial component is established by continuity of the flow entering the blades. This determines the entering absolute flow angle and, for a given blade height, blade width and partial admission, determines the relative flow angle for the blading. The various parameters are then adjusted in blade design until the absolute flow angle equals the blade angle. Performance of the blading is then calculated utilizing the medium loss correlation of Balje.

These calculations are carried out on the RSR turbine code if the gas blading option is specified. Because of the relatively large diameter required from the standpoint of separation, the relative flow angle entering the blades must be as small as possible to produce a reasonable blade height. An inlet blade angle of 15 degrees is used in the geothermal turbine. Since the flow is not accelerated in the 
blade row, the standard impulse profile provided by MTI for the geothermal turbine has been utilized in all of the designs.

Another option which can be used for gas blades is a radial-inflow design. This was used in the subscale geothermal turbine on the project. This type of blade design has significant advantages for ease of fabrication and replacement in the event of erosion or changes in the gas conditions. However, by forcing the gas exit to be located on the nozzle side, it complicates the design of the nozzle plate and casing.

Typically there is very little radius change for this type of blading due to the relatively large diameter of the separator. Thus, the blades can be designed using axial flow impulse blade methods. This is explained in the report by Mechanical Technology Incorporated in which they performed a design audit of the 12 inch RSB turbine which was tested on a geothermal well. Results of those tests are provided in the reports on the Coso Hot Springs tests.

\subsection{Diffuser}

The primary function of the diffuser is to remove the separated liquid cleanly from the rotary separator without inducing additional spray or other liquid carryover that goes out with the gas. A secondary function is to pressurize the liquid by converting liquid kinetic energy into pressure head. The diffuser for the $30 \mathrm{RSB}$ for this project is shown in figure 20.

The diffuser is an open passage which is inserted into the high velocity liquid on the rim of the separator. The most important criterion in avoiding sprays or other liquid splash is to provide knifeedge on the leading edge on the diffuser. The slightest flat or break will induce significant spray because of the high liquid velocity.

The diffuser must be aligned normal to the flow. Any changes in the attitude of the diffuser relative to the flow will induce sprays from the diffuser leading edge.

The bottom surface of the diffuser must be concentric to the separator surface or diverge slightly from the separator surface. In no case should the bottom surface of the diffuser converge towards the rotary separator surface. This will result in trapping and accelerating liquid flow in the separator rim which will certainly lead to cavitation damage on the separator itself.

The knife-edge for the diffuser should be fabricated with the exterior walls parallel to the hub and lips of the rotary separator. That is they should be parallel to the direction of the flow. The knifeedge is formed by decreasing the area internally in the diffuser. If the knife-edges are formed by divergent outer walls, sprays from the diffuser will be produced.

The liquid on the bottom of the diffuser of the separator flow will climb the diffuser outside surface. To minimize this effect, a shedder plate was provided to redirect the flow back into the separator itself. To contain and redirect the sprays from the front edge of the diffuser another shedder plate is provided on the diffuser body above the liquid level of the separator. This plate has sides that extend partway to the liquid surface and is designed to catch the spray and redirect it back into the separator surface itself. 
Design of the shedder plates is by trial and error. New diffuser designs are tested in a high-speed liquid layer to visually determine the spray trajectories and wakes in order to provide secondary containment redirection of those flows.

The diffuser internal passage should have the area slowly increase to effect efficient diffusion. The maximum included angle of divergence recommended is seven degrees. The divergent section is straight until an increase in area of four-to-one is attained.

Typically, the open area of the diffuser is designed to have at least $20 \%$ excess flow area above the maximum liquid-flow case. Test diffusers have worked well using this criterion

When the diffuser exit pressure is larger than the static pressure of the rotary separator casing, a hydraulic jump must occur internal to the diffuser. This jump occurs at the transition of the high velocity liquid layer to a filled or uniform mixture.

A very important consideration in design of the diffuser is to provide a very rigid structure to support the diffuser. Flow forces on the diffuser can be quite large. In addition, the transfer holes and baffles rotating past the diffuser produce a periodic force on the diffuser. If the diffuser natural frequency is close to, or a multiple of the passing frequency of the holes and/or baffles, a resonance situation can occur leading to diffuser structural failure. This occurred for another Biphase turbine in spite of the fact that the structure was very strong. The problem was resolved by additional strengthening and stiffening of the diffuser structure.

The diffuser tips have been fabricated from Inconel 625 or Inconel 718 and welded to the main diffuser body. These materials are resistant to erosion from the high-velocity water jet and impact erosion from entrained solids in the liquid. The use of Inconel alloys has produced diffusers that have shown no damage from erosion. On the other hand, the use of stainless steel inlets for diffuser has resulted in some cases of erosion damage from the flow.

Insertion of the diffuser into the flow results in several forces that manifest themselves as a liquid flow deceleration on the separator with a resulting power loss. These forces include the following:

- Downward force of the surf barrier (when used) on the liquid.

- Frictional drag of the high velocity liquid on the diffuser structure

- Leading-edge drag loss

- Momentum loss from sprays or back flow from the diffuser

- Wake-drag loss from the back side of the diffuser.

These losses have been studied and are included in the RSR Performance Code. Further work remains to quantify all of the losses occurring in the diffuser. 


\subsection{Euler Turbine Passages}

A liquid reaction turbine is an alternative to the drag turbine and a steam reaction passage is an alternate to the vapor blades. A reaction turbine with Euler passages is shown during operation in figure 21 .

This type of turbine utilizes radial passages to create a high pressure at the periphery of the turbine structure. The high pressure is created by the large centrifugal-force field present in the rapidly rotating flow. The high pressure is subsequently used to expand the liquid or steam separately through nozzles located at the periphery of the turbine. The high relative velocity produced by the pressure expansion when subtracted by the rotor tip speed leaves a relatively small absolute exit velocity. For the Dual Pressure Rotor, described later, the leaving velocity can be zero or in the direction opposite to the rotor velocity, generating additional power.

When the reaction turbine is used, most of the additional energy required to pump the liquid radially outboard is converted to shaft power. The analysis of this concept is in the RSR Turbine code.

\subsection{Turbine Code Output}

The output of the RSR turbine code is provided in Table 4 for the original wellhead conditions and the nozzle output conditions of Table1. The calculated shaft power is $857 \mathrm{~kW}$.

The same geometry was analyzed for the maximum test case of $11 / 20 / 97$. For those nozzle conditions, provided in Table 3, the RSR turbine code calculates $894 \mathrm{~kW}$ shaft power, Table 5. The higher power is achieved by virtue of the higher nozzle velocity that was achieved by lowering the casing pressure. This subtracts from the available steam energy.

The RSR turbine code calculation for the present well conditions and the nozzle output of Table 2 is provided in Table 6. As shown the predicted power is only $771 \mathrm{~kW}$ at a low exit pressure which leaves very little energy for the steam turbine.

The generator efficiency curve is provided in figure 22. Multiplying the shaft power output by the efficiency of figure 22 gives calculated electrical outputs of $806 \mathrm{kWe}, 841 \mathrm{kWe}$ and $486 \mathrm{kWe}$ respectively.

As will be seen later the predicted electrical power for the two test points test values are very close to the measured values. 


\section{Project Experience}

\subsection{Financing}

As discussed in the acknowledgement conventional financing was not available for the project. A great of time and resources were expended before and during the project obtaining competitively bid governmental grants and loan grants and obtaining loans from private sources and non-profit sources.

The financing problem was made more difficult by the problems encountered during the project which added time to the schedule and which caused extra expenses to solve the problems. Chief among these was the solids problem, which required extensive loss of available operating time to design and test methods to dislodge and fluidize the solids separated onto the rotor by the high centrifugal force field. Solution of the problems and final operation were only possible with the infusion of self-funding of an amount equal to the loan grant from the California Energy Commission.

The sources of funding and their amounts are provided below for reference purposes:

- U.S. Department of Energy

- California Energy Commission

- E\&Co

- Multiphase Power and Processing

- Douglas Energy Company
Cost Shared Grant

Cost Shared Loan Grant

Project Loan

Grant

Company Funds
$\$ 1,482,405$

$\$ 2,041,000$

$\$ 125,000$

$\$ 150,000$

$\$ 2,080,297$

Operations and development work required financing over a 6 year period instead of the original 4 year period contemplated. As a result the total funding required escalated from $\$ 3,648,405$ to $\$ 5,878,702$.

\subsection{Design}

\subsubsection{Process Design}

\subsubsection{Background}

The Biphase Turbine Power plant was designed for operation as a wellhead topping plant on an operating well at the Cerro Prieto Geothermal Field. The particular well chosen by CFE, well 103, had a high pressure and enthalpy. The well is used to produce $100,000 \mathrm{lbm} / \mathrm{hr}$ of 120 -psia steam for power production in the CFE $75 \mathrm{MWe}$ central power plant. The existing steam production facility at well 103 consisted of a typical single flash separator tank located at the wellhead as shown in figure 23. An orifice placed in the 10-inch diameter pipeline connecting the well to the flash tank controls the flow-rate from the well to the flash tank. The pressure in the flash tank, of $120 \mathrm{psia}$, is set by the pressure drop in the steam gathering system to the central plant plus the pressure required at the inlet to the steam turbine. The orifice provides the pressure drop from the wellhead pressure, 710 psia, to the 120-psia flash tank pressure. The flash tank receives the resulting two-phase flow 
and produces separate outlet flows of liquid at $140,000 \mathrm{lbm} / \mathrm{hr}$ and steam at $100,000 \mathrm{lbm} / \mathrm{hr}$. The steam passes from the separator thru a drop-let separator before entering the steam gathering system. The liquid output from the flash tank is vented to atmospheric pressure and the resulting steam vented to the atmosphere and the remaining liquid discharged to the system of canals, which direct the un-used liquid from all the wells to the settling ponds. The settling ponds allow the liquids to $\mathrm{cool}$ and provide the time required for precipitation of the dissolved solids before the remaining water is injected into the ground.

The addition of the Biphase turbine power plant to the wellhead flash system as a topping plant is shown in figure 23a. For topping plants on high-pressure wells such as this case, the steam from the Biphase turbine is expanded in a backpressure steam turbine generating additional power, and is returned to the central-station piping. The flow rate from the well remains the same and the steam flow is only slightly diminished. Following is an energy balance comparison for a single flash system and the Biphase topping plant, assuming equal well flows, based and the original well conditions at well 103 of 1996.

$\underline{\text { Flash system well conditions, }}$

- Well flow: $86.7 \mathrm{lbm} / \mathrm{s}$ of two-phase flow at $750 \mathrm{psia}$

- Throttle to 126 psia

- Deliver $49.4 \mathrm{lbm} / \mathrm{s}$ of steam to central plant, which produces $7,410 \mathrm{~kW}$

- Power produced from well: $7,410 \mathrm{~kW}$

\section{With Biphase power plant installation}

- Well flow: $86.7 \mathrm{lbm} / \mathrm{s}$ of two-phase flow at 750 psia

- Expand to 126 psia in Biphase system generating 4,150 kW

- Deliver $44.1 \mathrm{lbm} / \mathrm{s}$ of steam to central plant, which produces $6,610 \mathrm{~kW}$

- Power produced from well: $10,760 \mathrm{~kW}$

In this case the power production is increased by more than $45 \%$, with no change made to the well operating parameters. The variation of the additional power produced by the Biphase turbine over a range of well conditions is shown in figure 24, where $x_{0}$ represents the wellhead steam quality values. As can be seen increases from 10 to more than $50 \%$ are attainable, depending on the wellhead pressure, flash pressure and wellhead steam fraction (enthalpy).

The primary design requirement for the Biphase plant was that all operations of the plant either normal or emergency, full power or part-load would not alter the amount or pressure of the steam delivered to the CFE steam gathering system.

\subsubsection{Biphase Turbine Plant Process Design}

The Biphase plant process design provides for operation of the existing steam production facility or operation of the Biphase plant and a seam-less transfer between them. Five distinct process control sub-systems were required to provide this capability. These sub-systems are the 1) Biphase turbine 
flow control, 2) well bypass control, 3) steam output control, 4) liquid output control, 5) electrical power output control.

The Biphase turbine flow control sub-system consisted of piping and three remotely controlled valves connecting the wellhead to the Biphase turbine inlet. The first of the three valves, shown in in the plant process and instrumentation diagram, figure 25 as PCV108, provides for rapid closure and flow stoppage to the turbine to protect from turbine over-speed in the event of loss of electrical load on the turbine-generator. The valves shown in figure 25 as PCV101 and PCV102 provide for flow modulation to the turbine during startup, shutdown and power-level modulation.

The well bypass control subsystem consists of the remotely controlled valve shown in figure 25 as PCV901. This valve provides for the automatic transfer of the well flow between the flash tank and the Biphase turbine while maintaining the wellhead pressure constant as a means of maintaining constant well flow.

During startup of the Biphase turbine, the well flow to the turbine in addition to the normal flow to the flash tank would result in wellhead pressure reduction as the total well flow exceeds the normal production rate. The control system senses the pressure reduction and closes PCV901 to reduce the flow to the flash tank and maintain the wellhead pressure and flow constant. During a normal turbine shutdown, the system operates in the reverse manner to stop flow to the turbine and return full flow to the flash tank, while maintaining constant well flow and pressure.

The most important operation of the bypass system is during an emergency plant shutdown in which case the flow to the turbine is stopped in 1.5 seconds by the closure of the turbine trip valve, PCV108. In order to prevent possible damage to the well by such a rapid well flow cessation, the bypass valve PCV901 must respond as fast as the trip valve by diverting the well flow to the flash tank while maintaining constant wellhead pressure.

The steam outlet control subsystem consists of three remotely controlled steam-modulating valves, shown in figure 25 as PCV301, PCV302, and PCV306. Valve PCV301 controls the pressure of the steam in the Biphase turbine case when steam flow is directed to the steam turbine. Valve PCV302 controls steam pressure in the Biphase turbine when the steam turbine is not in operation and the steam is being directed to the flash tank. Valve PCV306 is used to control the pressure in the Biphase turbine during startup and shutdown when the pressure in the Biphase turbine is less than the flash tank pressure and the steam is vented to the atmosphere thru the silencer.

The liquid outlet control subsystem consists of two remotely controlled liquid-modulating valves shown in figure 25 as PCV201 and PCV203. Valve PCV201 controls the pressure of the liquid at the Biphase turbine exit when the liquid is being directed to the flash tank. Valve PCV203 is used to control the liquid exit pressure during startup and shutdown when the Biphase turbine pressure is less than the flash tank pressure and the liquid is discharged to the canal thru the silencer.

The electrical power control subsystem provides the necessary electrical power control and instrumentation required to interface the Biphase turbine generator output with the Cerro Prieto geothermal facility electrical network. 


\subsubsection{Balance of Plant Design}

\subsubsection{Steam Turbine}

The steam turbine was added to the Biphase turbine wellhead system after the Biphase turbine was placed in operation. The steam turbine was installed as a separate turbine generator instead of installing the steam turbine on a common shaft with the Biphase turbine generator. The steam turbine generator with integral lube oil system built into the turbine skid is shown in figure 26 . The steam turbine is a single stage radial inflow design with design conditions summarized as follows:

$\begin{array}{ll}\text { Inlet pressure, psia } & 350 \\ \text { Outlet pressure, psia } & 125 \\ \text { Steam flow rate, } 1 \mathrm{bm} / \mathrm{s} & 41.6 \\ \text { Turbine speed, rpm } & 24,375 \\ \text { Power output, } \mathrm{kW} & 2,100\end{array}$

The steam turbine has the capacity for adding a second stage rotor to the turbine case with flow optionally in series or parallel with the first stage. With the flow in parallel to the first stage the power output could be doubled if the steam flow could be doubled from the Biphase turbine.

The steam turbine output shaft is connected to the generator thru a dual compound helical reduction gear, which reduces the shaft speed to $1800 \mathrm{rpm}$. The generator is a synchronous type design with maximum power output of $4700 \mathrm{kWe}$ at 2400 volt. An auxiliary output shaft from the speed reduction gear is used to drive the main lube oil-circulating pump, which has a $50 \mathrm{gpm}$ oil circulation capacity at 45 psig. For bearing lubrication during startup and spin down of the turbine, there is a motor driven lube oil pump. Both pumps circulate the oil flow thru the duplex oil filter and air cooled heat exchanger powered by a $30 \mathrm{hp}$ motor and fan.

\subsubsection{Biphase Turbine Lubrication System}

The lubrication system for the Biphase turbine supplies pressurized water to the silicone carbide bearings, cooling and providing lubrication for them. Its purpose is to feed water to the bearing cavities at a pressure higher than the rotor casing whenever the turbine is rotating and doing this without the need for continuous monitoring by personnel.

The system takes water from a reservoir tank then pumps, filters, delivers, collects, cools and returns the water to the tank. As this system is vital to the operation of the turbine, secondary and tertiary means of providing the pressurized fluid to the bearings are required in event of equipment failures. Additionally, the lube system has the capability of allowing work to be done on some components during continuous operation. A control scheme has been devised to provide safe unmonitored operation through the use of electronic control and fail-safes.

\subsubsection{Process Control and Instrumentation System}

The control capabilities for the RSB turbine generator and the steam turbine generator and the 
Iubrication system for both turbines are provided by the ABB-Kent Taylor modcell hardware. This modcell hardware is programmed with $\mathrm{PC}$ type computers use ABB Builder software. The graphical display of the Biphase turbine, steam turbine and respective lubrication systems and operator interface with the control system are provided by two pc type computers using the Citect Company of Australia software. The computer operating system is Windows NT version 4.0.

\subsubsection{High Pressure Water Jet Rotor Wash System}

The attempts at extended operation of the Biphase turbine were initially limited to periods of typically 2 to 3 hours, by the accumulation of solids deposits on the rotor. The deposits were uniform on the rim of the rotor and did not cause a problem until the depth of the deposit became greater than 0.18 inches at which time they would come in contact with the stationary liquid pickup and produce rotor vibrations. As the layer became thicker the vibrations would increase rapidly causing the turbine tests to be stopped when the vibration levels reached 10 mils peak to peak.

It was found that the solids deposits could be dislodged from the rotor surface by the application of a high velocity jet of water. The solids remained suspended in the liquid layer on the rotor rim and were carried out with the liquid thru the diffuser. Three different water jet systems were tried.

The first system used a piston type electrically driven pump to provide a clean water flow of $5 \mathrm{gpm}$ at $2000 \mathrm{psig}$ to produce a jet velocity of $500 \mathrm{ft} / \mathrm{s}$. This was not successful in maintaining the rotor free of the solids deposits.

When the pump capacity and pressure were increased to $5 \mathrm{gpm}$ at $4000 \mathrm{psig}$ and the jet velocity increased to $750 \mathrm{ft} / \mathrm{s}$ the rotor could be maintained relatively free of the solids deposits when the rotor wash system was operated every 15 minutes for 15 seconds. However, over a 12-15 hour time period the solids built up to a level where contact was again seen to occur.

Since the water consumption rate was large, a third rotor wash system was developed using two-flow from the wellhead. At a two-phase flow rate of approximately $0.5 \mathrm{lbm} / \mathrm{s}$ with an exit velocity of $800 \mathrm{ft} / \mathrm{s}$ the rotor could be maintained completely free of solids deposits.

The arrangement of the water jet nozzles and the turbine rotor and diffuser are shown schematically in figure 27. Figure 28 shows the operation of the 4000 psi jets before installation in the turbine.

\subsubsection{Chemical Feed System}

Observations were made that showed deposits of solids were accumulating on the turbine rotor rim at rates of 100 cubic inches over a period of 4 to 8 hours. Chemical analysis of these solids deposits showed them to be iron oxides as shown in the analysis report contained in Appendix C. Chemical analysis of the liquid phase taken at the wellhead and steam condensate samples taken from the CFE separator showed the brine to have sufficient silica content to provide a potential silica deposition problem. The steam analysis showed the ph of steam at 5 to provide a significant corrosion problem for structural components. The results of these chemical analyses are contained in Appendix D. 
A system for injection of a corrosion inhibitor and precipitation inhibitor were installed. An antifoaming agent injection system was installed because the corrosion inhibitor had a foaming tendency. The injection systems consisted of chemical metering pumps, Neptune Co. pump model 500AN1. Two were installed to deliver the corrosion and precipitate inhibitors at the wellhead. The anti-foaming agent pump was installed at the Biphase turbine liquid outlet. The three chemicals provided by the Chemco Water Technologies Inc. and the feed rates are defined as follows

$\begin{array}{lll}\text { Corrosion inhibitor } & \text { Chemco 6816S } & 26 \mathrm{ml} / \mathrm{min} \\ \text { Scale inhibitor } & \text { Chemco Dp270 } & 21 \mathrm{ml} / \mathrm{min} \\ \text { Anti-foaming } & \text { Chemco } 1440 & 4 \mathrm{ml} / \mathrm{min}\end{array}$

The system appeared to inhibit the corrosivity of the brine and offer protection of the surfaces. Once the two-phase hydroblast and new lubrication system enabled longer duration operation the consumption of the additives were reduced with no apparent deleterious effects. The primary value seems to be during startup rather than during long term operation.

\subsection{Construction}

\subsubsection{Biphase Turbine Generator}

The 30 RSB turbine is a single rotor machine designed to operate over a broad range of geothermal process conditions of:

$\begin{array}{ll}\text { Wellhead pressure: } & 300 \text { to } 900 \mathrm{psig} \\ \text { Wellhead enthalpy: } & 400 \text { to } 1000 \mathrm{BTU} / \mathrm{lbm} \\ \text { Wellhead flow rate: } & 20 \text { to } 160 \mathrm{lbm} / \mathrm{s} \\ \text { Steam output pressure: } & 60 \text { to } 500 \mathrm{psia} \\ \text { Turbine shaft speed: } & 1800 \text { to } 3600 \mathrm{rpm} \\ \text { Power output: } & 0.5 \text { to } 2.0 \mathrm{MW}\end{array}$

The adaptability of the turbine to this range of conditions is provided by the interchange of the eight two-phase nozzles shown in Appendix E, ref. drawing E50049. The nozzles provide the expansion of the wellhead flow to the Biphase turbine, steam output pressure. This results in a two phase jet of $1000 \mathrm{ft} / \mathrm{s}$ velocity which in turn causes the separator to rotate and produce the centrifugal force field to separate the steam and liquid. Frictional momentum transfer transfers the kinetic energy of the separated liquid to the turbine rotor.

The induction type, electrical generator directly connected to the Biphase turbine shaft converts the mechanical output power of the separated liquid to electrical output power.

The kinetic energy of the steam is converted to additional output power by a single row of axial flow steam blades in the disc of the rotary separator shown in Appendix E, drawing E50072.

The kinetic energy remaining in the liquid can be converted to pressurization of the output liquid at pressure up to 500 to 1000 psi above the saturation value by operation of the liquid diffuser, shown in Appendix E, drawing E50031. The diffuser has a rectangular inlet that is 0.43 inches high and 0.75 inches wide. This cross-section increases to a square cross-section that is 1.12 by 1.12 inches 
over a length of 8.4 inches. This provides an effective divergence angle of 6.3 degrees.

The diffuser then turns thru a 17-degree angle so the diffuser is directed out of the plane of rotation of the rotor. There then is another cross-section change from square to round, 1.5-inch diameter which remains constant over a length of 22 inches. The cross-section is then increased to 4 inch schedule 80 pipe and terminates at the exit flange which seals on the mating flange on the out-side of the turbine casing.

The Biphase turbine receives a two-phase mixture of brine and steam from the geothermal wellhead. The flow from the well is split into two streams by the flow-splitter shown in Appendix E, drawing E50032, before entering the two inlets to the nozzle plate shown in Appendix E, drawing E50033. The nozzle plate further sub-divides the two inlet streams into four providing a uniform mixture to the eight nozzles.

The jet leaving the nozzles impinges on the turbine rotor rim where the separation of the gas and liquid takes place. The separated liquid goes through transfers holes, located in the rotor disk. On the other side of the rotor disk, the liquid enters the stationary diffuser and is carried out of the turbine case.

The separated steam passes through the axial blades, located in the disk of the rotor and leaves the turbine case thru the 10 inch diameter exit port.

\section{DESIGN AND OPERATING CHARACTERISTICS}

Manufacturer
Model
Rated output power
Rated output power at well 103
Rotor speed
Rotor trip speed, rpm
Inlet pressure to nozzles (well 103)
Inlet pressure to nozzles
Discharged pressure
Case maximum pressure
Mass flow
Lube water supply pressure

Manufacturer

Model

Rated output power

Rated output power at well 103

Rotor speed

Inlet pressure to nozzles (well 103)

Inlet pressure to nozzles

Discharged pressure

Case maximum pressure

Lube water supply pressure

DOUGLAS ENERGY CO.
$30 \mathrm{RSB}$
$2,200 \mathrm{~kW}$
$1,100 \mathrm{~kW}$
$3,600 \mathrm{rpm}$
$3,900 \mathrm{rpm}$
$670 \mathrm{psia}$
$780 \mathrm{psia}$
$425 \mathrm{psia}$
$550 \mathrm{psia}$
$241,200 \mathrm{lb} / \mathrm{h}$
$450 \mathrm{psia}$

The Biphase turbine housing consists of two parts, the housing and nozzle plate, which are bolted together to form the turbine pressure vessel. Two seals provide the seal between the nozzle plate and rotor housing. The first is a one half inch diameter cross-section " $\mathrm{C}$ "-ring with 40 inch diameter and the second is a high-temperature, one half inch diameter cross-section, plastic " $\mathrm{O}$ " ring with 44 inch diameter from the General Seal Company part number E-2-0600.

The housing supports are designed to hold the turbine shaft alignment while allowing thermal movement of the housing. The assembly of the turbine rotor, nozzle plate and housing are shown in 
Appendix E drawing E50084.

The rotor assembly consists of the shaft, shown in Appendix E drawing E50096 and a fabricated rotor/rim assembly, shown in Appendix E, drawing E50082. The rotor is assembled by first a thermal expansion of the disc to provide a heat shrink onto the shaft. The rim is installed by a second thermal expansion of the rim to provide a heat shrink on the rotor disc. The disk contains the axial blades and the rim contains the nozzle impingement surface and transfer holes for the separated liquid.

The rotor shaft extends out of the turbine case thru the bearing housings shown in Appendix E, drawing E50084. Each bearing housing has a two shaft seals. The first seal referred to as the process seal, prevents geothermal fluids inside the turbine case from entering the bearing housing. The second seal referred to as the lubricant seal, prevents the bearing lubricating water within the bearing housing from leaking to the atmosphere.

The process seal assembly is bolted to the housing and located in place by a shim, anti-rotation key, lock washer and lock nut. The seal retainer, which is firmly locked to the shaft, transmits the rotary motion of the shaft to the sealing ring through a positive interlock notch drive arrangement. The precision lapped surface of the sealing ring rotates against the lapped surface of the mating ring, assuring an effective sealing surface.

A seal chamber is formed between the seal body and housing, and pressurized water, coming from the bearing lubricates and cools the seal. The water then returns to the lubrication skid with a small amount of water allowed to pass thru the seal into the turbine case to maintain the seal surface free of geothermal fluid deposits. The seal water pressure is regulated to be greater by approximately 25 psi than the steam pressure in the turbine case.

The lubricant seal on the shaft completes the pressurized seal of the shaft within the bearing housing. This seal is a two stage type mechanical shaft seal. This seal is bolted to the housing and has two lips, which rub against the hardened surface of the shaft. This seal contains no rotating parts and allows a small amount of water to leak to the atmospheric pressure chambers and then returned through gravity drains to the water reservoir.

Each bearing housing contains a journal bearing assembly. The journal bearings are of the tilting pad type and support the shaft-rotor assembly. The journal bearings have five, silicon carbide tilting pads, which are located by a cage ring within a stainless steel housing. The five tilting silicon carbide pads ride on a silicon carbide sleeve which is located on the shaft and positioned in place with a anti-rotating key and locked in place with a lock-nut.

The bearing housing within the nozzle plate contains a thrust bearing assembly in addition to the journal bearing. The thrust bearing has twelve, tilting silicon carbide pads on the active side (the sides which takes the thrust load) and a solid silicon carbide ring on the inactive side (the side which locates the shaft axially). The thrust load is transmitted from the shaft to the thrust bearing through a thrust collar. The thrust bearing assembly locates the shaft axially and absorbs the axial thrust of the rotor on the shaft. 
The journal and thrust bearings operate with the bearing surfaces separated by a hydrodynamic film created by a pressurized lubricating water. The water enters the bearing cavity on the inactive side of the thrust bearing and leaves the bearing through the gap between the tilting pads and sleeve. The bearing and seal cavities are solidly filled with the pressurized lubricating water.

Each bearing housing contains instrumentation feed-thru passages for the vibration and speed sensors. Each journal bearing assembly has two vibration measurement probes and the thrust bearing assembly has two axial position measurement probes. There is a 60-tooth gear with two speed sensors mounted on the shaft on the outside of the bearing housing on the nozzle side of the turbine case.

The rotary separator turbine shaft is connected to the generator shaft with a flexible disk type coupling shown in Appendix E drawing D50081. The coupling hubs are thermally shrunk on each end of the shaft. A coupling guard is provided for personnel protection.

The complete Biphase turbine assembly is shown in Appendix E drawing D50081. The turbine assembly was manufactured at the Allied Engineering Company of Oakland, California. The turbine was shipped to the ARB Company of Paramount, California for skid mounting and assembly with the generator in December 1996.

The turbine was installed on a structural framework with the generator as shown in Appendix E, drawing D50082. The control and instrumentation components, conduit and wiring were installed to skid mounted junction boxes. The completed turbine skid assembly was shipped to the geothermal site at Cerro Prieto, Mexico on May 3, 1997. This shipment consisted of five tractor-trailers containing the turbine skid on one and the balance of plant equipment on the remaining.

\subsubsection{Balance of Plant Design}

The balance of plant equipment shipped with the Biphase turbine skid consisted of the following major pieces of equipment:

- Electrical equipment building

- Generator output transformer, $2.4 \mathrm{kV} / 13.8 \mathrm{kV}, 5 \mathrm{Mkva}$

- Control and construction trailer

- Equipment storage building

- Biphase turbine water lubrication system

The electrical equipment building contains the following major equipment groups:

Component name

Utility-tie circuit breaker

Biphase local control
Console No Function

1 Provides connection of utility power at $13.8 \mathrm{kV}$ to facility step-down transformer to $2.4 \mathrm{kV}$

2 Provides local control and display of 


\begin{tabular}{|c|c|c|}
\hline Induction generator breaker & 3 & $\begin{array}{l}\text { Biphase turbine electrical parameters } \\
\text { Provides induction generator connec- } \\
\text { tion to transformer input }\end{array}$ \\
\hline Induction generator instruments & 4 and 5 & Induction generator protective relays \\
\hline Synchronous generator & 6 and 7 & Synchronous generator protective relays \\
\hline Synchronous generator breaker & 8 & $\begin{array}{l}\text { Provides synchronous generator } \\
\text { connection to transformer input }\end{array}$ \\
\hline Woodward governor & 9 & $\begin{array}{l}\text { Provides automatic speed control of } \\
\text { steam turbine speed during startup }\end{array}$ \\
\hline Control system & 10 & $\begin{array}{l}\text { Contains } 8-32 \text { channel input-output } \\
\text { interfaces between field devices and } \\
\text { control room computers }\end{array}$ \\
\hline
\end{tabular}

The equipment was installed on concrete foundations with the general arrangement as shown in Appendix E, drawing D50223.

The ARB Company was used as the site construction manager to supervise and coordinate the installation of the piping, electrical conduit and wiring to interconnect all of the above plant components, and the control, instrumentation components not previously installed. The Biphase turbine skid interconnection piping to the well is shown in Appendix E drawings E50165 thru E50168.

The field installation was completed for first electrical system tests of the Biphase turbine generator on June 6,1997. In these tests the turbine was operated at full speed of $3600 \mathrm{rpm}$ with steam from the CFE separator in order to verify proper operation of the electrical power control and instrumentation systems required to connect the output of the Biphase generator to the CFE electrical grid. These tests were completed on August 20, 1997 with the first power output from the Biphase turbine to the CFE grid.

Over the following period of more than 2 years the total power output to the CFE grid was 77.5 megawatt hours.

\subsection{Tests}

\subsubsection{Hydrostatic Tests}

Hydrostatic pressure tests were conducted to verify the mechanical integrity and leak-free condition of all the piping installed. The tests were conducted at pressures of 1.5 times the maximum working pressure. The piping classifications and test pressures are summarized as follows:

$\begin{array}{cll}\text { Pressure class } & \begin{array}{l}\text { Test } \\ \text { Pressure, psig }\end{array} & \text { Service } \\ \text { High pressure } & 900 & \text { Well flow to Biphase turbine }\end{array}$




\begin{tabular}{|c|c|c|}
\hline Medium pressure & 650 & $\begin{array}{l}\text { Steam flow from Biphase turbine } \\
\text { to steam turbine inlet }\end{array}$ \\
\hline Low pressure & 450 & $\begin{array}{l}\text { Steam flow from Biphase turbine } \\
\text { to CFE separator }\end{array}$ \\
\hline
\end{tabular}

The test report for the above tests plus those conducted on ancillary piping lines or systems are shown in Appendix F. The pipe list is also provided in Appendix F to identify the pipe lines shown in the pressure test reports. Drawing E50165 is included in Appendix F to identify the physical location of the pipe sections referred to the test report.

\subsubsection{Bypass Valve Test}

A test was conducted on August 12, 1998 to demonstrate to CFE observers, the proper functioning of the well flow bypass system. This system was installed to protect the well from the adverse effects of large pressure and flow rate fluctuations that might occur from rapid flow rate changes to the Biphase turbine which do occur if there is a loss of electrical load to the generator. In such a case the trip valve on the turbine inlet closes within 1.5 seconds to stop the well flow to the turbine to prevent turbine over-speed.

The well bypass system consists of fast acting valve of the same type used as the turbine trip valve. In the event of a turbine trip, the bypass valve, PCV901, will be automatically adjusted to maintain the wellhead pressure constant and thus maintain constant well flow. As the well flow to the Biphase turbine is being decreased by the closing of the turbine inlet trip, PCV901 and throttle valves, PCV101 and PCV102, the bypass valve, PCV901, is opening to provide for continuous well flow to the CFE separator. The details of this test are contained in Appendix G, Test 27 Report.

\subsubsection{Pre-operational Tests}

Prior to operation of the Biphase turbine on two phase well flow, pre-operational tests were conducted to verify the proper operation of ancillary power plant systems required to support the Biphase turbine operation as a wellhead topping power plant. The first of these tests was to demonstrate the safe and accurate operation of the electrical power instrumentation and control system. These tests included operational tests of the following sub-systems.

\subsubsection{Electrical System Pre-Operational Tests}

The electrical power system controls the flow of electrical power, it provides for the metering of electrical parameters and protects equipment and personnel from electrical faults.

The electrical metering and protection are divided into four distinct equipment related areas. These are:

- The induction generator.

- The synchronous generator. 
- The main 5,000 kVA power transformer and inter tie to the CFE utility grid.

- The $100 \mathrm{kVA}$ facility power distribution transformer

\section{Induction Generator}

The following electrical parameters are monitored by analog meters on the induction generator breaker compartment: 3 phase AC RMS amperes, 3 phase AC RMS volts, frequency, power factor, $\mathrm{kWe}$ and $\mathrm{kWhr}$. These and additional parameters are monitored by an Electro Industries, Inc. power transducer located inside the main power control cabinet and displayed in digital format on a related face plate meter located on the front of the same cabinet. This transducer also sends all the induction generator electrical operation data to the control system for additional display and recording.

\section{Synchronous Generator}

The following electrical parameters are monitored by analog meters on the synchronous generator breaker compartment: 3 phase AC RMS amperes, 3 phase AC RMS volts, frequency, power factor, $\mathrm{kW}$ and $\mathrm{kWhr}$. A synchroscope also indicates phase and frequency matching during the synchronization of the generator. All the analog indicated parameters and additional parameters are monitored by an Electro Industries, Inc. power transducer located inside the main power control cabinet and displayed in digital format on a related face plate meter located on the front of the same cabinet. This transducer also sends all the synchronous generator electrical operation data to the control system for additional display and recording. The tests of the protective relays for the synchronous generator were postponed until July 1999 following the installation of the steam turbine and synchronous generator. The test results for these devices are contained in Appendix E.

\section{Utility Power}

Two Process Systems, Inc. multi function digital meters display the electrical parameters of the power flow to and from the CFE utility. The 'Import' meter displays the parameters of the power flow from the utility to the plant, during plant down time. The 'Export' meter displays the parameters of the power flow from the plant to the utility, during power generation.

Both of these meters display the following parameters: for each phase; $\mathrm{AC}$ volts, $\mathrm{AC}$ amperes, $\mathrm{kW}$, $\mathrm{kVAr}$ and power factor, also displayed are the total $\mathrm{kW}$, total $\mathrm{kVA}$, total $\mathrm{kVAr}$, total $\mathrm{kWhr}$ delivered and the average power factor.

In addition the 'Export' meter, under its' utility grouped display, shows separately for each phase the total harmonic distortion in $\mathrm{kW}$, in $\mathrm{AC}$ volts and in $\mathrm{AC}$ amperes.

Also, on the electrical power panel an analog meter displays the AC amperes for each phase, a second analog meter displays the phase to phase and the phase to neutral AC volts and a third analog meter displays the line frequency.

\section{Protective Relaying}


The protective relays for both the induction generator and synchronous generators were tested by the Analysis de Sistemis Electricos de Potentcia Company of Mexicali, Baja California. The test report is provided in Appendix $\mathrm{H}$.

\section{Induction Generator}

This generator is protected by G.E. induction, electro-mechanical type relays located in the induction generator breaker and instrumentation compartments. Listed by their designations, these relays are: 1G50151A, 1G50151C, 1G50151N, 1G27, 1G67A, 1G67B, 1G67C and 1G47. Additional protection is provided by Crompton Co. electronic set point and definite time delay type relays located in the electrical power panel. Listed by their designations, these relays are: IG87AB, IG87BC IG $87 \mathrm{CA}$ and 1 G59.

\section{Synchronous Generator}

This generator is protected by G.E. Co. induction, electro-mechanical type relays located in the synchronous generator breaker and instrumentation compartments. Listed by their designations, these relays are: SG5015 IA, SG50151 B, SG50I5IC, SG59, SG32, SG40, SG46, SG27, SG8IU, SG5IN, SG87, SG87G.

Crompton Co. Electronic set point and definite time delay type relays located in the electrical power panel are provided for this protection. Listed by their designations, these relays are: PT50A,B,C, PT5IA,B,C, PT50G, PT5IG, PT6I and PT27AB and PT27AC.

\section{Trip and Emergency Shutdown Logic}

\section{Induction Generator Fault Trip}

An induction generator fault trip initiates: respective alarm, induction generator breaker trip, emergency shutdown, synchronous generator breaker trip and induction generator lockout latch. Other than the respective G.E. relay trip indicating flags and resets, all respective alarms, pilot lights, pushbuttons and selector switches are on the electrical power panel.

The following is the system reset sequence after the cause of a trip is investigated and corrected:

- Reset respective G.E. relay, if this is where the trip originated.

- Reset induction generator lockout circuit latch by pressing the respective reset pushbutton..

- Reset alarm panel by pressing the alarm reset pushbutton.

- Reset emergency shutdown circuit by pressing the respective reset pushbutton.

\section{Synchronous Generator Fault Trip}

A synchronous generator fault trip initiates: respective alarm, synchronous generator breaker trip, emergency shutdown, induction generator breaker trip and synchronous generator lockout latch. The respective G.E. relay trip indicating flags, resets, and the lockout relay reset handle are on the 
synchronous generator breaker and instrumentation compartments. The trip alarms are indicated on the electrical power panel.

The following is the system reset sequence after the cause of a trip is investigated and corrected:

- Reset the G.E. relay that caused the trip.

- Reset synchronous generator lockout relay handle if cause of trip is differential fault, or differential ground fault, or ground fault, since only these faults cause lockout.

- Reset alarm panel by pressing the alarm reset pushbutton.

- Reset emergency shutdown circuit by pressing the respective reset pushbutton.

\section{0 kVA Distribution Transformer Fault Trip}

A distribution transformer fault trip initiates: respective alarm, emergency shutdown, and utility tie main breaker trip and lockout latch, synchronous generator breaker trip and induction generator breaker trip.

The following is the system reset sequence after the cause of a trip is investigated and corrected:

- Reset utility tie main breaker lockout latch by pressing respective reset pushbutton.

- Reset emergency shutdown lockout by pressing respective reset pushbutton.

- Reset alarm panel by pressing alarm reset pushbutton.

\section{5,000 kVA Power Transformer Fault Trip}

A distribution transformer fault trip initiates: respective alarm, emergency shutdown, utility tie main breaker trip and lockout latch, synchronous generator breaker trip and induction generator.

The following is the system reset sequence after the cause of a trip is investigated and corrected:

- Reset utility tie main breaker lockout latch by pressing respective reset pushbutton.

- Reset emergency shutdown lockout by pressing respective reset pushbutton.

- Reset alarm panel by pressing alarm reset pushbutton.

\subsubsection{Biphase Turbine Preheat and Steam Startup Tests}

Tests were conducted of the steam flow control system designed to provide a controlled flow of steam from the CFE separator to preheat the Biphase turbine for a period of 15 minutes and then provide additional motive steam to start rotation of the turbine and bring it to a speed of $1000 \mathrm{rpm}$ for an additional 10 minutes to complete the heating of the rotor and case.

The control system was programmed to subsequently increase the speed at a rate of $500 \mathrm{rpm}$ per minute up to $3600 \mathrm{rpm}$. The steam flow to the turbine was controlled by the computer control of a 6" Masonelean Camflex type-throttling valve, PCV1001. The flow from the valve was admitted to 
the turbine inlets immediately downstream of the main turbine throttle valves, PCV101 and PCV102.

A steam flow rate of $10,000 \mathrm{lbm} / \mathrm{hr}$ was used to preheat the turbine. Turbine rotor rotation was initiated by increasing the steam flow to $20,000 \mathrm{lbm} / \mathrm{hr}$. The steam flow was automatically reduced by the control system to $15,000 \mathrm{lbm} / \mathrm{hr}$ in order to hold the rotor speed at $1000 \mathrm{rpm}$ to complete the turbine pre-heat. The analysis of the startup characteristics of the turbine that were verified by these tests is shown in Appendix I.

\subsubsection{Biphase Turbine Over-Speed Protection Tests}

Tests were conducted to demonstrate the turbine would be prevented from rotor speed acceleration from the normal operating speed of 3600 to speeds above $3800 \mathrm{rpm}$ by the over-speed protection system in the event of loss of electrical load to the generator when the turbine is producing output power.

A rotor speed measurement system with dual sensors provides automatic closing of the turbine trip and throttle valves in the event the rotor speed increases above $3675 \mathrm{rpm}$. Tests were conducted with the generator not connected to the utility grid, which permitted gradual speed increase to demonstrate the automatic shutdown of the turbine when the speed exceeded $3675 \mathrm{rpm}$.

The second part of the over-speed test was to operate the turbine with $400 \mathrm{kWe}$ output to the utility grid and demonstrate the rotor speed did not exceed $3800 \mathrm{rpm}$ when the generator circuit breaker was opened. The circuit breaker opening provided the signal to the over-speed system to close the trip and throttle valves within the prescribed closing time of 1.5 seconds. The analyses of the rotor acceleration characteristics upon loss of load are shown in Appendix J.

The predicted speed increase with time after loss of load is shown in figure 1 of Appendix J. The curve shows the speed increase without flow decrease to be above $4000 \mathrm{rpm}$ in one second. With flow decrease produced by valve closing in three seconds and inclusion of windage losses on the rotor, the maximum speed is $3950 \mathrm{rpm}$.

The measured speed increase with the Fischer, eccentric type ball valves produced a 1.5 second closing time and the observed speed increase was limited to $3700 \mathrm{rpm}$.

\subsubsection{Synchronization Tests}

The final test conducted in preparation for power production test with operation of the Biphase turbine on well flow was to operate the turbine on steam alone with $3600 \mathrm{rpm}$ turbine speed and connect the generator to the utility grid. These tests were completed successfully after several attempts.

The details of these tests are described in Appendix K, Test 1 thru 9 Test Report. Appendix K contains also the summary reports for the balance of the plant tests 10 thru 35 . 


\subsubsection{Switch-on Tests}

Tests were conducted to demonstrate to CFE what if any changes in their well and steam production operation might occur by the startup and partial or full power operation of the Biphase turbine. CFE personnel observed several such tests over the course of the 474 hours of turbine operations.

Appendix $\mathrm{L}$ contains the operating data for a demonstration test at the condition of maximum turbine output power. The first page of Appendix L shows a summary of the process conditions for the well and the Biphase power plant at a time before Biphase turbine operation was initiated.

The conditions of the well before turbine startup are: 1) the bypass valve, PCV901, being fully open and the Biphase turbine throttle valves, PCV101and PCV102, being fully closed establish the prestart condition. At this condition the wellhead pressure is $590.6 \mathrm{psig}$ and the steam flow rate out of the CFE separator into the steam-gathering pipeline is $126,607 \mathrm{lbm} / \mathrm{hr}$ at a pressure of $104 \mathrm{psig}$.

The second page of Appendix L shows the similar data summary taken a condition with the turbine operating at full power. At this condition the turbine electrical power output is $808 \mathrm{kWe}$ and the turbine throttle valves are 63 and 61 percent open. The bypass valve, PCV901 has been closed to $10 \%$ open in an attempt to pass all the well flow thru the Biphase turbine. This has raised the wellhead pressure to $623 \mathrm{psig}$ and reduced the well flow slightly as shown by the steam flow out of the CFE separator to $96,766 \mathrm{lbm} / \mathrm{hr}$ at $100 \mathrm{psig}$.

The third page contains and analysis of the operating conditions provided by simplified performance model for the Biphase turbine as contained in the control system computer software.

The fourth page of Appendix L contains the results of a detailed mass and energy balance for the same operating conditions. The operating conditions are the same as the measured and the calculated power output is within 2 percent of the measured value. The steam output from the separator flash tank is shown to be $27.685 \mathrm{lbm} / \mathrm{s}, 99,666 \mathrm{lbm} / \mathrm{hr}$ as compared to the measured value of $96,764 \mathrm{lbm} / \mathrm{hr}$.

To simplify the startup of the Biphase and steam turbines, nineteen automatic control sequences were programmed into the control system. Each sequence performs one or more control actions required to complete a particular operating mode selected by the operator. The operating modes are listed in table 1 of Appendix M. Appendix M also contains a description of the operating modes.

\subsubsection{Production Test}

A test was initiated on April 25, 2000 and continued for 166 hours at steady state conditions. Appendix $\mathrm{N}$, page 1 contains the data summary at the beginning of the test and page 2 contains the data summary at the end of the test. The output power was the same at both conditions but the well bypass being $26 \%$ open at the start and $16.6 \%$ open at the end precludes an exact mass and energy balance because of the unknown proportion of the steam and liquid entering the turbine or the separator. 
An estimate of the turbine operating conditions is shown in the calculated mass and energy balance shown in page 3 of Appendix $N$. It must be assumed that the total flow entering the turbine corresponding to the bypass valve opening of $26 \%$ was $74 \%$ of the total well flow of $62 \mathrm{lbm} / \mathrm{s}$ or $45.8 \mathrm{lbm} / \mathrm{s}$ and the enthalpy of the flow entering the turbine is $630 \mathrm{Btu} / \mathrm{lbm}$. These assumptions show the electrical output power is $253 \mathrm{kWe}$. This power level represents an electrical output that is $16.9 \%$ of full load for the generator. At this part load operation the manufactures quoted generator efficiency is $49.6 \%$. Thus the mechanical output power from the Biphase turbine was $253 / 0.496$ or $510 \mathrm{~kW}$.

\subsubsection{Availability Tests}

The first availability test coincided with the production test described above. During the period of 166 hours described above the availability of the Biphase turbine was $100 \%$. The test was terminated when an Annubar flowmeter, external to the Biphase turbine, failed producing a massive steam leak which required a controlled shutdown of the Biphase turbine.

The second availability test was started after repairing the Annubar leak. The Biphase turbine was operated for 70 hours with extremely stable output at $100 \%$ availability. This test was terminated by failure of the control system described previously. The control system failure caused damage to the bearings and seals and resulted in the turbine being placed in a secured status.

\subsection{Operational Experience}

\subsubsection{Biphase Turbine}

\subsubsection{Startup}

It was demonstrated that the Biphase turbine could be started with either steam from the CFE separator or with two-phase flow from the well. With either motive media, the amount of flow to over-come the breakaway torque was typically twice the amount of flow required to maintain rotor speed at $1000 \mathrm{rpm}$. Thus once the rotor started rotation, it was necessary to quickly reduce the opening of the throttle valve to prevent a large over shoot in the turbine speed. The automatic speed control system provided the proper flow throttling to provide an asymptotic speed increase up to the $1000 \mathrm{rpm}$ level. It was necessary however to prevent the throttle valves from going to less than $5 \%$ open upon rotor break-away because the throttle valves did not open until the PID loop signal to the valve was greater than $5 \%$. This was a result of the valves sticking on the valve seat when fully closed. Once this problem was overcome the speed ramps from zero to $1000 \mathrm{rpm}$ and from 1000 to $3600 \mathrm{rpm}$ were performed without problem, under control of the speed controller.

\subsubsection{Performance}

The power output from the Biphase turbine was predictable and controllable. As previously discussed the decline in wellhead pressure and enthalpy was such that the fixed area two-phase nozzles could not swallow the entire flow without increasing the wellhead pressure. This in turn decreased the flowrate, which resulted in less steam for the central power plant. 
The bypass of some flow did not interfere with control or power production. However, it did create an uncertainty as to the enthalpy at the nozzle inlet due to preferential bypass of steam relative to water due to the 90 degree turn at the bypass location.

As discussed in Section 6 the measured performance was very close to predicted performance for the cases where the wellhead pressure was allowed to increase to enable the nozzles to swallow all or nearly all of the flow. The tests further substantiate the results of the two-phase nozzle code and turbine code to determine Biphase turbine performance.

\subsubsection{Solids}

The operational history of the Biphase turbine at Cerro Prieto extends from the first operation of the turbine on geothermal process flow on June 26, 1997 to May 23, 2000 with a total of 437 operating hours. This operation was conducted in series of 35 separate tests. This operating history is contained in Appendix B with a detailed description for the 35 tests contained in Appendix K. Three of the tests, 33, 34, and 35, were of extended duration totaling 287 hours. The remaining 33 had an average duration of 4.7 hours. Except for the first 9 tests, which were limited in duration by the electrical system operations, the remaining 24 tests were limited in duration primarily because of solids deposition related problems.

The solids deposition were chemically analyzed and found to consist of a range of iron oxides as shown in the analysis reports in Appendix C.

The solids deposits accumulated, due to centrifugal separation from the liquid, on the turbine rotor rim. There was little solids accumulation on the nozzle side of the rotor rim as a result of the 1000 $\mathrm{ft} / \mathrm{s}$ nozzle exit flow maintaining the solids suspended in the liquid until the liquid passed thru the rotor disc. After passing thru the liquid transfer holes the solids are free to separate from the liquid and build-up on the rotor rim.

Once the solids thickness exceeded the 0.22 inch gap between the rim and the diffuser inlet, there was physical contact between the solids, which has a tangential velocity of $487 \mathrm{ft} / \mathrm{s}$, and the stationary diffuser. The result of this contact is a rapid increase in rotor vibrations as measured at the four vibration sensors. There are two vibration sensors positioned 90 degrees apart at each bearing. The vibration amplitudes typically remained constant, at 2 to 4 mils, for the first hour of operation while the solids thickness was developing up to the 0.22 inch level. Operations beyond that point, resulted in a continuous increase in vibration at a typical rate of 14 mils per hour. The result of such a vibration increase rate would produced vibration levels at the operating limit for the turbine of 10 mils in 30 minutes.

Post test examination of the rotor and turbine case interior revealed the copious solids deposition on the rotor rim totaling several pounds. The iron oxide solids found on the rotor rim were found to soft, powdery, black in color and oily. Additional iron oxide solids deposits were found on the rotor disc and walls of the turbine case. These solids were significantly different in physical nature. The deposits on the rotor disc would develop to a maximum thickness of 0.06 inch and would then fall off in large, relatively hard pieces. These deposits were analyzed also and found to be of the same general chemical composition as the solids on the rotor. 
The chemical analysis of these two solids are shown in Appendix $\mathrm{C}$ and referred to as hard and medium scales. There are two theories as to the source of the iron oxide solids. The first is that the low ph of the steam results in corrosion of the system piping. The second is the solids first form as iron hydroxide precipitates from the brine during the flash up the well bore. Such a solids deposit would be soft, powdery and white in color. The latter explanation is consistent with several post test examinations of the turbine interior, which showed the solids deposits to be white in color until the admission of atmospheric air allowed the iron hydroxide to react quickly with the oxygen to form the black iron oxide deposits in a matter of seconds.

Subsequent measures were adopted to control and eliminate the solids deposition assuming that both sources of solids production were present. These measures consisted of chemical treatment of the well flow before entering the turbine. These measures were aimed at corrosion and precipitate control and are described in section 4.5.2.3. In the event that neither chemical treatment was able to suppress the solids deposition on the rotor, a rotor wash system was developed as described in section 4.2.2.4 to maintain the solids in liquid suspension until the flow exited the turbine thru the diffuser. The extended duration tests 32,34 , and 35 were intended to include operations to identify the effectiveness of the three scale control measures separately. This was not accomplished because the tests were terminated due to unrelated events.

The conclusion that has been permitted is that the ability to extend turbine operations from the previous average of 4.7 hours up to the maximum achieved of 166 hours was the combined effectiveness of all three systems in eliminating solids deposition on the rotor.

\subsubsection{Bearings}

The bearing assemblies used to support the turbine shaft were a first of a kind design. To eliminate the conventional potential for contamination of either the bearing lubricating oil contamination with geothermal process fluids or the geothermal process fluids with lubricating oil, water was selected as the lubricating media. To prevent the contamination of the water lubricant and bearings by the intrusion of geothermal fluids, the design utilized a bearing cavity pressure, which was maintained at a pressure of $25 \mathrm{psi}$ above the steam pressure within the turbine case.

The use of water as a bearing lubricant required the use of silicon carbide as the material of construction for the load bearing elements. The Glacier Metal Company of Middlesex, England offered this as an option to their standard tilting pad radial bearing design shown in figure 29 . One of these radial bearings was provide at each end of the turbine shaft.

The bearing assembly on the nozzle side of the turbine included a tilting pad thrust bearing with silicon carbide elements as shown in figure 30. These bearings are shown incorporated in the turbine design in drawing D50084. The operating history of this bearing design was excellent. There was no damage or evidence of wear on the silicon carbide elements except for tests 31 and 35 were lubrication system failures resulted in damage to the bearings requiring replacement of the silicon carbide pads. 


\subsubsection{Seals}

In order to provide a bearing housing that could be pressurized up to $450 \mathrm{psig}$ and not permit significant amounts of water leakage either into the atmosphere or into the turbine case, shaft seals were included in the bearing assemblies. Between the bearing housing and the turbine case, a John Crane shaft seal was used. Silicon carbide to carbon sealing surfaces were provided for low leakage rates and seal cooling with the bearing lubricant water. The seal was designed to provide water leakage rates of less than $0.5 \mathrm{gpm}$ with a pressure differential of $25 \mathrm{psid}$ at temperatures up to 225 degrees $\mathrm{F}$ and static pressures up to 450 psig.

The Bergman Seals America Company of Houston, Texas provided the shaft seal between the bearing housing and the atmosphere. The seal design is a carbon to carbon face type seal. The seal was designed to provide water leakage rates of less than $0.5 \mathrm{gpm}$ with a pressure differential of 450 psid at temperatures up to 225 degrees F.

The operating experience with both seals was excellent. No failures occurred except on the occasions of lubricating system failure which damaged the sealing elements.

\subsubsection{Balance of Plant}

\subsubsection{Steam Turbine Startup}

The steam turbine was installed at the power plant site after the Biphase turbine. Operational tests of the steam turbine seal system were conducted to verify the proper operation of the steam seals, which isolates the geothermal steam from the turbine bearing lubrication oil system.

The seal system is shown schematically in Appendix O, drawing 665-065-001. The seal system provides a means of preventing the mixing of steam, which leaks across the labyrinth seal with the oil, which leaks across the oil seal. A steam-operated ejector provides a vacuum of 10 inches of water to draw the leakage steam for mixing with atmospheric air from the vented side of the oil seal.

The steam turbine was readied for tests on November 19, 1999 with the completion of electrical control and instrumentation system tests. The details of the steam turbine electrical and control system are contained in Appendix P drawing bac990600 sheets 1 thru 45.

\subsubsection{Performance}

The steam turbine was first operated on July 22,1999 up to full speed, $(24,845 \mathrm{rpm})$ at no load. Steam was obtained from the exit of the CFE wellhead flash tank since the Biphase Turbine was not operational.

Electrical power system calibrations and loop tests were completed with the first power output to the utility grid in December 1999.

The operating summary for steam turbine operations to date is shown in table 7 which shows a maximum power output of $600 \mathrm{kWe}$. This power output is consistent with the off-design conditions 
resulting from the steam inlet and outlet pressures of 120 and 16 psia respectively in lieu of the steam pressures of 350 and 120 respectively at design.

\subsubsection{Chemical System}

The Chemco Water Technology Company of Vancouver, Washington provided the system designed to provide chemical injection for solids deposition control. The system provides chemical injection at three locations as shown in the schematic in figure 31. The chemicals names, feed rates, purpose are summarized as follows:

$\begin{array}{cccl}\begin{array}{c}\text { Injection } \\ \text { Location }\end{array} & \begin{array}{c}\text { Chemco Product } \\ \text { No. }\end{array} & \begin{array}{c}\text { Feed Rate } \\ \text { Ml/min. }\end{array} & \text { Purpose } \\ \text { No. } & & 21 & \text { Solids precipitation prevention } \\ 1 & \text { DPL270 } & 26 & \text { Corrosion prevention } \\ 2 & 6861 \mathrm{~S} & 4 & \text { Anti-foaming agent }\end{array}$

The chemicals were provided in 200-gallon tote type containers. The flow of the chemicals from the totes is provided by variable-displacement, chemical metering pumps schematically shown in figure 32. The required flow rates are established by adjusting the pump displacement with the aid of the draw-down cylinder, which provides a means of timing the volume change to establish the flow rate. The flow is injected into the process thru an injection quill, which is shown in figure 33 .

The chemical injection system was placed in operation between tests 30 and 31 . Based on the observations that solids deposition on the rotor was not a problem limiting turbine operations after test 30 , the chemical injections were at least partially responsible, since previous operations of the rotor wash system alone did not eliminate the solids deposits on the rotor. The exact benefit of the chemical injection as compared to the water wash system was not evaluated.

\subsubsection{Instrumentation}

The various types of process instrumentation are listed below with the comments regarding their operational performance in regard to accuracy and reliability

Type of Process

Measurement

Manufacturer

Model No.

Accuracy

Reliability

Pressure

Static-Gauge

Rosemont

pt 1120

dpt 1120

Differential Liquid Level Rosemont

dpt1120

excellent

excellent

Differential Flow rate Rosemont

excellent

note 1

Temperature

Geothermal process

Omega

TE type J

excellent

note 2 


\section{Flow Rate}

Geothermal steam \& liquid Merian

Speed

Turbine

\section{Vibrations}

Turbine rotor

\section{Power}

Generator electrical

Generator electrical
Accutube 23L medium note 3

excellent excellent

Bentley Series $1600 \quad$ excellent excellent

Electro-Ind. excellent

excellent note 4

excellent

Note 1: the use of differential pressure transducers for liquid level measurement on a process where the static pressure was an order of magnitude greater than the differential pressure to be read was not a reliable situation because of operator errors in the accidental application of full process pressure to one side of the transducer causing damage to the transducer.

Note 2: the use of $1 / 4$ " diameter inconel sheath thermocouples were not reliable when inserted into geothermal process streams unless protected by a $3 / 4$ " schedule 80 thermo-well

Note 3: the flow meter assembly proved to be unreliable due to the corrosion of the attachment pipe which corroded to develop a major leak forcing the termination of test 34

Note 4 the wattmeter was very difficult to field calibrate because of the requirements to download required software over the Internet or via modem.

The details of the instrumentation and control system inputs and outputs are shown in Appendix Q.

\subsubsection{Lubrication System}

A detailed description of the water lubrication system for the Biphase turbine seals and bearings is contained in Appendix R. The lubrication system was the most difficult of the power plant subsystems to operate properly. The operating difficulties were caused by 1) the inability of the water pumping system to maintain a constant pressure differential of 25 psid between of the water supply pressure and the steam pressure within the turbine and 2) the type of pumps used to pressure the water used for bearing cooling and lubrication.

There were two major manifestations of the above two conditions. The first was the lubrication system characteristic that caused problems was the inability of the pumping system to maintain the $25 \mathrm{psi}$ differential of the water pressure in the bearings above the turbine casing steam pressure. The problem was most serious when the turbine was being throttled up or down. In this case the steam pressure could be varied between 50 and 350 psig but the water pressure could not be maintained at the 75 to 375 psig levels without some variations which on some occasions allowed the differential to go to zero and as high as $100 \mathrm{psid}$. The result on several occasions was damage to the shaft seals.

The second manifestation of the pump-induced problem was related to the pumps used initially being piston-type positive-displacement pumps. These pumps apparently had output pressure pulsation that excited a mode of vibrations within the bearings. This mode of vibration was 
undetectable until the vibrations caused by solids deposition on the rotor were eliminated with the rotor-wash system, which did not become effective until after test 25 .

Test 26 was the first test where the high pressure water jet system was used to prevent the buildup of the solids deposits but was also used to eliminate the oscillatory vibrations caused by the water lubrication pump pressure pulsations. The oscillatory nature of the vibration is shown in figure 34 . This is a one-hour vibration record for the four radial vibration momtors and the one axial thrust monitor during the turbine startup with steam only, at time "a" the water jet system was activated which completely eliminated the oscillatory vibrations. For monitor no. 5 which is the "y" sensor on bearing no. 2 the vibration amplitudes were varying from 3.75 to 9 mils with a 2 minute period.

When the water jet was activated the amplitude was reduced to a steady value of 3 mils. After 5 minutes the water jet was stopped and the oscillatory vibrations returned immediately. at time " $b$ " the water jet was re-established and left on four the duration of the startup which the addition of twophase well flow at time "c". At time "d" the startup was complete and steady state Operation was established at about the $75 \mathrm{kWe}$ output power level and the water jet was stopped.

The oscillatory vibrations experienced during the steam startup, did not return because the two-phase nozzle flow onto the rotor provides the same type of loading of the bearings to suppress the vibrations produced by lubrication water pressure pulsations within the bearings. For the remaining five hours of operation, the water jets were activated every fifteen minutes for 30 seconds at a flow rate of $5 \mathrm{gpm}$. This was concluded to have been sufficient water jet cleansing of the rotor to prevent the previously observed buildup of solids.

Figure 35 shows the same vibration records as figure 34, but over the entire 5 hour duration of test 26. For the operating period from 11:40 to shutdown at 16:2 1, the flow conditions were held constant and the power output remained at approximately $400 \mathrm{kWe}$. During this period the vibration trends displayed previously unseen characteristic where their average amplitude of 4 mils peak-topeak (ptp) was varying sinosoidally between 1.5 and 6.5 mils with a period of 1.2 cycles per hour. This period of sinosoidal variation of the vibration amplitudes was exactly 100 times slower than the oscillatory vibrations during the startup with steam alone where the sinosoidal variations of vibrations were 120 cycles per hour. This change in the period of vibrations is considered a result of the dynamic damping of the two-phase flow onto the rotor, which suppresses the dynamic instability in the bearings, which are excited by the pressure pulsations of the lubrication system.

Figure 36 shows the process data corresponding to figure 35. Figure 37 shows the corresponding lubrication system data. Figure 38 shows the corresponding valve position data and figure 39 pressure data.

The hypothesis of bearing instability excited by pump pulsations was further substantiated in tests 27,28 and 29 which were repeats of test 26 but with the hydraulic pulsation damper installed on the lubrication water pump discharge. In these three tests similar steady state operation was maintained with the water jets as used previously, but there were no variations of the vibration levels observed during startup or at power levels at 50,75 or $100 \%$ of rated power of $800 \mathrm{kWe}$.

Runs 28 and 29 demonstrated similar proper vibration characteristics. During run 29 while operating 
at nearly full power of $750 \mathrm{kWe}$, a structural failure occurred to section of tubing supporting one of the water jet nozzles. The section of tubing that failed was one half inch in diameter and three inches long. This short tube section was attached to the inside wall of the turbine case and terminates at the three inch length of the tube where the jet nozzle is attached.

This jet is positioned to direct the water jet on the inlet of the steam blades. A calculation shows the tube failure may have been due to fatigue from cyclic pressure fluctuations caused by the steam blade passing frequency. As a result of the tube failure the tube and water nozzle weighing $3 \mathrm{oz}$. total fell into the turbine rotor rim. This caused a step change in vibration amplitude levels from 4 to 12 mils with no other untoward effects. The turbine was powered down normally and opened for inspection to reveal no other damage. The bearings and seal were subsequently removed and inspected to show no effects of this incident or the prior 133 hours of operation. .

Following the lubrication pump failure which terminated test 31 on June 9, 1999, the lubrication system was re-designed to permit replacement of the piston pumps with multistage centrifugal type pumps Over the course of the next series of tests 32 thru 35 with 290 hours of turbine operation there were no experiences of solids or pump induced vibrations.

\subsubsection{Valves}

The control of the Biphase and steam turbines was accomplished by the remote control of pneumatically operated valves. Masonelean camflex type control valves were selected for this function. The listing of the control valves is shown in Appendix S. These valves were very unreliable. They operated reliably between $10 \%$ and fully open under some conditions. The valves would not respond to control signals to move from closed to anywhere between zero and $10 \%$ open and would open instantly to any position above $10 \%$. With full well head pressure of 600 psig or above the valves would not open.

The valves that were to operate with process pressures above 350 psig were replaced with Fisher eccentric type ball valves, which eliminated the opening problem at high pressure and reduced the closing time from 2.5 seconds to 1.4 seconds. The same problem of not opening smoothly from the closed position still existed but the range was reduced from zero to $10 \%$ open to zero to $5 \%$.

\subsubsection{Control System}

The control system for the Biphase turbine was overly sophisticated for a first of, demonstration project. The automatic ramps programmed into the system had to be continually over ridden to perform startup and load changing operations. Two internal power supply failures occurred.

The first power supply failure occurred before Biphase turbine operations were begun and caused no problems. The second power supply failure occurred 70 hours after the start of test 35 and resulted in damage to the turbine bearings because the control module was not programmed to execute an emergency shut-down of the turbine in the event of a failure of the control system modules.

In addition, the particular module that failed had been programmed to operate the lubrication pumps. The pumps were not provided with latching relays and were turned off when the module failed. 


\subsubsection{Well Pressure and Enthalpy Decline}

The observed decline in maximum power production capability of the Biphase turbine was correlated by performance calculations for the turbine using the well flow, pressure and enthalpy data measured by CFE. The CFE data is shown in figure 40 for well 103 for the period 1995 thru 2000. These data show a steady decline in the wellhead enthalpy from 830 to $630 \mathrm{Btu} / \mathrm{lbm}$ and a corresponding decrease in wellhead pressure from 950 to 580 . The well production rate has remained relatively constant at 140 metric tons per hour by periodically increasing the size of the throttling orifice at the wellhead.

\subsubsection{Project Subcontractors}

The Biphase turbine power plant was designed, constructed, and installed with the aid of the subcontractors listed in Appendix T. 


\section{Electrical generation delivered to $\mathrm{CFE}$}

The total electrical power generation delivered to CFE over the 2 year 9 month period of operation was $77,549 \mathrm{kWh}$. Table 8 provides the energy delivered during each of the periods of operation described in Appendix B.

The peak power of the Biphase turbine, $808 \mathrm{kWe}$, was close to the estimated power, $806 \mathrm{kWe}$, at the time the project was started. However, as previously described, the problems with solids and balance of plant equipment diminished the total time on line.

Energy delivery would have been greater with the steam turbine, but the decline in wellhead enthalpy and pressure limited the total power that could be generated. 


\section{Comparison of Predicted and Measured Performance}

A comparison of predicted power with the measured power showed the Biphase turbine to be operating at power levels close to those predicted by the nozzle and turbine codes discussed in Section 2. Figure 41 compares the measured power with predicted. Measured electrical values are corrected by the generator curves of figure 22 to obtain shaft power which is compared to predicted shaft power.

Agreement within about $5 \%$ is demonstrated for the tests operated at the highest wellhead pressures and the corresponding inlet pressures (605-610 psia). At lower, off-design wellhead pressures good agreement was still obtained except for cases where significant bypass flow was required.

The main uncertainties in the predicted values are the wellhead enthalpy and the total flow rate through the Biphase turbine.

The wellhead enthalpy used was the value determined by CFE in testing the well. Well tests are done several times per year. The steam flow rate and brine flow rate are determined while manually maintaining a level in the separator. Measurement of the wellhead pressure and separator pressure provides the information necessary to determine the enthalpy. In calculating the expected power from the Biphase turbine, the measured previous wellhead enthalpy closest to the test date was utilized.

Figure 42 is a copy of the well 103 parameters measured by CFE since 1990 . The values of wellhead enthalpy utilized for the three operational conditions are marked on the curve.

The flowrate through the Biphase turbine is dependent on the wellhead enthalpy, the degree of throttling and the amount of flow bypassing the turbine. For many conditions some flow must bypass the turbine because the two-phase nozzles have a fixed throat area which dictates how much flow can be swallowed. Accurate measurements of the bypass flow rate was not possible since it was twophase flow.

The flowrate predicted by the two-phase nozzle code has been found to be within $5 \%$ of the measured flow, reference 8 . Therefore the actual nozzle throat area was used with the code to predict the flowrate and subsequently, power.

The bypass valve partitions the flow such that some goes to the separator and some to the Biphase turbine. However, the degree of steam-brine partitioning is not known. If a significant bypass flow is encountered the amount of steam flowing through the bypass may be more or less than the average for the flow. This in turn can either increase or decrease the inlet enthalpy for the Biphase turbine.

To compare the power, those runs with a small bypass or no bypass flow were utilized. These are the test runs of $11 / 7 / 97,8 / 14 / 98,6 / 3 / 99$ and $3 / 31 / 00$. The code output data for these runs are provided in Appendix $Y$. 


\section{Availability}

\subsection{Biphase Turbine}

The Biphase turbine had a low availability prior to development of an effective solids handling device. From the start of two-phase flow on August 20,1997 until failure of the lubrication system in June 1999 the turbine logged 437 hours of a total of 24,168 hours available for an availability factor of $1.8 \%$. The majority of this down time was spent waiting for replacement parts, re-designing and fabricating solids apparatus and waiting for funding. After restart in March of 2000 with an effective two-phase online washing system the turbine logged 290 hours out of an available time exclusive of balance of plant problems of 290 hours for an availability of $100 \%$. The plant availability was $22 \%$.

Examination of the turbine after 437 hours showed no erosion or corrosion damage. Mild scaling on the outside of the rotor was experienced but the scale periodically flaked off during operation, similar to the 4000 hour Biphase turbine demonstration at Roosevelt Hot Springs.

Figures 43 and 44 are photographs of the nozzles after operation. As can be seen sharp corners still exist and no internal deposits resulted from the testing.

Figure 45 shows the two-phase separation surface. No erosion, corrosion or scale was produced by the two-phase nozzle flow which reached absolute velocities in the $1100 \mathrm{ft} / \mathrm{s}$ range and relative impingement velocities in the $600 \mathrm{ft} / \mathrm{s}$ range.

The diffuser side of the separator is shown in figure 46 after operation. The effectiveness of the twophase online washing is apparent as there are no solids deposits.

The diffuser inlet is shown in figures 47 and 48. Sharp corners are still present and no erosion or liquid cutting occurred.

The excellent condition of the Biphase turbine flow surfaces as well as the results of the 4,000 hour demonstration Biphase turbine at Roosevelt Hot Springs support the readiness of this technology for geothermal applications.

\subsection{Balance of Plant}

The performance of the balance of plant was not adequate to support the Biphase turbine operation. As described earlier several problems developed, some of which caused damage to mechanical components of the turbine. All of the problems were resolved except for the failures in the $\mathrm{ABB}$ control system, which caused the final failure of the bearings and seals on the turbine. The total operating time for the plant was 437 hours. The total available time until failure of the control system was 24,168 hours. The total availability was $1.8 \%$. However, by far the largest fraction of plant down time was due to development of a solids handling method and due to waiting for replacement components due to a lack of resources for adequate spare parts. If the time due to these problems is subtracted from the available operating time the estimated availability would be $80-90 \%$. 


\section{Improvements in the Biphase Turbine}

\subsection{Dual Pressure Rotor Design}

A new rotor design was completed which can be applied to the geothermal turbine to improve the efficiency. It is based on the Euler turbine, but with the improvement of adding a second pressure letdown.

The single pressure Euler turbine was invented in 1754 by Euler. The original application for the turbine was as a water wheel. The turbine converts incoming kinetic energy in a fluid stream to shaft power through an internal compression and re-acceleration process.

Figure 49 is an example of the single pressure Euler turbine. Fluid, 1, is accelerated in a nozzle, 2, forming a stream having kinetic energy. The stream has its tangential component either accelerated to or decelerated to the velocity of the turbine structure, 3 . The rotating liquid flows radially outward, $\mathbf{4}$, at a velocity that is low relative to the incoming tangential velocity. This characteristic is a key difference from normal impulse or reaction turbines. The centrifugal acceleration field created by the rotating structure produces a body force on the fluid, increasing its pressure. At the periphery of the structure, $\mathbf{5}$, the increased pressure is utilized to accelerate the fluid through a nozzle, $\mathbf{6}$, acquiring a velocity relative to the rotating structure in the direction counter to the rotation of the turbine structure. The fluid leaving the structure has an absolute velocity below the velocity of the tip of the rotor. This illustrated in the velocity diagram in figure 50. The energy transfer into the rotor is determined from Euler's equation:

$$
\mathrm{H}=\mathrm{C}_{1} \mathrm{U}_{1}-\mathrm{C}_{2} \mathrm{U}_{2}
$$

Where:

$$
\begin{aligned}
& \mathrm{H}=\text { the head transferred to the rotor } \\
& \mathrm{C}_{1}=\text { the tangential component of velocity of the fluid leaving } \\
& \text { the first nozzle } \\
& \mathrm{U}_{1}=\text { the tangential component of the rotor velocity at the } \\
& \text { location of the first nozzle } \\
& \mathrm{C}_{2}=\text { the absolute velocity of the fluid leaving the rotor at the } \\
& \text { exit of the second nozzle } \\
& \mathrm{U}_{2}=\text { the velocity of the rotating structure at the location of the } \\
& \text { second nozzle }
\end{aligned}
$$

For an incompressible fluid the pressure rise is given by:

$$
\mathrm{p}_{2}-\mathrm{p}_{1}=\rho \omega^{2}\left(\mathrm{r}_{2}^{2}-\mathrm{r}_{1}^{2}\right) / 2 \mathrm{~g}
$$

Where:

$\mathrm{p}_{2}=$ the pressure at the inlet of the rotating (second) nozzle

$\mathrm{p}_{1}=$ the pressure at the exit of the stationary (first) nozzle 


$$
\begin{aligned}
& \rho=\text { fluid density } \\
& \omega=\text { rotational speed } \\
& r=\text { radius to stations } 2 \text { and } 1 \text { respectively } \\
& g=\text { gravitational constant }
\end{aligned}
$$

If the fluid is expanded through the second nozzles the relative velocity produced is:

$$
\mathrm{W}_{2}=\eta_{\mathrm{v} 2}\left[2 \mathrm{~g}\left(\mathrm{p}_{2}-\mathrm{p}_{1}\right) / \rho\right]^{1 / 2}
$$

Where:

$$
\eta_{\mathrm{v} 2}=\text { velocity coefficient of second nozzles }
$$

The efficiency of power transfer is given by:

$$
\eta_{\mathrm{t}}=\left[\mathrm{C}_{1} \mathrm{U}_{1}-\left(\mathrm{U}_{2}-\mathrm{W}_{2}\right) \mathrm{U}_{2}\right] / \mathrm{C}_{1}{ }^{2} / 2
$$

The efficiency of the Euler turbine is limited by the extent of the centrifugal pressure rise and the resulting relative velocity $W_{2}$, which is always less than the rotor tip speed $U_{2}$. When applied to the separated brine on the geothermal turbine rotor an energy conversion efficiency of 70-80\% can be attained instead of $50 \%$ efficiency produced by the "drag turbine" geometry of figure 12. Figure $50 \mathrm{a}$ is a photograph of a two-phase Euler turbine which demonstrated this advantage.

The steam energy can also be converted in an Euler turbine passage as described above. A hitherto unknown method to increase the relative velocity $\mathrm{W}_{2}$, thereby increasing the efficiency of the Euler turbine, is to provide a further decrease in the pressure leaving the steam Euler passage (seals are provided between the water Euler passage outlet and the steam Euler passage outlet to prevent the saturated water from flashing in the rotating nozzles). In doing so the single rotor machine is converted to a two-stage steam turbine and becomes a combined impulse and reaction steam turbine with internal compression.

Figure 51 is a basic illustration of a dual pressure Euler turbine, reference 9 . The fluid in the first nozzle is expanded from the initial pressure $p_{0}$ to a pressure of $p_{1}$. Once again the fluid becomes locked into the moving rotor structure at the inner radius $r_{1}$. Fluid flows radially outward while being locked into the rotor structure. A seal, 7, is provided such that the pressure of the surrounding fluid can be maintained at a value $\mathrm{p}_{3}$ which is lower than the pressure into which the first nozzle discharges. The fluid is reaccelerated in the second nozzle at the tip of the rotor; however, the pressure difference, $\mathrm{p}_{2}-\mathrm{p}_{3}$, is no longer limited by the centrifugal pressure rise. Instead, the pressure difference is the sum of the centrifugally induced pressure rise plus the pressure difference between the pressure at the exit of the first nozzle and the ambient pressure $p_{3}$. The relative velocity is then:

$$
\mathrm{W}_{2}^{\prime}=\eta_{\mathrm{v} 2}\left[2 \mathrm{~g}\left(\mathrm{p}_{2}-\mathrm{p}_{1}+\mathrm{p}_{1}-\mathrm{p}_{3}\right) / \rho\right]^{1 / 2}
$$

This equation shows that the relative velocity can be increased to as high a value as desired by decreasing $\mathrm{p}_{3}$. 
Figure 52 shows two velocity diagrams for the dpE turbine. For the first velocity diagram, the exhaust pressure is lowered just enough that the absolute liquid velocity leaving the turbine is zero. In this case, the head produced is equal to:

$$
\mathrm{H}=\mathrm{U}_{1} \mathrm{C}_{1}
$$

In the second diagram, the pressure has been lowered such that the absolute leaving velocity is in the opposite direction from rotor speed. In this case, the power transferred into the rotor is:

$$
\mathrm{H}=\mathrm{U}_{1} \mathrm{C}_{1}+\mathrm{U}_{2} \mathrm{C}_{2}
$$

The added work occurs at a high tip speed and hence, the added work is very efficient.

The basic principles are the same for a gaseous or vapor working fluid as for liquid. In this case, from reference 10 , the centrifugal pressure rise is:

$$
\mathrm{p}_{2} / \mathrm{p}_{1}=\left[1+\omega^{2}\left(\mathrm{r}_{2}^{2}-\mathrm{r}_{1}^{2}\right)(\kappa-1) / \kappa 2 \mathrm{~g}_{\mathrm{c}} \mathrm{ZRT}_{1}\right]^{\kappa /(\kappa-1)}
$$

Where:

$\kappa=$ specific heat ratio of vapor

$\mathrm{Z}=$ compressibility

$\mathrm{R}=$ perfect gas constant

$\mathrm{T}_{1}=$ temperature at entrance of moving rotor

The relative velocity from the nozzle expansion is:

$$
\mathrm{W}_{2}=\eta_{\mathrm{v} 2}\left[2 \mathrm{~g}_{\mathrm{c}} \mathrm{J}\left(\mathrm{h}_{2}-\mathrm{h}_{3 \mathrm{i}}\right)\right]^{1 / 2}
$$

Where:

$\mathrm{J}=$ Joule constant

$\mathrm{h}_{2}=$ enthalpy at outer radius of compression section (at rotating nozzle

entrance)

$\mathrm{h}_{3 \mathrm{i}}=$ isentropic enthalpy at exit pressure, $\mathrm{p}_{3}$

The power and efficiency relations previously presented remain the same.

Figure 53 is a plot of efficiency versus intermediate expansion pressure for a dpE turbine operating with steam only. The calculation considers windage, seal and momentum losses as well as nozzle efficiencies. In this case, the efficiency is 0.57 at the limit where the intermediate pressure is equal to the final discharge pressure of 29.7 psia corresponding to a single pressure Euler steam turbine. As the intermediate pressure is increased, the efficiency reaches a maximum of 0.81 at an intermediate pressure of $50 \mathrm{psia}$. In the limit where the intermediate pressure is equal to the inlet pressure of 74.7 psia, the dpE turbine becomes a Hero turbine and the efficiency is only 0.49 


\subsection{Performance Of Dual Pressure Rotor For Well 103}

The above relations were programmed into a DPR code. The power contribution from the separated liquid is determined by operating the nozzle code and the rotary separator turbine code considering only the liquid contribution. The power contribution from the steam is determined by operating the DPR code using the separated steam conditions as the input parameters.

For Well 103, Table 5 gives the nozzle code output at the current conditions for expansion to 167 psig. The exit velocity, $1080 \mathrm{ft} / \mathrm{s}$, and the brine flow rate, $48.24 \mathrm{lb} / \mathrm{s}$, and the steam flowrate, 23.76 $\mathrm{lb} / \mathrm{s}$, were input to the rotary separator turbine code. The results are given in Table 9 . The gas blading output was deleted for clarity. As shown the net liquid power output including the highpressure steam windage, bearing and seal losses is $489 \mathrm{~kW}$ shaft power.

The steam tangential velocity at the radius of the Euler passage inlet is $1020 \mathrm{ft} / \mathrm{s}$, lower than the nozzle exit velocity of $1080 \mathrm{ft} / \mathrm{s}$, due to the cosine loss and frictional losses on the separator. Using the existing casing gave an outer radius of 32 inches for the steam Euler passage. The existing generator required an rpm of 3600. Application of the dual pressure code to the steam with an inlet pressure of 171.7 psia and an exit pressure of 125 psia produce the results of Table 10 .

The steam power in the Euler passage is $767 \mathrm{~kW}$ shaft. When added to the liquid power this gives a total output of $1256 \mathrm{~kW}$. The additional steam power due to the Euler passage is $480 \mathrm{~kW}$ (subtracting the reference axial impulse blade power of $289 \mathrm{~kW}$ ). This corresponds to a back pressure steam turbine efficiency of 0.73 for the steam conditions - without the capital cost and complexity of the backpressure turbine. At this load the manufacturer's efficiency curve for the existing generator gives a value of 0.95 . The electrical output would be $1193 \mathrm{kWe}$ for the existing equipment.

As a comparison, the rotary separator turbine code predicts a shaft power of $664 \mathrm{~kW}$ and a generator output power of $426 \mathrm{kWe}$ for the existing 30RSB at the current well 103 conditions (the generator efficiency from the manufacturer's curve is only .64 at this high degree of part load). The measured power at this point $395 \mathrm{kWe}$ was in very close agreement. The backpressure steam turbine generated only $66 \mathrm{kWe}$ at these conditions because of the poor part load efficiency. Thus the maximum total power from the existing Biphase 30RSB and backpressure steam turbine at these conditions is 461 kWe.

If a smaller backpressure steam turbine could be used with an efficiency of $70 \%$ at the existing flow conditions the power that could be generated from this combination is $855 \mathrm{kWe}$.

Thus, the DPR rotor can generate significantly more power for the existing wellhead conditions than the 30RSB Biphase turbine plus the backpressure steam turbine.

The leaving steam velocity is $614 \mathrm{ft} / \mathrm{s}$. If a higher rotor speed and gearbox were used this loss could be reduced. For a $7200 \mathrm{rpm}$ rotor and gear box the leaving velocity is reduced to only $110 \mathrm{ft} / \mathrm{s}$ and the steam Euler power increased by about $200 \mathrm{~kW}$. 
In order to compare the Biphase DPR turbine with the existing plant and a flash steam turbine topping plant a previous test run at higher pressure (Scan 261) was analyzed. The following results were obtained:

- Flash Steam Turbine Topping Plant (70\% turbine)

$1571 \mathrm{~kW}$

- Measured 30RSB plus 70\% Backpressure Steam Turbine $1824 \mathrm{~kW}$

- Biphase DPR turbine @ 7200 rpm

$2064 \mathrm{~kW}$

Thus a significantly higher power output is attainable with a lower capital cost and less controls and ancillary systems. Estimates for additional power plants show a reduction in capital cost from $\$ 523 / \mathrm{kW}$ to $\$ 395 / \mathrm{kW}$ without considering the power increase.

\subsection{Design Of Dual Pressure Rotor To Retrofit Existing Turbine}

A DPR rotor was designed to be installed in the existing 30RSB turbine at well 103 to demonstrate its performance. The design criteria were:

- Utilize existing nozzles, casing, generator, seals and bearings

- Internal modifications to casing permitted to install DPR seals and liquid removal volute

- Low fabrication cost

The DPR replacement rotor is shown in figure 54. Two-phase flow from the nozzles impinges on the separator surface, $\mathbf{1}$. The separator surface and lips are identical to the existing rotor.

The separated liquid slows to the rotor surface velocity adding power to the rotor. The liquid flows through the entrances to the Euler passages, 2. The liquid flows radially outward in the Euler passages, is pressurized by the high $\mathrm{G}$ field and is accelerated through the liquid reaction nozzles, $\mathbf{3}$, adding power to the rotor.

The separated steam flows through the supporting ribs, 4, and enters the steam Euler passages. The steam flows radially outward in the Euler passages and is compressed by the high $\mathrm{G}$ field. The steam is accelerated through the steam reaction nozzles, $\mathbf{5}$, to a lower pressure than the separation and liquid exit pressure. For the existing well conditions analyzed above, the separation pressure and liquid exit pressure is 171.7 psia. The steam exit pressure is 125 psia.

Labyrinth seals, 6, are machined into the rotor to minimize steam leakage from the separator space and liquid exhaust space into the steam exhaust space. The seals are designed for a maximum leakage of $2 \%$ of the steam flow which is a $2 \%$ power reduction on the steam power.

Figure 55 is a cross section of the DPR replacement rotor which shows the steam Euler passages, 1 , which are fed by the separated steam.

The weight of the rotor, axial dimensions and shaft bore are identical to the existing 30RSB rotor, thus the shaft seals and bearings see the same duty. The diffuser and diffuser side online washing system are eliminated. Figure 56 shows a cross section of the installation of the DPR rotor in the 
existing turbine. As shown the required modifications are very straight forward to incorporate the new rotor.

An on line washing system will be added to periodically clean the steam Euler passages. It should be noted that there are no sharp corners on the steam passages or anywhere else. No diffuser is required. These factors, in themselves should improve the durability of the rotor relative to the axial flow blading in the $30 \mathrm{RSB}$ rotor. 


\section{Impact of Biphase Technology on Geothermal Power Production}

\subsection{Cost of Power}

In order to examine the economics of addition of Biphase topping turbines a phase 2 project was examined.

Phase 2 of the Biphase application to Cerro Prieto consists of 10 existing wells to be equipped with Biphase wellhead power plants. These plants will add about $20 \mathrm{MW}$ to the Cerro Prieto output. The Biphase turbine Model 30 RSB with a dual pressure rotor would be applied to the wells.

For the design presented here, each Biphase turbine plant includes a dual pressure rotor. Steam exits the Biphase turbine at the pressure required by the Cerro Prieto central plants.

Geothermal wells were selected for a Phase 2 project design on the basis of pressure, steam, quality, flow rate, and required delivery pressure. In order to make this selection available well data from 1997 was used. Calculations were made to define the Biphase power plant output for each well. Wells capable of $700 \mathrm{~kW}$ or more Biphase output (singly) were considered for Phase 2.

Cerro Prieto central plant CP-I accepts steam from wells at pressures of 119 to 126 psia. Four of the wells selected for the conceptual design deliver at this pressure; they are E15, M47, E2 and E59. These wells are grouped in 2 pairs for Power Plants RSB-2 and RSB-3. The Phase 1 Well 103 designated RSB-1 is included in this group.

Six selected wells deliver steam to central plant CP-II at 198-215 psia; these are E46, M198, E27, E56, E48 and E49. These wells are grouped in 3 pairs, RSB-4, RSB-5 and RSB-6.

Well characteristics and plant power levels are summarized in Table 11. Table 11 gives power levels possible with individual Biphase power plants if they were built on the individual wells. In practice, one larger Biphase plant would be built for each pair of wells, as shown in Table 12. It can be noted that the power delivered by a pair of wells is less than the sum of power possible from individual wells. This power loss occurs in mixing the flows and in loss in the extended piping.

Each of the five new Biphase power plants would be equipped with an automatic control system similar to that operating in the Phase 1 plant. All six of the plants, including RSB-1, would be monitored and controlled from one central control station, which would be manned with an operating staff. None of the plants will be manned during normal operations. The central control station will also serve as the headquarters for maintenance activities. The power plants would be connected to the central control station by fiber optic cable.

Each power plant would have independent electrical systems, including switchgear and protective relaying. Electricity would be generated at $4160 \mathrm{~V}$, metered and delivered at this voltage. At each group of plants, a power transformer would be installed so that the electricity can be delivered to $\mathrm{CFE}$ at $13.8 \mathrm{kV}$.

The cost of the Phase 1 Power Plant RSB-1 is known with good accuracy because of the completion 
of the plant and its installation.

The cost of RSB-1 power plant is given in Table 13. Engineering, the turbine skid costs, electrical and control cost, and installation cost are given. Research and development costs associated with the initial project are not tabulated. They will be amortized for the total project power of 80 megawatts.

A proforma, Table 15, was prepared for the five plants to be constructed in phase 2 .

Assumptions for the proforma are:

- Financing and power sales agreement, 10 years

- Power sales at 3.5 cents/ $\mathrm{kWh}$ equivalent, escalated at $2 \%$

- Fuel price to CFE is $\$ 1.33$ per MMB of steam, a premium of $20 \%$ above CFE's estimated cost

- Escalation of labor at $3 \%$ and maintenance, consumables, royalty and insurance at $2 \%$

- Depreciation period is 10 years

The assumption of a power sales price of 3.5 cents/ $\mathrm{kWh}$ is believed to be conservative. This value is below the "Marginal Cost" forecast in 1999 for Baja California. Douglas Energy believes that the demand for the electricity will continue to increase. Increases in the price of gas will lead to higher values of marginal cost while the price of geothermal steam remains constant. The price is believed to be less than CFE's current cost to generate geothermal electricity. For the five new plants, the proforma of Table 15 indicates a profitable project. Financing was based on financing $80 \%$ of the capital cost for 10 years at $12 \%$ interest. Based on this financing a return on equity of greater than $50 \%$ after taxes results for the phase 2 project. Because of the low power price used in the proforma this is believed to be the minimum case.

As the system procurement plans for the 5 plants develop, a high percent of the components and installation will be procured in Mexico and subject to peso procurement. The Biphase turbine will probably be imported although assembly and casing fabrication may occur in Mexico.

\subsection{Increased Resource Utilization}

The increase in resource utilization will be increased above the values shown in figure 57 because of the improved efficiency of the Biphase turbine resulting from the dual pressure rotor. However, that curve can be used for a first estimation.

To illustrate the application of current Biphase technology to resource efficiency improvement several additional calculations will be made, including a flash steam topping plant and a conventional binary bottoming plant, using well E-54 as an example.

\section{Geothermal Topping with High Pressure Separator and Steam Turbine}

If a steam topping plant is applied to the first stage flash additional power is produced. The power versus flash pressure was calculate with the topping steam turbine expanding to the 200 psia separator pressure from the flash pressure. A steam turbine efficiency of $70 \%$ was assumed, however the outlet wetness at the highest pressure, $10.2 \%$ would probably result in a lower efficiency. 
The results show the maximum power, $1238 \mathrm{~kW}$, to occur in this case with separation at the wellhead pressure and no further flashes. However the highest operational inlet pressure to date for a geothermal steam turbine is believed to be 300 psia. At that pressure the power drops to $624 \mathrm{~kW}$. We believe that $400 \mathrm{psia}$ is the maximum inlet pressure that can be reasonably expected for geothermal topping steam turbines. At that point the added power is $959 \mathrm{~kW}$.

The liquid flow from the $1^{\text {st }}$ stage separator is $202,542 \mathrm{lb} / \mathrm{h}$. Since the flow is all liquid we can use the mean temperature rule for the optimum flash. The temperature at the first flash is $382 \mathrm{~F}$ and the temperature at the second flash is $300 \mathrm{~F}$ ( 67 psia). The optimum will be $341 \mathrm{~F}$ at a saturation flash pressure of 119.5 psia. The additional power generated by the added steam turbine is $95 \mathrm{~kW}$.

\section{Geothermal Topping with Biphase Turbine}

The same well conditions were analyzed for the Biphase turbine with a dual pressure rotor. A performance code was used which is based on the measured results for rotary separator turbines with Euler passages. The code was applied in an iterative manner to reach near optimum for both the high pressure flash and the low pressure flash.

The results are provided in Tables 16 and 17.

For the high pressure flash the output power is $1431 \mathrm{~kW}$ with a net efficiency of 674 .

For the low pressure flash the maximum power is $127 \mathrm{~kW}$ with a net efficiency of 333 .

The total power produced by the Biphase turbines is $1558 \mathrm{~kW}$ versus a total of $1050 \mathrm{~kW}$ for the two topping steam turbine power plants. In either case the energy recovery from the low temperature flash would not be economical to recover so the real economic comparison is $\mathbf{1 4 3 1} \mathbf{k W}$ versus 959 $\mathbf{k W}$, a $49 \%$ increase. The Biphase turbine produces more power with no separator than even the highest pressure case for the steam turbine $-\mathbf{1 2 3 8} \mathbf{k W}$ with a 614 psia separator. This is a $16 \%$ increase without accounting for the ejector steam which will be required by the steam turbine which will reduce the plant steam.

\section{Geothermal Binary Plant}

A conventional binary plant for geothermal power generation from brine is shown schematically in figure 10. As can be seen the binary plant uses a boiler to vaporize the working fluid, such as isobutene, to drive a vapor turbine. The vapor turbine operates at high $\mathrm{rpm}$, typically 15,000 $20,000 \mathrm{rpm}$, and requires a gearbox as shown to drive a conventional generator.

The vapor leaving the turbine is condensed and returned to the boiler.

Because of the vaporization at a constant temperature a pinch point limitation exists on the available energy for conversion. Figure 58 illustrates this problem. The liquid brine has a continuous temperature decrease as the heat is transferred into the binary working fluid. However, the constant temperature of vaporization as the binary fluid receives heat from the brine limits the conversion efficiency for that fraction of the heat. This is illustrated by the temperature difference shown on the 
curve. If the binary working fluid could work in a heat engine at " $T$ " instead of " $T-\Delta T$ " the Carnot efficiency and hence conversion efficiency would be higher.

The binary plant can only be applied to the brine from the second flash. Since it has a low conversion efficiency and rejects its waste heat to ambient, all the heat input above that temperature would lose a corresponding amount of steam to the existing power plant.

For the conditions of well E-54 the total brine flow after conversion in the first flash by a Biphase topping turbine is $204,450 \mathrm{lb} / \mathrm{h}$. After flashing the brine to $67 \mathrm{psia}$ and separating the steam the brine flow is $185,170 \mathrm{lb} / \mathrm{h}$. If the brine is cooled to $150 \mathrm{~F}$ the available heat is $28,125,000 \mathrm{~B} / \mathrm{h}$.

The Carnot efficiency is:

$$
\eta_{\mathrm{c}}=1-\left(\mathrm{T}_{\mathrm{c}} \operatorname{loc} \mathrm{T}_{1} / \mathrm{T}_{2}\right) /\left(\mathrm{T}_{2}-\mathrm{T}_{1}\right)
$$

For the conditions of the well E-54 brine assume T2 $=150 \mathrm{~F}=610 \mathrm{R}, \mathrm{T} 1=285 \mathrm{~F}=745 \mathrm{R}(15 \mathrm{degF}$ heat exchanger difference) and $T c=100 \mathrm{~F}=560 \mathrm{R}$. Then the Carnot efficiency is

$$
\begin{aligned}
\eta_{\mathrm{c}} & =1-(560)(.1999) / 135 \\
& =.1745
\end{aligned}
$$

A typical vaporizing binary cycle has an efficiency that is $50 \%$ of the Carnot efficiency. Therefore we may assume a cycle efficiency that is .087 .

The power generation is therefore:

$$
\begin{aligned}
P_{b} & =(.087)(28,125,000) / 3413 \\
& =717 \mathrm{~kW}
\end{aligned}
$$

If the binary cycle were bottoming a single flash system it could generate more power because of the higher brine temperature as previously shown.

\section{Geothermal Biphase Binary Plant}

The Biphase turbine can be used in a heat cycle which has a higher efficiency than the vaporizing binary. As shown in figure 11, in the Biphase cycle liquid working fluid is heated in a countercurrent, liquid-liquid heat exchanger. The heated working fluid is flashed directly in a two-phase nozzle and impingement turbine generating power. Because of the two-phase flow, the turbine rpm can be $3600 \mathrm{rpm}$ directly driving the generator with no gear box. The two-phase mixture leaving the turbine rejects heat in the condenser until $t$ is all liquid. The liquid is then pumped back through the heat exchanger to close the cycle.

Figure 58 illustrates the thermodynamic advantage for the Biphase cycle. The liquid working fluid is continuously heated, following the Carnot path. Studies have shown the Biphase cycle efficiency to be about $60-65 \%$ of Carnot efficiency. The power generation for well E-54 is therefore: 


$$
\begin{aligned}
P_{b b} & =(.6)(.1745)(28,125,000) / 3413 \\
& =863 \mathrm{~kW}
\end{aligned}
$$

As before the additional power generation will be higher for single flash wells and for wells with lower wellhead enthalpy.

\section{Summary for Well $\mathbf{E}-54$}

For the current configuration of well E-54 the actual estimates of power give:

$\begin{array}{llll}\text { Condition } & \begin{array}{l}\text { Power } \\ \mathrm{kW}\end{array} & \begin{array}{c}\text { Heat Rate } \\ \mathrm{B} / \mathrm{kWh}\end{array} & \text { Efficiency } \\ \text { As is with No Piping Losses } & 6,992 & 24,305 & .14 \\ \text { + Topping Steam Turbines } & 7,847 & 21,657 & .157 \\ \text { + Topping Biphase Turbines } & 8,254 & 20,589 & .165 \\ \text { + Vapor Binary } & 8,565 & 19,841 & .172 \\ \text { + Biphase Binary } & 9,117 & 18,640 & .183\end{array}$

For the Cerro Prieto geothermal field an analysis was performed of Biphase topping turbines for selected wells provided by CFE. The total power increase was estimated to be 79 megawatts.

\subsection{Reduction in Greenhouse Emissions}

Each megawatt of power generated by a Biphase geothermal turbine displaces power that would have to be generated from the combustion of fossil fuels. Each megawatt displaces 7100 tons per year of carbon dioxide emissions. Therefore full implementation of the topping turbine installations at Cerro Prieto would save 561,000 tons per year of carbon dioxide emissions.

\subsection{Predicted Market}

The updated "Application and Economic Study" is provided in Appendix A. The study was updated based on the results of the project and the economics of the new dual pressure rotor design. The previous market estimate was for 264 megawatts existing market for retrofit units and 715 megawatts of new installations in the next 5 years. It should be emphasized that these are market estimates and do not reflect a capture percentage or the investments required for capturing the available market. 
The results are valid if the dates are shifted by 5 years from the time the study was done. The total however, should be increased by $20 \%$ in keeping with the higher output of the Biphase turbines. 


\section{Conclusions and Recommendations for Project and Technology}

The current project was highly successful in proving the performance of the single rotor Biphase turbine in a commercial installation. However, problems with solids, the decline in the well enthalpy and pressure and poor performance of balance of plant components prevented the project from being economically sound. Conversion of the California Energy Commission loan grant to a loan is not a viable option for the project.

Technology to handle the solids was developed and eventually proven. The design of a new rotor enabling two pressure letdowns was also accomplished. The dual pressure rotor will have an important impact on the economics of Biphase turbine topping installations by eliminating the need for a backpressure steam turbine. This enables a large reduction in capital cost and improves the portability of the installation. The efficiency of the Biphase turbine is improved from the $40-50 \%$ range to the $70 \%$ range.

The present power plant should be retained as a research and demonstration facility. The present agreement with CFE to sell power will enable the operating costs to be met for power producing demonstrations. The two immediate demonstration programs recommended are:

- Installation of a dual pressure rotor in the existing Biphase turbine casing. Demonstration of power production and reliability with the existing well flow.

- Design and installation of a Biphase binary power system using the existing separated brine as a heat source and the existing electrical switchgear and controls for operation. Demonstrate the efficiency and cost of this alternative bottoming system.

As shown in the report, the impact on the economics and efficiency of geothermal power production will be quite large if these technology improvements are demonstrated. The results of the DOE and California Energy Commission project have been favorable to date and justify the full utilization of the existing installation. 


\section{References}

1. Hughes, E., Summary Report: Rotary Separator Turbine, RP1196, Electric Power Research Institute, Palo Alto, 1986.

2. U.S. Department of Energy, Bi-Phase Turbine, Cooperative Agreement De-FC36-93CH10590, Oct 1993, September 1995

3. California Energy Commission, Biphase Turbine Demonstration at Coso Hot Springs, Project Number 912-93-001, June, 1994

4. Studhalter, W., Cerini, D., and Hays, L., Demonstration of an Advanced Biphase Turbine at Coso Hot Springs, Proceedings of the Geothermal Program Review XIII, U.S. Department of Energy, San Francisco, March 1995.

5. Comisión Federal de Electricidad, Convenio de Colaboracion para la Investigacion be Turbinas Bifasicas en Pozos Geotermicos de Alta Presion del C.G. Cerro Prieto, September, 1994

6. California Energy Commission, Biphase Turbine Demonstration Project Addition of Back Pressure Steam Turbine, Project Number 912-93-001A.1, June 1996

7. Hays, L. and Elliott, D., Two-Phase Engine, U.S. Patent 3,879,949, April 1975

8. Elliott, D., and Weinberg, E., Acceleration of Liquids in Two-Phase Nozzles, Technical Report 32-987, Jet Propulsion Laboratory, Pasadena, July 1968

9. Hays, L., Dual Pressure Euler Turbine, ,U.S. Patent Pending 09/539,342, March 2000

10. Hays, L., The Compressible EulerTurbine, Internal Report, Douglas Energy Company, Placentia, California, Jan 2000 


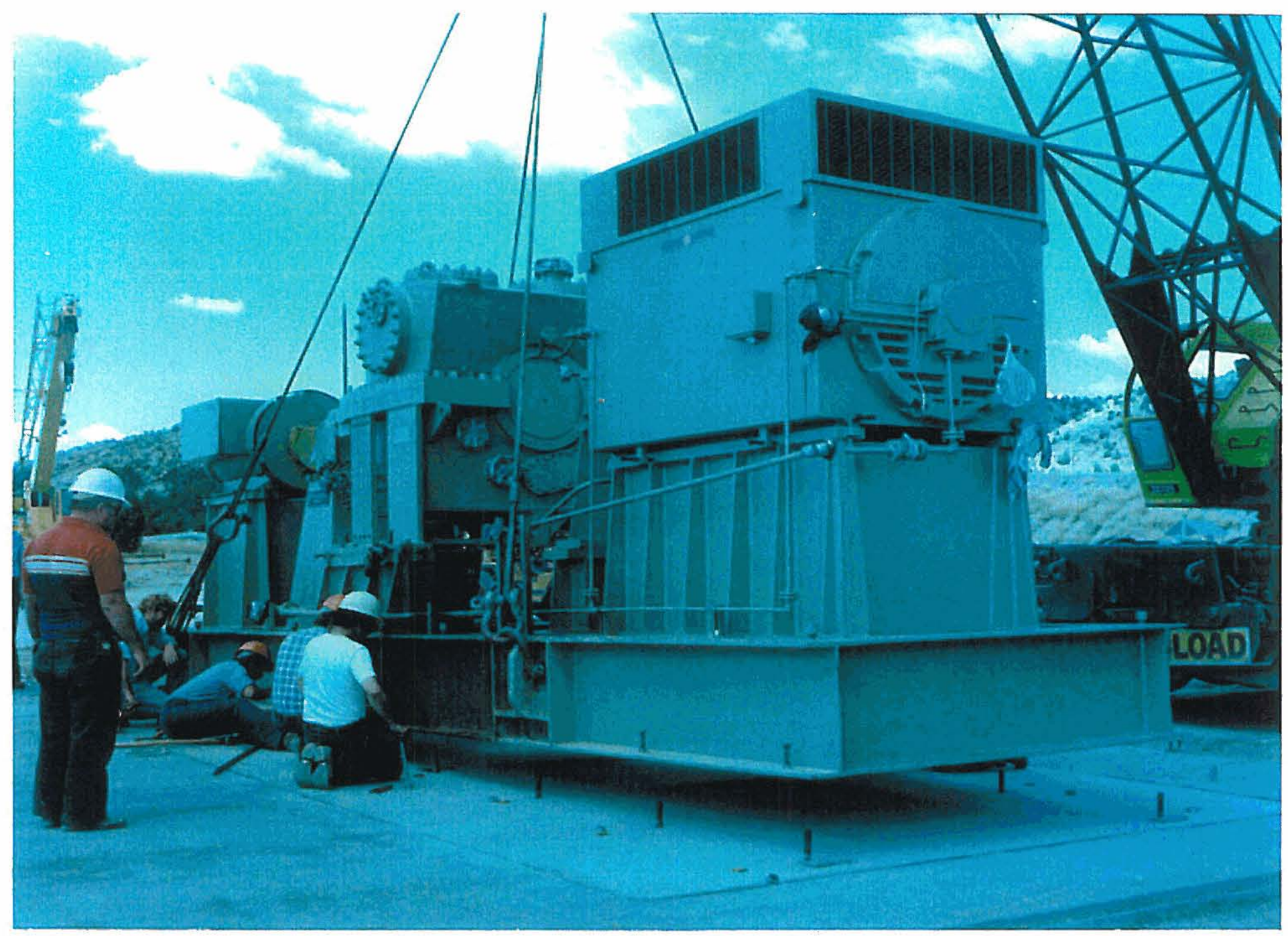

Figure 1 Biphase Geothermal Turbine During Installation at Roosevelt Hot Springs - Operation at 1.6 Megawatts for 4,000 hours 


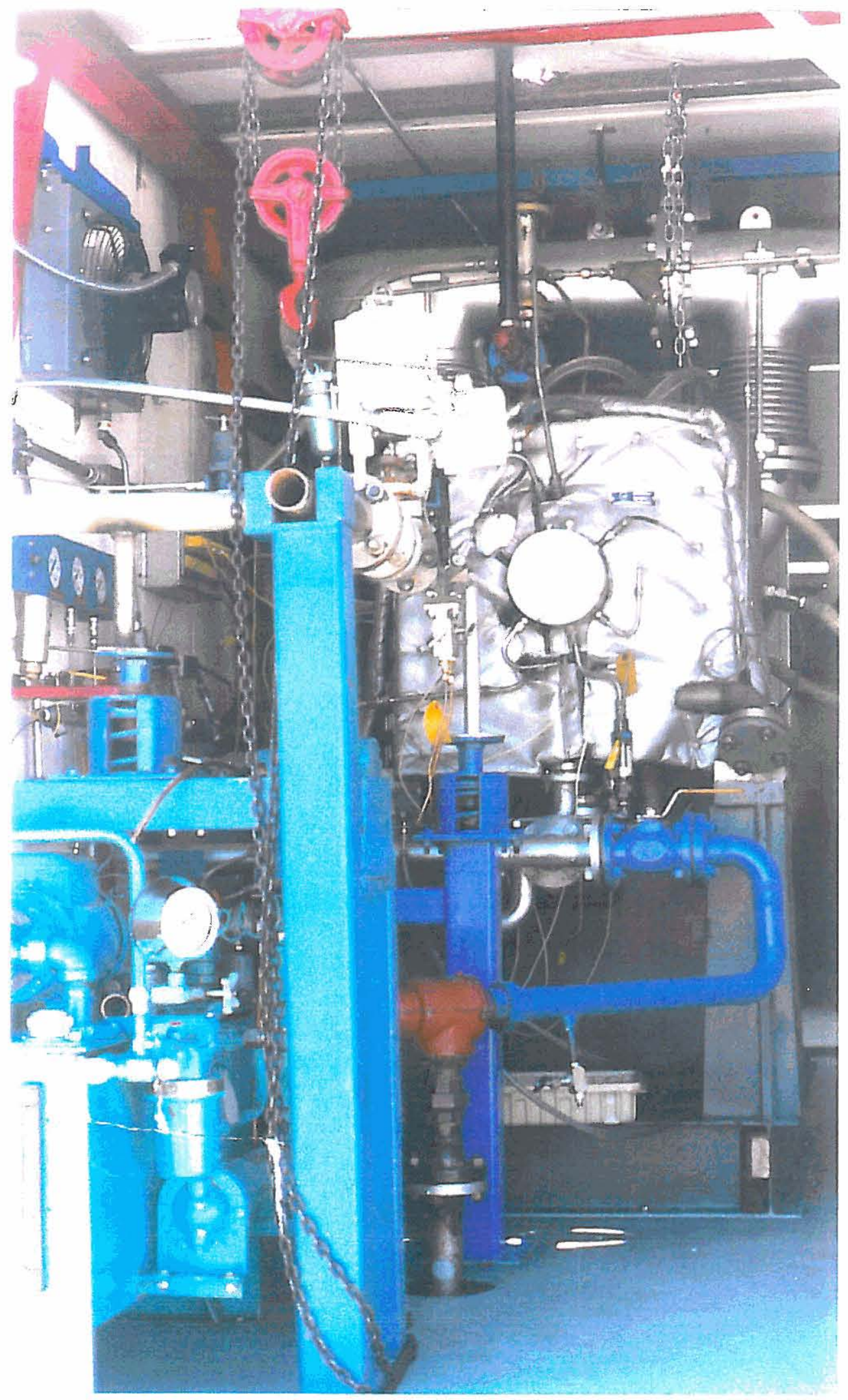

Figure 2 Biphase Subscale Geothermal Turbine During Testing at Coso Hot Springs 


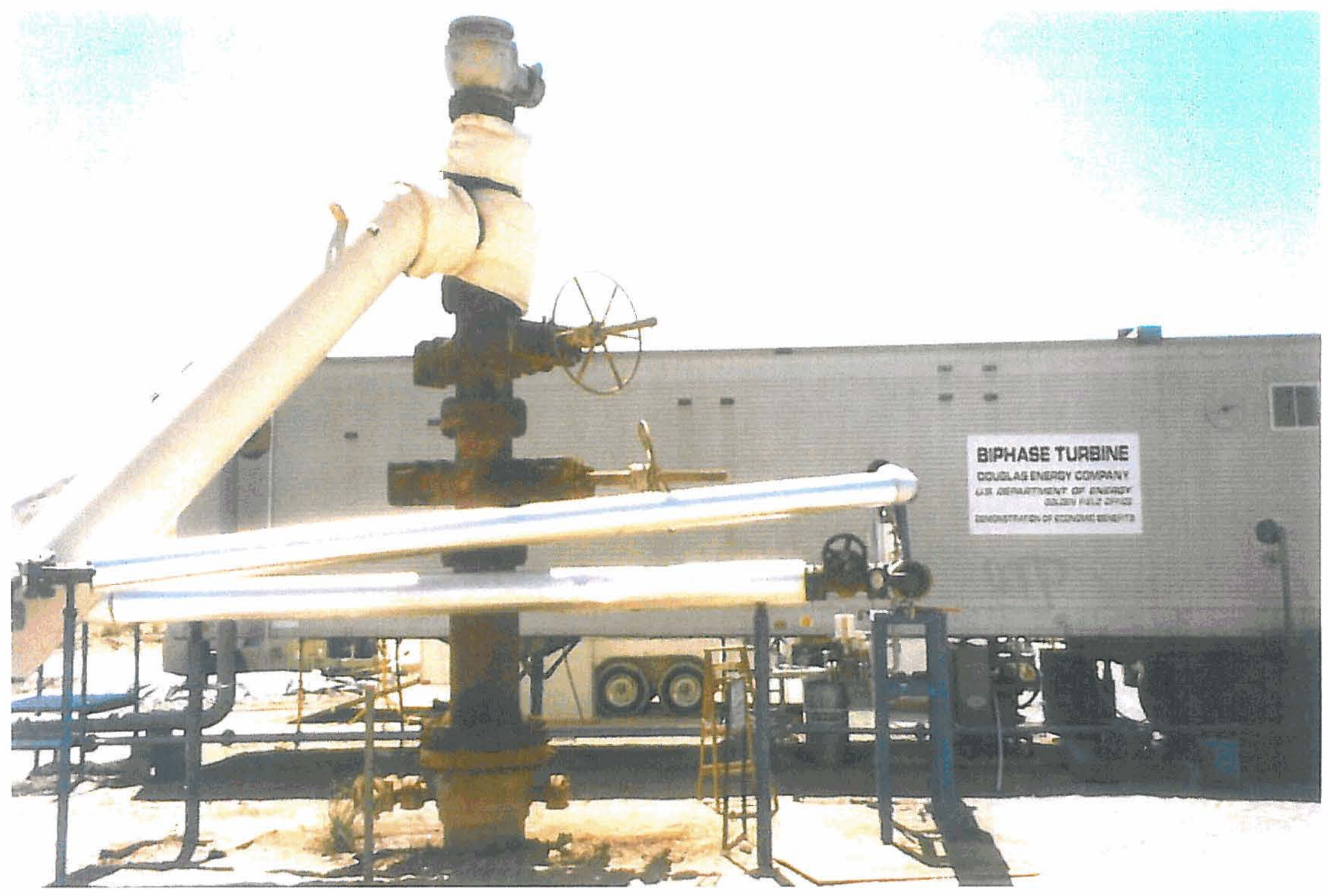

Figure 3 Biphase Turbine Test System at Coso Hot Springs, California 


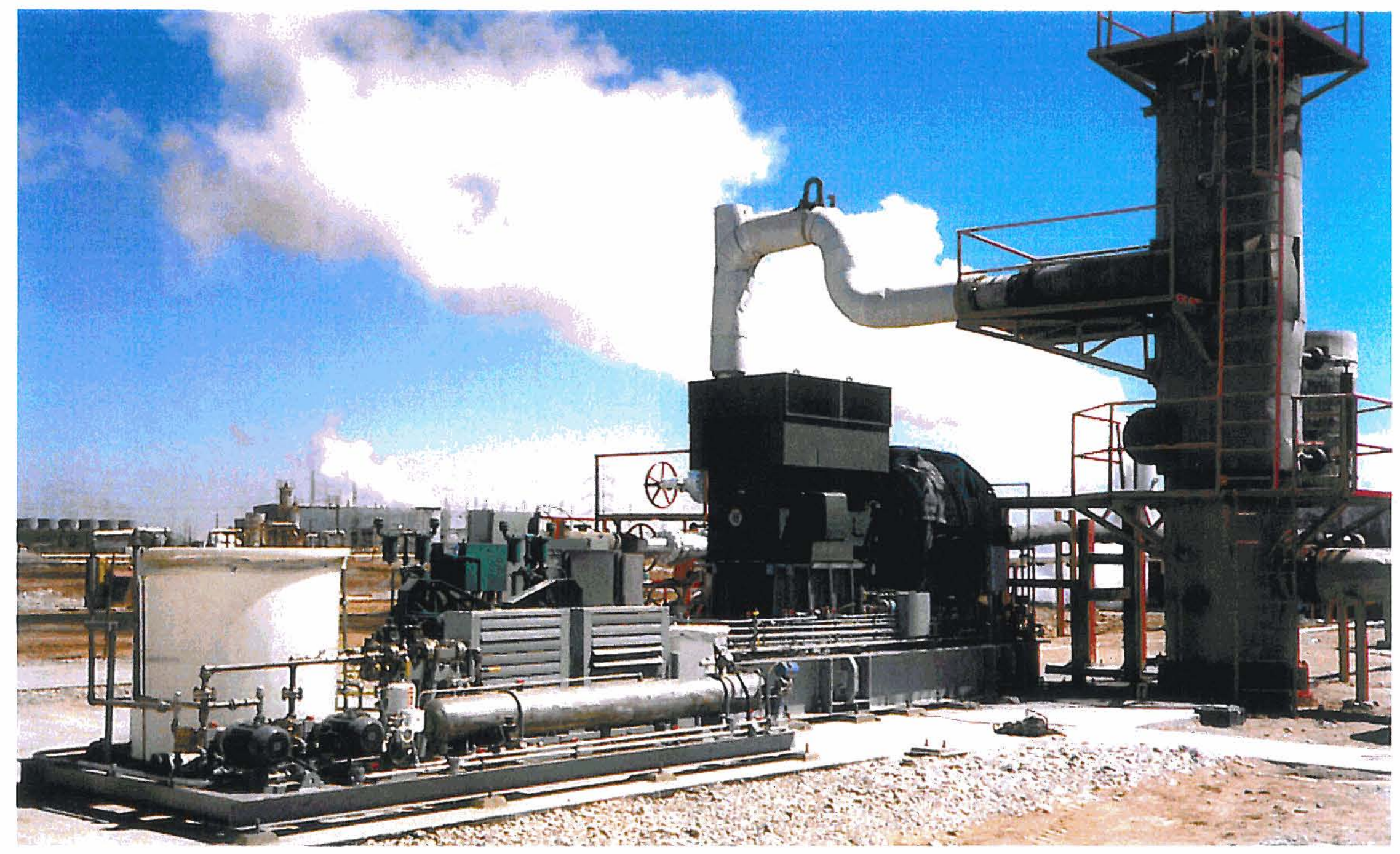

Figure 4 Biphase Turbine at Cerro Prieto 


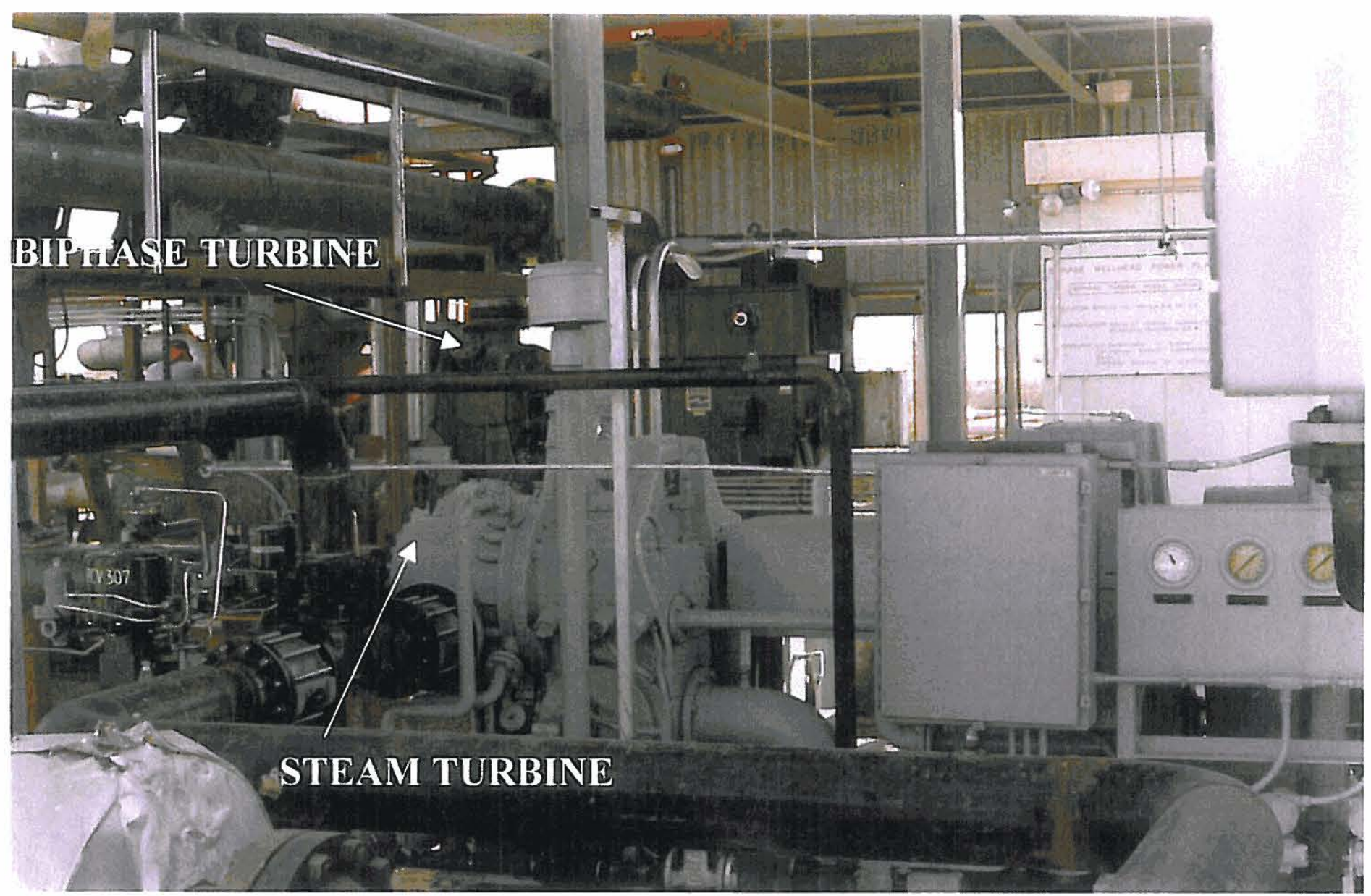

Figure 5 Biphase Turbine And Back Pressure Steam Turbine Installed At Well 103 At Cerro Prieto 


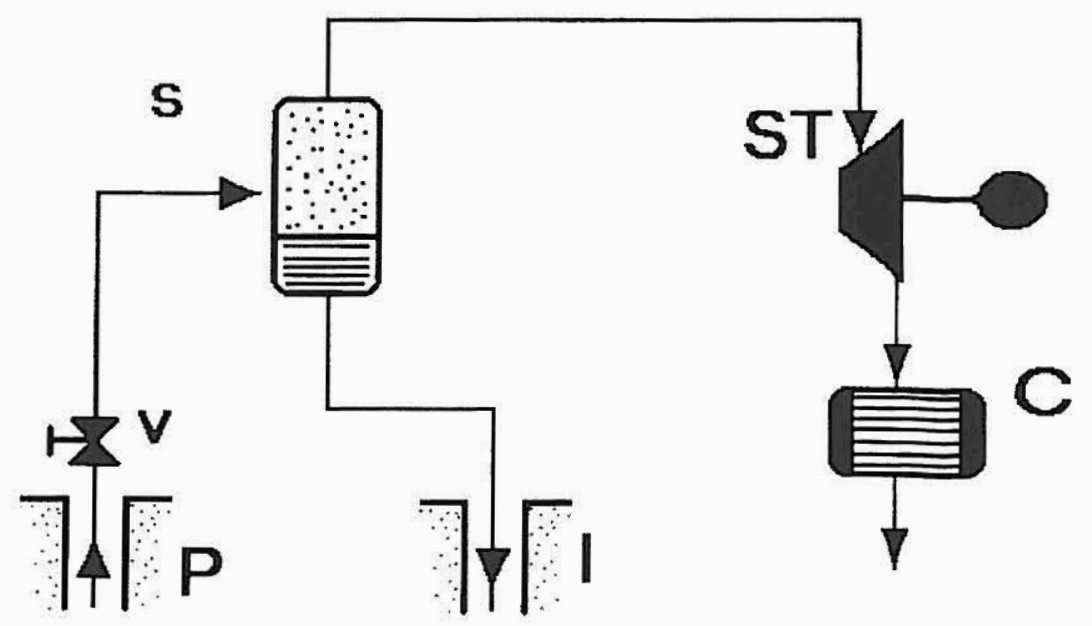

Figure 6 Single-Flash Plant 


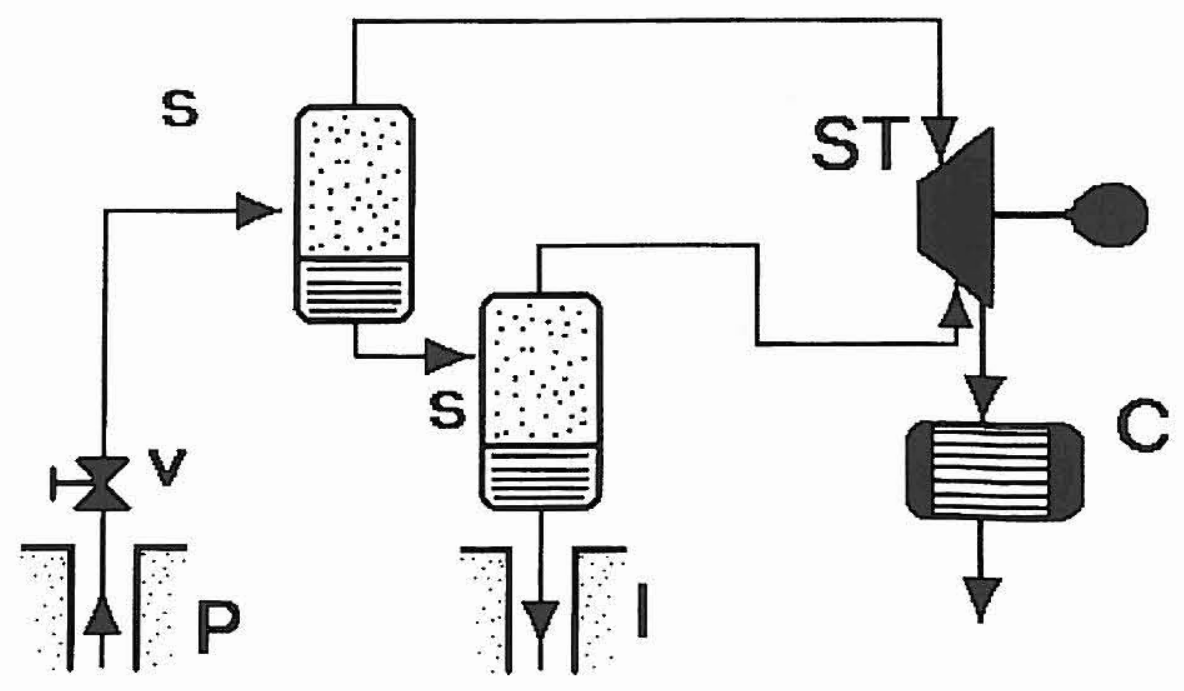

Figure 7 Double-Flash Plant 


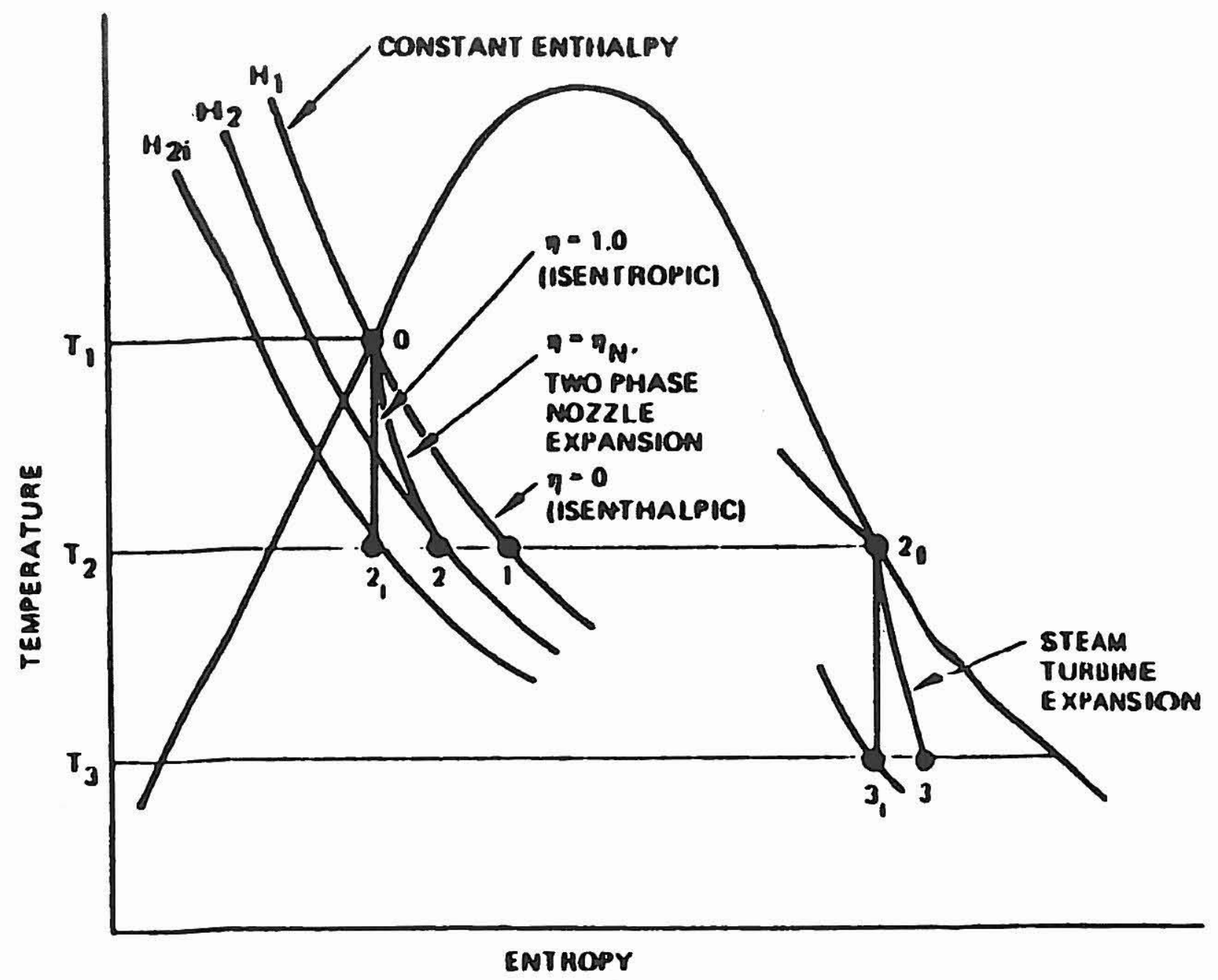

Figure 8 Temperature Entropy Diagram for Single-Flash System and for Rotary Separator Turbine System 


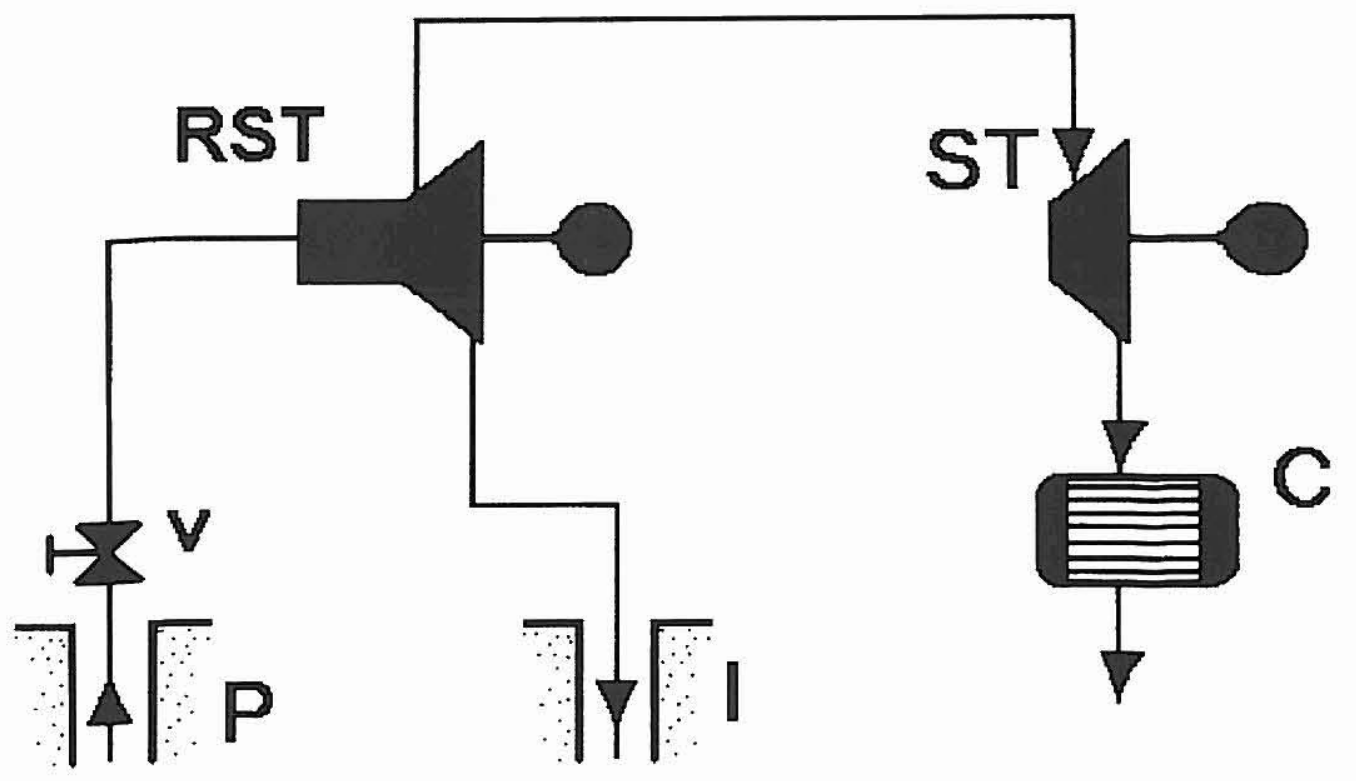

Figure 9 Single-Flash Plant with RST in Place of the Cyclon e Separator 


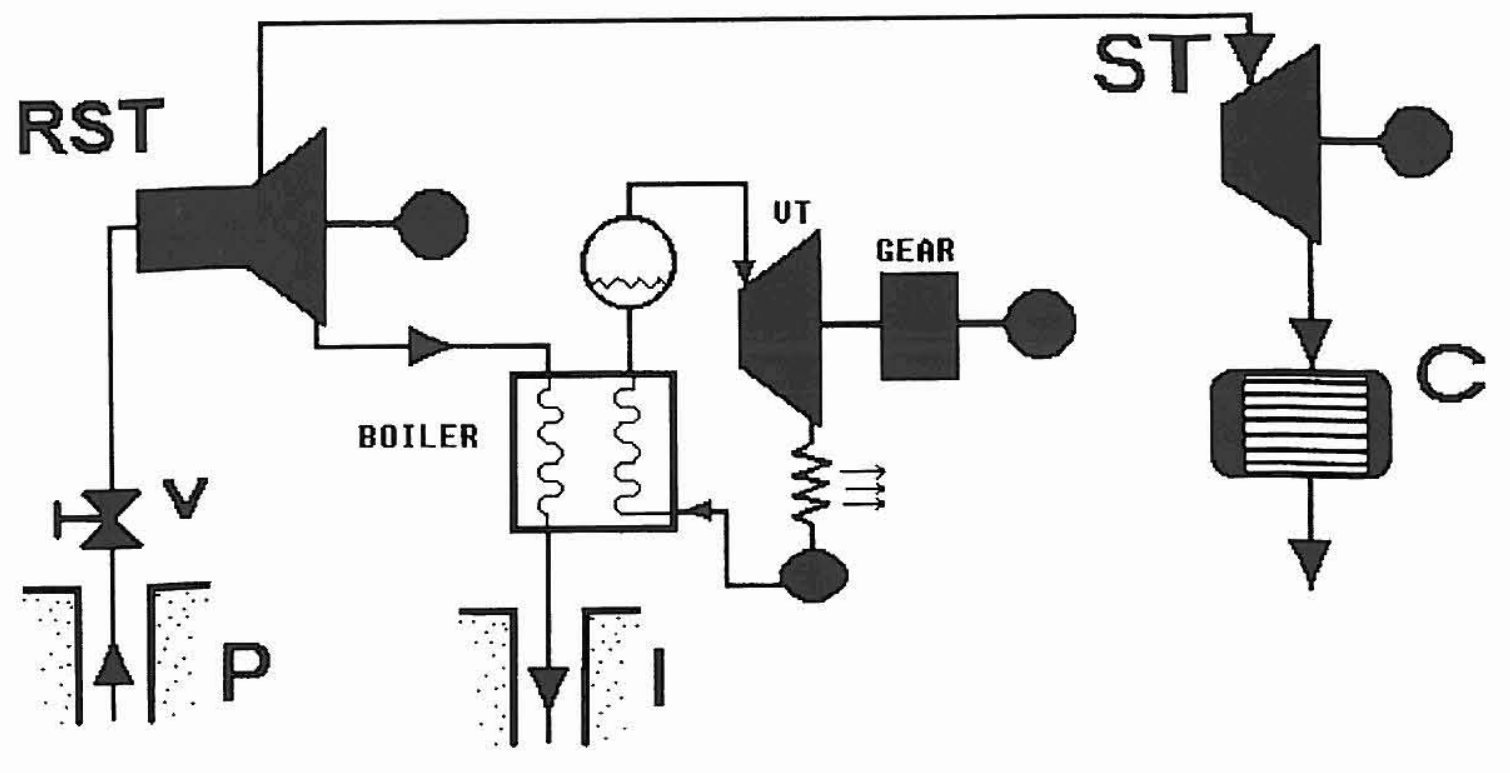

Figure 10 Conventional Binary Bottoming Cycle 


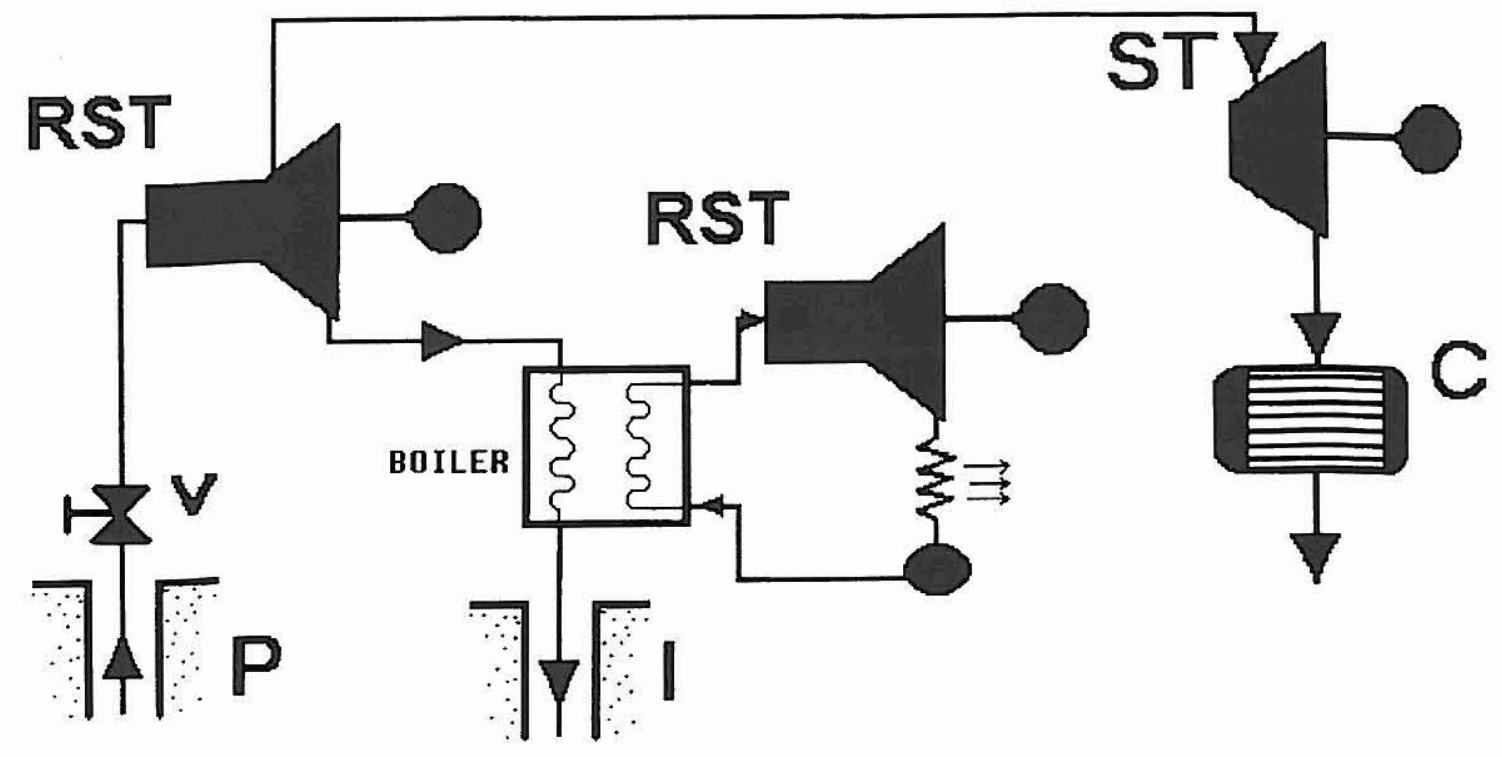

Figure 11 Single-Flash Plant with RST in Place of the Cyclone Separator and Binary Bottoming Cycle 


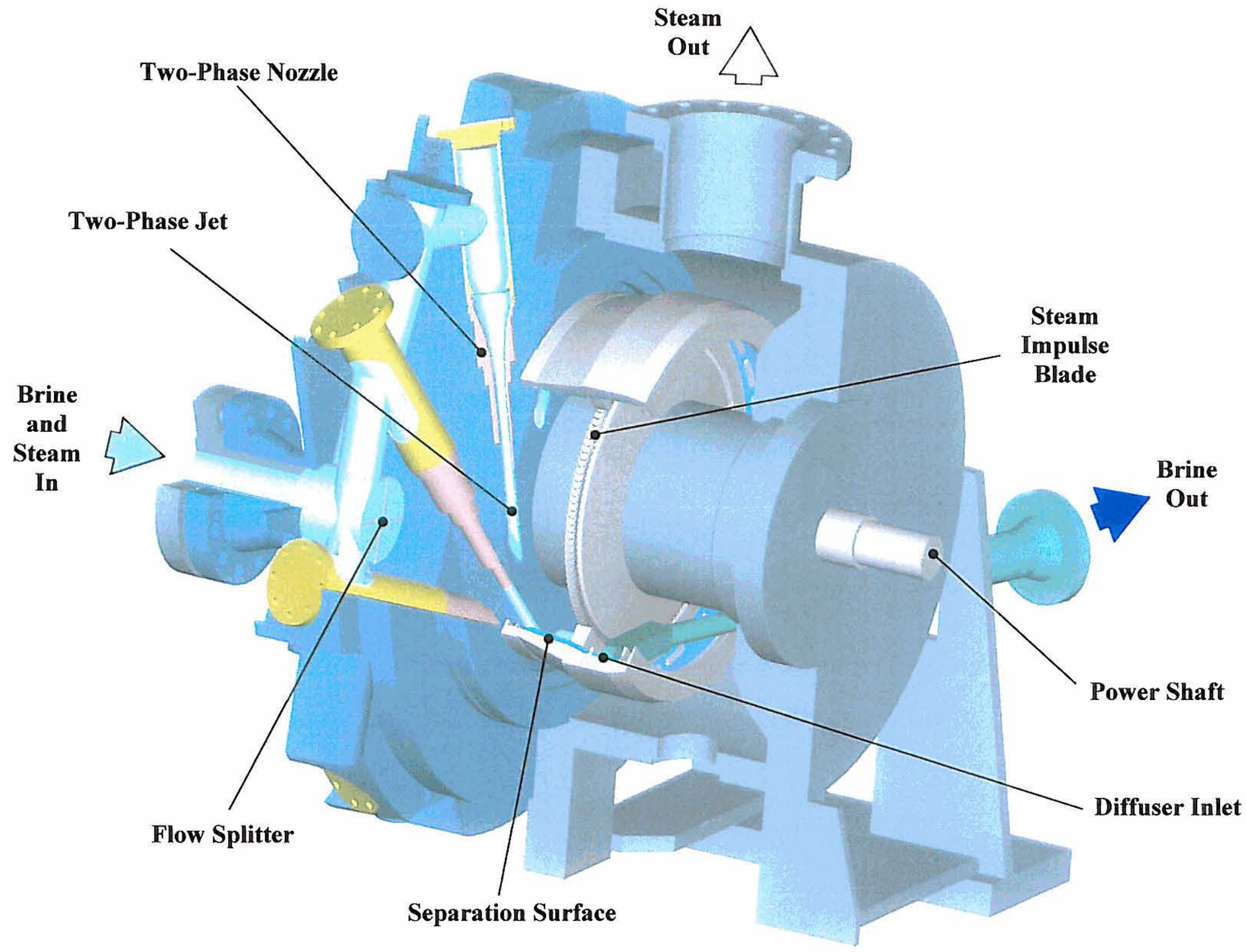

Figure 12 Biphase Geothermal Turbine 


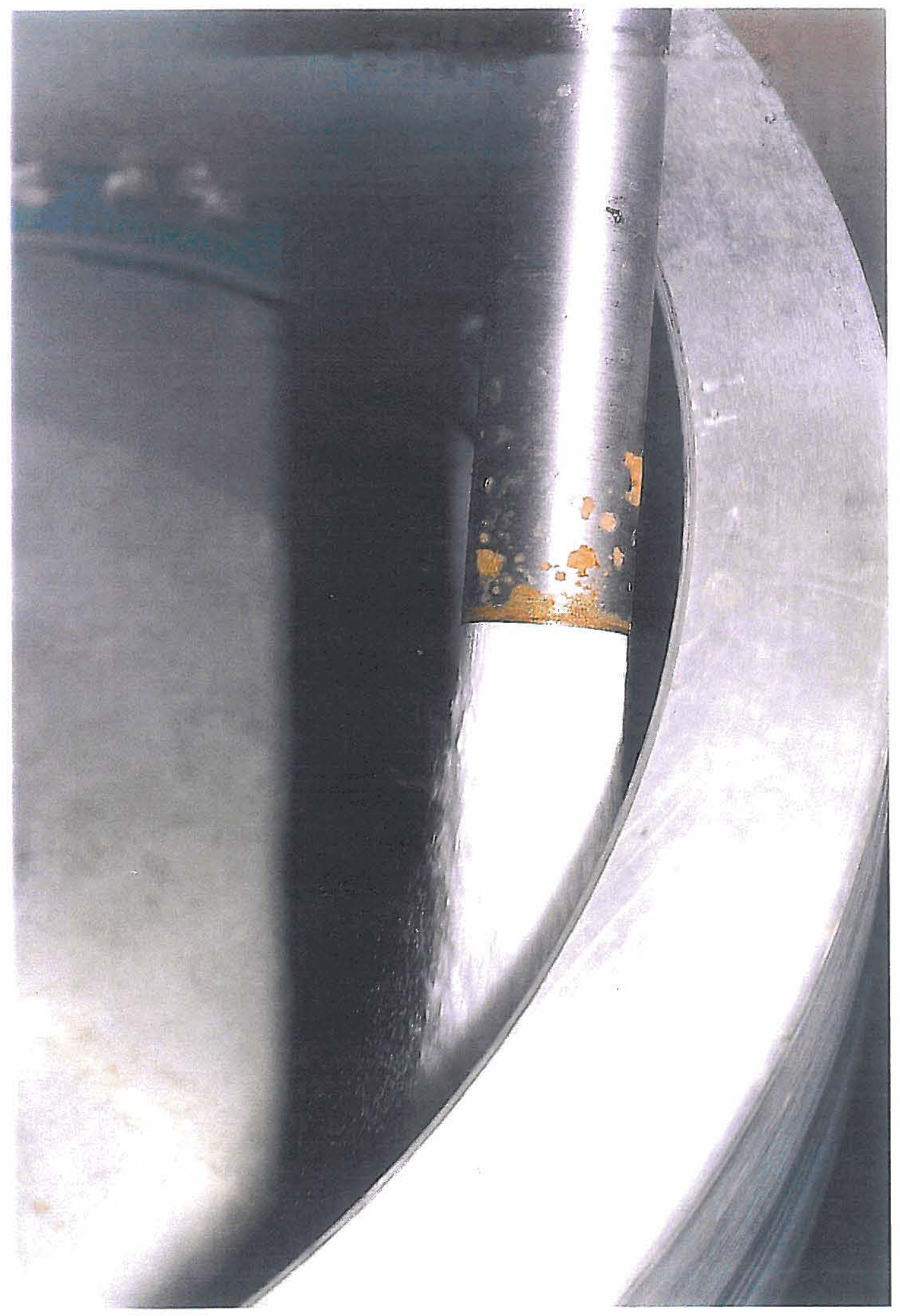

Figure 13 Two-Phase Nozzle 


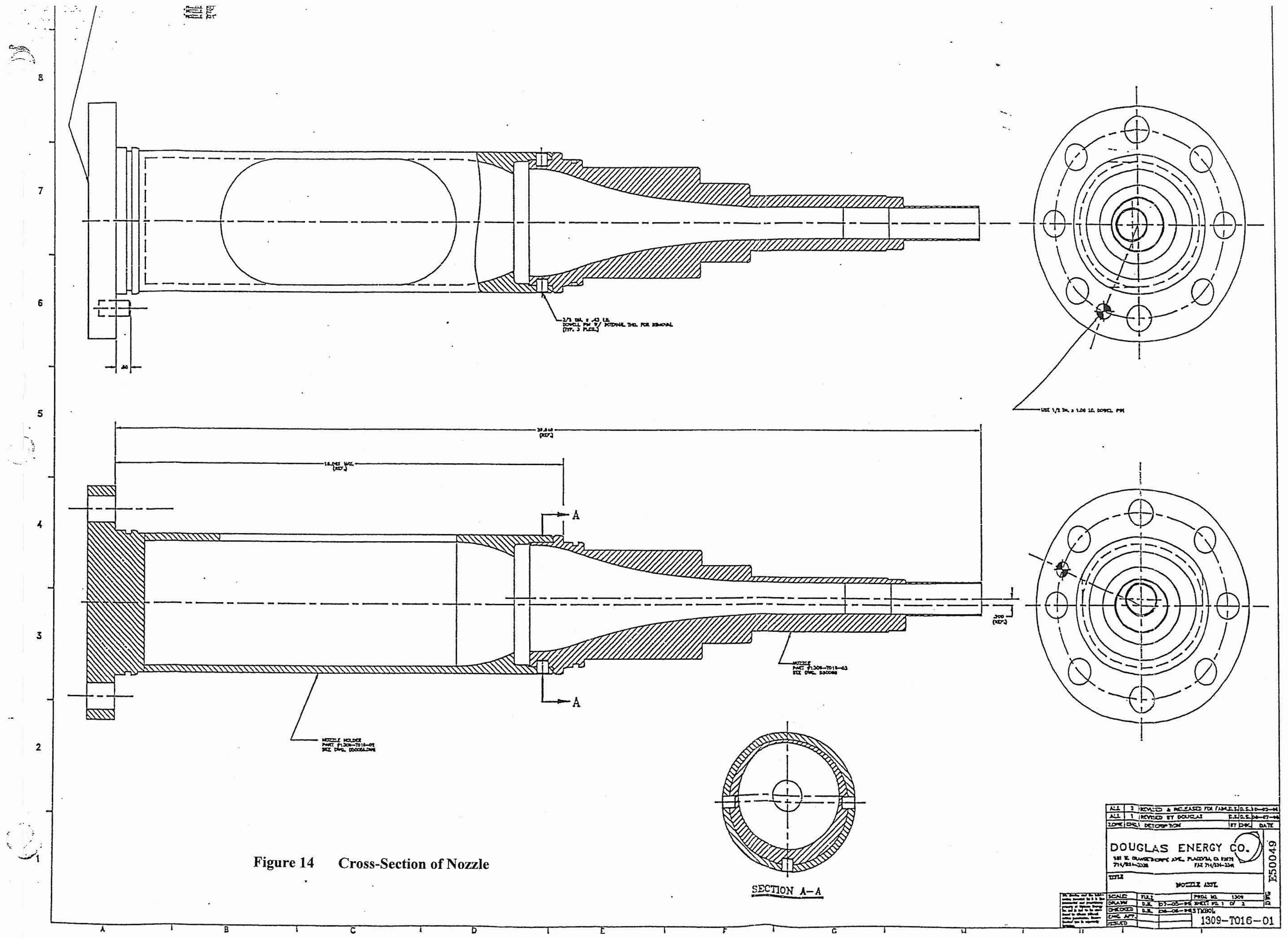




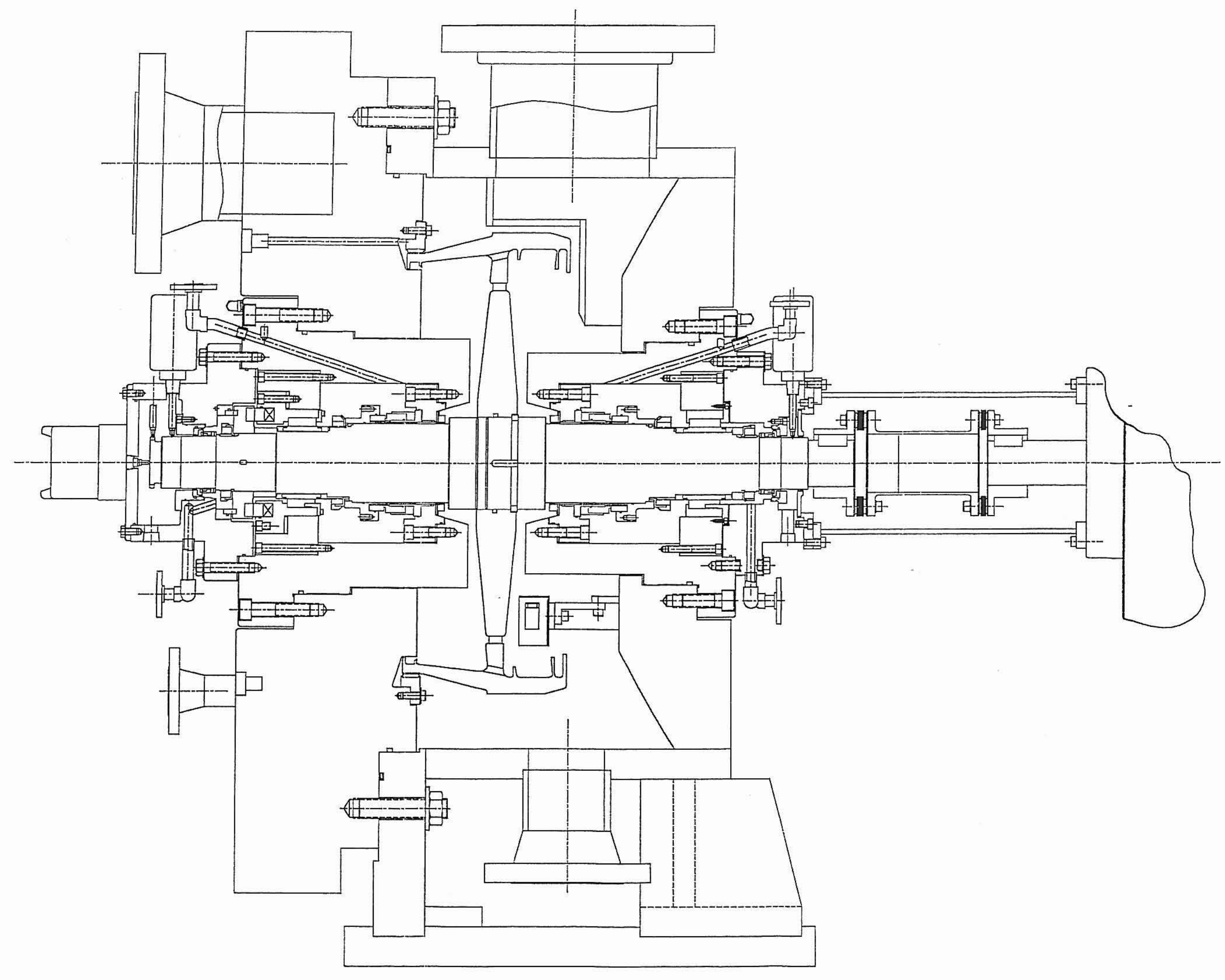

Figure 15 Cross Section of 30 RSB 


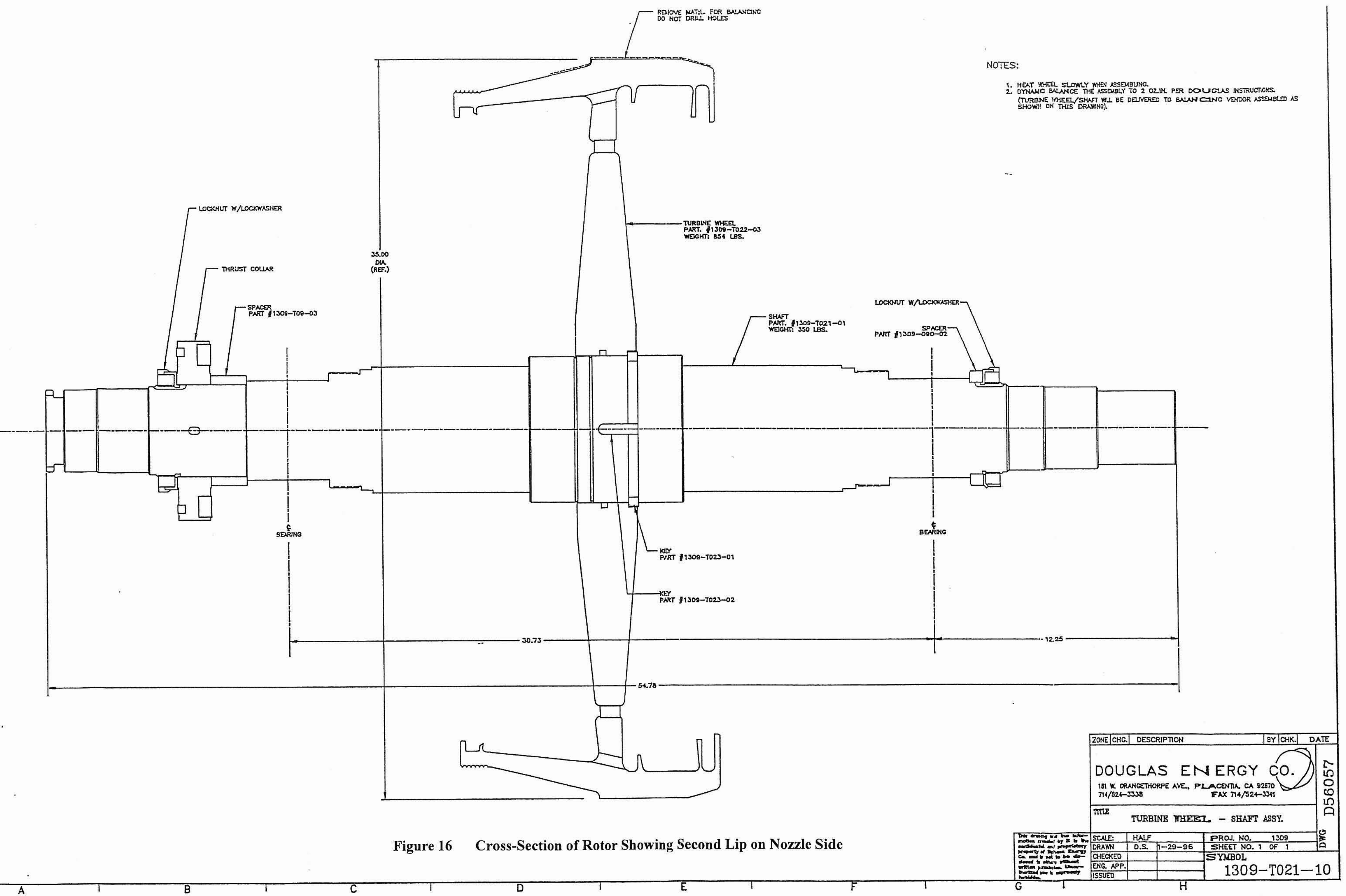




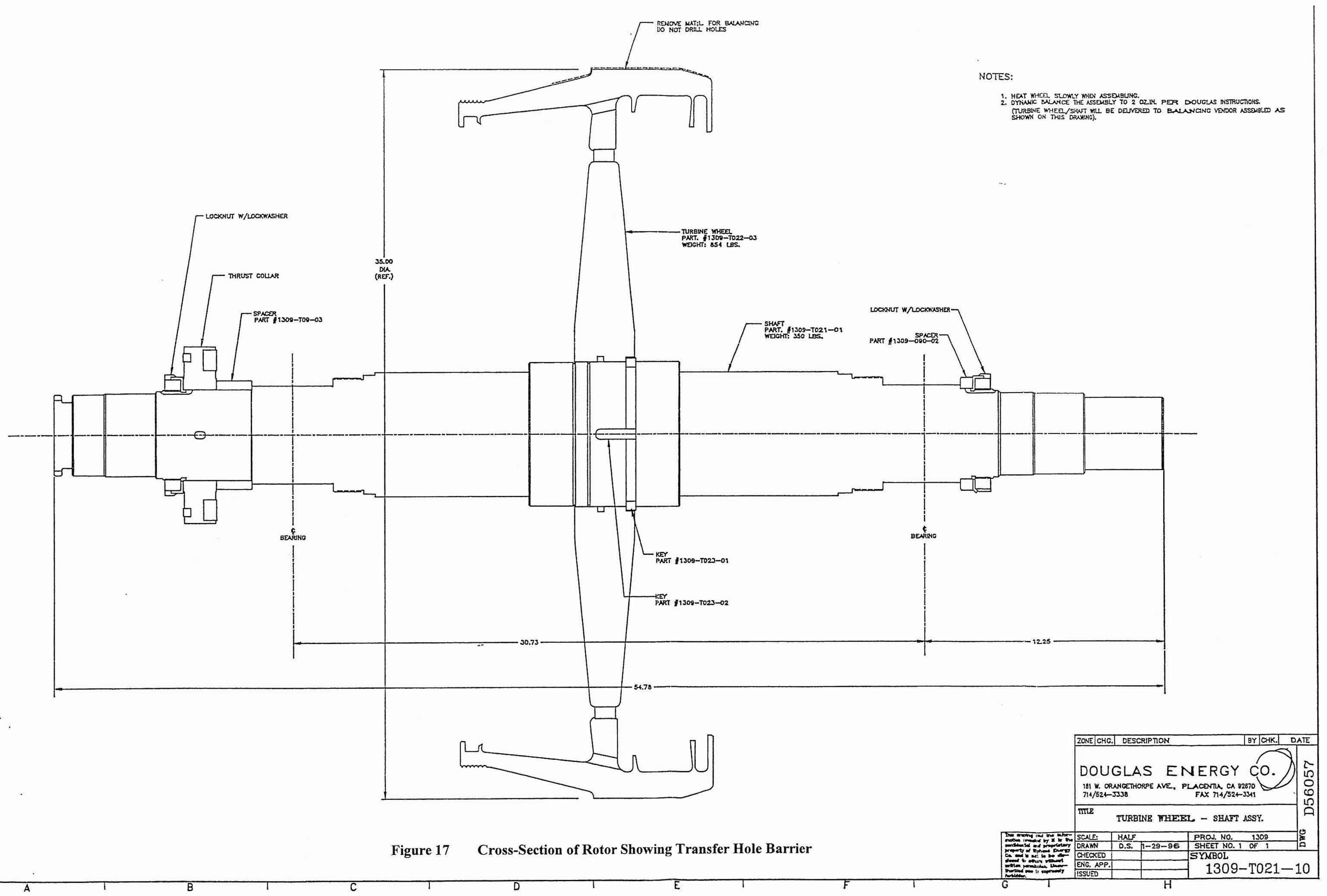




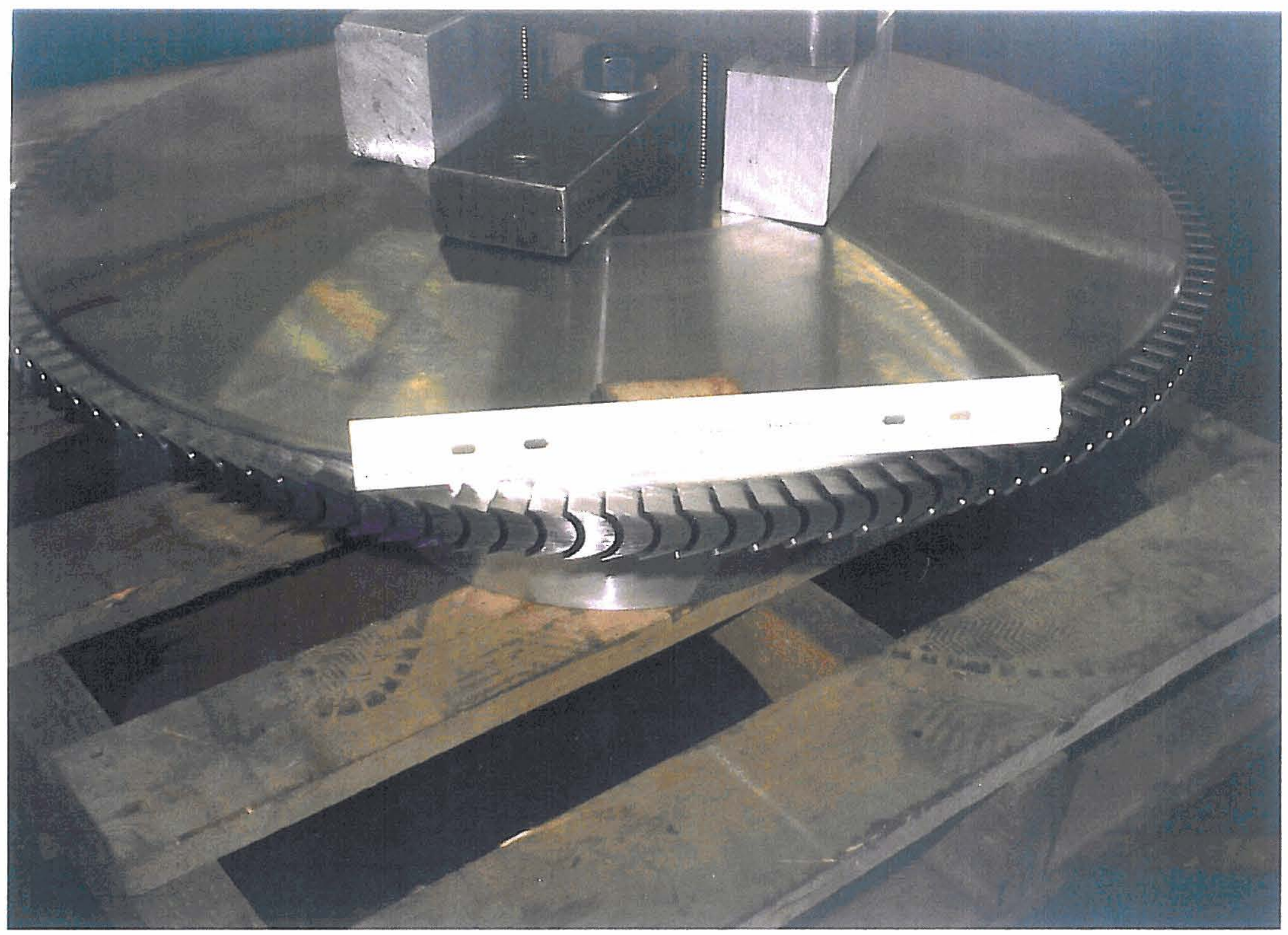

Figure 18 Biphase Turbine Axial Flow Steam Blades Before Final Assembly 


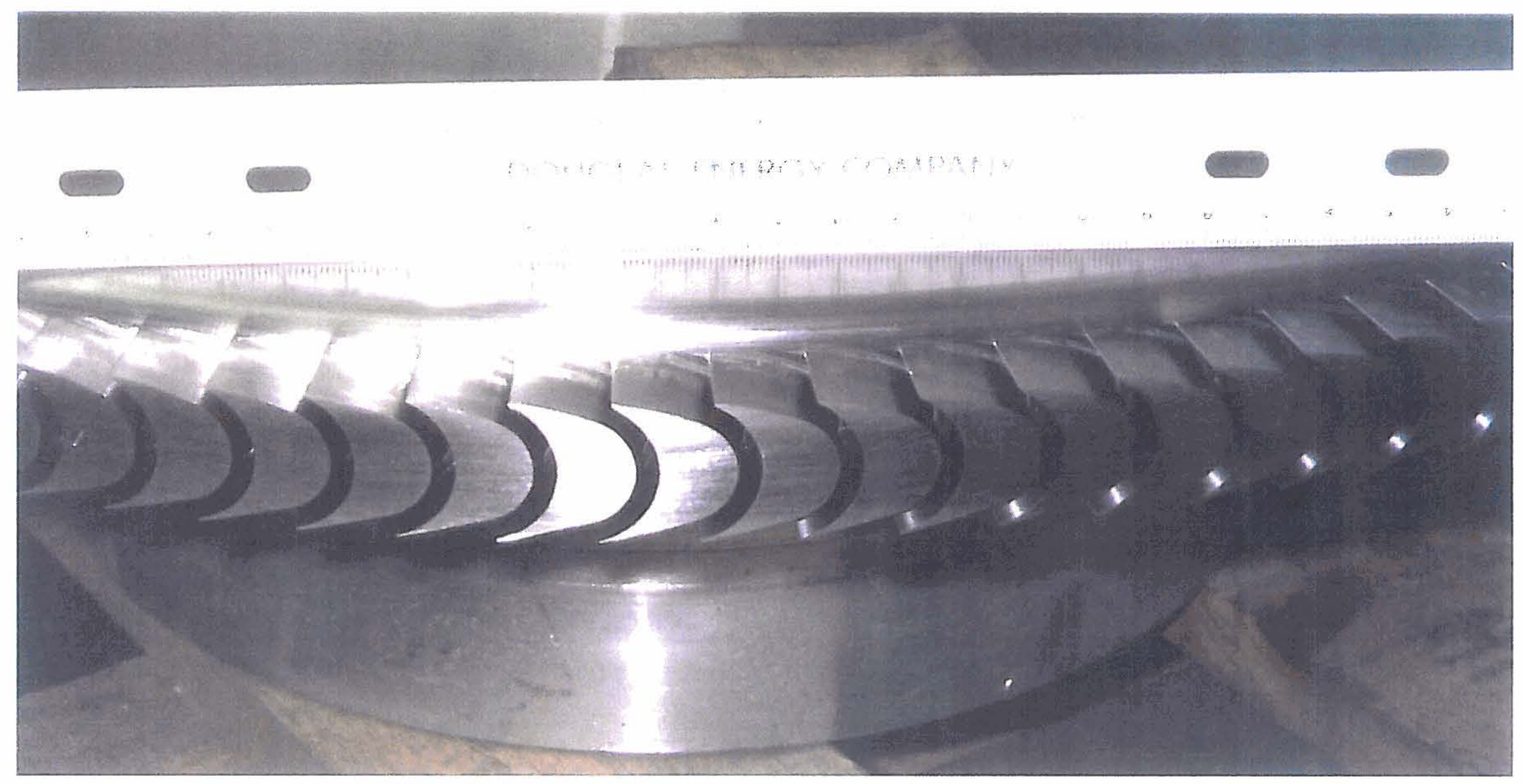

Figure 19 Close up of Steam Blading 


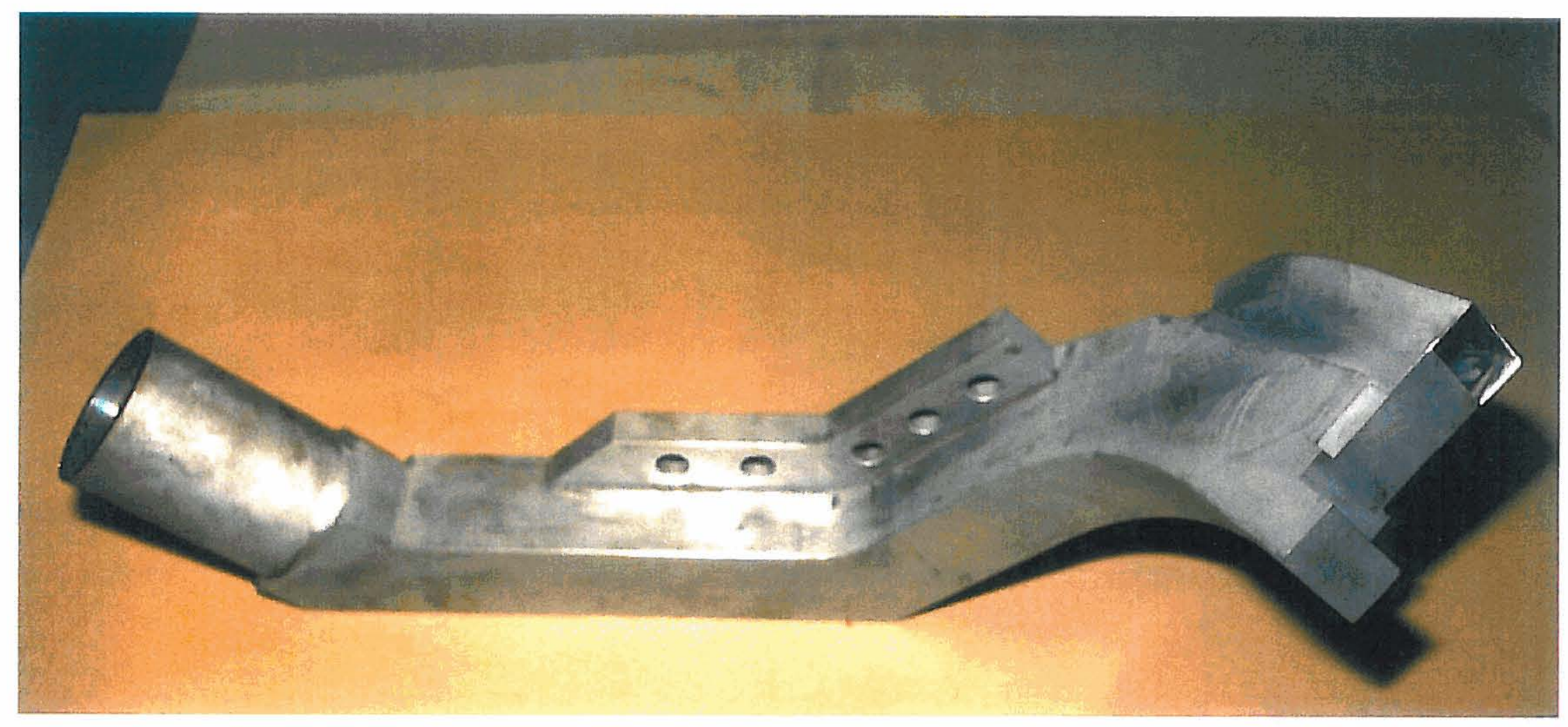

Figure 20 Diffuser for Geothermal Turbine 


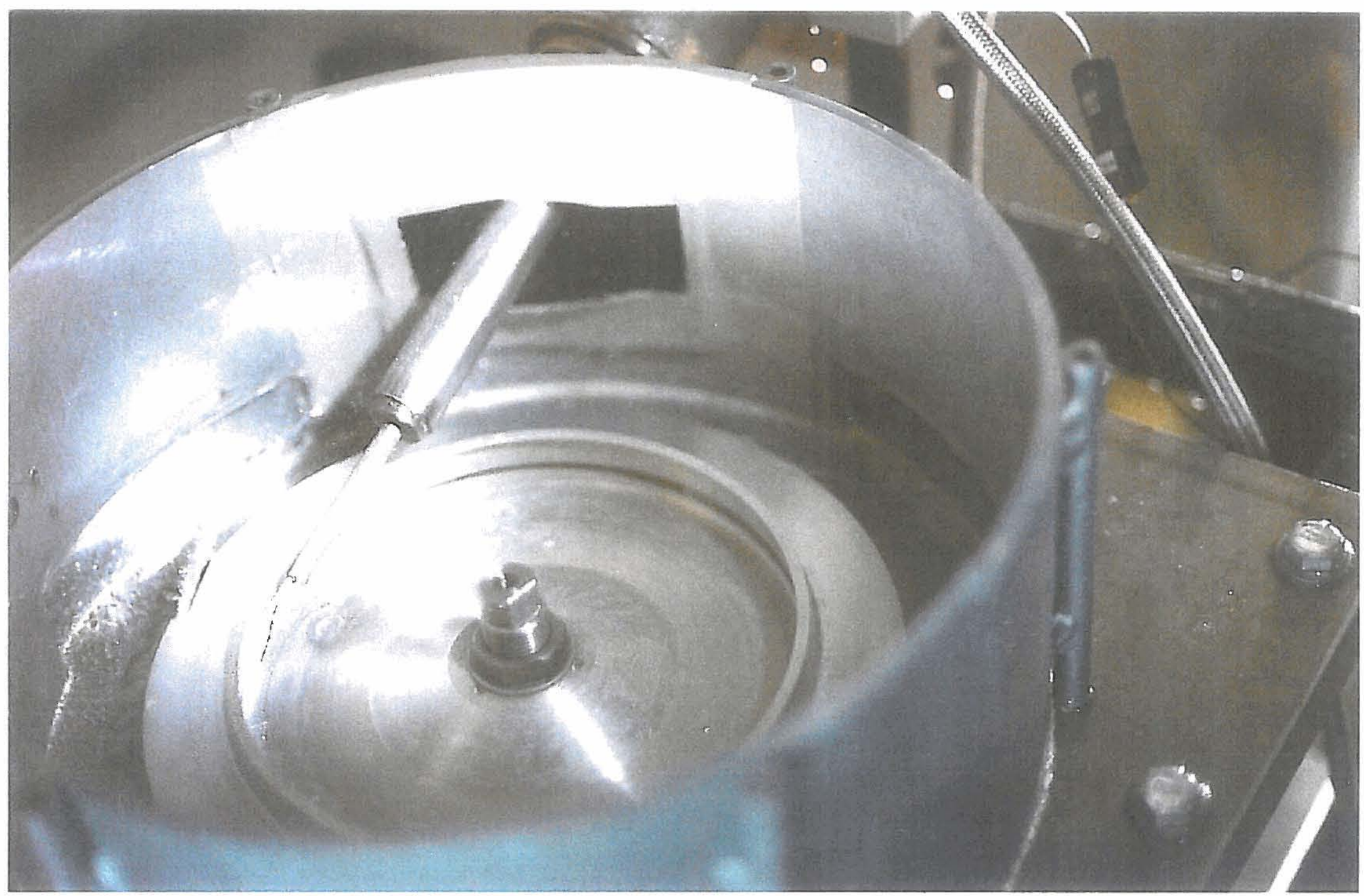

Figure 21 Laboratory Operation of Reaction Turbine with Air and Water 


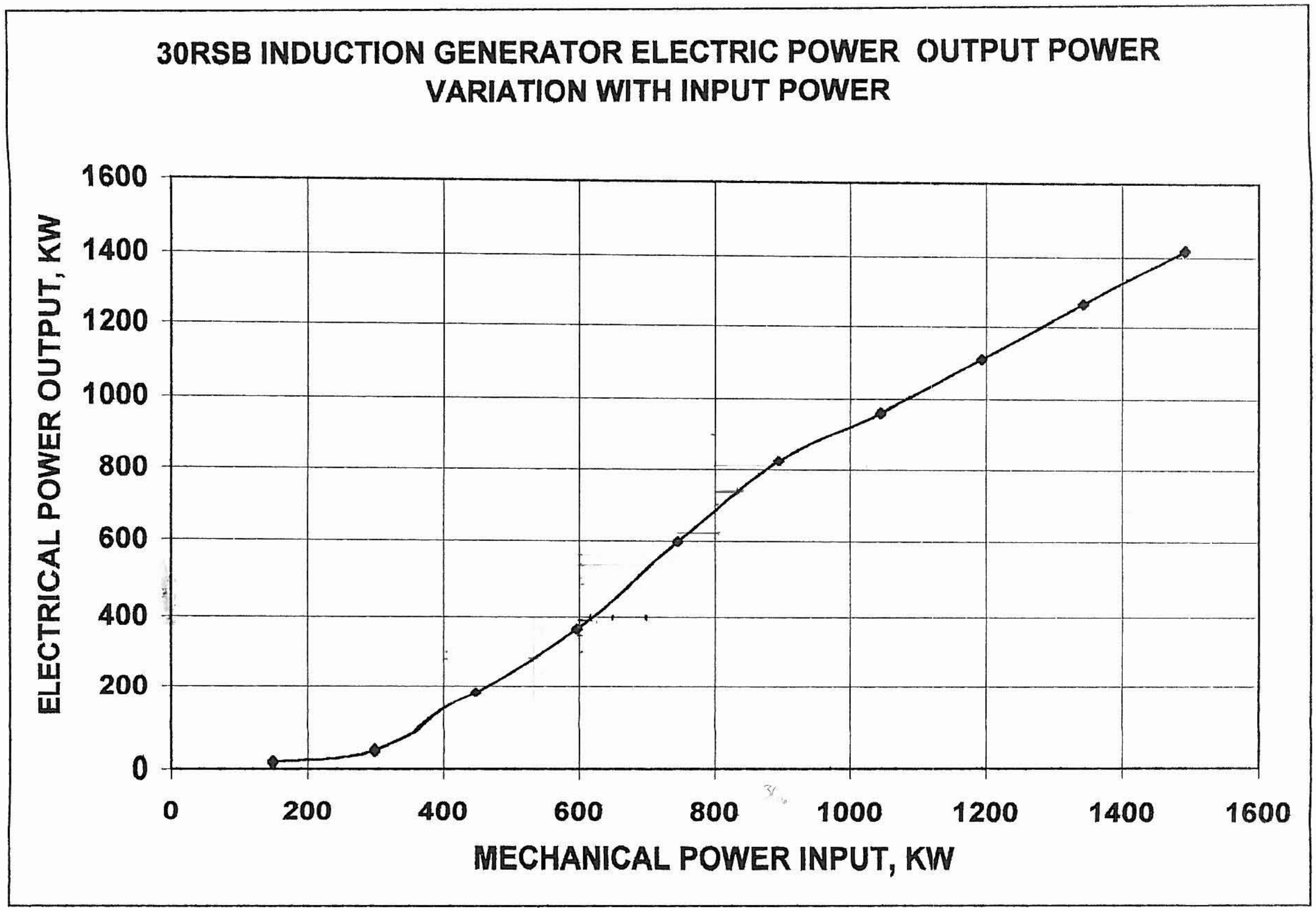

Figure 22 Biphase Turbine Generator Efficiency 


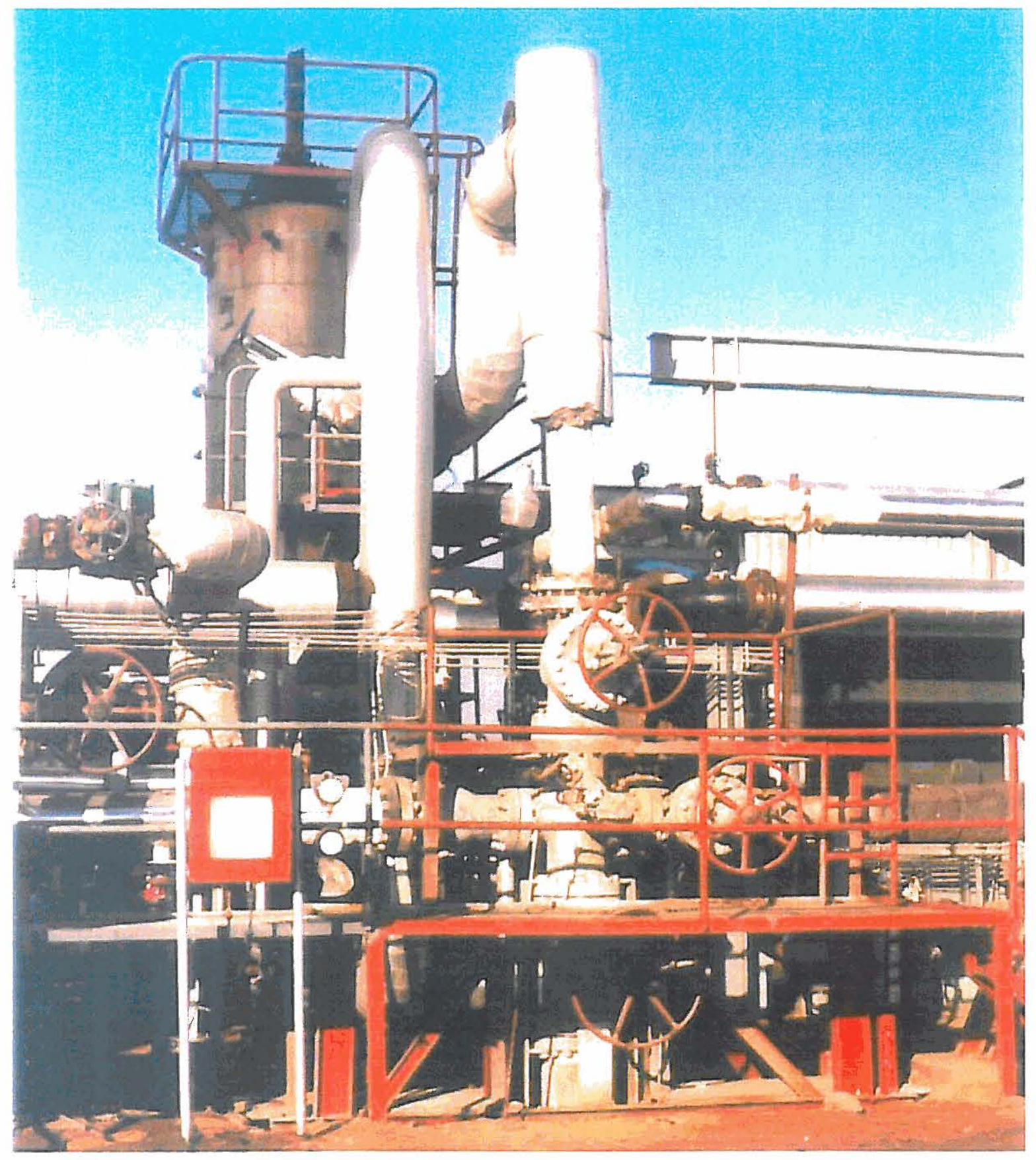

Figure 23 Well 103 Wellhead and Separator 

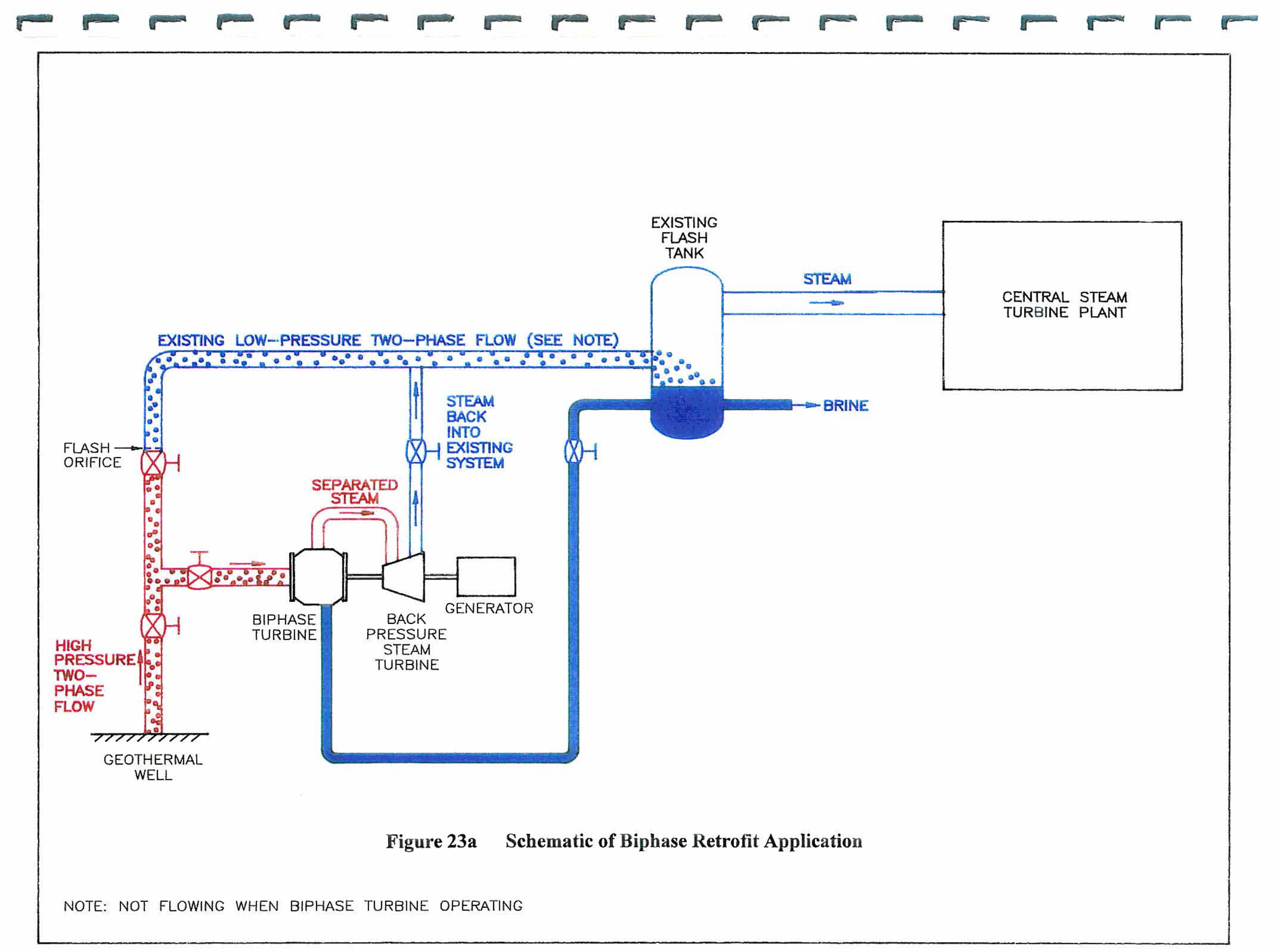


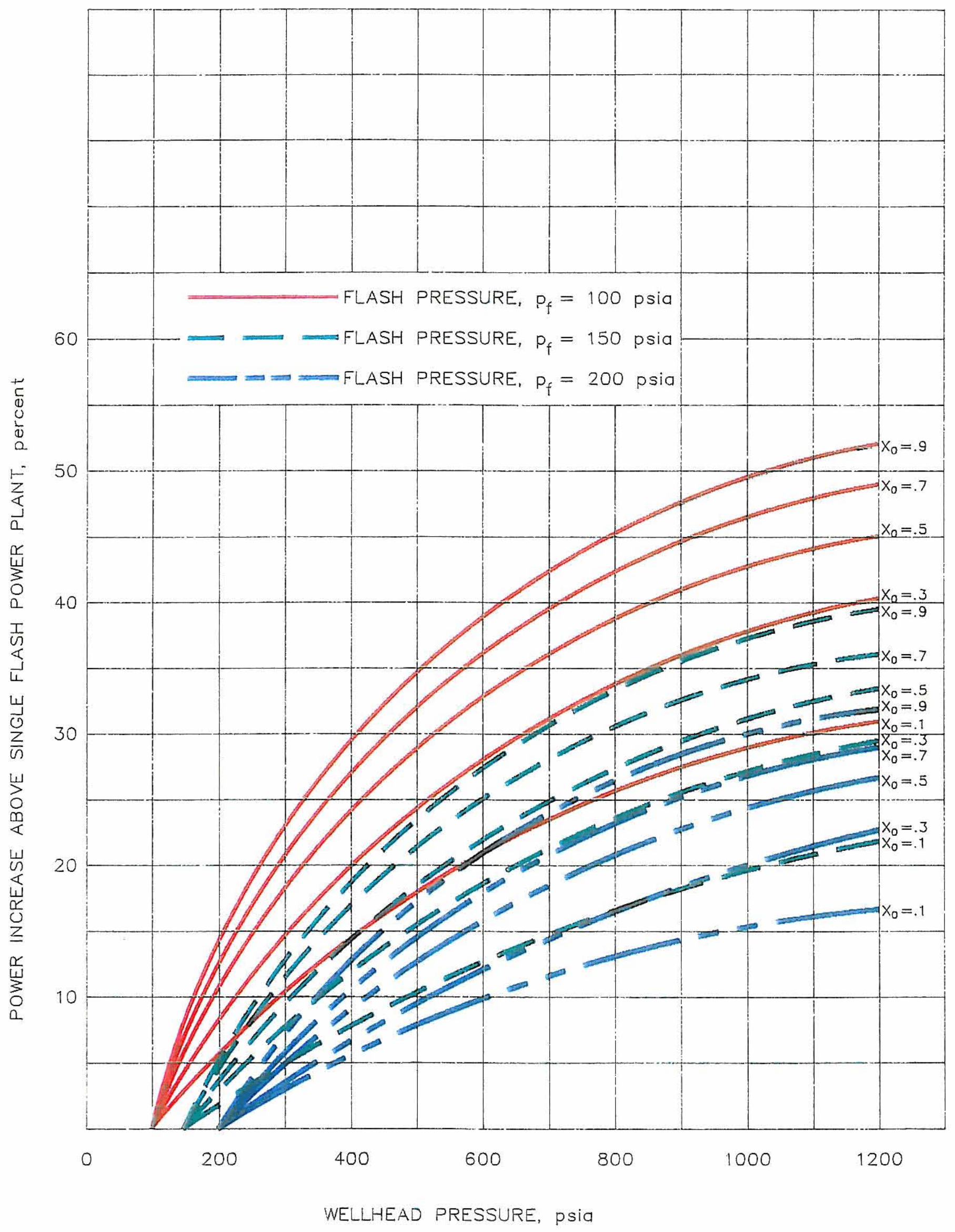

Figure 24 Power Increase Percentage for Biphase Turbine Addition to Flash Steam System 


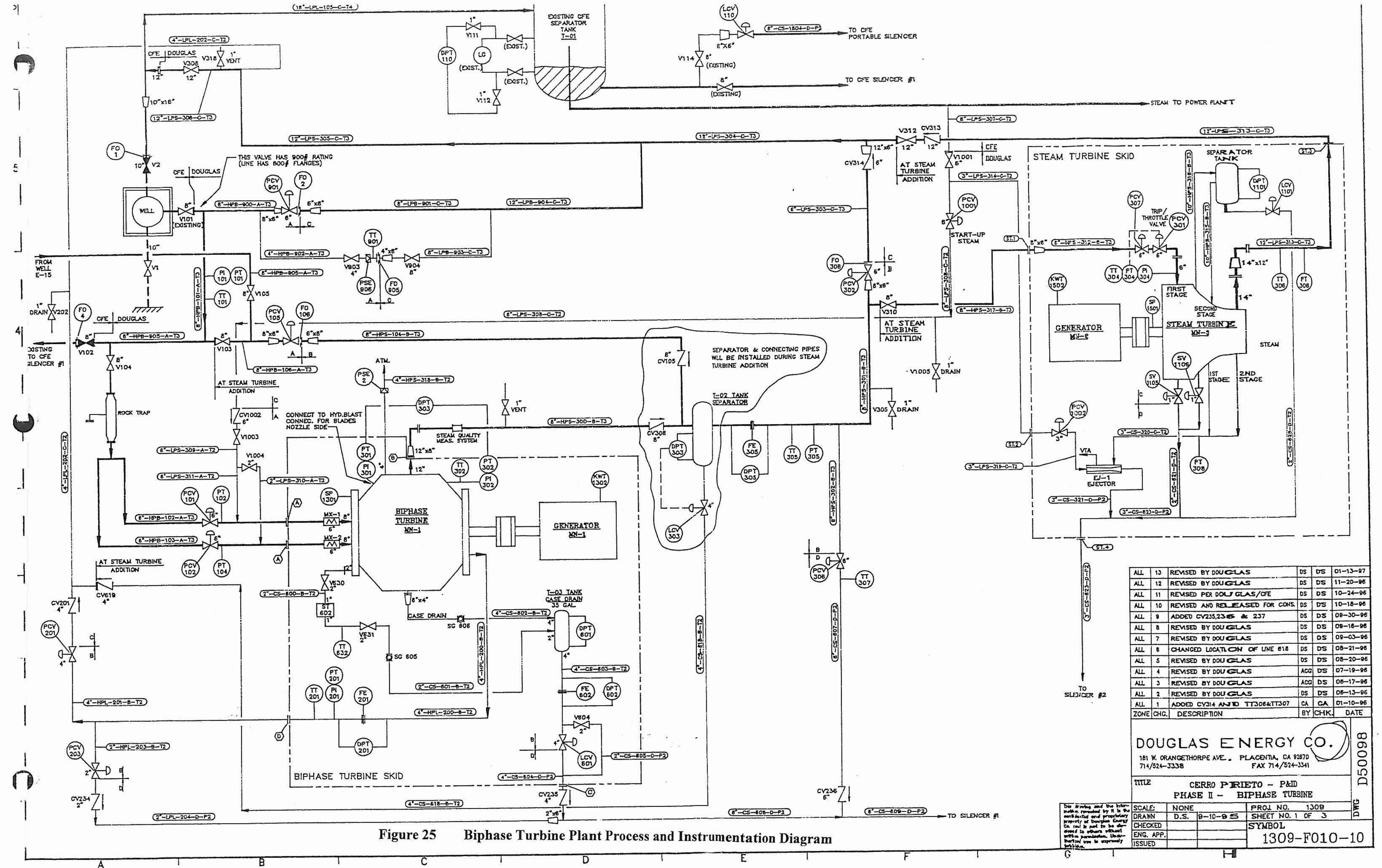




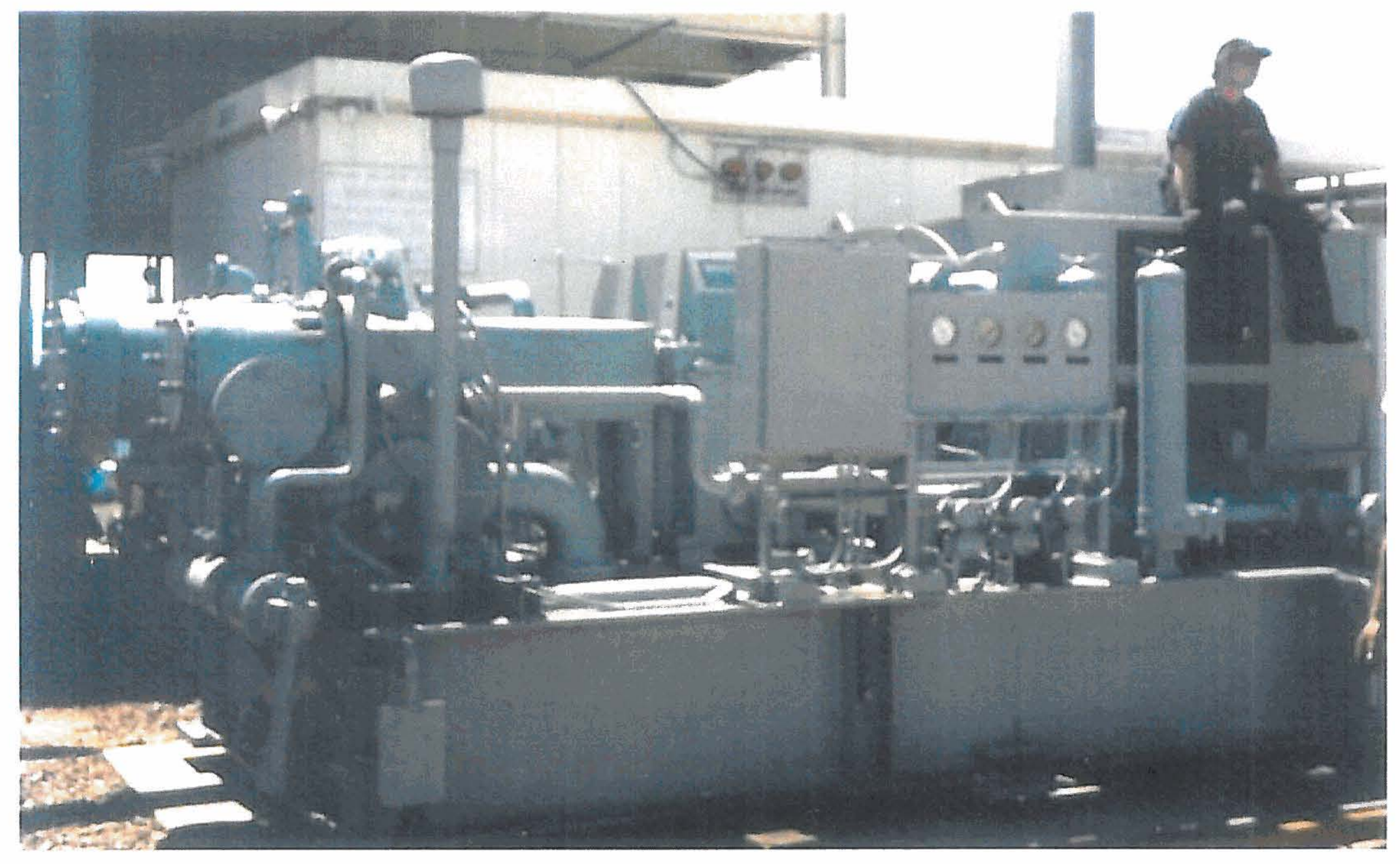

Figure 26 Steam Turbine and Lube Oil System 

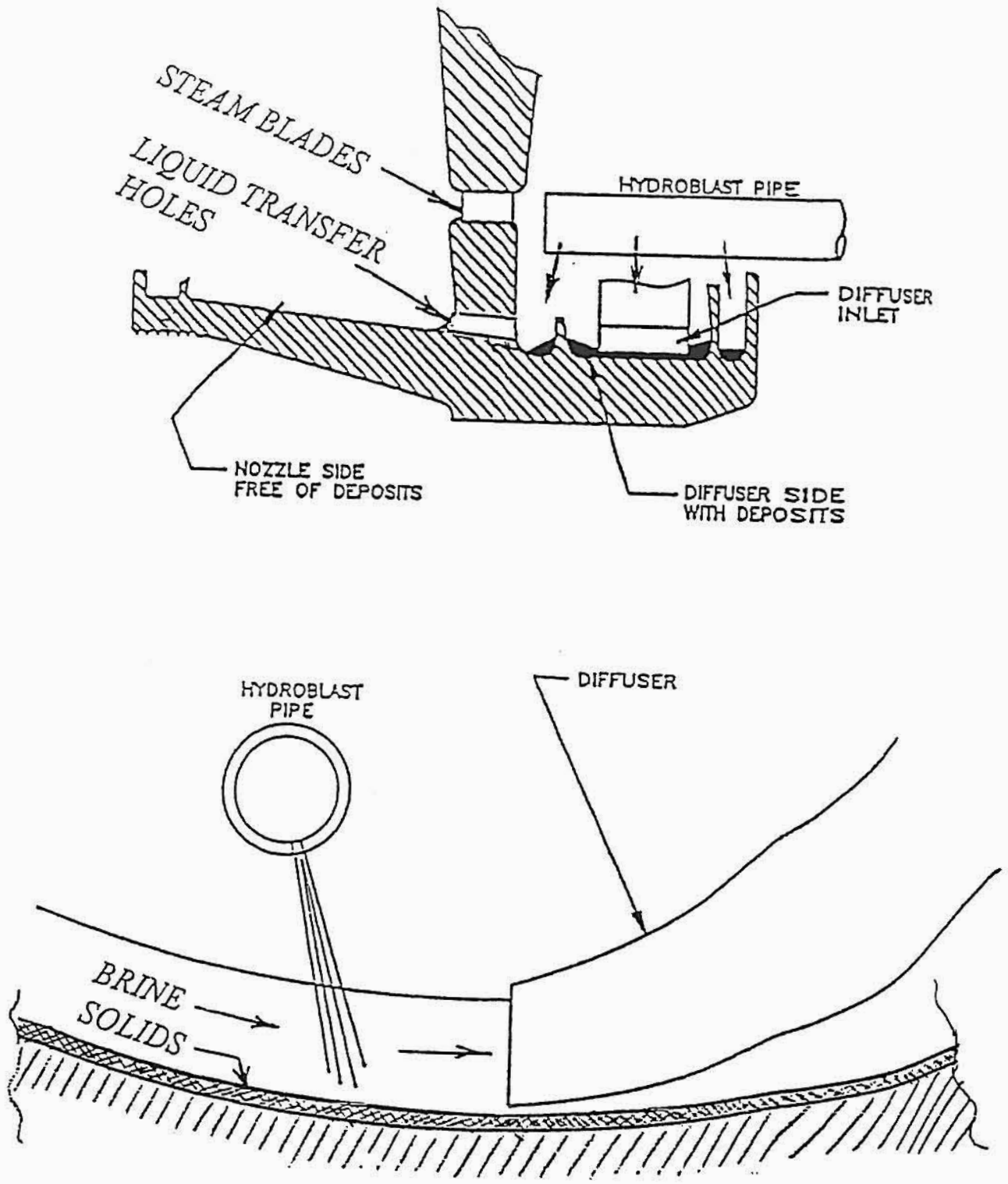

Figure 27 Schematic of Deposits and Use of Hydroblast Nozzles to Fluidize 


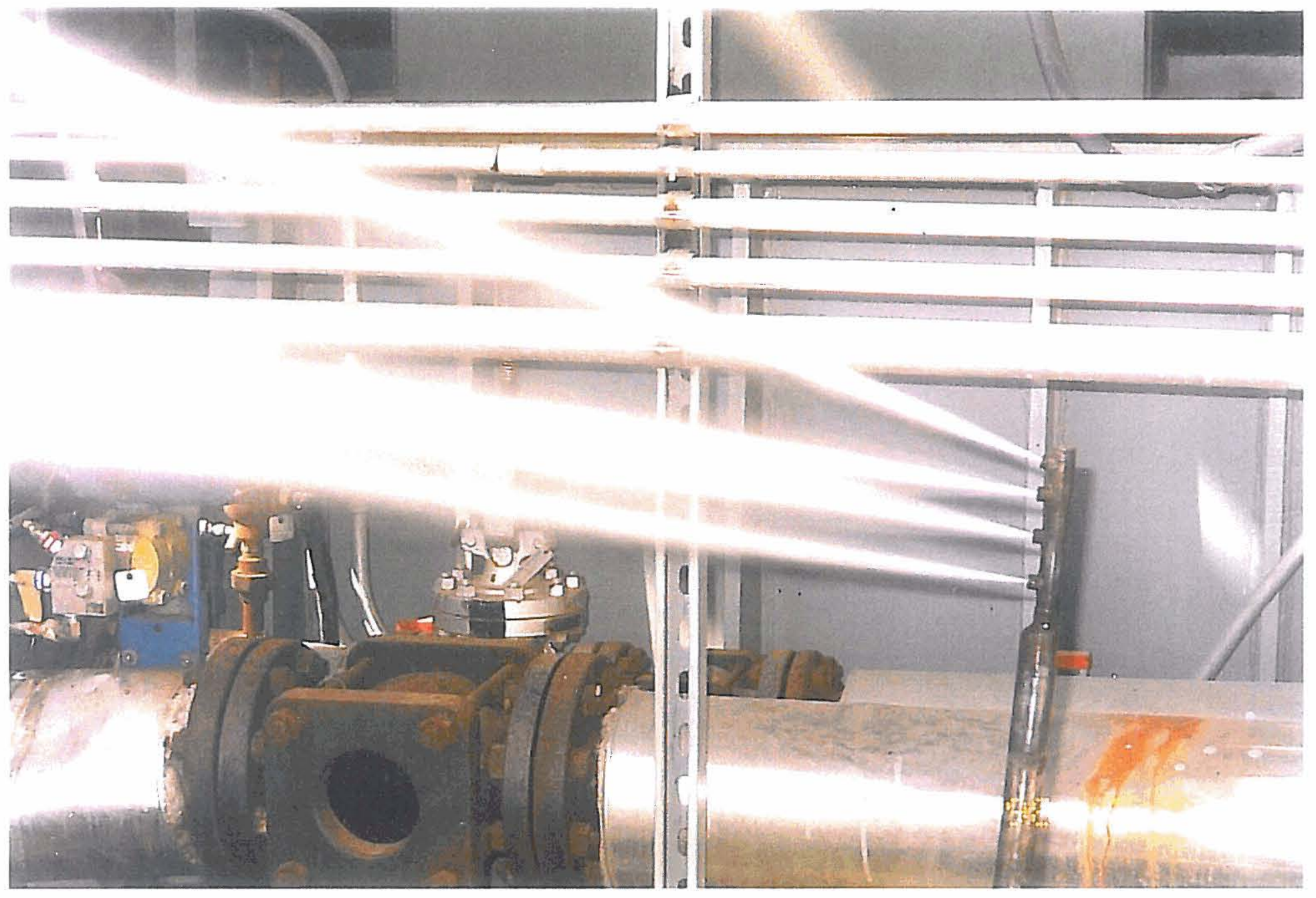

Figure 28 Operation of High Pressure Water Jets 


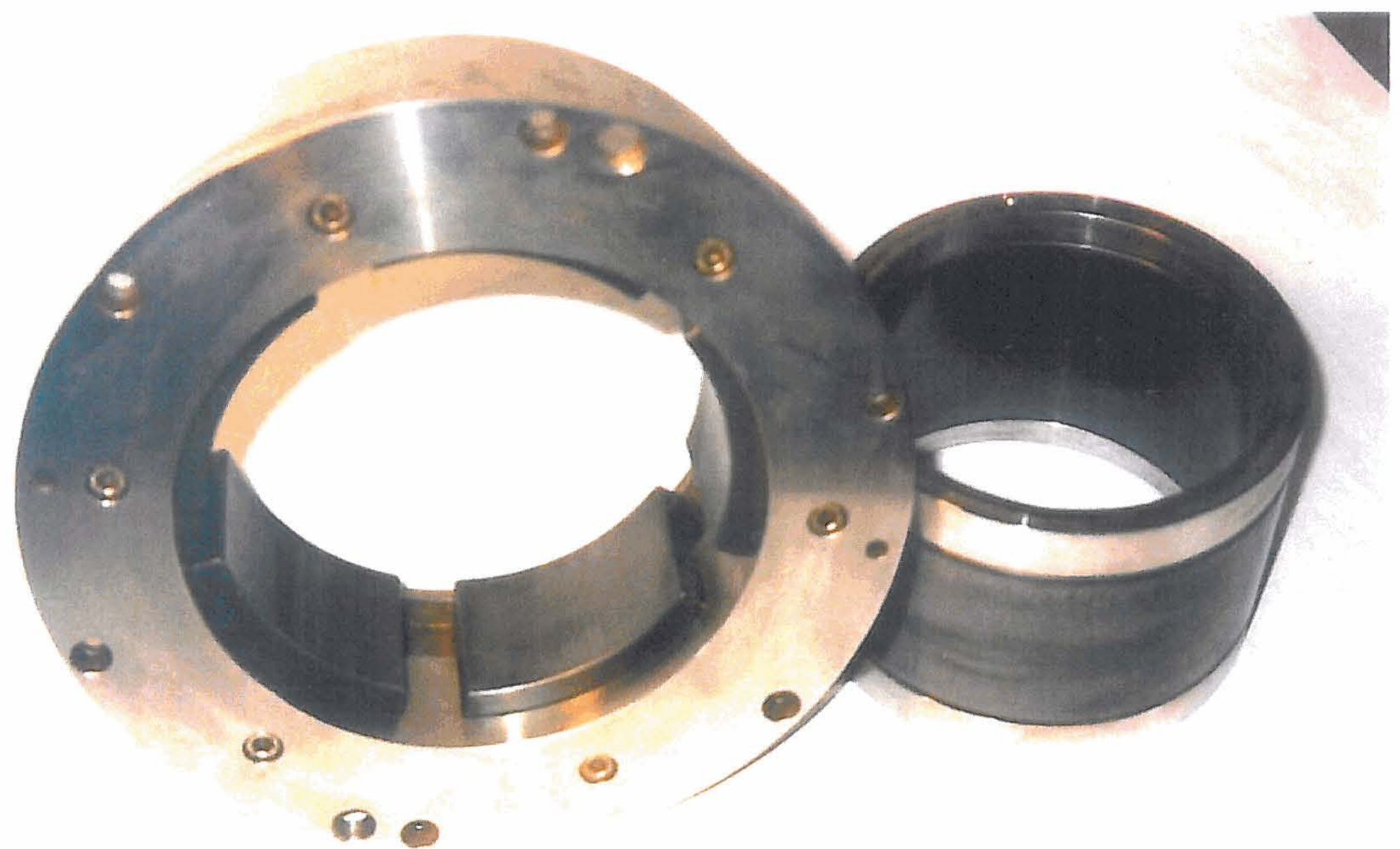

Figure 29 Silicon Carbide Journal Bearings 


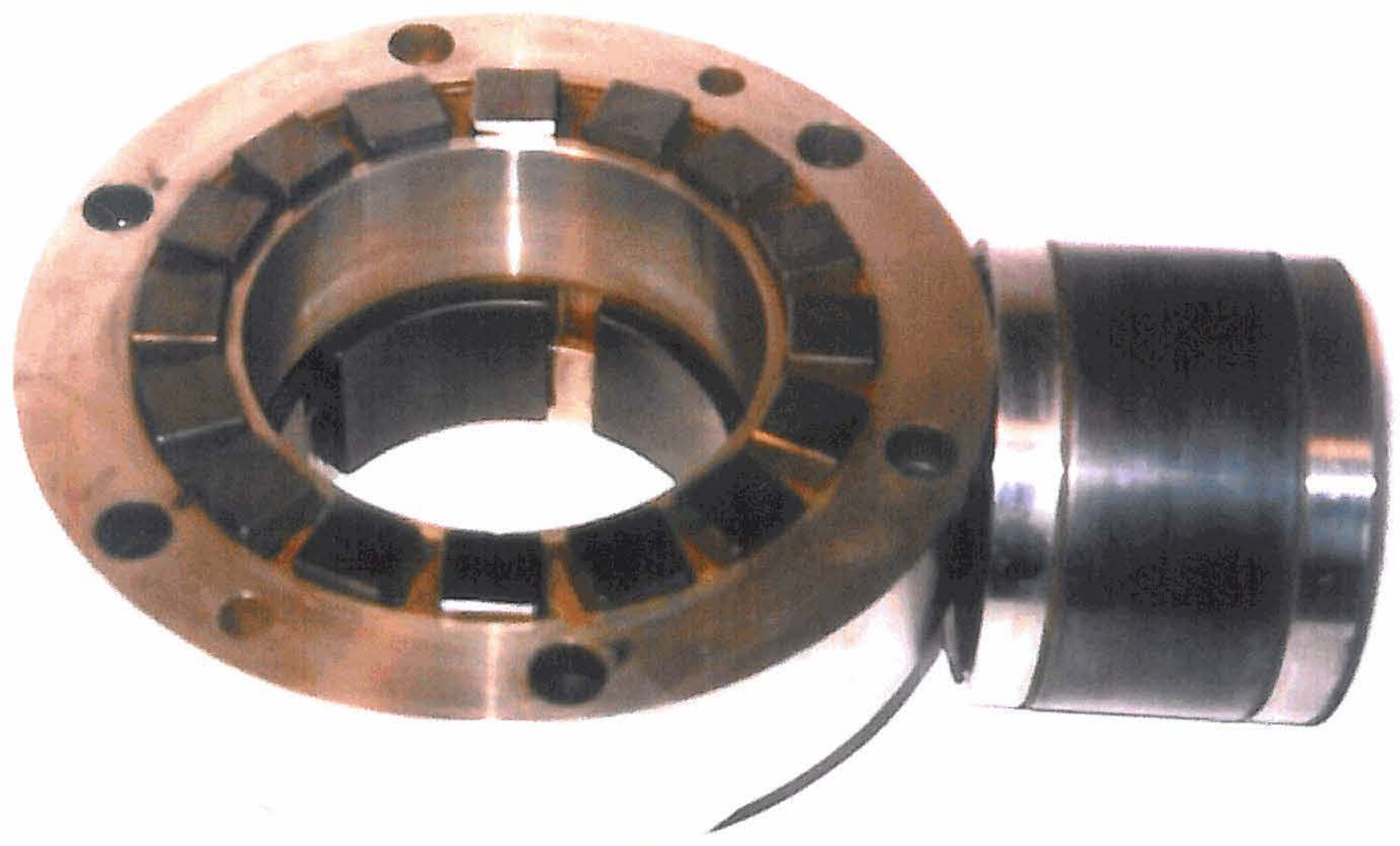

Figure $30 \quad$ Silicon Carbide Thrust Bearings 


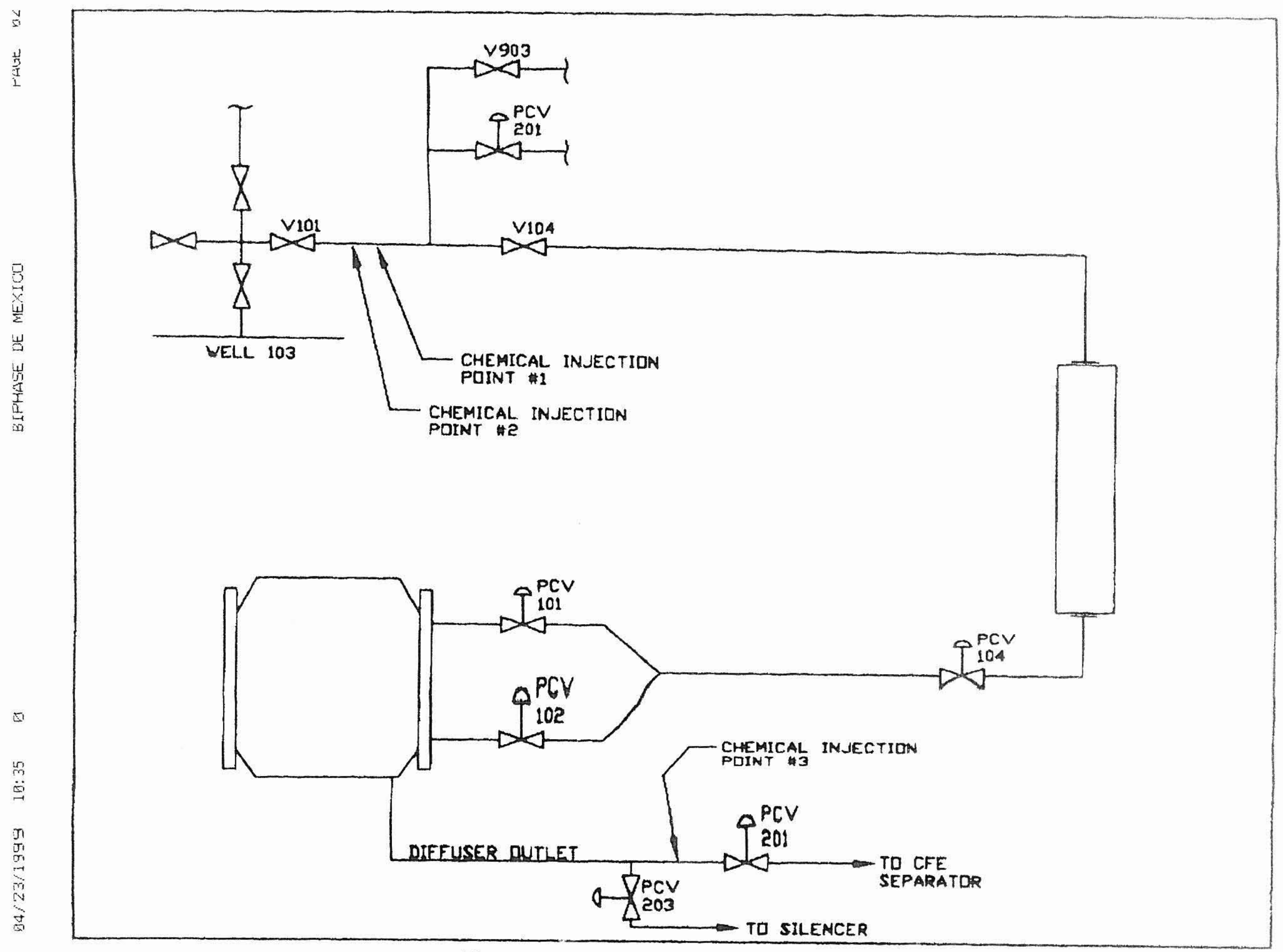

Figure 31 Chemical Injection System Schematic 


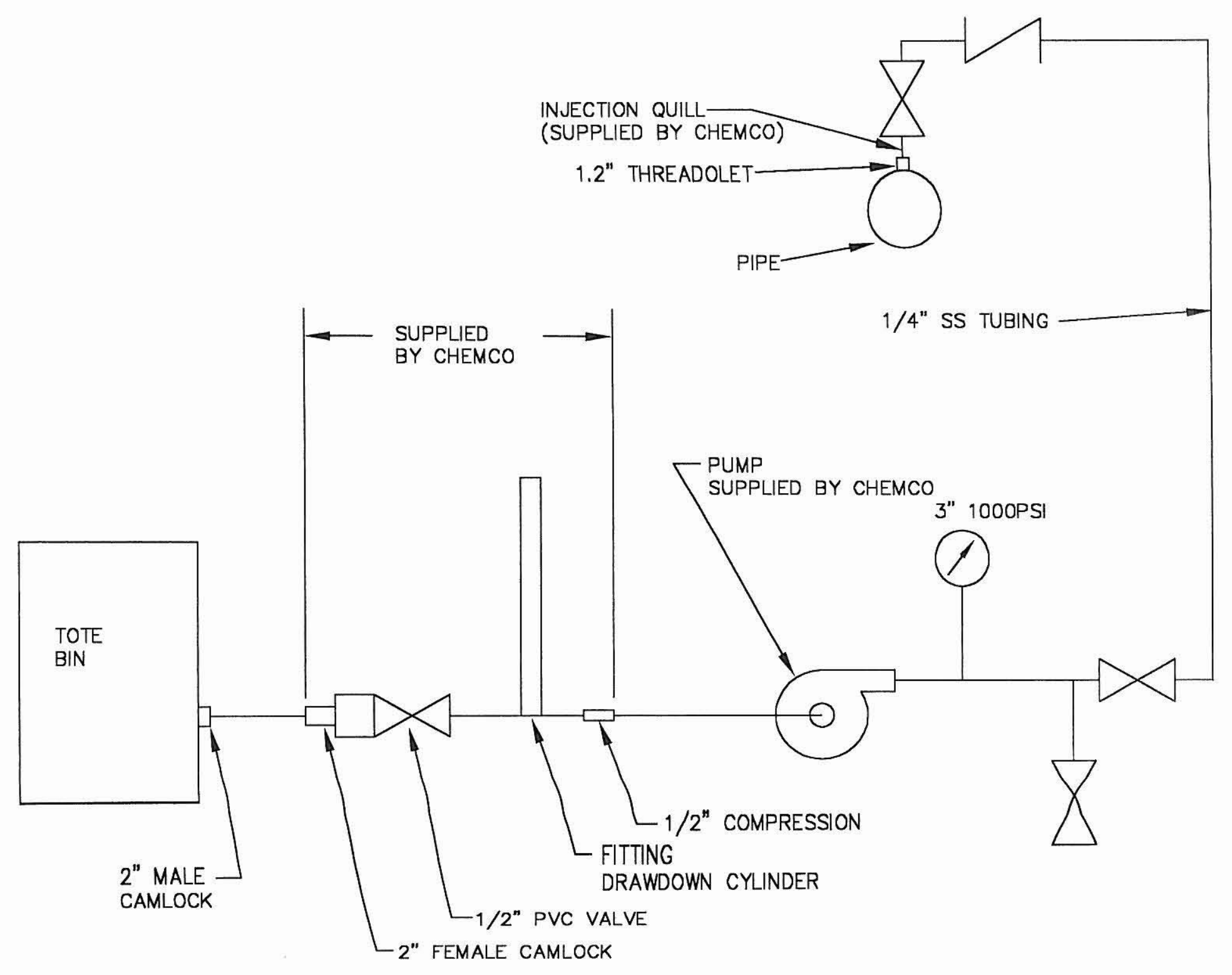

Figure 32 Typical Chemical Injection System Details, 1 of 3 
Figure 33 Typical Chemical Injection Port, 1 of 3

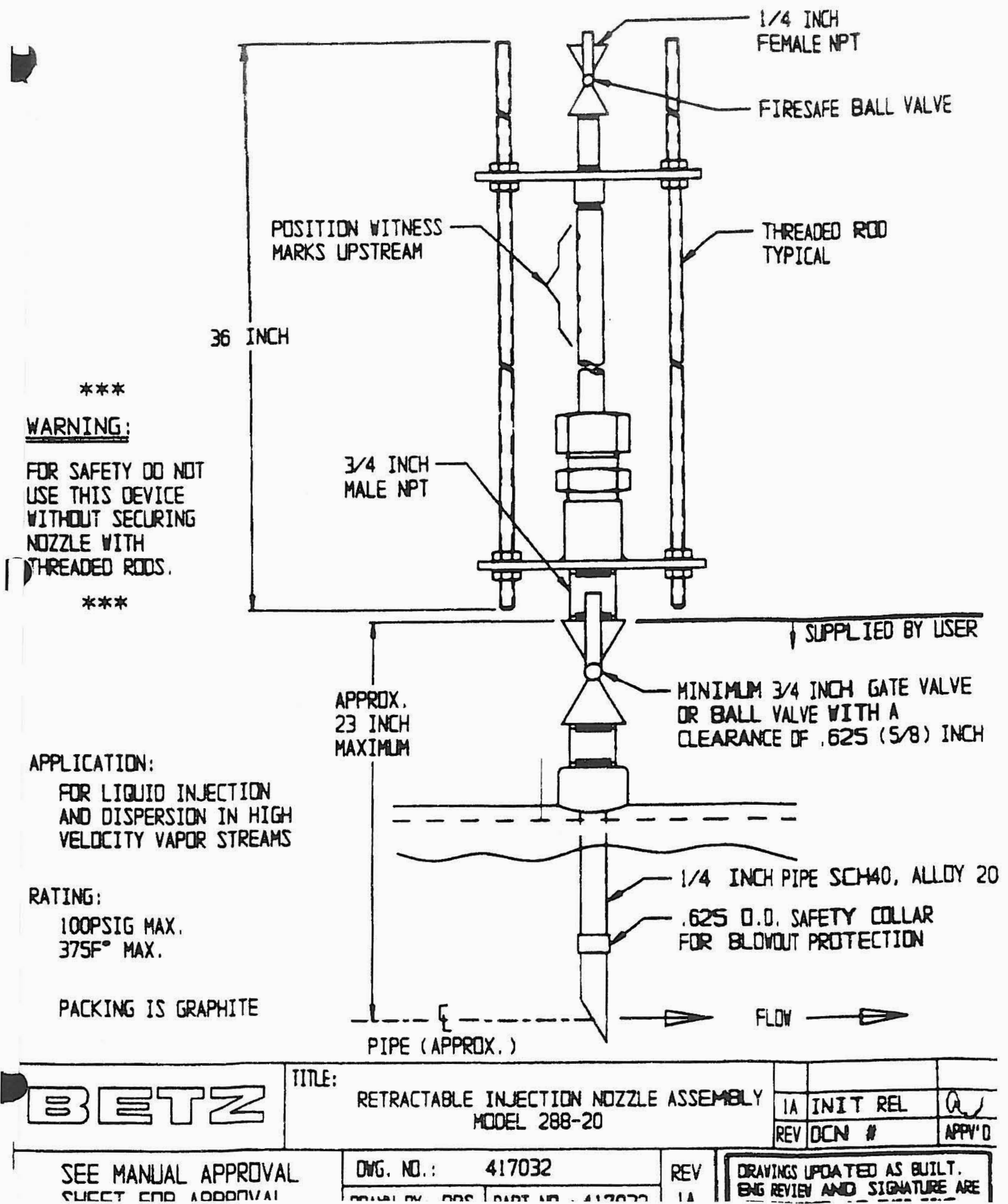



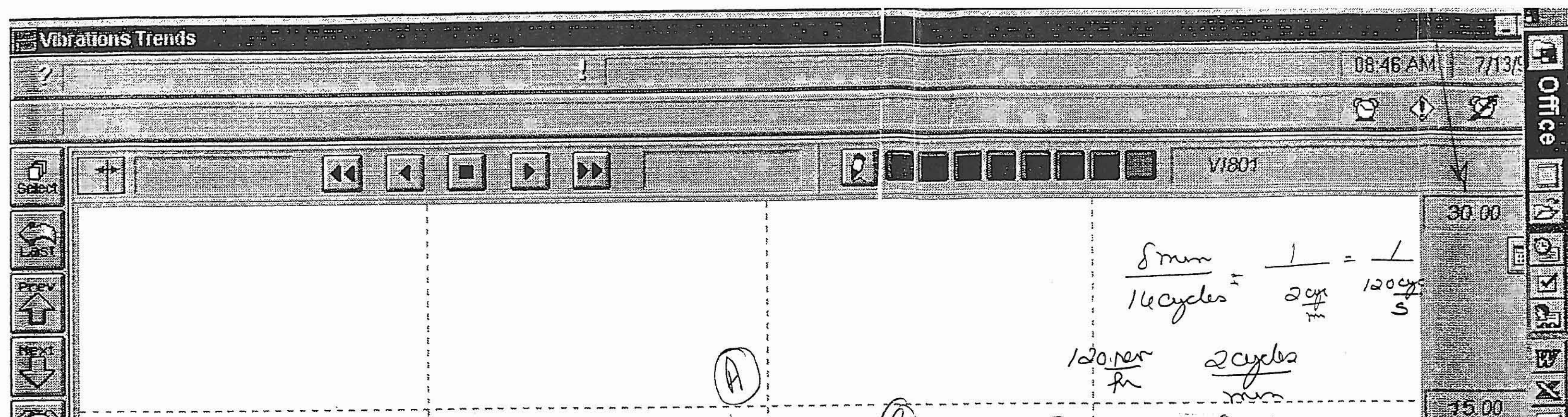

15

(1) 


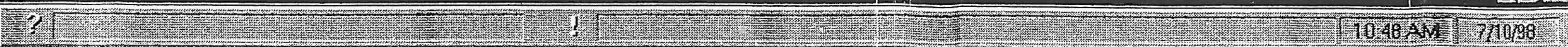

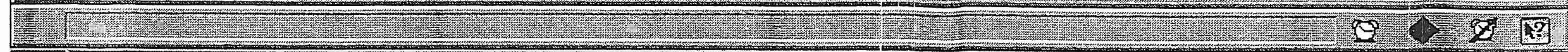

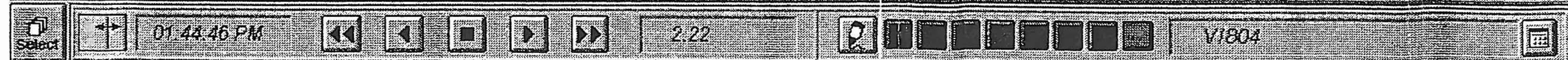

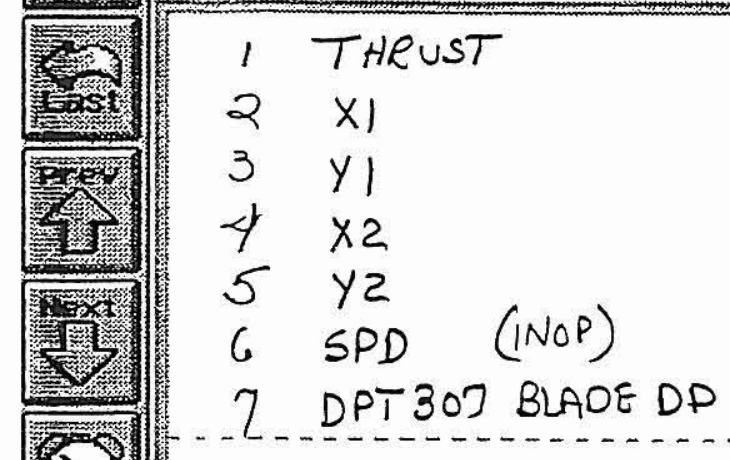

3

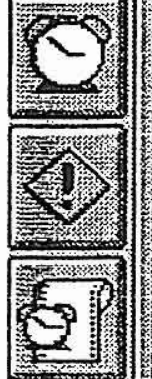

$\begin{array}{ccc} & \vdots \\ \vdots & \vdots \\ & \vdots \\ & \vdots \\ & \vdots \\ & \vdots \\ & \vdots \\ & \vdots\end{array}$
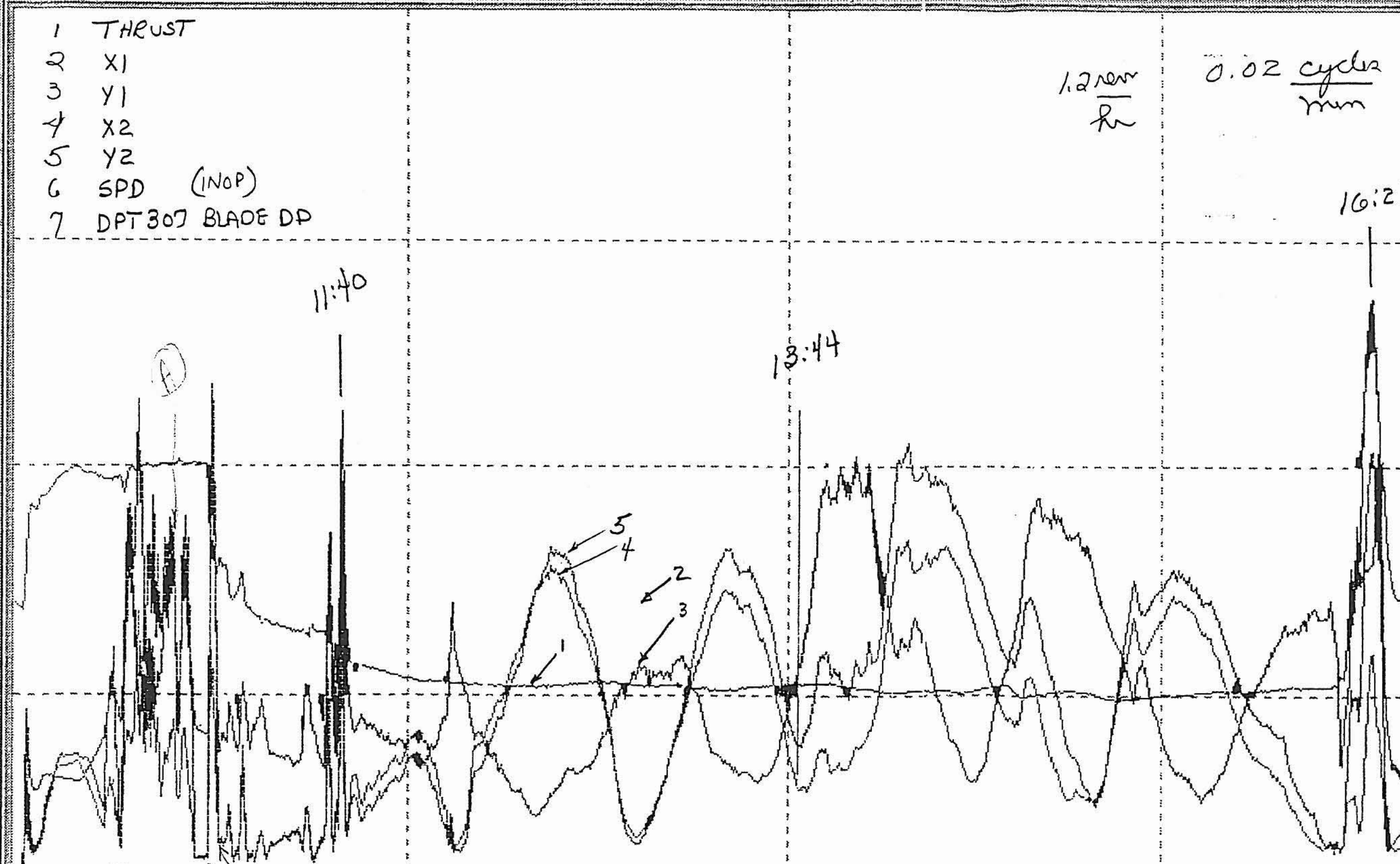

(b) 1 (1) (1)
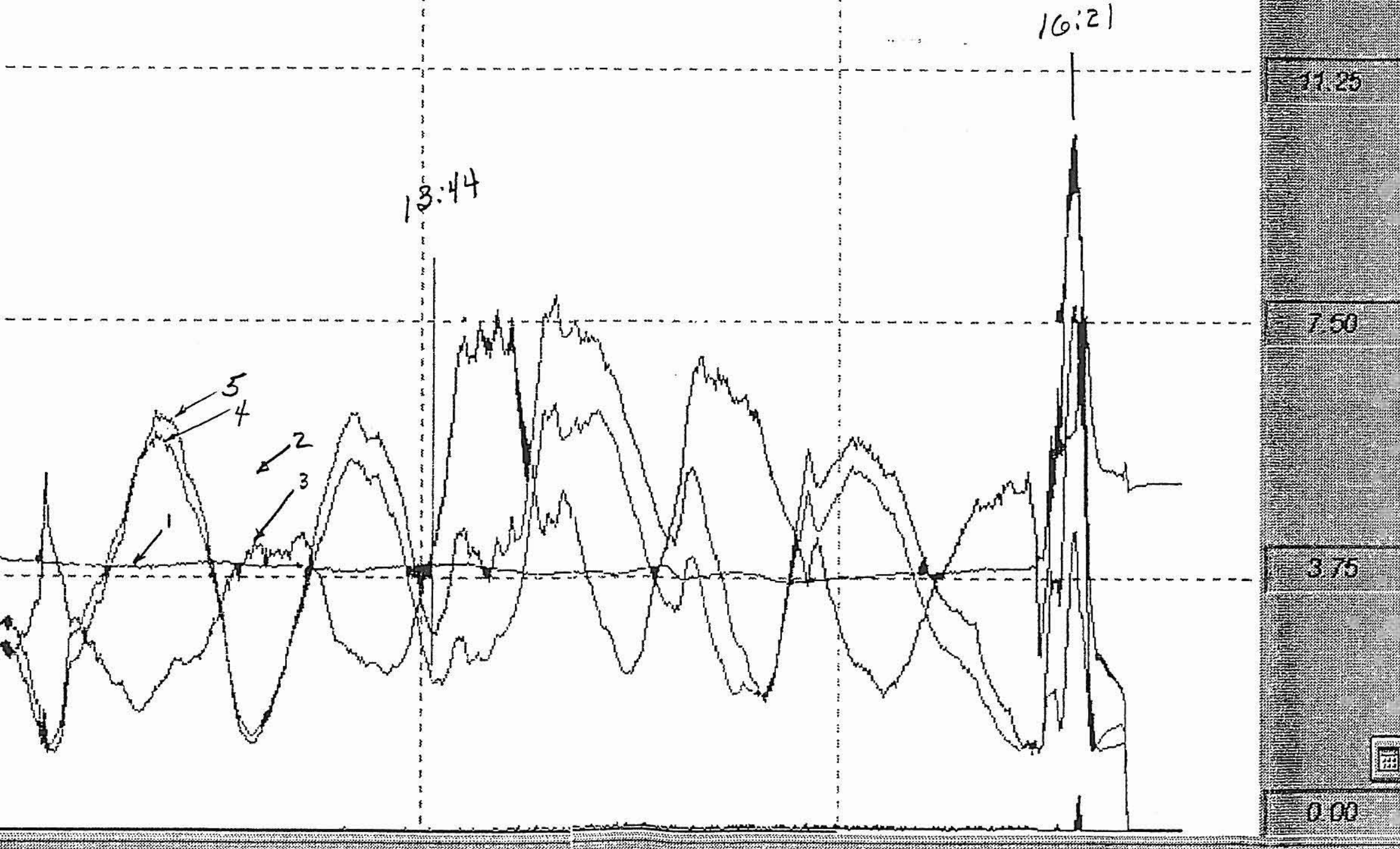

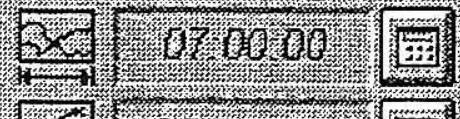

《四回回

国圆圆圆圆

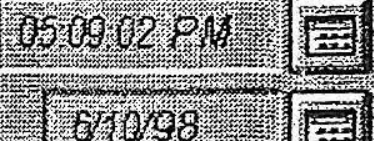




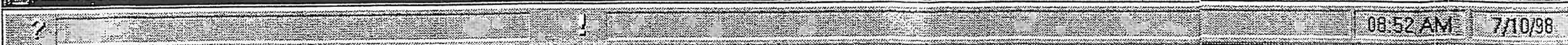

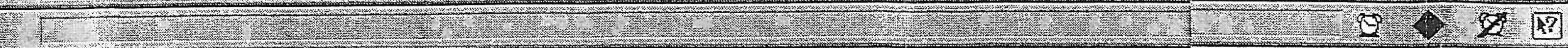

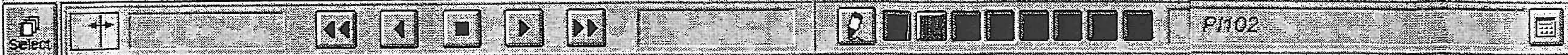
7 DPT 305 STM F20W 11:40:00

2 PT 102

3 DT 104

4 KWT

5 DPT 201 L10 FLOW

6 PT 302 CASE PRES

7 FI 1002 CFE STM

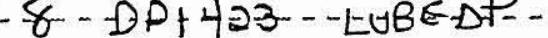

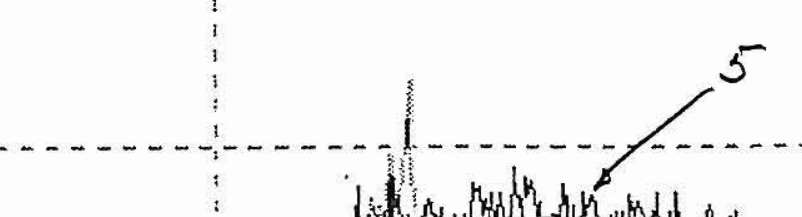

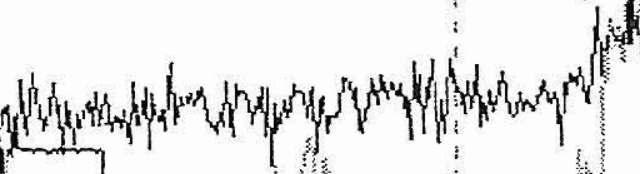
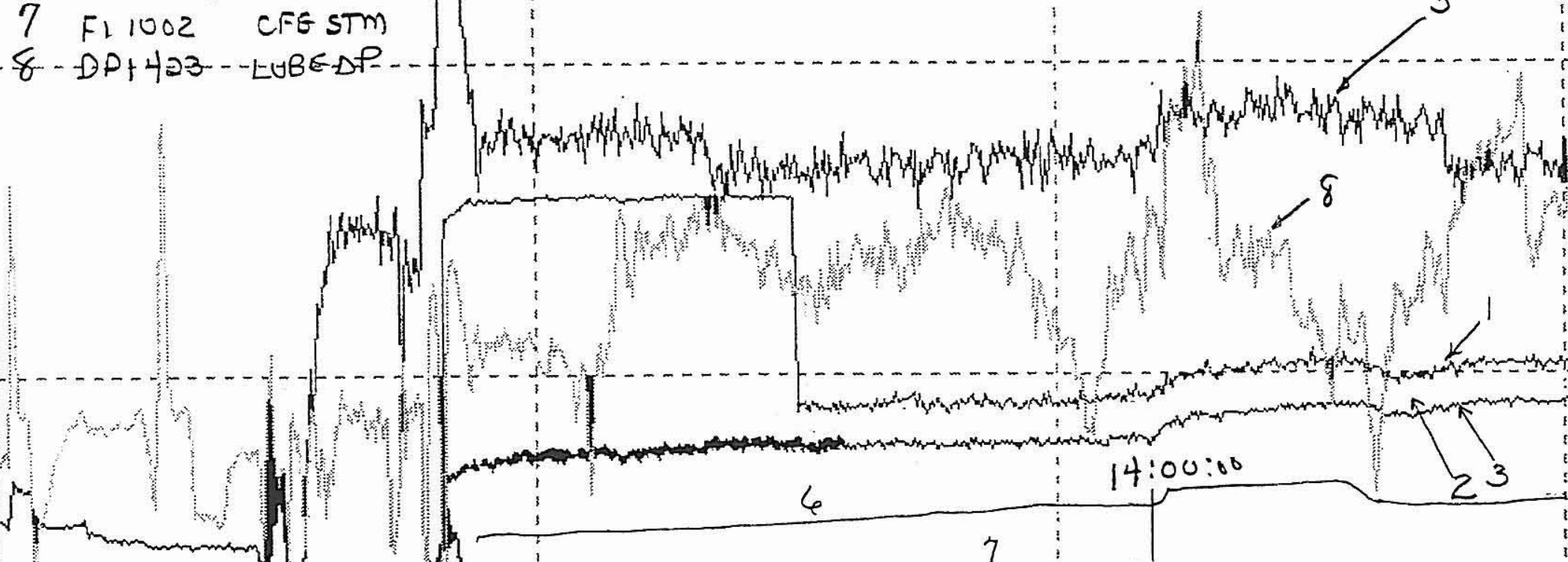

1.
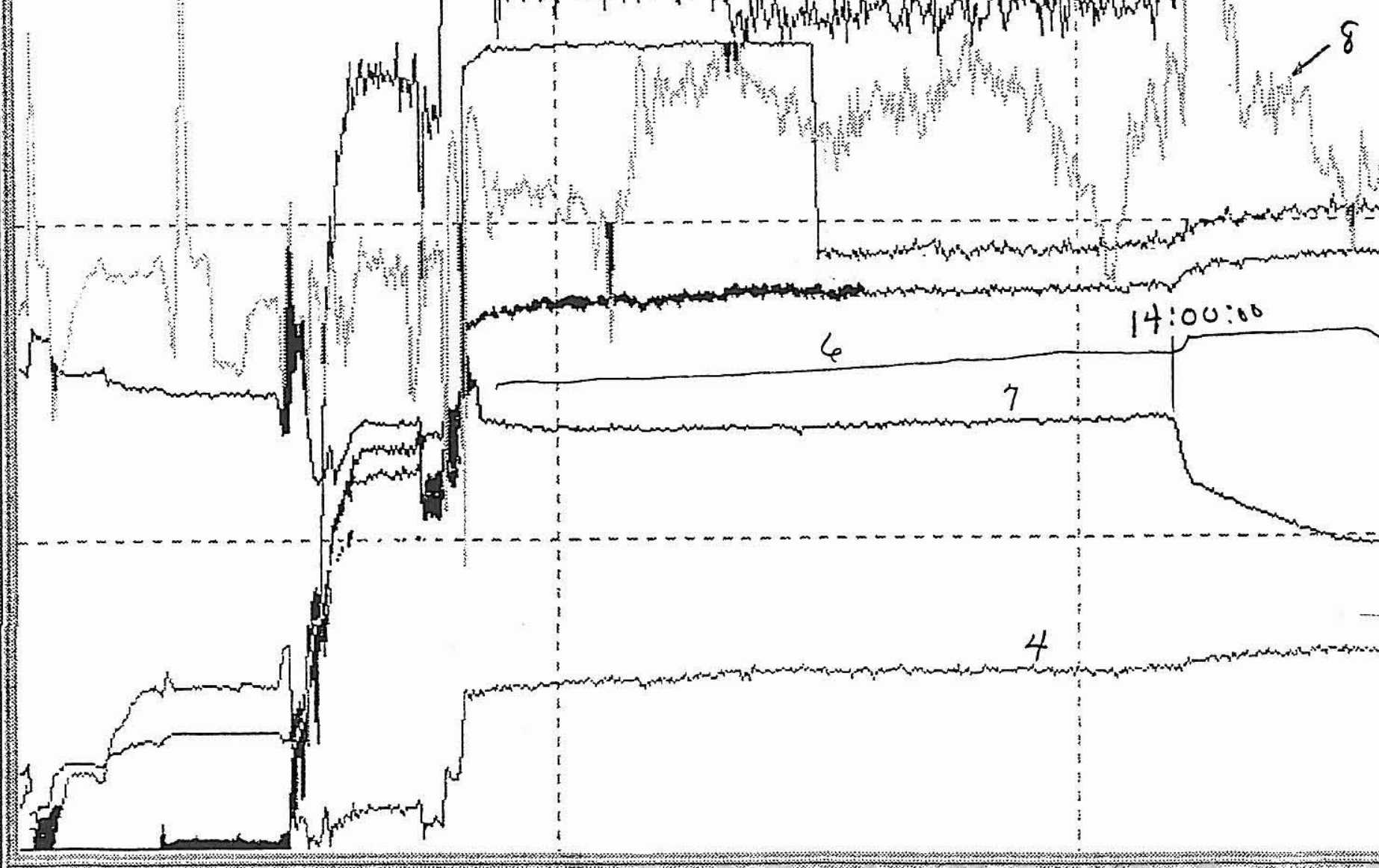

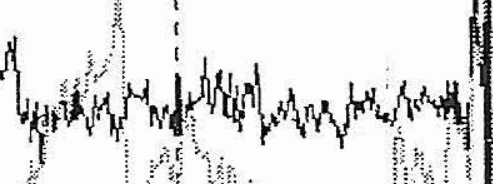

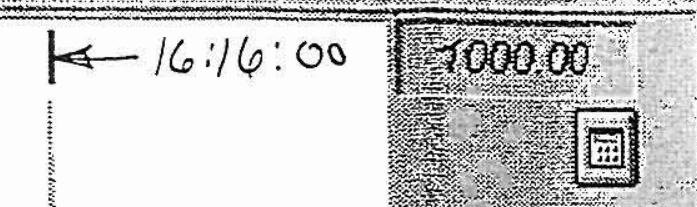

n

70.09:25 All

国:00:00 国 67098 


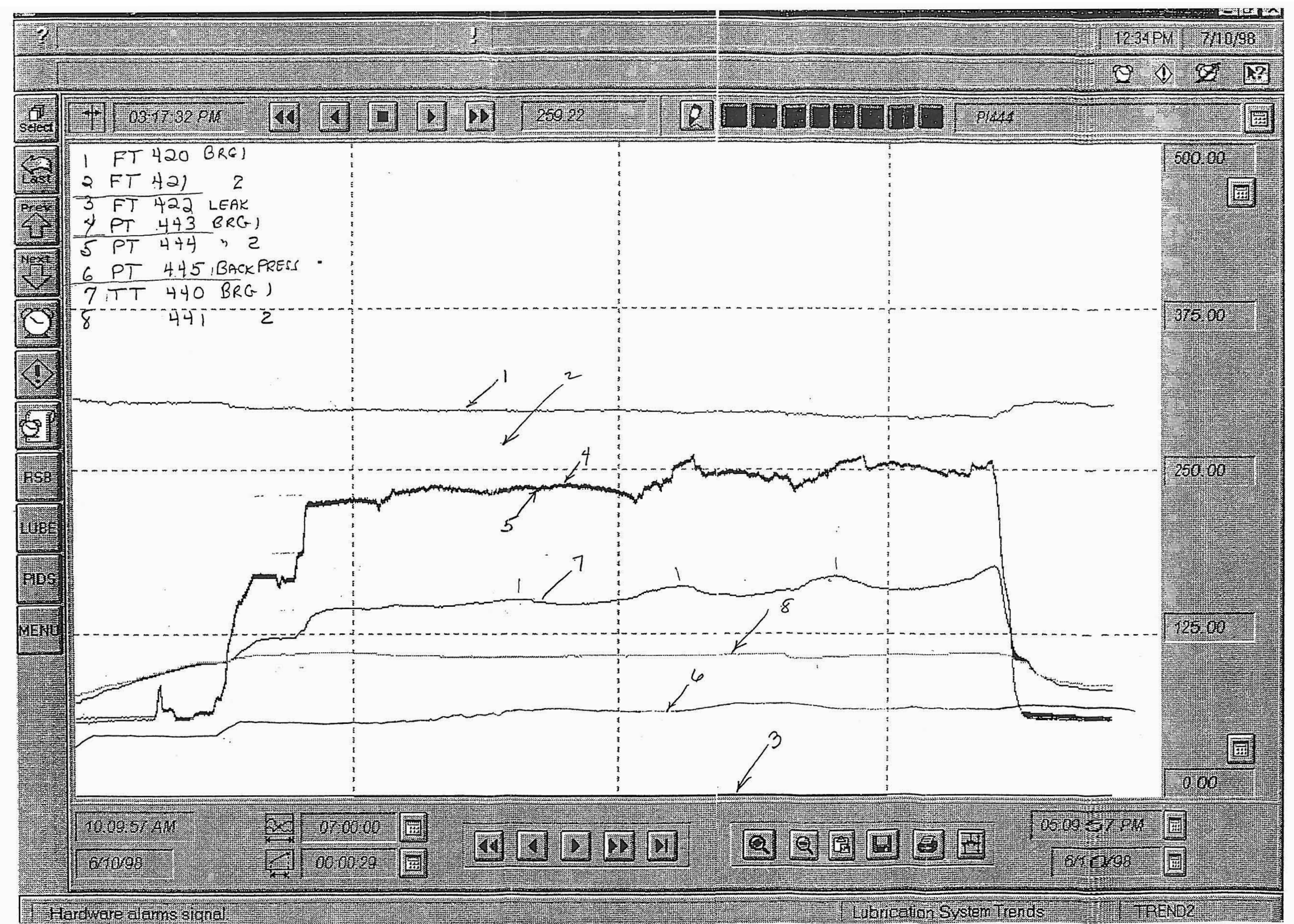

Figure 37 Lubrication System Data Plots Test 26 


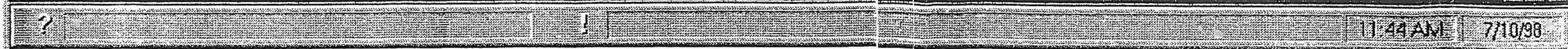

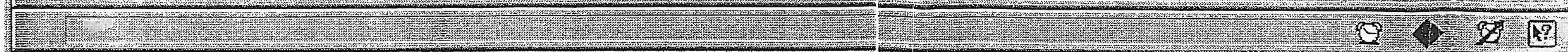

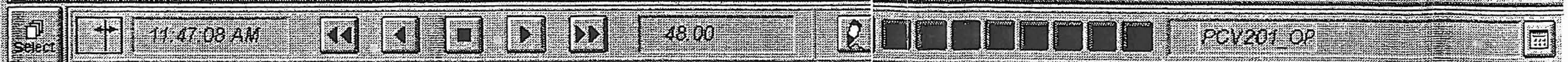

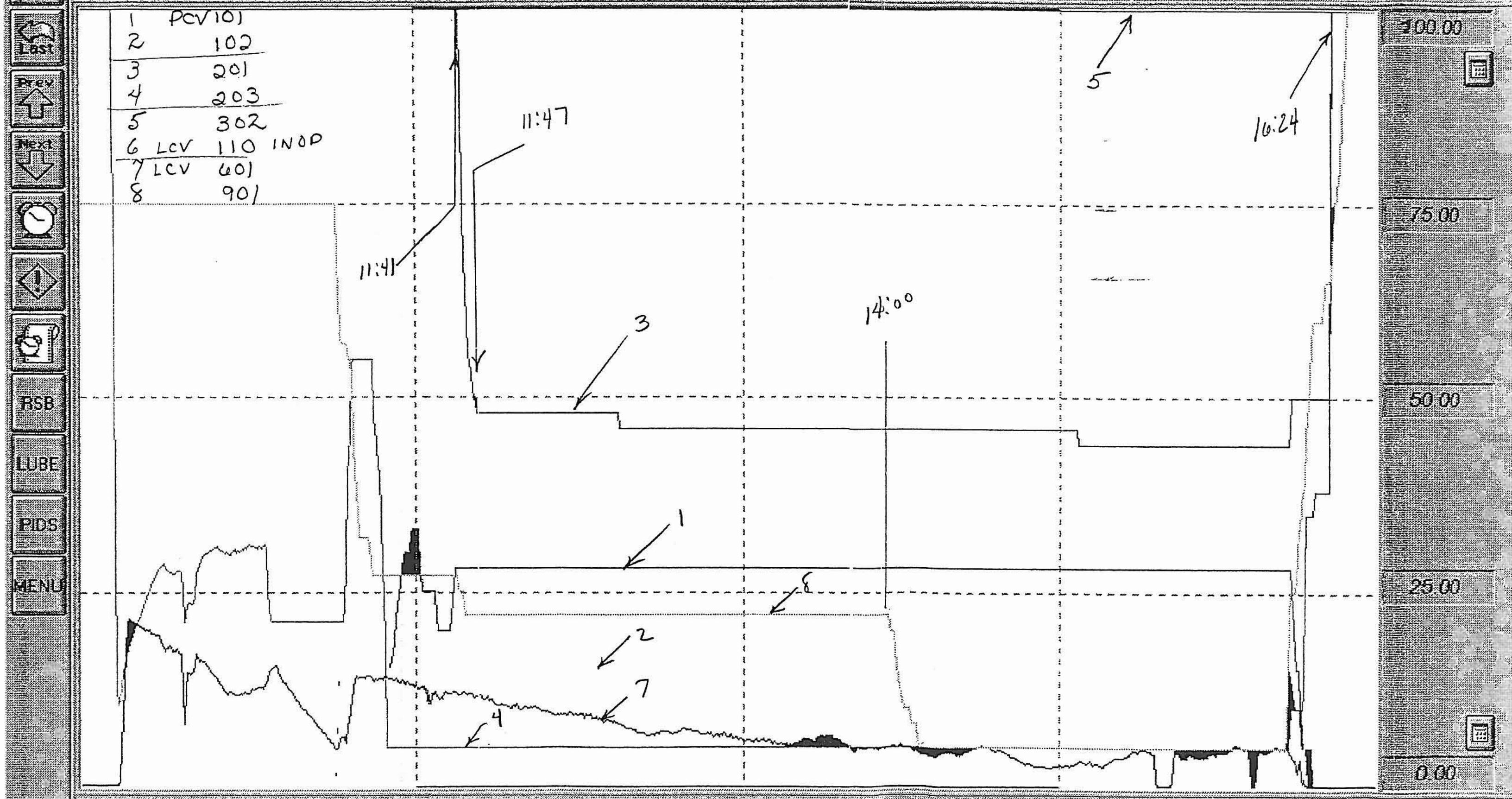

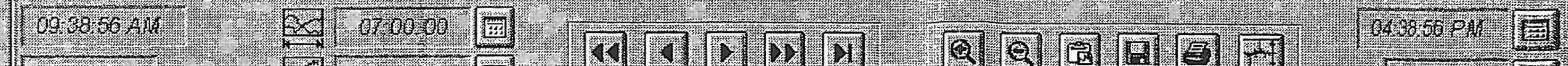

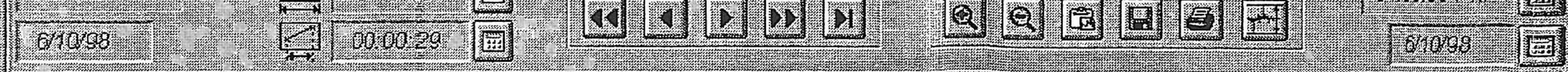

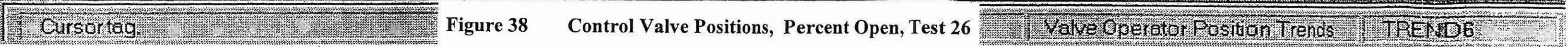


(7)

TS 1 PT 305

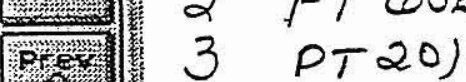

7.

12 ex 5 PT 101

W. 6 PT 104

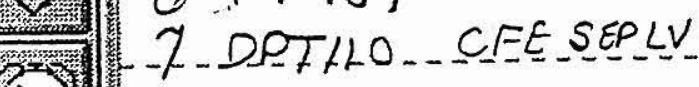

- 8 PT30I

T)

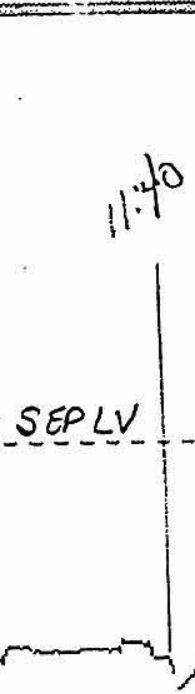

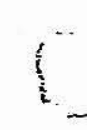

Gp
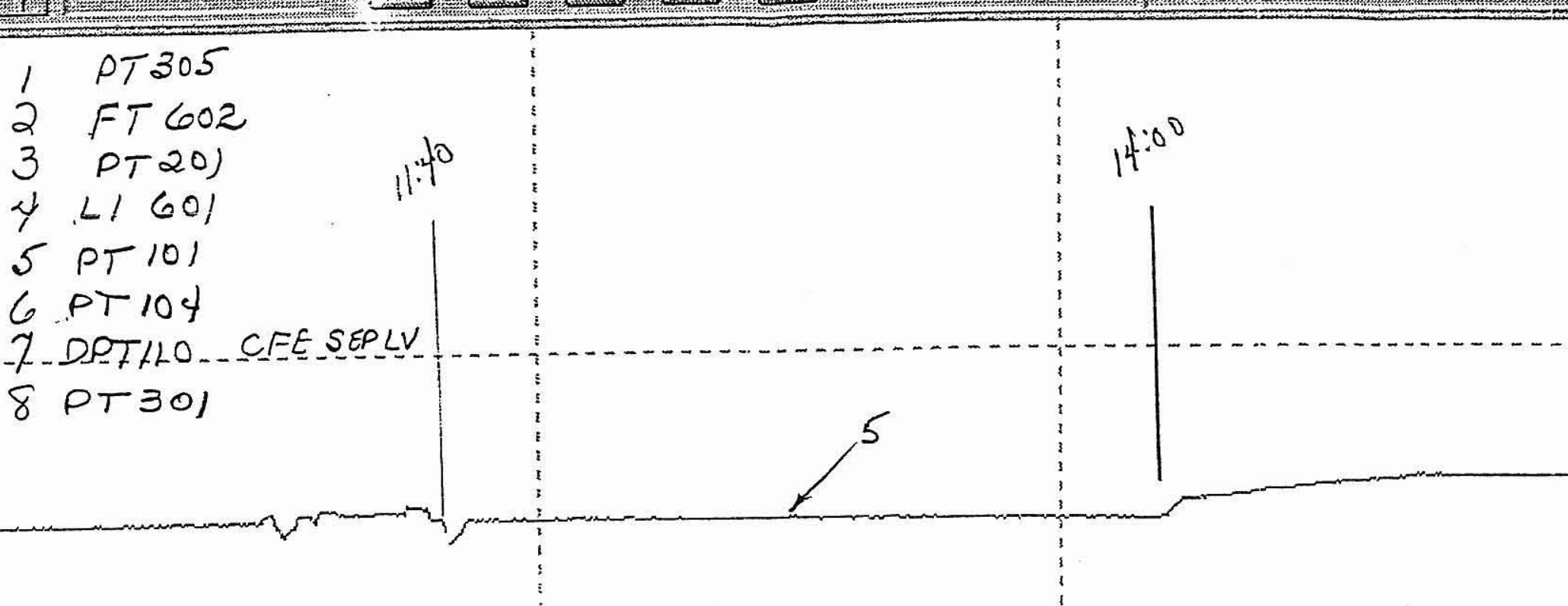

$5^{2}: 313^{3^{2}}$

FSB

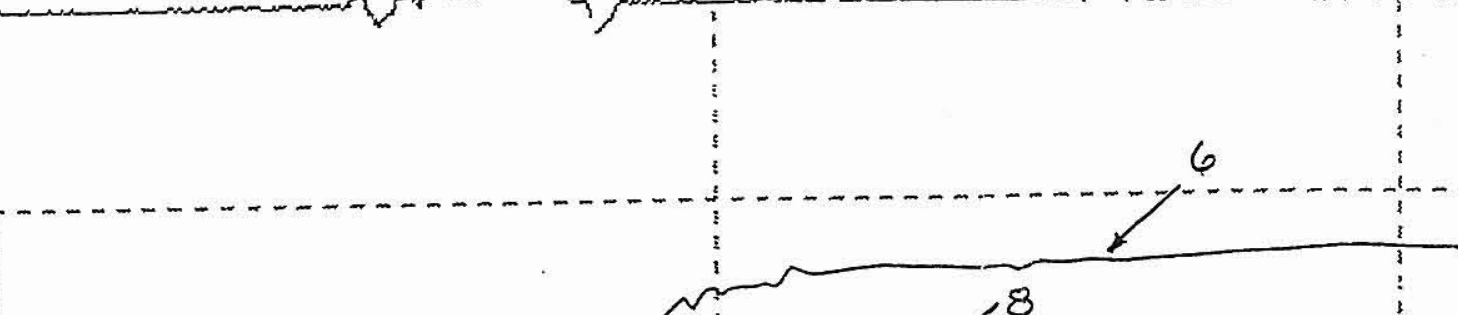

\section{UBE}
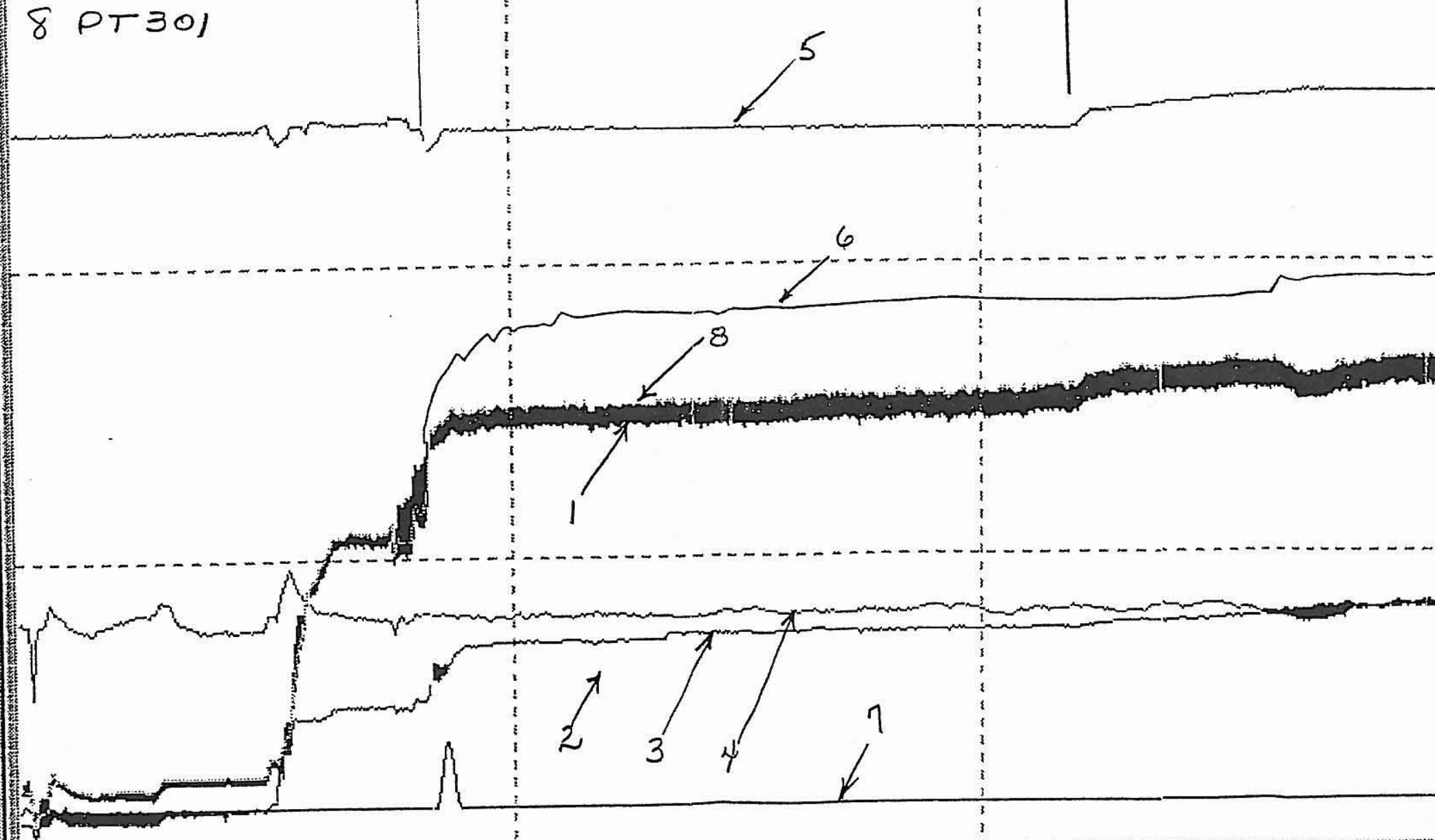

10:0907 AN 


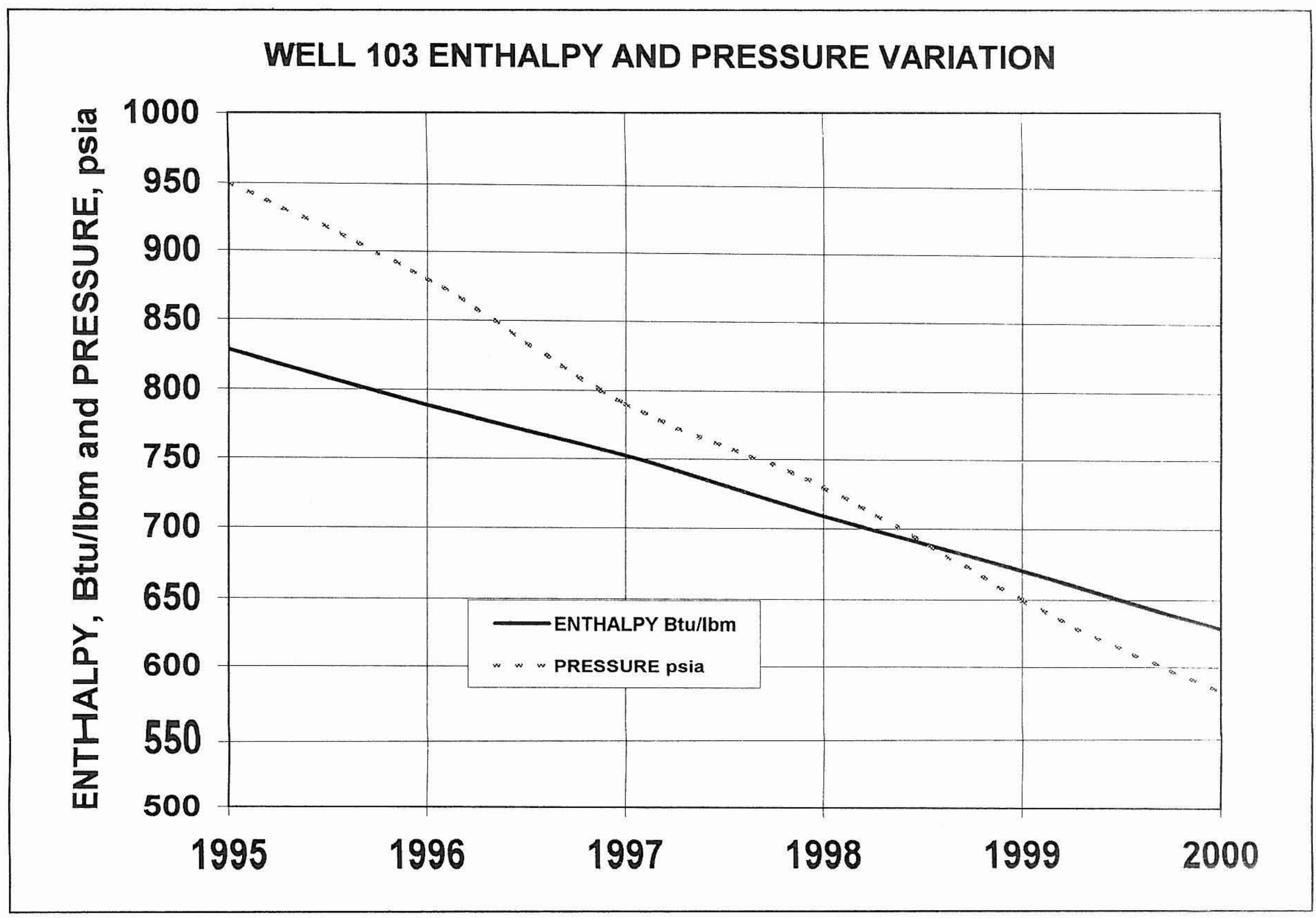

Figure 40 Wellhead Enthalpy and Pressure Variation with Time 
Figure 41 Comparison of Measured and Predicted Power for Biphase Turbine at Well 103

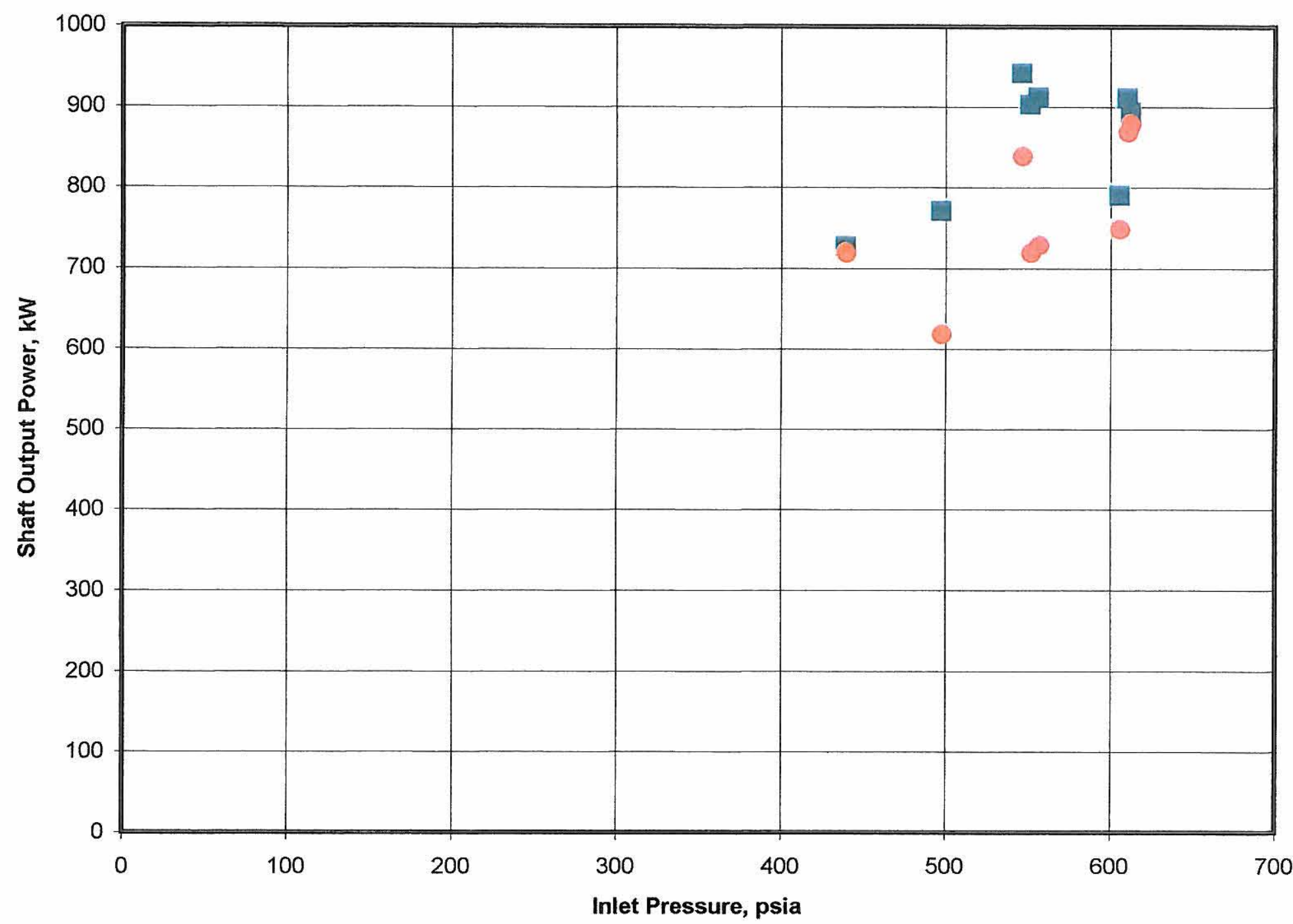

Predicted Power Measured Power 


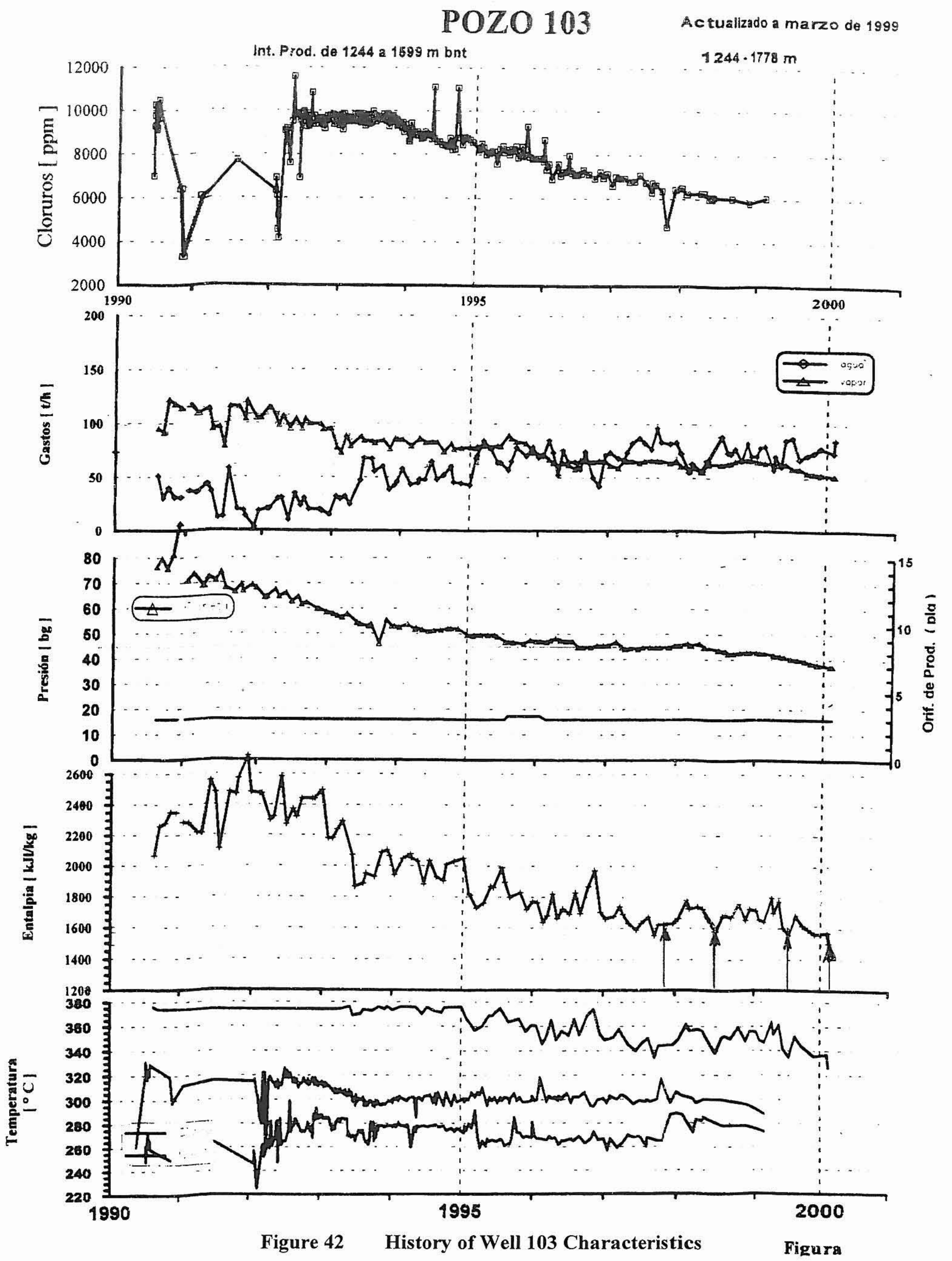




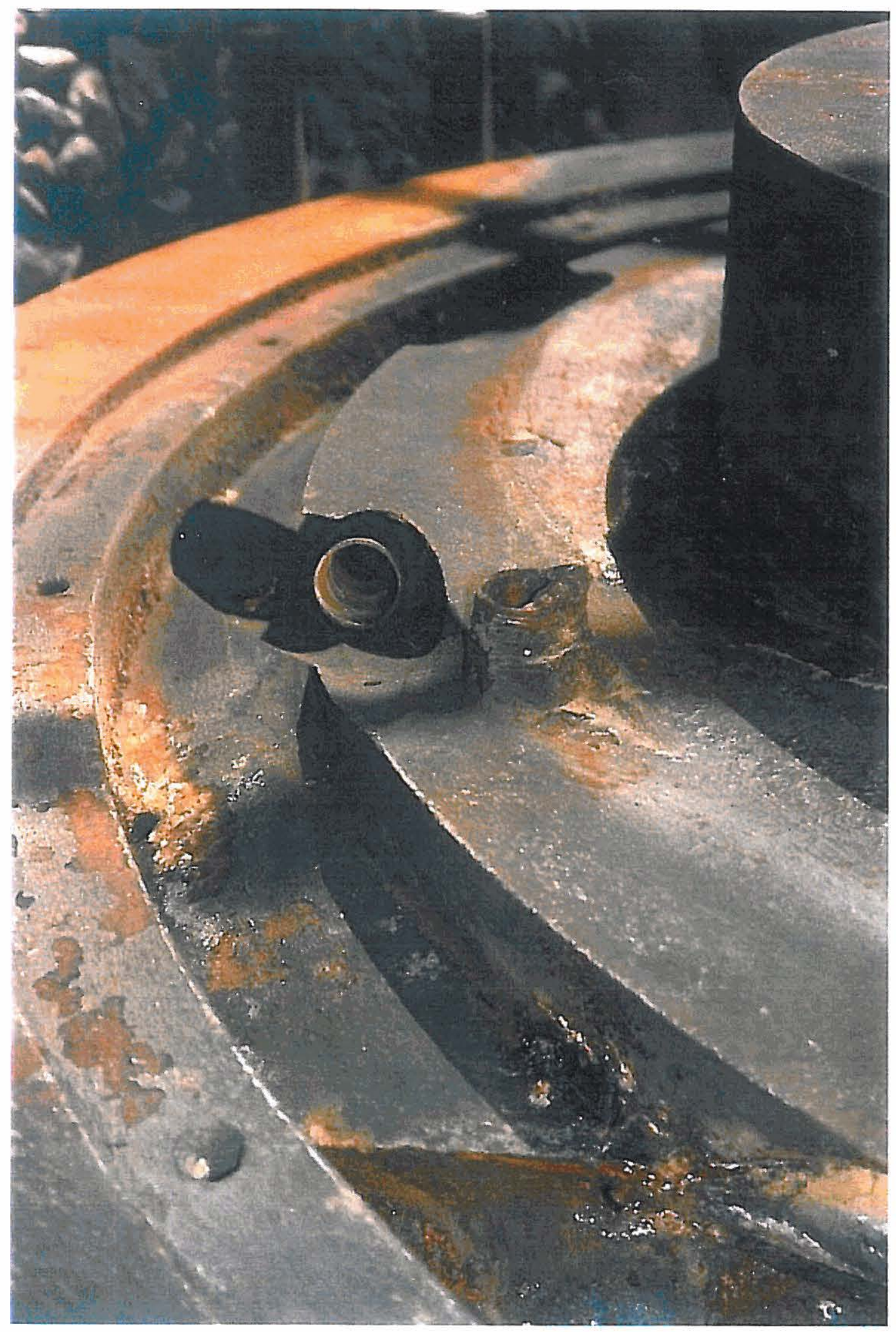

Figure 43 Nozzle Exit After Operation 


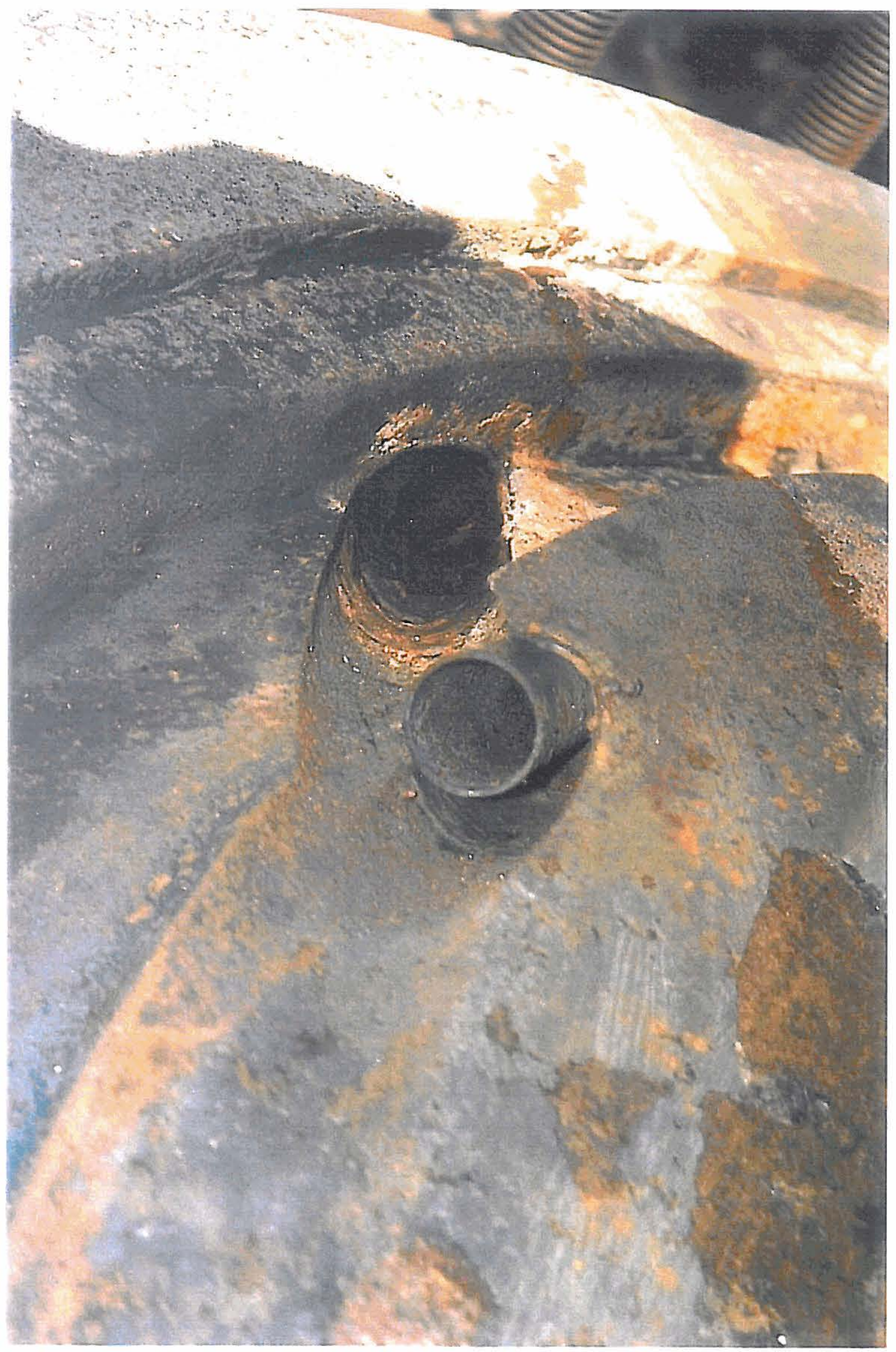

Figure 44 Nozzle Exit and End Wall After Operation 


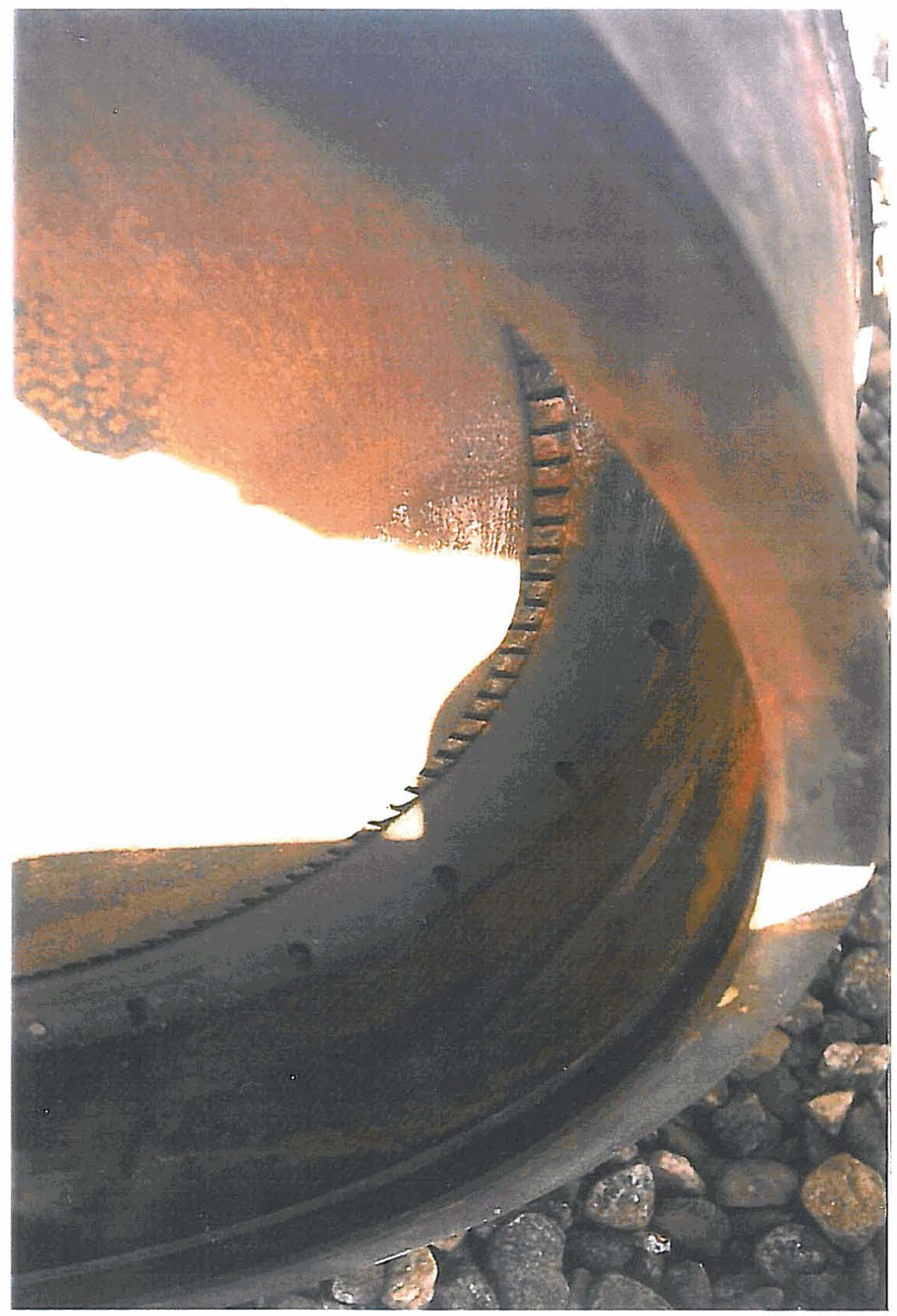

Figure 45 Two-Phase Separator Surface 


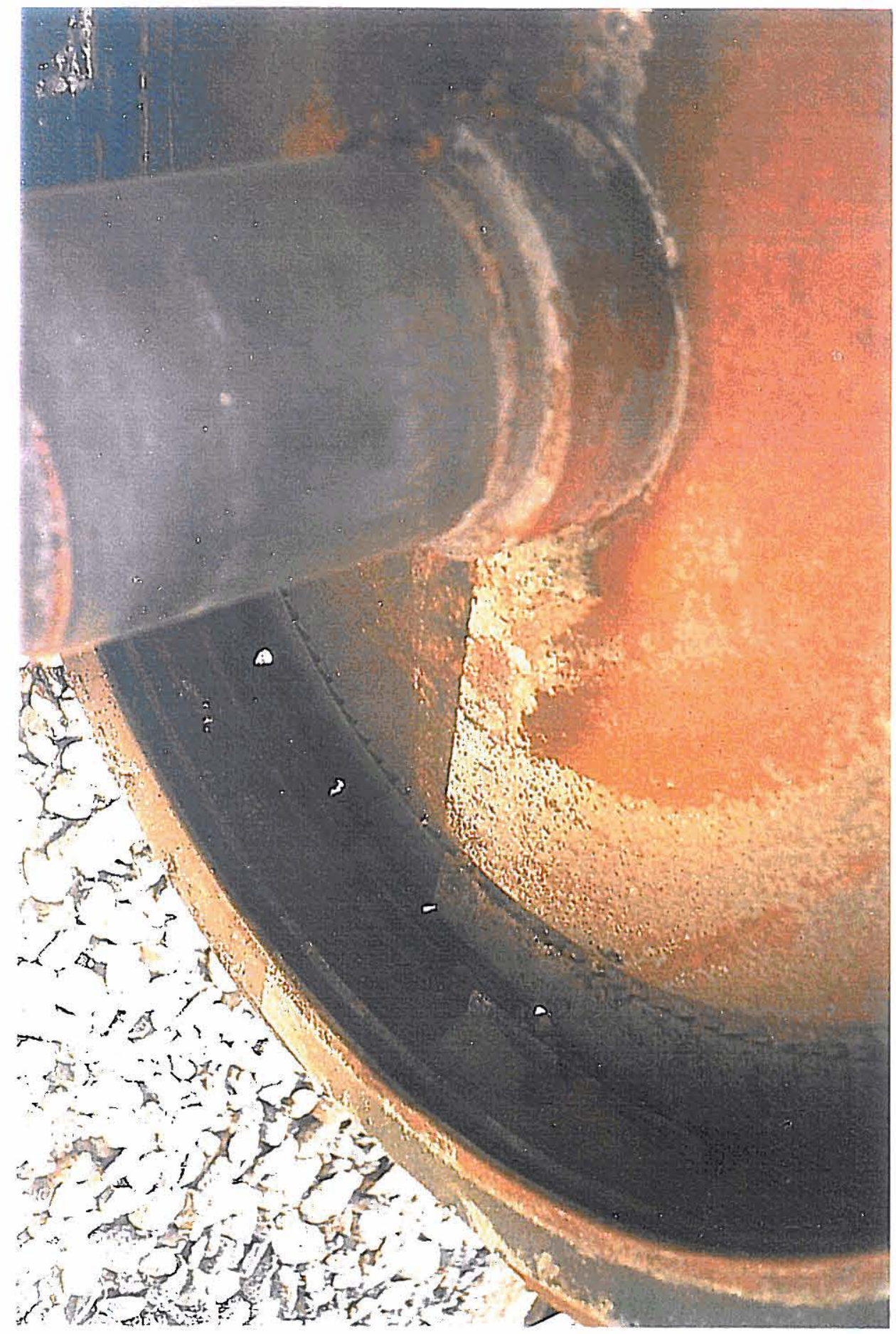

Figure 46 Diffuser Side of Separator Surface 


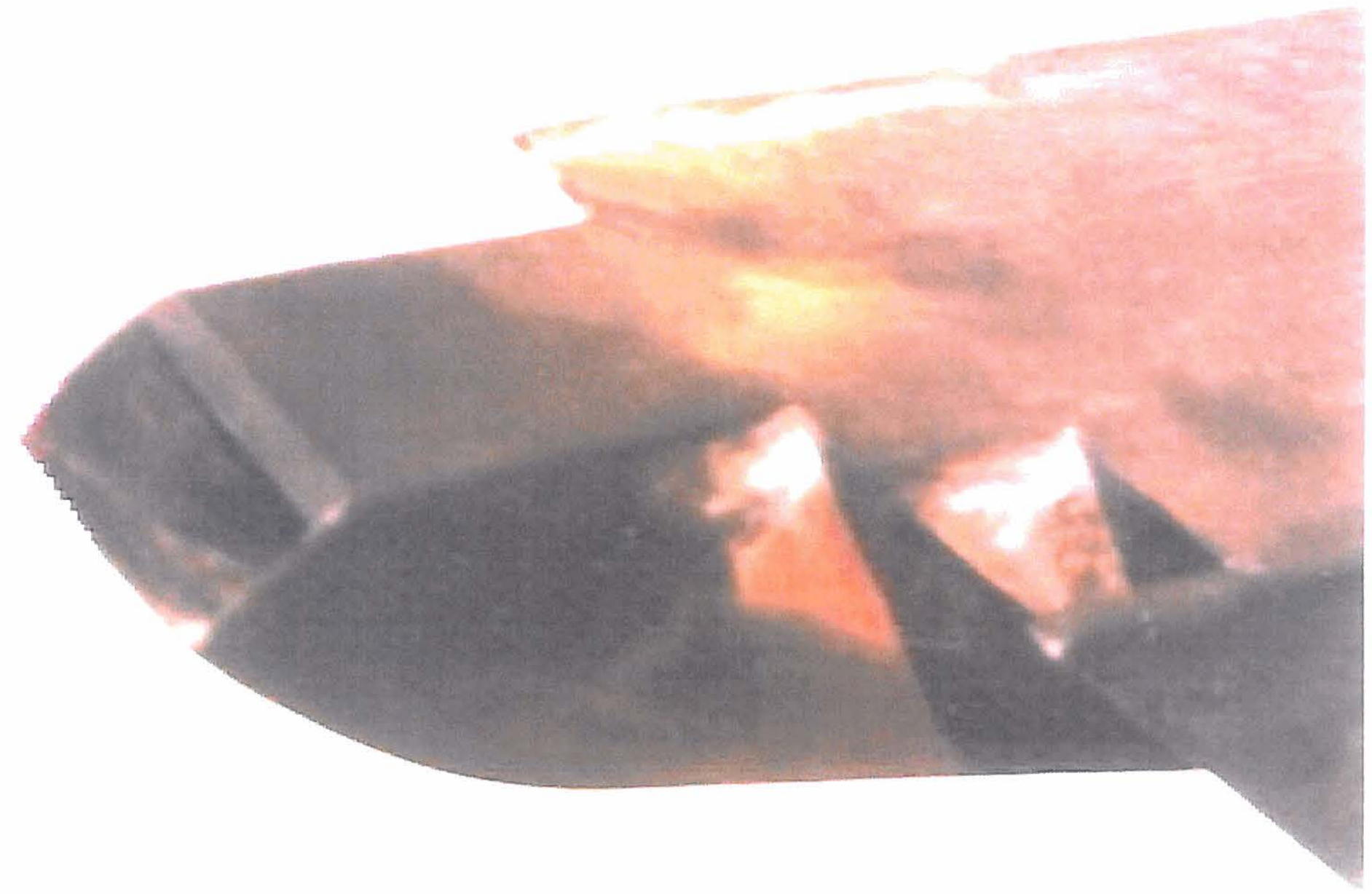

Figure 47 Diffuser Inlet After Operation, View 1 


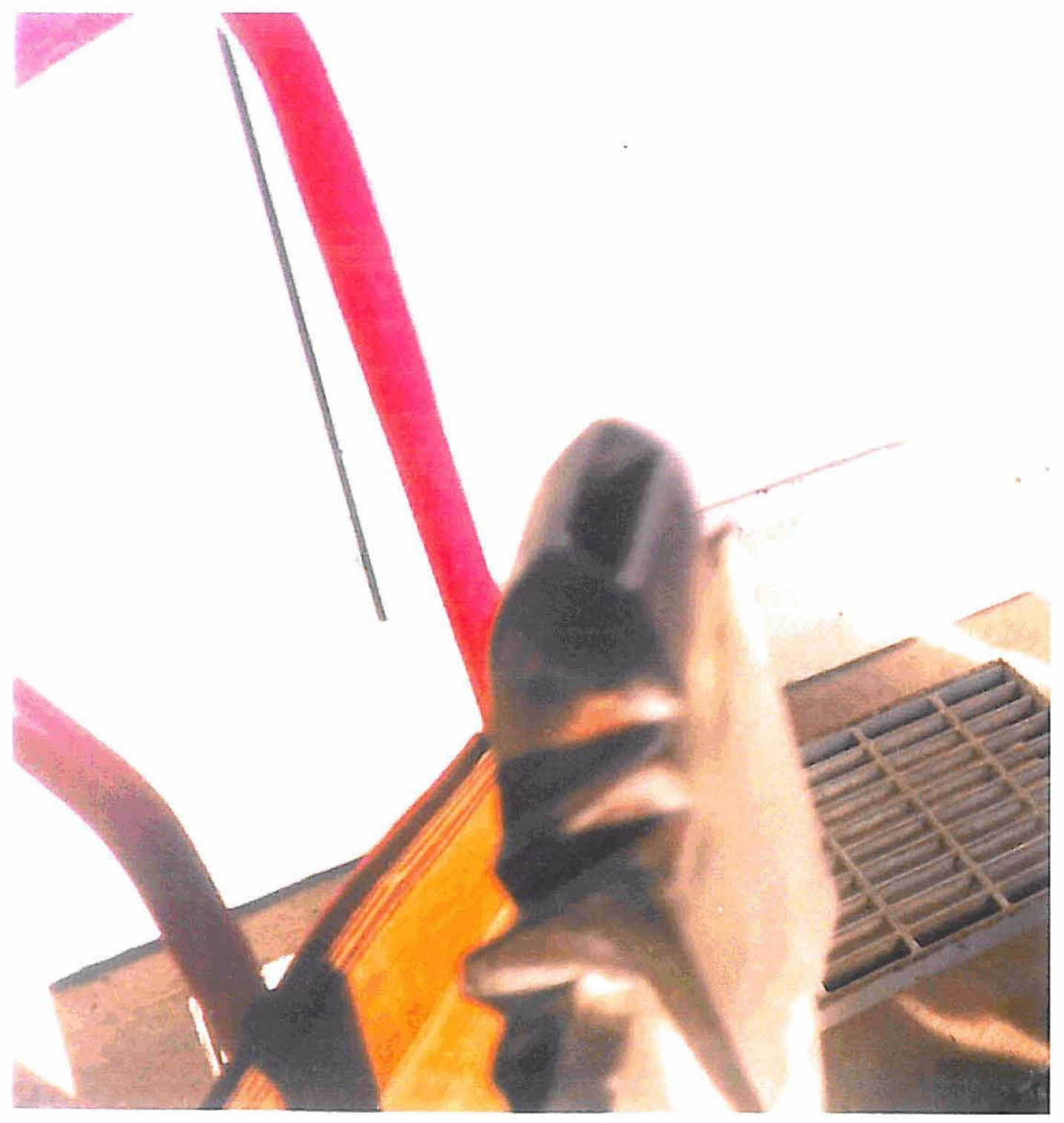

Figure 48 Diffuser Inlet After Operation, View 2 


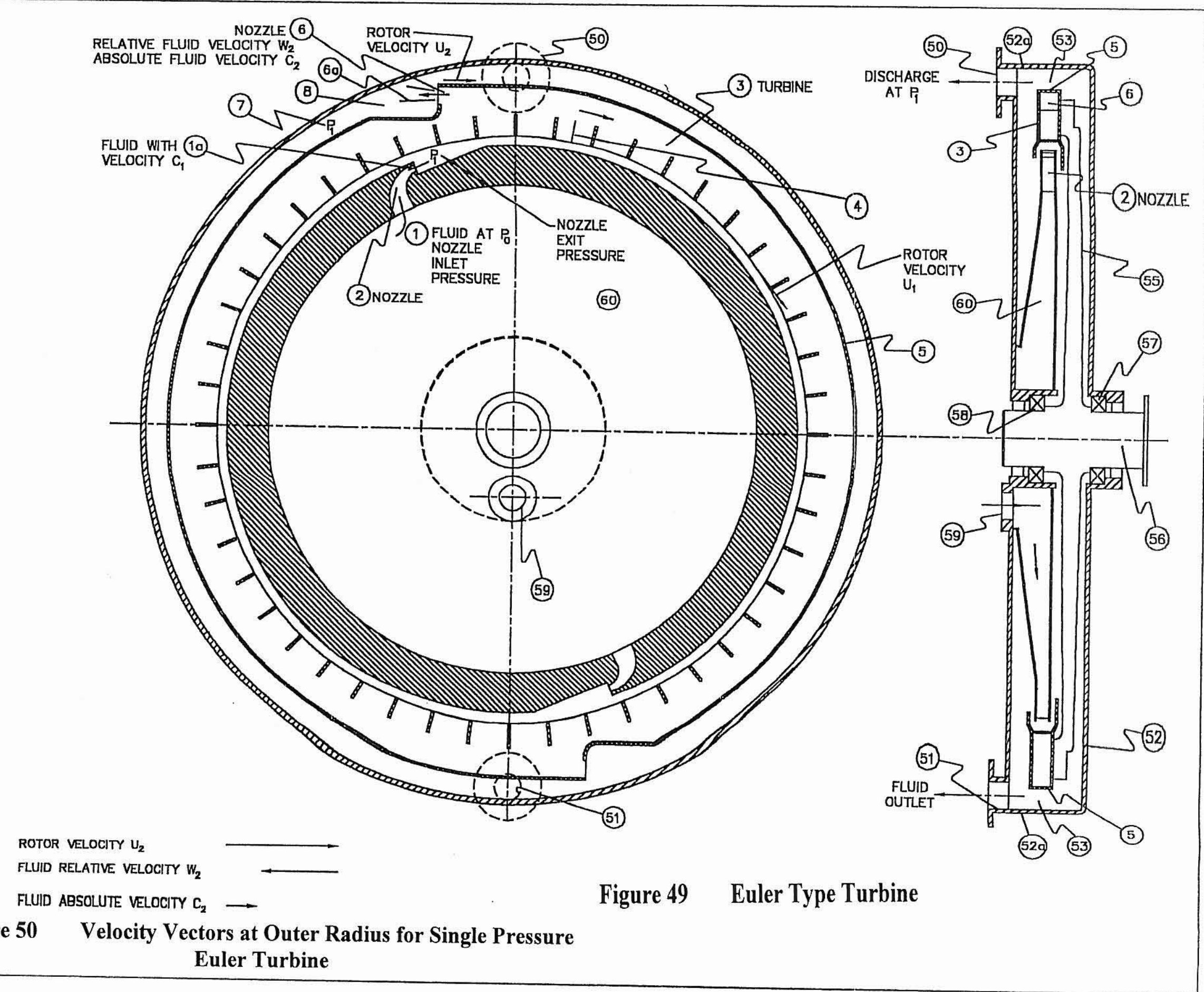




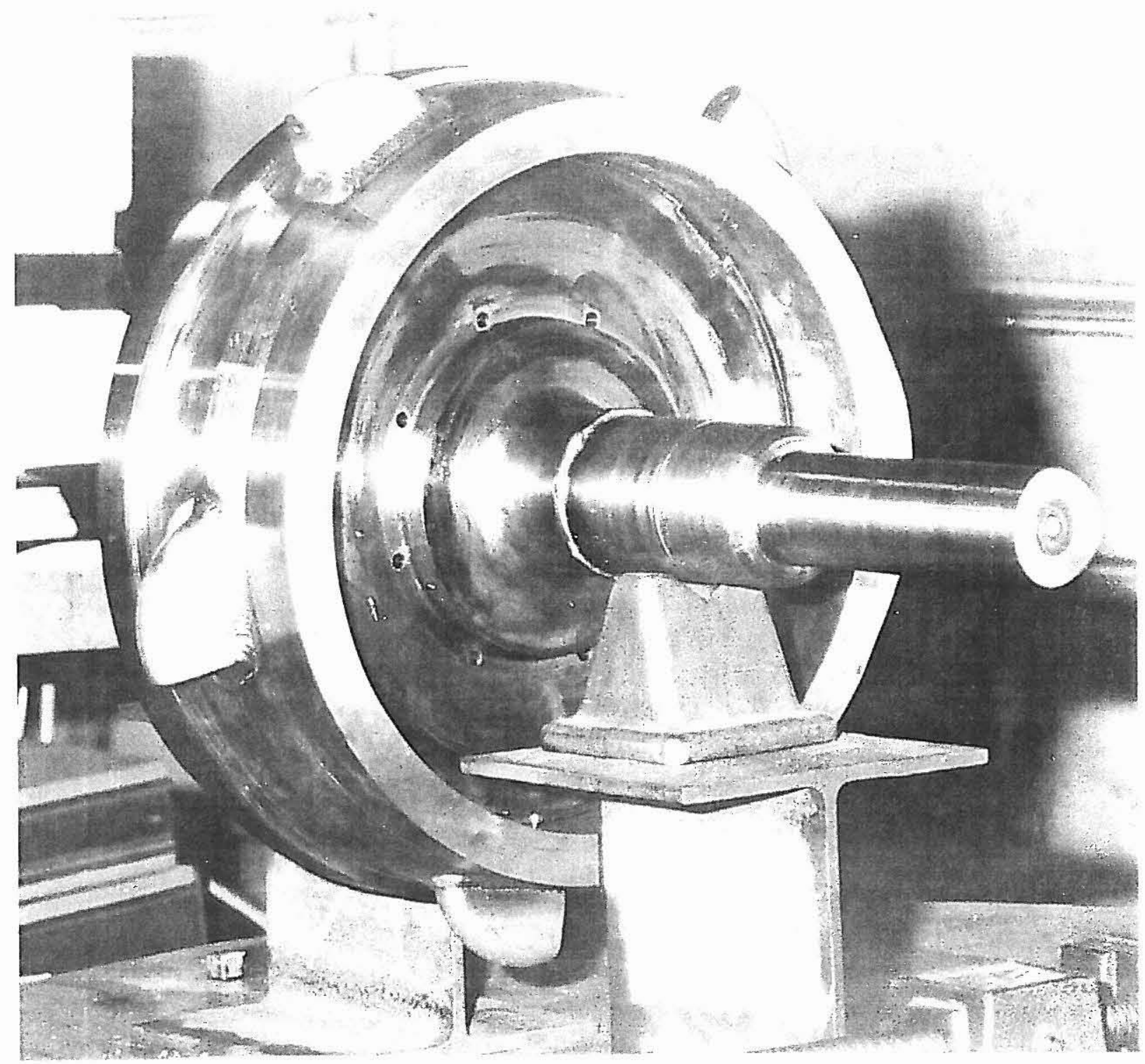

Figure 50a Two-Phase Euler Turbine Rotor Operated with High Pressure Steam and Water 


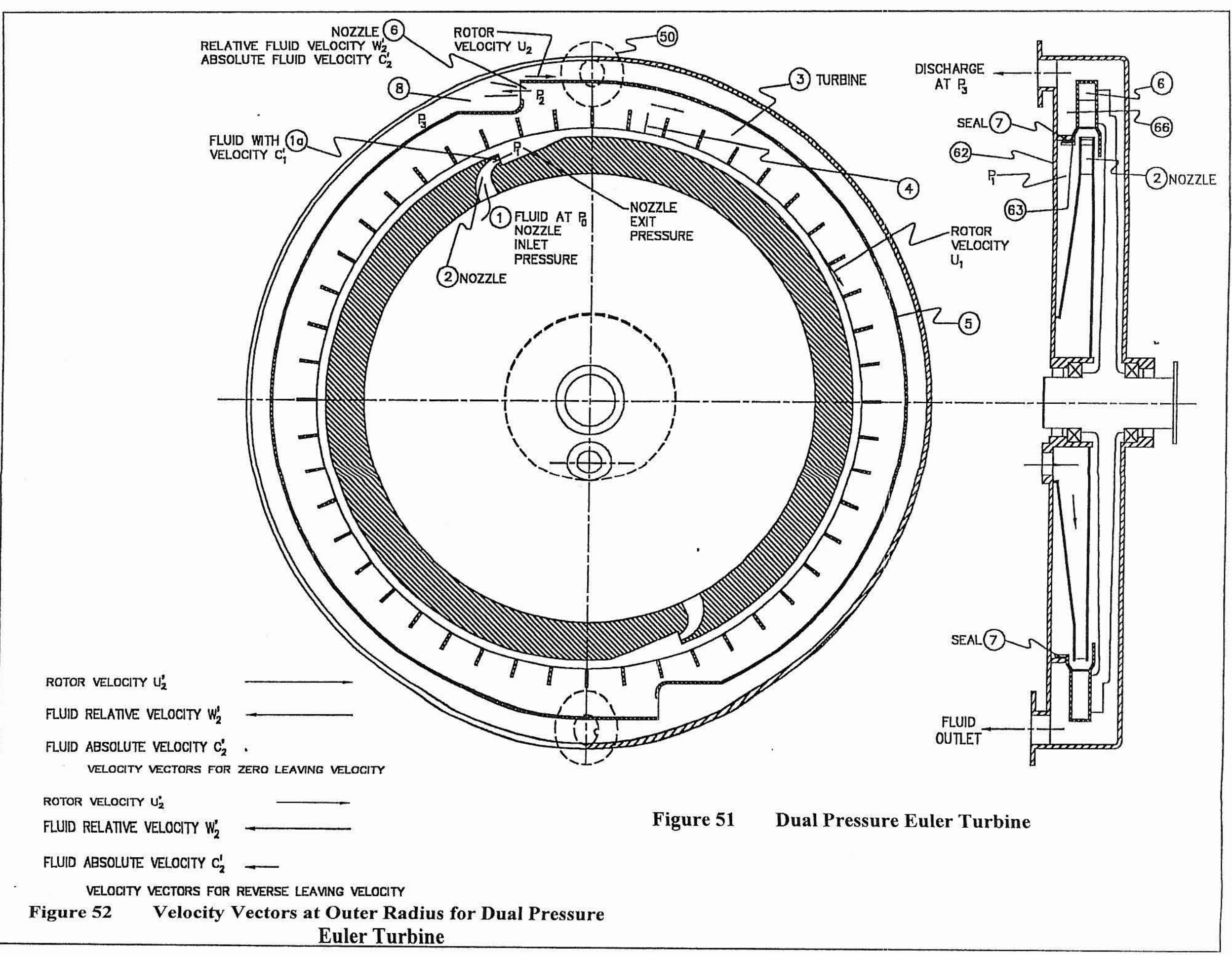


Figure 53 Efficiency of Dual Pressure Euler Steam Turbine Versus Intermediate Expansion Pressure, Overall Expansion from 74.7 psia to 29.7 psia

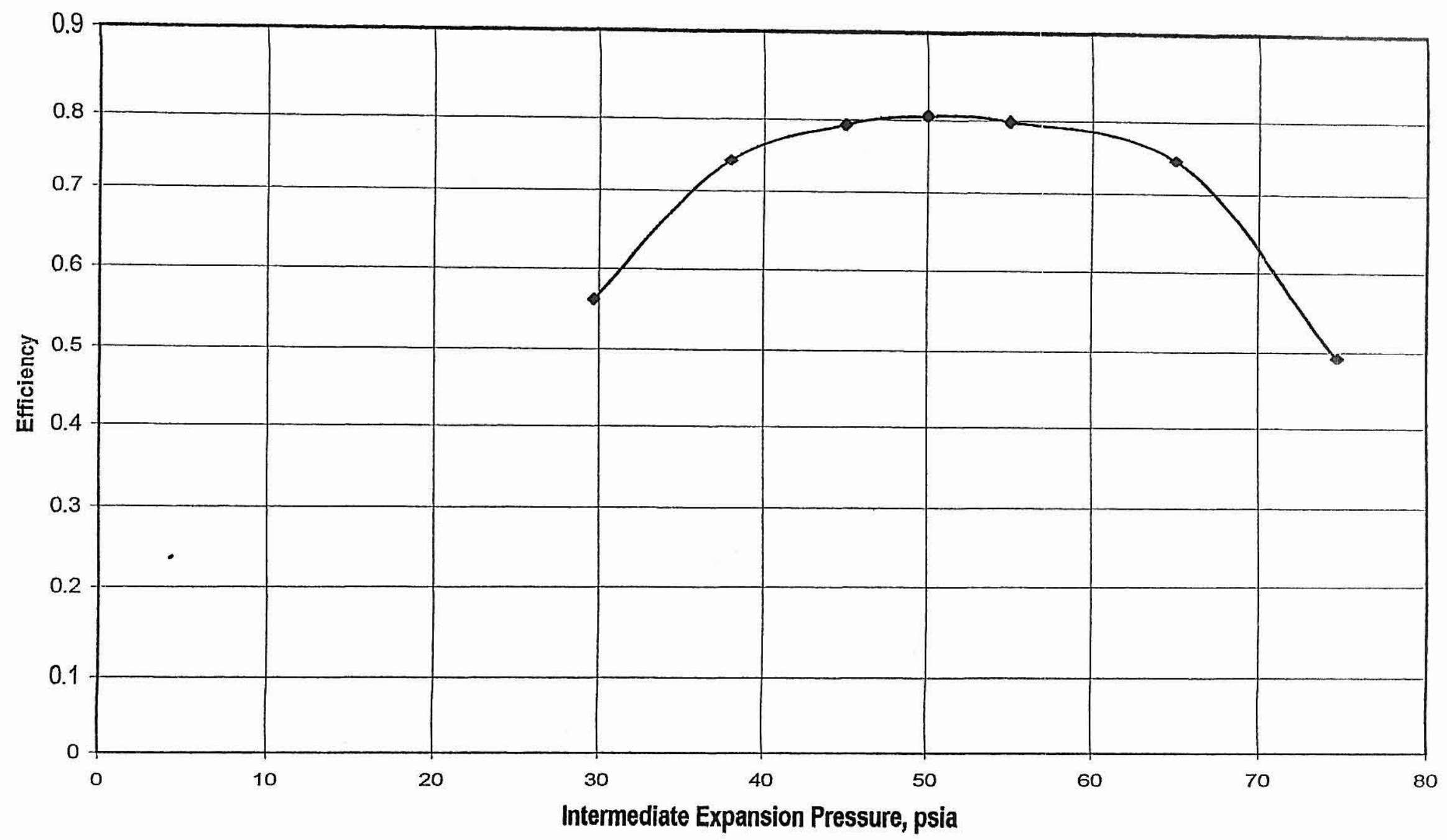




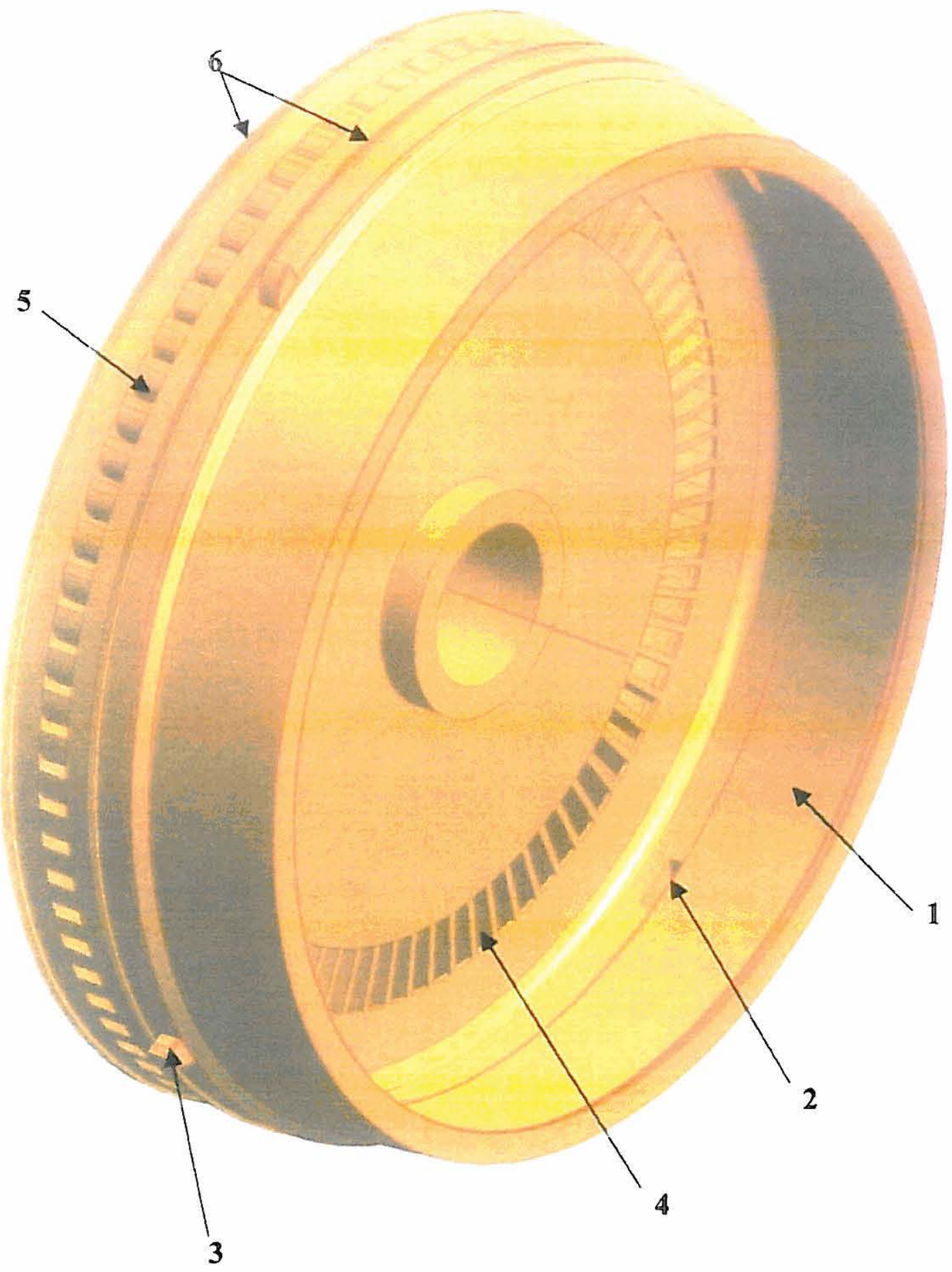

Figure 54 Biphase $\mathbb{D}$ ual Pressure $\mathbb{R}$ otor for Existing Geothermal Turbine at Cerro Prieto 

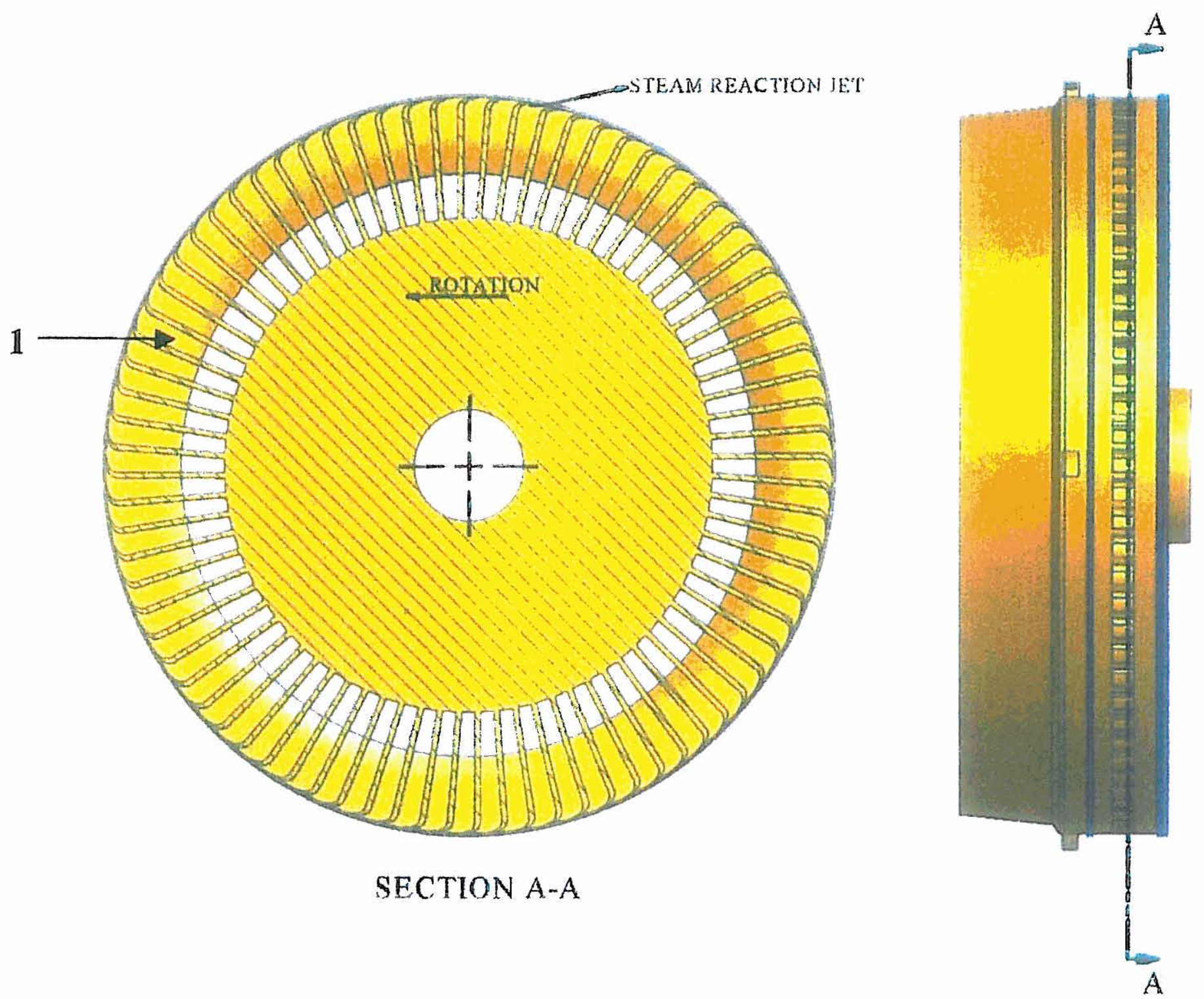

Figure 55 Cross-Section of Biphase Dual Pressure Rotor For Geothermal Turbine at Cerro Prieto 


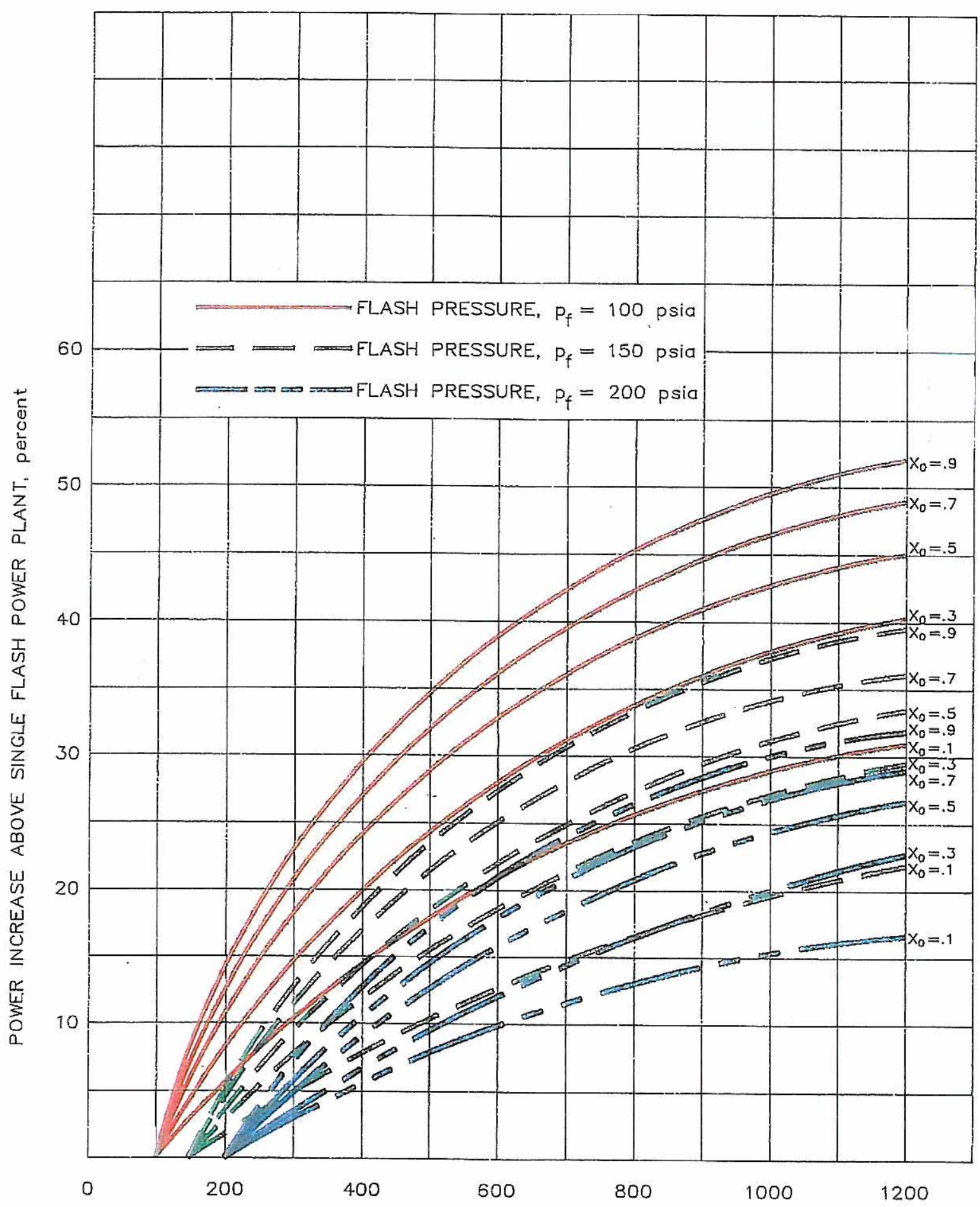

WELLHEAD PRESSURE, psia

Figure 57 Power Increase Percentage for Biphase Turbine Addition to Flash Steam System 


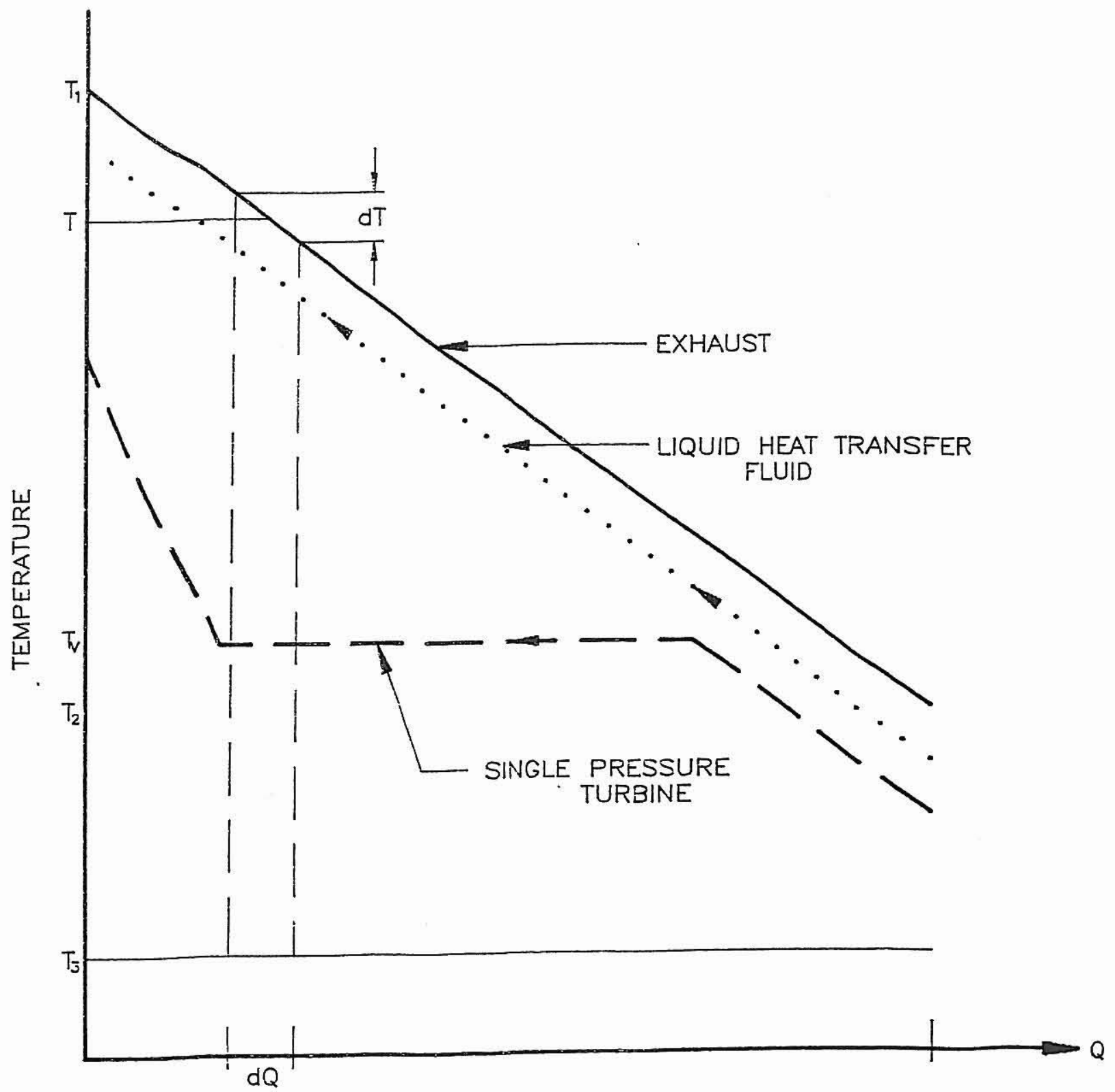

Figure 58 Heat Transfer for Binary Bottoming Cycle and Biphase Bottoming Cycle 
Table 1 Two-Phase Nozzle Code Output for Original Wellhead conditions of Well 103

Fluid: Water in equilibrium with its vapor.

*** INDICATES THROAT CONDITIONS

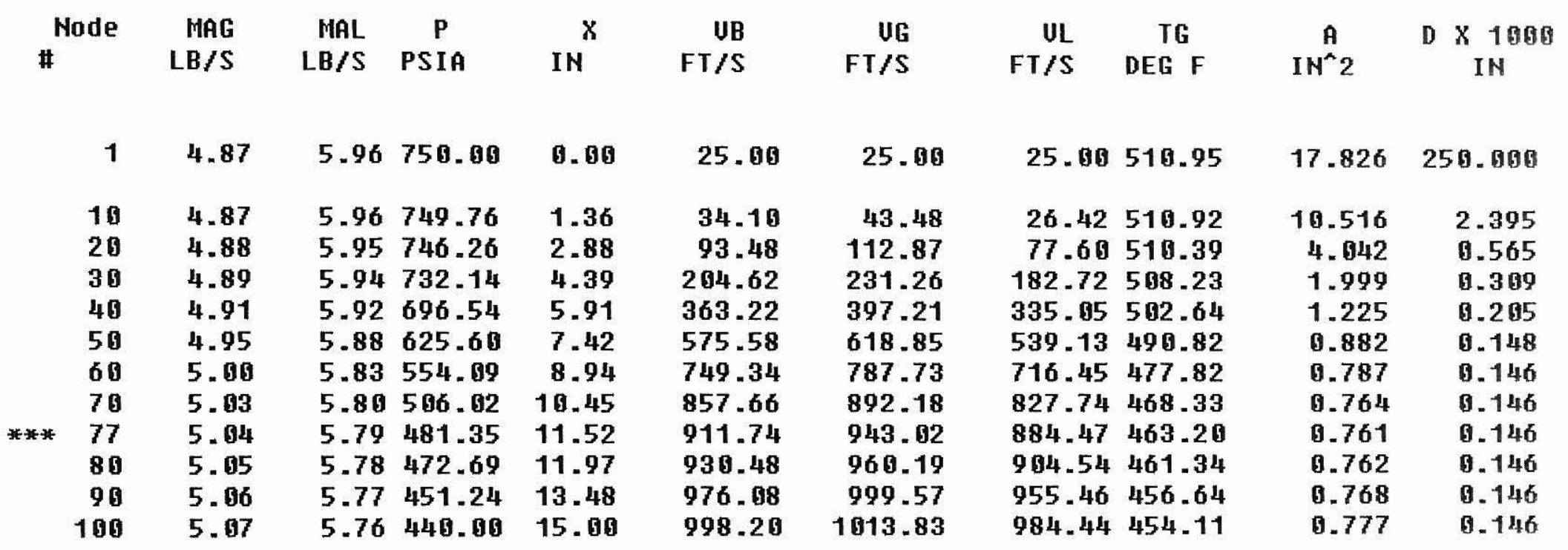


Table 2 Two-Phase Nozzle Code Output for Current Wellhead Conditions at We1l 103

Fluid: Water in equilibrium with its vapor.

** INDICATES THROAT CONDITIONS

\begin{tabular}{|c|c|c|c|c|c|c|c|c|c|c|c|}
\hline $\begin{array}{r}\text { Mode } \\
\text { EFF }\end{array}$ & MAG & MAL & $\mathbf{P}$ & $x$ & UB & UG & UL & TG & A & D $\times 1000$ & \\
\hline ETA & LB/S & $\mathrm{LB} / \mathrm{S}$ & PSIA & IN & $\mathrm{FT} / \mathrm{S}$ & $\mathrm{FT} / \mathrm{S}$ & $\mathrm{FT} / \mathrm{S}$ & DEG $F$ & $\mathrm{IN}^{\wedge} 2$ & IN & TH \\
\hline $.00000^{1}$ & 2.48 & 6.50 & 496.70 & 5.515 & 25.50 & 25.00 & 25.09 & 466.42 & 14.692 & 250.000 & 0 \\
\hline $\begin{array}{r}10 \\
5.05690\end{array}$ & 2.48 & 6.50 & 496.45 & 1.36 & 33.24 & 50.45 & 26.67 & 466.36 & 7.314 & 2.330 & \\
\hline $\begin{array}{r}20 \\
0.35667\end{array}$ & 2.49 & 6.49 & 492.78 & 2.88 & 87.96 & 121.11 & 75.26 & 465.65 & 3.030 & 0.633 & \\
\hline $\begin{array}{r}30 \\
\text { 5. } 09551\end{array}$ & 2.51 & 6.47 & 477.97 & 4.39 & 195.48 & 241.56 & 177.60 & 462.48 & 1.557 & 0.339 & \\
\hline $\begin{array}{r}40 \\
5.05042\end{array}$ & 2.57 & 6.41 & 440.65 & 5.91 & 354.71 & 414.69 & 330.69 & 454.26 & 0.994 & 0.219 & \\
\hline $\begin{array}{r}50 \\
0.00532\end{array}$ & 2.69 & 6.29 & 366.28 & 7.42 & 581.76 & 660.47 & 546.75 & 436.14 & 0.774 & 0.152 & \\
\hline $\begin{array}{l}* * * 56 \\
0.00929\end{array}$ & 2.77 & 6.21 & 317.15 & 8.33 & 714.10 & 792.01 & 679.40 & 422.54 & 0.766 & 0.149 & \\
\hline 0.09628 & 2.81 & 6.17 & 291.31 & 8.94 & 784.09 & 862.64 & 748.56 & 414.72 & 19.768 & 10.749 & \\
\hline $\begin{array}{r}79 \\
-015028\end{array}$ & 2.96 & 6.58 & 249.91 & 10.45 & 924.53 & 1001.91 & 887.57 & 397.78 & 0.816 & 0.149 & (1) \\
\hline $\begin{array}{r}80 \\
-65329\end{array}$ & 2.97 & 6.01 & 205.98 & 11.97 & $1028-11$ & 1100.90 & $992-14=$ & 384.33 & 0.880 & 10.149 & a \\
\hline $\begin{array}{r}90 \\
.00531\end{array}$ & 3.62 & 5.96 & 183.48 & 13.48 & 1698.97 & 1169.99 & 1067.603 & 374.70 & 0.944 & 10.149 & 9 \\
\hline $\begin{array}{r}160 \\
-00034\end{array}$ & 3.94 & 5.94 & 171.70 & 15.09 & 1136.99 & 1180.60 & 1114.663 & 369.28 & 0.996 & 0.149 & 0 \\
\hline
\end{tabular}


Table 3 Two-Phase Nozzle Code Output for Maximum Pressure Tested at Well 163

Fluid: Water in equilibrium with its vapor.

*** INDICATES THROAT CONDITIONS

\begin{tabular}{|c|c|c|c|c|c|c|c|c|c|c|c|}
\hline & lode & MAG & MAL & $\mathbf{P}$ & $x$ & UB & UG & UL & TG & A & D $\times 1001$ \\
\hline & 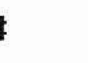 & $\mathrm{LB} / \mathrm{S}$ & $\mathrm{LB} / \mathrm{S}$ & PSIA & IN & $\mathrm{FT} / \mathrm{S}$ & $\mathrm{FT} / \mathrm{S}$ & $\mathrm{FT} / \mathrm{S}$ & DEG F & $\mathrm{IN}^{\wedge} 2$ & IN \\
\hline & 1 & 3.35 & 6.85 & 612.00 & 0.00 & 25.00 & 25.00 & 25.010 & 488.44 & 15.337 & 250.0100 \\
\hline & 10 & 3.35 & 6.85 & 611.72 & 1.36 & 34.12 & 48.72 & 27.00 & 488.39 & 8.2133 & 2.361 \\
\hline & 20 & 3.35 & 6.85 & 607.58 & 2.88 & 93.77 & 121.50 & 80.21 & 487.66 & 3.268 & 0.577 \\
\hline & 30 & 3.37 & 6.83 & 590.85 & 4.39 & 207.85 & 246.20 & 188.91 & 484.65 & 1.648 & 0.312 \\
\hline & 40 & 3.43 & 6.77 & 548.71 & 5.91 & 374.35 & 424.54 & 349.20 & 476.79 & 1.038 & 0.204 \\
\hline & 51 & 3.54 & 6.66 & 464.72 & 7.42 & 606.59 & 672.12 & 571.85 & 459.62 & 0.790 & 0.143 \\
\hline E** & 59 & 3.64 & 6.56 & 386.95 & 8.79 & 793.56 & 856.11 & 758.79 & 441.44 & 0.760 & 0.141 \\
\hline & 60 & 3.65 & 6.55 & 380.07 & 8.94 & 899.89 & 872.31 & 775.05 & 439.70 & 0.761 & 0.141 \\
\hline & 70 & 3.74 & 6.46 & 323.16 & 10.45 & 946.20 & 1006.50 & 911.35 & 424.29 & 0.786 & 0.141 \\
\hline & 80 & 3.80 & 6.49 & 283.71 & 11.97 & 1644 . 132 & 1699.27 & 1011.29 & 412.32 & 0.827 & 0.141 \\
\hline & 90 & 3.83 & 6.37 & 258.36 & 13.48 & 1169.20 & 1155.14 & 1081.53 & 463.91 & 0.870 & 0.141 \\
\hline & 100 & 3.86 & 6.34 & 245.95 & 15.010 & 1143.24 & 1174.81 & 1124.05 & 399.25 & 9.964 & 5.141 \\
\hline
\end{tabular}


Table 4 Turbine Code 0utput for Original Conditions at Well 1 b3

Case Name: orig163 Input File Name:orig103.dat

output File Name:orig103 MOZZLE

\begin{tabular}{|c|c|c|c|c|c|c|c|c|}
\hline $\begin{array}{l}\text { \#ozzles } \\
\quad 8\end{array}$ & $\begin{array}{l}\text { theta1 } \\
\text { deg } \\
20.00\end{array}$ & $\begin{array}{l}\text { Theta2 } \\
\text { deg } \\
21.53\end{array}$ & $\begin{array}{l}\text { Dexit } \\
\text { in } \\
5.994\end{array}$ & $\begin{array}{l}\text { Pexit } \\
\text { psia } \\
\quad 446.00\end{array}$ & $\begin{array}{c}\text { HI } \\
1 b / 5 \\
46.68\end{array}$ & $\begin{array}{c}\mathrm{Mg} \\
1 \mathrm{~b} / 5 \\
46.56\end{array}$ & $\begin{array}{l}\text { Ub } \\
\mathrm{ft} / \mathrm{s} \\
998.00\end{array}$ & $\begin{array}{l}\text { Pjet } \\
\text { kW } \\
1816.42\end{array}$ \\
\hline
\end{tabular}

\begin{tabular}{|c|c|c|c|c|c|c|c|}
\hline LIQUID & ROTOR & & le $=$ Des & gn & & & \\
\hline $\begin{array}{c}\text { Dsep } \\
\text { in } \\
30.51\end{array}$ & $\begin{array}{l}\text { NozCLR } \\
\text { in }\end{array}$ & Lip & $\begin{array}{l}\text { Width } \\
\text { in }\end{array}$ & $\begin{array}{c}\text { N } \\
\text { RPH }\end{array}$ & $\mathrm{U} / \mathrm{C}$ & $\begin{array}{l}\mathrm{Ub} \\
\mathrm{ft} / \mathrm{s}\end{array}$ & $\underset{k W}{\text { Pdrag }}$ \\
\hline
\end{tabular}

DIFFUSER Radius = 16.63 in.

Power Dissipation in $\mathrm{kW}$

Friction Waue Rider Centrifugal Radius Diffuser Exit

Los5 Loss Pressure Change Efficiency Pres

$\begin{array}{llllll}-3.54 & -6.60 & -5.33 & -18.22 & 0.60 & 1292.52\end{array}$

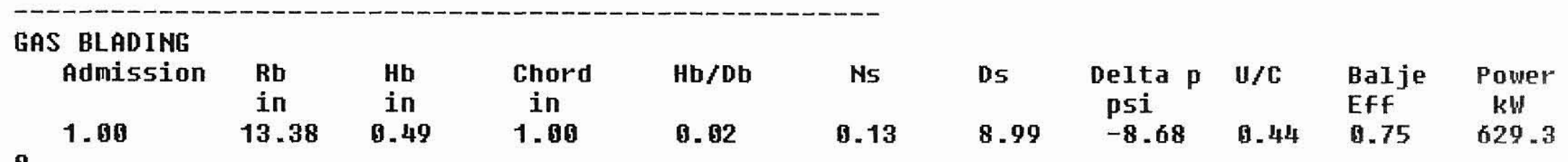

8

\begin{tabular}{llllcc}
\multicolumn{2}{l}{ UELOCITIES } & & & & \\
U1 & W1 & Ctheta1 & U2 & W2 & Ctheta2 \\
$\mathrm{ft} / \mathrm{s}$ & $\mathrm{ft} / \mathrm{s}$ & $\mathrm{ft} / \mathrm{s}$ & $\mathrm{ft} / \mathrm{s}$ & $\mathrm{ft} / \mathrm{s}$ & $\mathrm{ft} / \mathrm{s}$ \\
$\mathbf{4 2 0 . 3 4}$ & 549.69 & 933.26 & 420.34 & 549.69 & 91.30
\end{tabular}

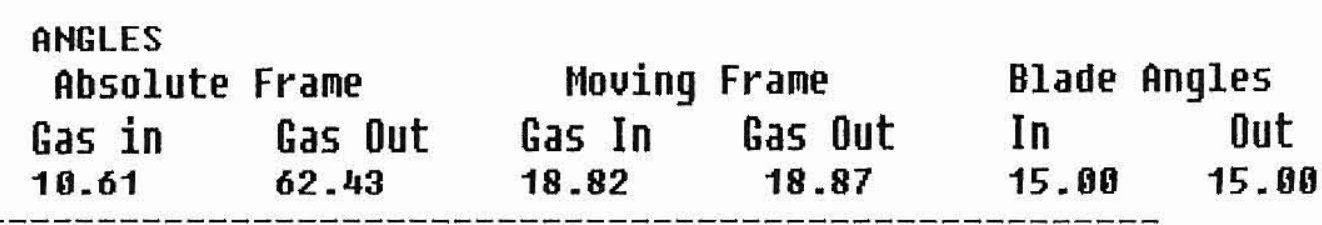

\begin{tabular}{|c|c|c|c|c|c|}
\hline $\begin{array}{l}\text { \#Separator } \\
\text { Loss } \\
-53.76\end{array}$ & $\begin{array}{l}\text { Cylinder } \\
\text { windage } \\
-34.01\end{array}$ & $\begin{array}{c}\text { Disk } \\
\text { Windage } \\
-44.51\end{array}$ & $\begin{array}{l}\text { alip } \\
\text { Windage } \\
-22.62\end{array}$ & $\begin{array}{l}\text { Separator } \\
\text { Power } \\
30.18\end{array}$ & $\begin{array}{c}\text { Uortex } \\
\text { Power } \\
1.79\end{array}$ \\
\hline
\end{tabular}

POWER SUMHARY in $\mathrm{kW}$ 
$r \cdots \angle 3 \cdot \cdots \cdot$

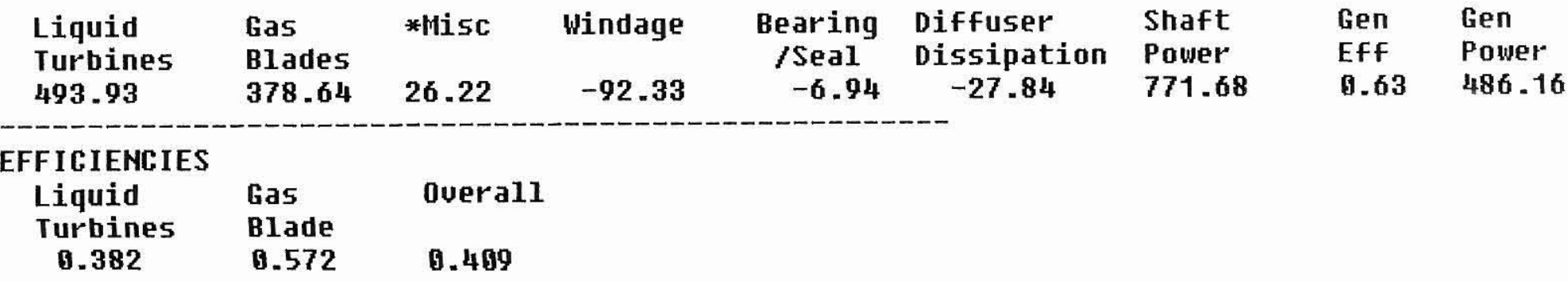

* Power from friction on separator and free vortex.

a Reference only, Lip Windage included in Disc Windage.

\# Reference only, separator loss is included in gas velocity caclulation. 
Table 5 Turbine Code Output for Maximum Pressure Conditions at We11 193

Case Name: scan262 Input File Name:scan262.dat

Output File Mame:scan262 NOZZLE

$\begin{array}{lllllcccc}\# & \text { theta1 } & \text { Theta2 } & \text { Dexit } & \text { Pexit } & M 1 & M g & \text { Ub } & \text { Pjet } \\ \text { Mozzles } & \text { deg } & \text { deg } & \text { in } & \text { psia } & 1 b / 5 & 1 b / 5 & f t / 5 & k W \\ 8 & 20.00 & 21.53 & 0.994 & 244.06 & 50.72 & 30.88 & 1143.00 & 2243.98\end{array}$

\begin{tabular}{|c|c|c|c|c|c|c|c|}
\hline LIQUID & ROTOR & & e $=$ Des & gn & & & \\
\hline $\begin{array}{c}\text { Dsep } \\
\text { in } \\
30.51\end{array}$ & $\begin{array}{l}\text { MozCLR } \\
\text { in } \\
14.19\end{array}$ & $\begin{array}{l}\text { Lip } \\
\text { in } \\
14.69\end{array}$ & $\begin{array}{l}\text { Width } \\
\text { in } \\
14.91\end{array}$ & $\begin{array}{c}\mathrm{N} \\
\mathrm{RPH} \\
3600\end{array}$ & $\mathrm{U} / \mathrm{C}$ & $\begin{array}{l}\mathrm{Ub} \\
\mathrm{ft} / \mathrm{s} \\
479.25\end{array}$ & $\begin{array}{c}\text { Pdrag } \\
\mathrm{kW} \\
532.56\end{array}$ \\
\hline
\end{tabular}

DIFFUSER Radius $=16.03 \mathrm{in}$.

Power Dissipation in $\mathrm{kW}$

$\begin{array}{lccccc}\text { Friction } & \text { Wave Rider } & \text { Centrifugal } & \text { Radius } & \text { Diffuser } & \text { Exit } \\ \text { Los5 } & \text { Loss } & \text { Pressure } & \text { Change } & \text { Efficiency } & \text { Pres } \\ -3.54 & -6.00 & -6.46 & -19.50 & 0.60 & 1094.59\end{array}$

\begin{tabular}{|c|c|c|c|c|c|}
\hline \multicolumn{6}{|l|}{ GAS BLADING } \\
\hline Admission & $\begin{array}{l}\text { Rb } \\
\text { in }\end{array}$ & $\begin{array}{l}\text { Hb } \\
\text { in }\end{array}$ & $\begin{array}{l}\text { Chord } \\
\text { in }\end{array}$ & $\mathrm{Hb} / \mathrm{Db}$ & Ns \\
\hline 1.00 & 13.38 & 0.49 & 1.00 & 10. 192 & 0.12 \\
\hline \multicolumn{6}{|c|}{ UELOCITIES } \\
\hline $\begin{array}{l}U 1 \\
\mathrm{ft} / \mathrm{s} \\
420.34\end{array}$ & $\begin{array}{l}\text { W1 } \\
\mathrm{ft} / \mathrm{s} \\
67.29\end{array}$ & $\begin{array}{l}\text { Ctheta1 } \\
\text { ft/s } \\
1050.74\end{array}$ & $\begin{array}{l}112 \\
\mathrm{ft} / \mathrm{s} \\
420.34\end{array}$ & $\begin{array}{c}\text { W2 } \\
\mathrm{ft} / \mathrm{s} \\
667.29\end{array}$ & $\begin{array}{l}\text { Ctheta2 } \\
\text { ft/5 } \\
297.67\end{array}$ \\
\hline
\end{tabular}

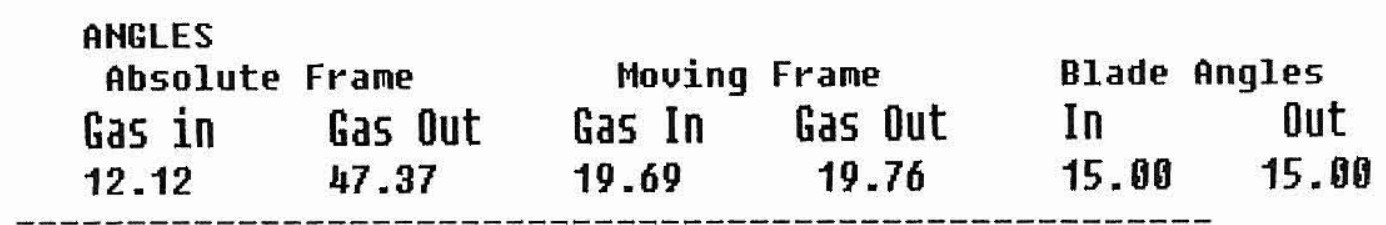
FRICTION ANALYSIS (all results are in $\mathrm{kW}$ )

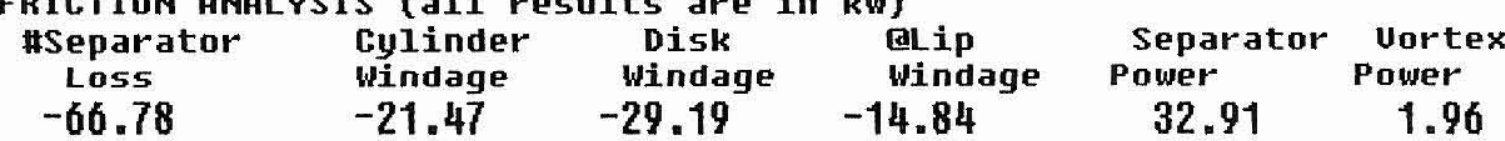

POWER SUMMARY in $\mathrm{kW}$ 


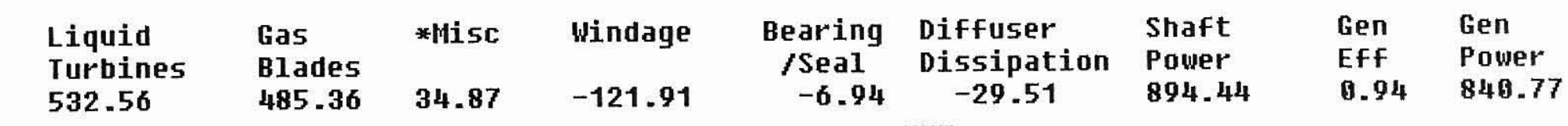

EFFICIENCIES

$\begin{array}{lll}\text { Liquid } & \text { Gas } & \text { Duerall } \\ \text { Turbines } & \text { Blade } & \\ 0.382 & 0.572 & 0.412\end{array}$

* Power from friction on separator and free vortex.

ra Reference only, Lip Windage included in Disc Windage.

\# Reference only, separator 1055 is included in gas velocity caclulation. 
Table 6 Turbine Code Output for Current Conditions at We11 103

Case Name: run323 Input File Name:run323.dat

output File Name:run323 NOZZLE

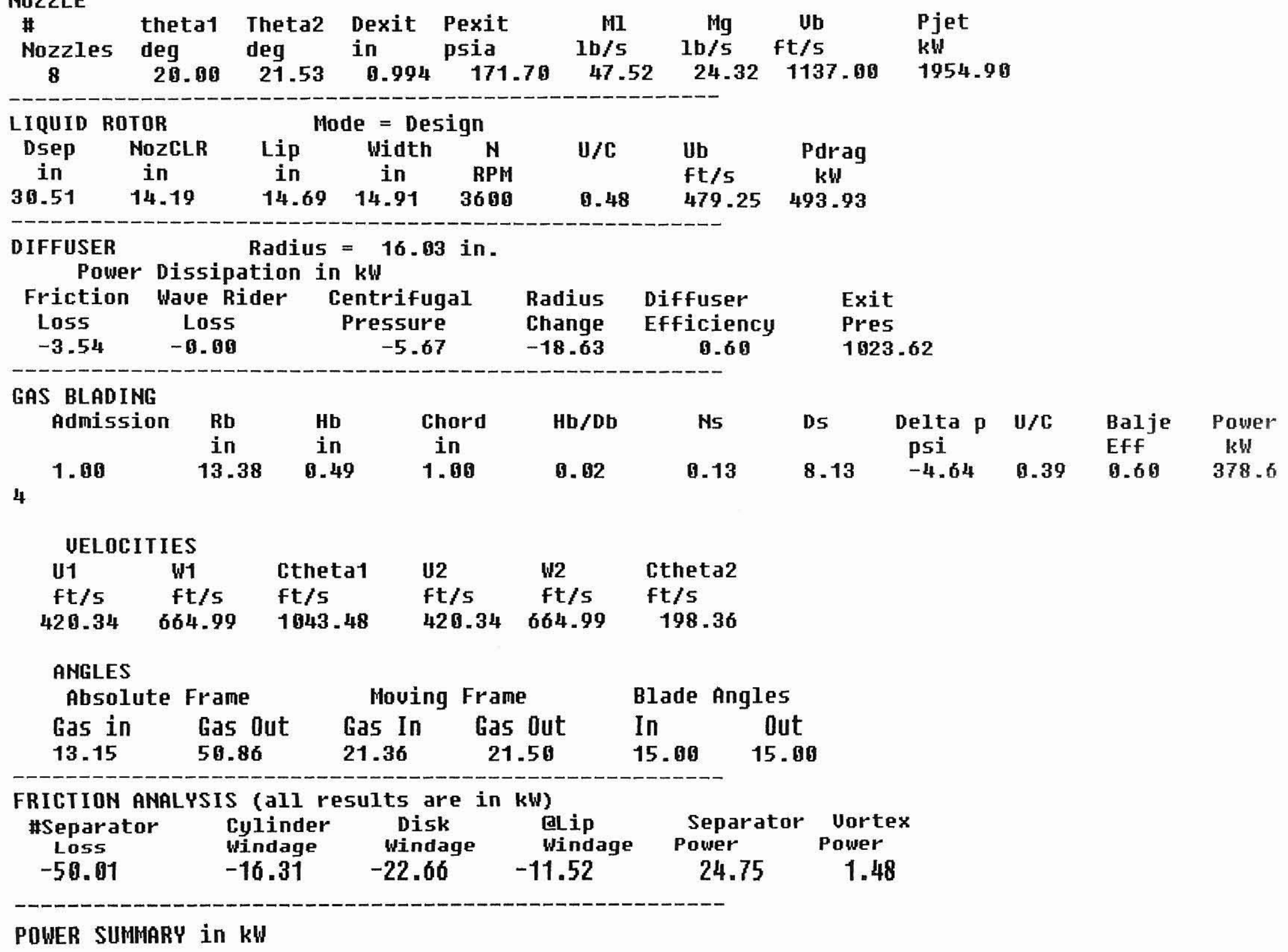




\begin{tabular}{|c|c|c|c|c|c|c|c|c|}
\hline $\begin{array}{l}\text { Liquid } \\
\text { Turbines } \\
365.88\end{array}$ & $\begin{array}{l}\text { Gas } \\
\text { B1ades } \\
629.38\end{array}$ & $\begin{array}{l}* \text { Misc } \\
31.97\end{array}$ & $\begin{array}{l}\text { Windage } \\
-135.89\end{array}$ & $\begin{array}{c}\text { Bearing } \\
\text { /Seal } \\
-6.94\end{array}$ & $\begin{array}{l}\text { Diffuser } \\
\text { Dissipation } \\
\text {-27.69 }\end{array}$ & $\begin{array}{l}\text { Shaft } \\
\text { Power } \\
857.31\end{array}$ & $\begin{array}{l}\text { Gen } \\
\text { Eff } \\
B .94\end{array}$ & $\begin{array}{l}\text { Gen } \\
\text { Power } \\
865.87\end{array}$ \\
\hline $\begin{array}{c}\text { EFFICIENCIES } \\
\text { Liquid } \\
\text { Turbines } \\
0.379\end{array}$ & $\begin{array}{l}\text { Gas } \\
\text { Blade } \\
9.745\end{array}$ & $\begin{array}{l}\text { Ouer: } \\
0.48\end{array}$ & & & & & & \\
\hline
\end{tabular}




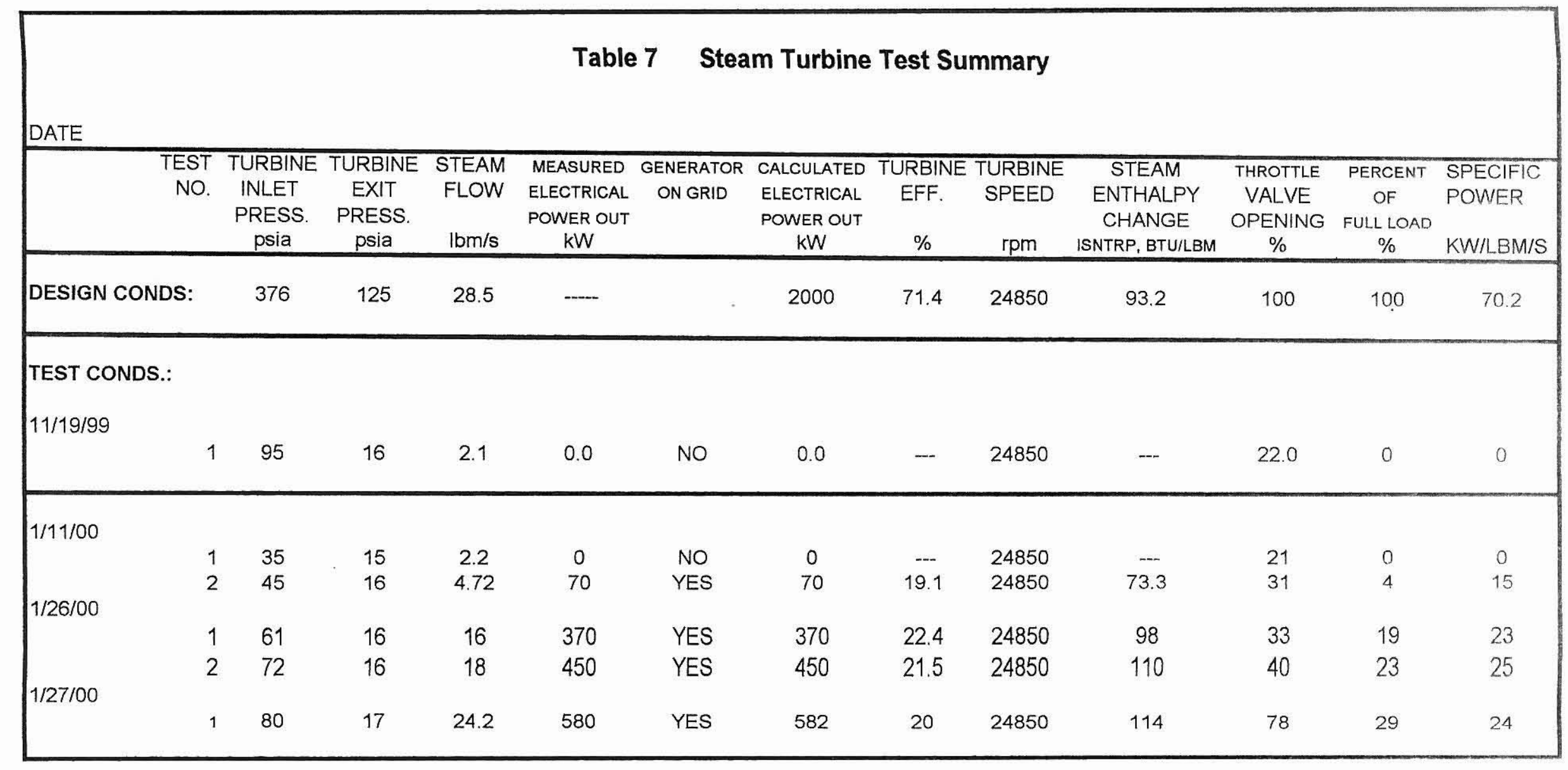




\section{Table 8 Summary of Power Generation by}

Biphase Turbine at Cerro Prieto

\begin{tabular}{cccc}
$\begin{array}{c}\text { TEST } \\
\text { NO. }\end{array}$ & $\begin{array}{c}\text { TIME } \\
\text { hrs. }\end{array}$ & $\begin{array}{c}\text { POWER } \\
\text { kWe }\end{array}$ & $\begin{array}{c}\text { ENERGY } \\
\text { kWhr }\end{array}$ \\
14 & 0.5 & 160 & 85 \\
15 & 1.0 & 100 & 100 \\
16 & 1.0 & 45 & 45 \\
17 & 0.0 & 0 & 0 \\
18 & 0.0 & 0 & 0 \\
19 & 0.0 & 0 & 0 \\
20 & 1.5 & 650 & 975 \\
21 & 0.9 & 510 & 459 \\
22 & 0.0 & 0 & 0 \\
23 & 0.0 & 0 & 0 \\
24 & 0.9 & 180 & 153 \\
25 & 0.6 & 75 & 45 \\
26 & 2.5 & 380 & 950 \\
27 & 0.4 & 110 & 44 \\
28 & 1.5 & 20 & 30 \\
29 & 0.6 & 500 & 300 \\
30 & 4.7 & 560 & 2604 \\
31 & 1.0 & 150 & 153 \\
32 & 40.2 & 310 & 12462 \\
33 & 0.6 & 295 & 168 \\
34 & 153.0 & 283 & 43299 \\
35 & 61.0 & 257 & 15677 \\
& & & \\
\cline { 3 - 4 } & & TOTAL $=$ & 77550 \\
\hline
\end{tabular}


Table 9 Turbine Code Output for Existing Wellhead Conditions at Well 103 with Liquid Reaction Jets and No Steam Output

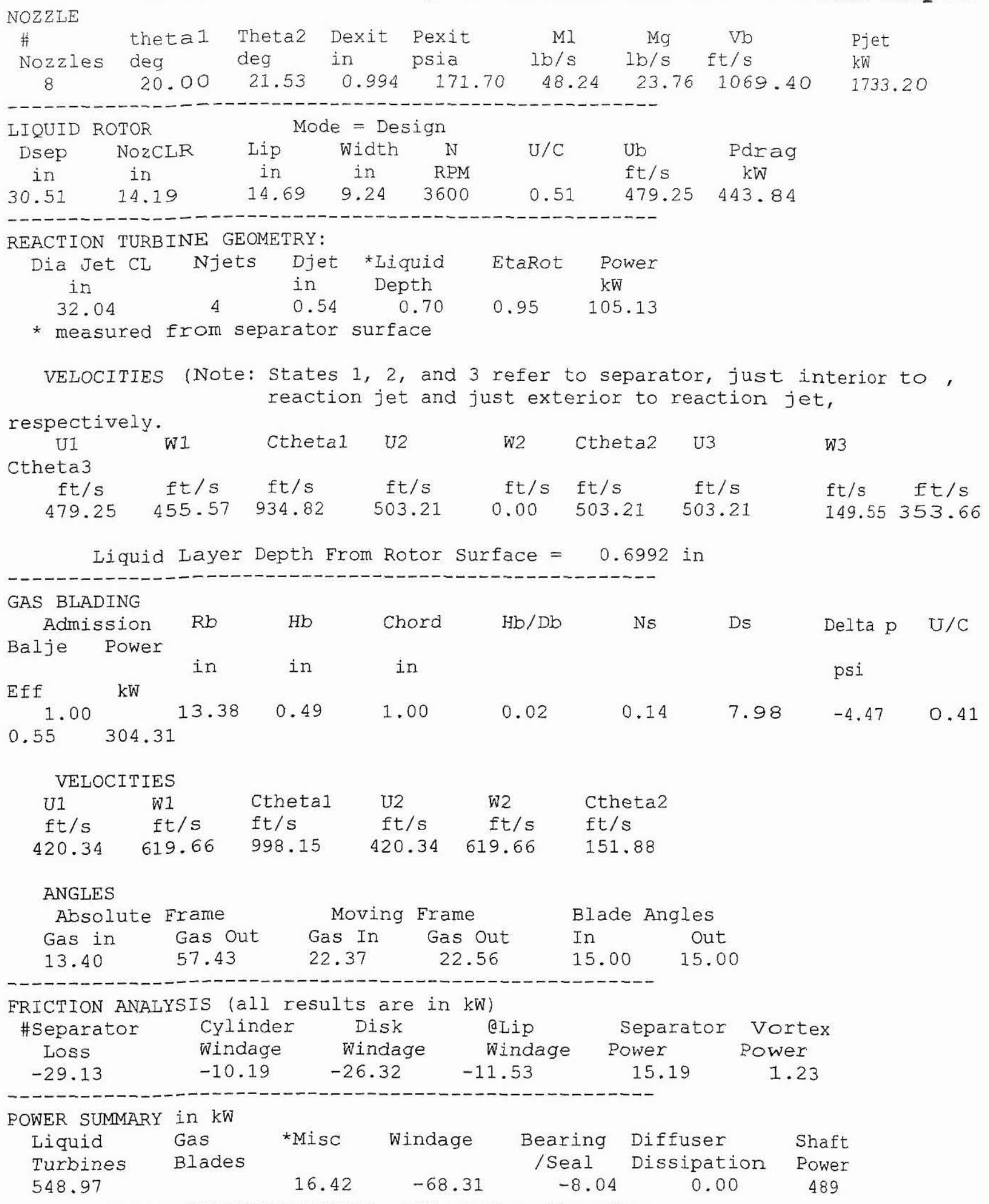


* Power from Eriction on separator and free vortex.

e Reference on $1 y$, Lip Windage included in Disc Windage.

\# Reference only, separator loss is included in gas velocity caclulation. 


\section{Table 10 Dual Pressure Euler Turbine Code Output for Existing Conditions at Well 103}

\author{
Nozzle Angle \\ Reaction jet Angle \\ Rotor Speed \\ Reaction jet Daimeter \\ Number of Reaction Jets \\ Inner rotor radius \\ $\mathrm{RJ}$ centerline radius \\ Nozzle Inlet Pressure \\ Nozzle Inlet Quality \\ Inlet Droplet Diameter \\ Inlet Velocity \\ Nozzle Length \\ Number of Nozzles \\ Nozzle Exit Pressure \\ Rection jet exit pressure \\ Nozzle exit velocity
}

Reaction jet velocity coeficient(liq)

Reaction jet velocity coeficient(vap)

Mass flow rate

Nozzle Inlet Ethalpy

Nozzle inlet Temperature

Nozzle Inlet Entropy

Nozzle Exit Temperature $(s=c)$

Nozzle Exit Enthalpy $(s=c)$

Nozzle entahlpy change $(s=c)$

Separator Velocity

Actual Noz. Enthalpy change

Nozzle Exit Enthalpy

Nozzle Exit Temperature

Nozzle exit quality

Nozzle Efficiency

Rotor Velocity

Rotor angular velocity

Reaction jet ent. Pressure

Reaction jet ent enthalpy

Reaction jet ent Temp

Reaction jet ent entropy

Reaction jet entrance quality

Reaction jet exit enthalpy $(s=c)$

Reaction jet enthalpy change $(s=c)$

\begin{tabular}{|l|r|l|}
\hline \multicolumn{2}{|c|}{ Design } \\
\hline & 20 & \\
\hline$N$ & 10 & \\
\hline Drj & 3600 & rpm \\
\hline Nrj & 1 & in \\
\hline r1 & 4 & \\
\hline r2 & 14.5 & in \\
\hline po & 16 & in \\
\hline & 497 & psia \\
\hline
\end{tabular}

\begin{tabular}{|c|c|c|}
\hline & 0.1 & in \\
\hline & 50 & $\mathrm{ft} / \mathrm{sec}$ \\
\hline & 15 & in \\
\hline & 8 & \\
\hline $\mathrm{p} 1$ & 171.7 & psia \\
\hline p3 & 125 & psia \\
\hline $\mathrm{C} 1$ & 1018.42 & $\mathrm{ft} / \mathrm{sec}$ \\
\hline PhiRot & 0.95 & \\
\hline etav2 & 0.975 & \\
\hline$m$ & 72 & $\mathrm{lb} / \mathrm{sec}$ \\
\hline ho & 648.36472 & $\mathrm{~b} / \mathrm{lbm}$ \\
\hline To & 466.38941 & $\mathrm{~F}$ \\
\hline So & 0.8637359 & $\mathrm{~b} / \mathrm{lbm}-\mathrm{R}$ \\
\hline $\mathrm{T1}$ & 369.22887 & $\mathrm{~F}$ \\
\hline$(\mathrm{h} 1) \mathrm{s}=\mathrm{c}$ & 620.47148 & $\mathrm{~b} / \mathrm{lbm}$ \\
\hline (dhs)o-1 & 27.893237 & $\mathrm{~b} / \mathrm{lbm}$ \\
\hline Ub1 & 455.53093 & \\
\hline$(\mathrm{dh}) 0-1$ & 23.443069 & $\mathrm{~b} / \mathrm{lbm}$ \\
\hline h1' & 624.92165 & $\mathrm{~b} / \mathrm{lbm}$ \\
\hline$T 1^{\prime}$ & 369.22887 & $\mathrm{~F}$ \\
\hline$x 1$ & 0.3311562 & \\
\hline (Eta)noz & 0.8404571 & \\
\hline Ub1 & 455.53093 & $\mathrm{ft} / \mathrm{sec}$ \\
\hline Omega & 376.99112 & $\mathrm{rad} / \mathrm{s}$ \\
\hline p2 & & psia \\
\hline h2 & & $\mathrm{b} / \mathrm{lbm}$ \\
\hline T2 & 371.2555 & $F$ \\
\hline$s 2$ & 1.5582555 & $\mathrm{~b} / \mathrm{lbm}-\mathrm{R}$ \\
\hline$x 2$ & 1 & 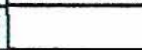 \\
\hline (h3)s & 1169.9569 & $F$ \\
\hline$(\mathrm{dhs}) 2-3$ & 27.103008 & $\mathrm{~b} / \mathrm{lbm}$ \\
\hline
\end{tabular}


RJ Exit vel (Moving frame)

Rotor Vel

RJ Exit vel (Abs frame)

Reaction jet enthalpy change

Reaction jet exit enthalpy

Reacion jet exit quality

Reaction jet exit temperature

RJ Exit Viscosity

RJ exit Density

Nozzle Exit Liquid FlowRate

Rel. Liquid RJ exit velocity

Abs Liquid RJ Exit Velocity

Liquid Turbine Power

Nozzle Exit Vapor FlowRate

Vapor Turbine Power

Gross Power Produced

RJ exit enthalpy $(s=c)$

Device isentropic Enthalpy change

Isentropic Power

Overall Efficiency sans windage

Reynolds number for rotor

Windage Power

Net Power Production

Overall Efficiency with windage

Area Required to handle design flowrate

Reaction jet diameter

\begin{tabular}{|l|c|l|}
\hline$(\mathrm{W} 3) \mathrm{V}$ & 1067.1331 & $\mathrm{ft} / \mathrm{sec}$ \\
\hline$(\mathrm{U} 3) \mathrm{v}$ & 502.65482 & $\mathrm{ft} / \mathrm{sec}$ \\
\hline$(\mathrm{C} 3) \mathrm{v}$ & -564.47823 & $\mathrm{ft} / \mathrm{sec}$ \\
\hline$(\mathrm{dh}) 2-3$ & 29.879029 & $\mathrm{~b} / \mathrm{lbm}$ \\
\hline $\mathrm{h} 3$ & 1167.1809 & $\mathrm{~b} / \mathrm{lbm}$ \\
\hline $\mathrm{x} 3$ & 0.9727025 & \\
\hline T3 & 344.34629 & $\mathrm{~F}$ \\
\hline MU3 & 0.0001044 & $\mathrm{lbm} / \mathrm{ft}-\mathrm{s}$ \\
\hline (Rhog)3 & 0.2788849 & $\mathrm{lbm} / \mathrm{ft} \wedge$ \\
\hline
\end{tabular}

\begin{tabular}{|l|r|l|}
\hline$(\mathrm{ml}) 1$ & 48.156754 & $\mathrm{lbm} / \mathrm{s}$ \\
\hline \multirow{2}{*}{$(\mathrm{W} 3) !$} & 207.11294 & $\mathrm{ft} / \mathrm{sec}$ \\
\hline & 295.54189 & $\mathrm{ft} / \mathrm{sec}$ \\
\hline $\mathrm{Pl}$ & 479.99617 & $\mathrm{~kW}$ \\
\hline$(\mathrm{mv}) 2$ & 23.843246 & $\mathrm{lbm} / \mathrm{s}$ \\
\hline $\mathrm{Pv}$ & 751.23363 & $\mathrm{~kW}$ \\
\hline $\mathrm{P}$ & 1231.2298 & $\mathrm{~kW}$ \\
\hline$(\mathrm{h} 3) \mathrm{s}=\mathrm{c}$ & 611.55843 & $\mathrm{~b} / \mathrm{lbm}$ \\
\hline$(\mathrm{dh}) 1-3$ & 36.806287 & $\mathrm{~b} / \mathrm{lbm}$ \\
\hline $\mathrm{Ps}$ & 2535.9355 & $\mathrm{~kW}$ \\
\hline Eff & 0.4855131 & \\
\hline $\mathrm{RE}$ & 1790840.9 & \\
\hline $\mathrm{Cm}$ & 0.0081986 & \\
\hline $\mathrm{Pw}$ & 10.88503 & $\mathrm{~kW}$ \\
\hline $\mathrm{Pnet}$ & 1220.3448 & $\mathrm{~kW}$ \\
\hline Eta & 0.4812207 & \\
\hline Ae & 0.2273394 & $\mathrm{ft} 2$ \\
\hline De & 0.2690063 & $\mathrm{ft}$ \\
\hline
\end{tabular}


Table 11 Phase 2 Geothermal Wells

\begin{tabular}{|c|c|c|c|c|c|}
\hline $\begin{array}{c}\text { Combined } \\
\text { Plant }\end{array}$ & Well No. & $\begin{array}{c}\text { Wellhead } \\
\text { Pressure } \\
\text { psia }\end{array}$ & $\begin{array}{c}\text { Delivered } \\
\text { Steam Pressure } \\
\text { psia }\end{array}$ & $\begin{array}{c}\text { Wellhead } \\
\text { Flow Rate } \\
\text { lb/s }\end{array}$ & $\begin{array}{c}\text { Individual } \\
\text { Biphase Plant Power } \\
\mathrm{kW}\end{array}$ \\
\hline
\end{tabular}

\section{GROUP 1. STEAM DELIVERED AT 119-126 PSIA TO CP-I}

\begin{tabular}{|cccccc|}
\hline RSB-1 & $\begin{array}{c}103 \\
\text { (Phase 1) }\end{array}$ & 699 & 121 & 77.7 & Test Well \\
\hline RSB-2 & E15 & 510 & 126 & 57.7 & 3079 \\
& M47 & 435 & 115 & 64.2 & 1570 \\
\hline RSB-3 & E2 & 615 & 121 & 62.6 & 2642 \\
& E59 & 465 & 119 & 41.9 & 1549 \\
\hline
\end{tabular}

GROUP 2. STEAM DELIVERED AT 198-215 PSIA TO CP-II OR CP-III

\begin{tabular}{|lccccc|}
\hline RSB-4 & E46 & 595 & 204 & 61.5 & 2989 \\
& M198 & 673 & 215 & 48.0 & 1795 \\
\hline RSB-5 & E27 & 665 & 197 & 50.8 & 2307 \\
& E56 & 995 & 198 & 61.1 & 3241 \\
\hline RSB-6 & E48 & 865 & 211 & 99.0 & 2120 \\
& E49 & 965 & 213 & 104.7 & 2355 \\
\hline
\end{tabular}

Table 12 Biphase Power Plants, Phase 2 Conceptual Design

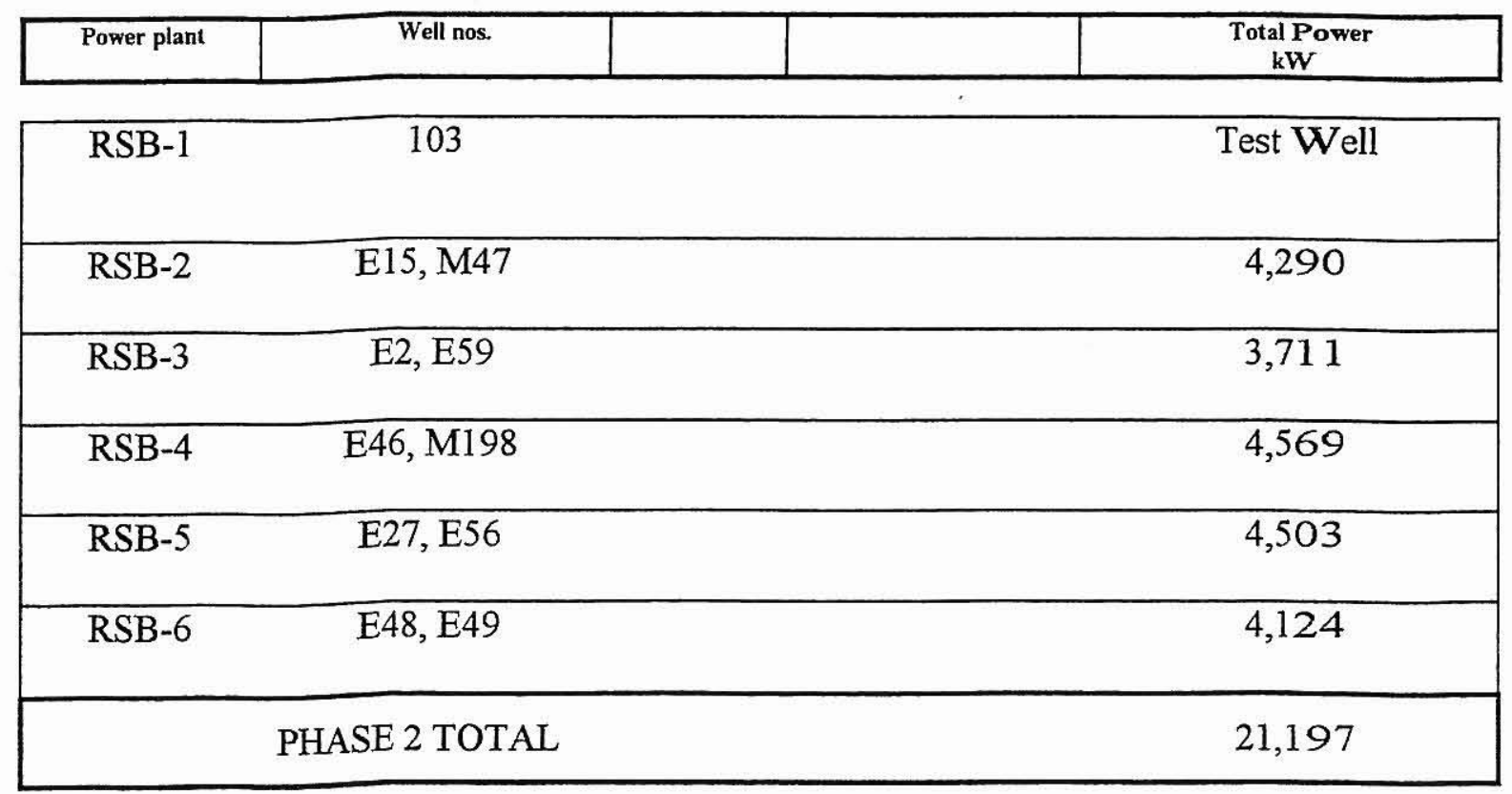


Table 13 Cost Of Biphase Plant Rsb-1, Phase 1

\begin{tabular}{|c|c|c|c|}
\hline GROUP & ITEM & COST, k \$ & TOTALS \\
\hline \multirow{6}{*}{ Engineering } & & & 767 \\
\hline & Project & 145 & \\
\hline & Mechanical Design & 170 & \\
\hline & Electrical Design & 142 & \\
\hline & Fabrication & 165 & \\
\hline & Installation & 145 & \\
\hline \multirow{7}{*}{ Mechanical } & & & 1033 \\
\hline & Turbine, Biphase & 558 & \\
\hline & Turbine, Steam & 275 & \\
\hline & Biphase Lube System & 65 & \\
\hline & Steam Turbine Lube System & 15 & \\
\hline & Speed Reduction Gears & 55 & \\
\hline & Spare Parts & 65 & \\
\hline \multirow[t]{8}{*}{ Electrical } & & & 239 \\
\hline & Biphase Generator & 58 & \\
\hline & Steam Turbine Generator & 1 & \\
\hline & Switchgear Building & 55 & \\
\hline & Switchgear \& Breakers & 45 & \\
\hline & Protective Relays & 15 & \\
\hline & Transformer & 40 & \\
\hline & UPS & 25 & \\
\hline \multirow[t]{4}{*}{ Controls } & & & 251 \\
\hline & Valves & 87 & \\
\hline & Instrumentation & 30 & \\
\hline & Control Interface & 134 & \\
\hline \multirow[t]{6}{*}{ Site } & & & 205 \\
\hline & Foundations & 30 & \\
\hline & Piping & 60 & \\
\hline & Flash Tank & 40 & \\
\hline & Electrical & 45 & \\
\hline & Insulation & 30 & \\
\hline \multicolumn{2}{|c|}{ Total Cost, Plant RSB-1, k\$ } & & 2,495 \\
\hline Spec & /kW (Design & & 580 \\
\hline
\end{tabular}


Table 14 Cost Comparison: RSB-1 To 20MW System (RSB-2 to RSB-6)

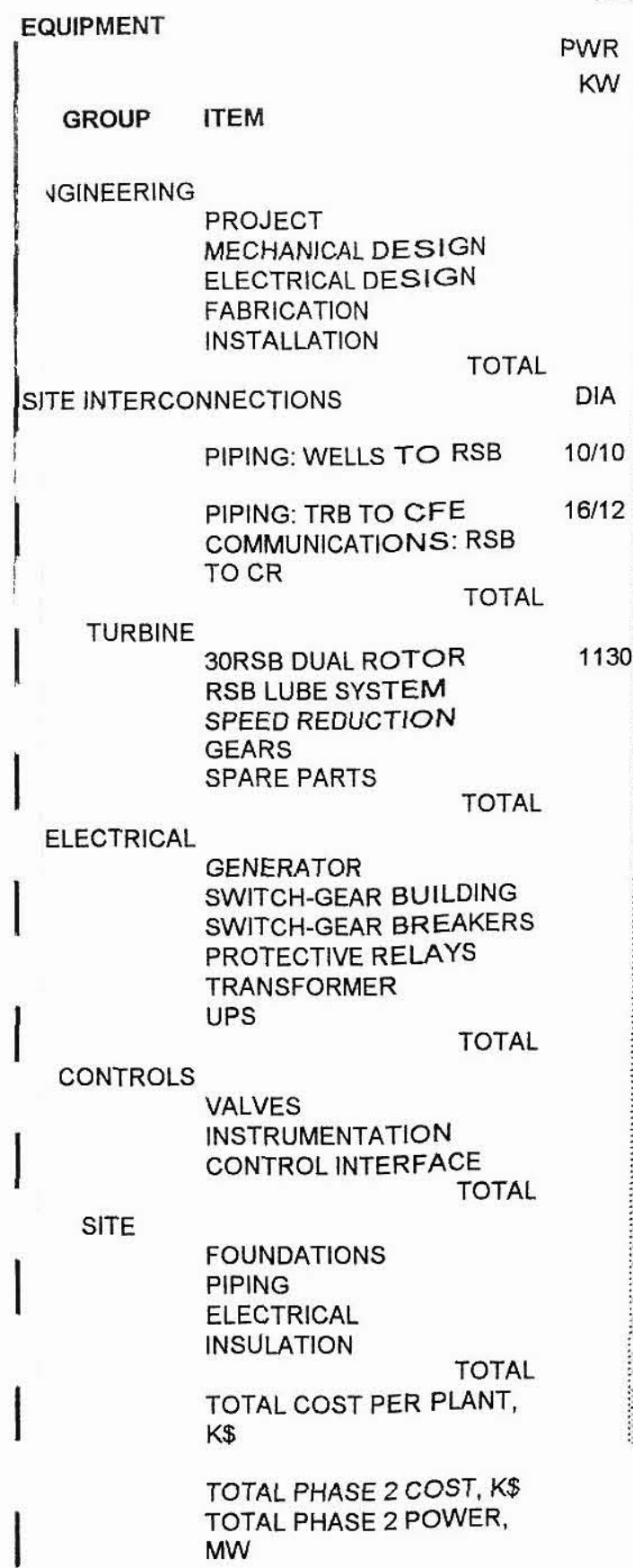

47.7
24.8
15.4
20.5
27.4


Table 15 Proforma for Phase 2 Build, Own, Operate and Transfer Project

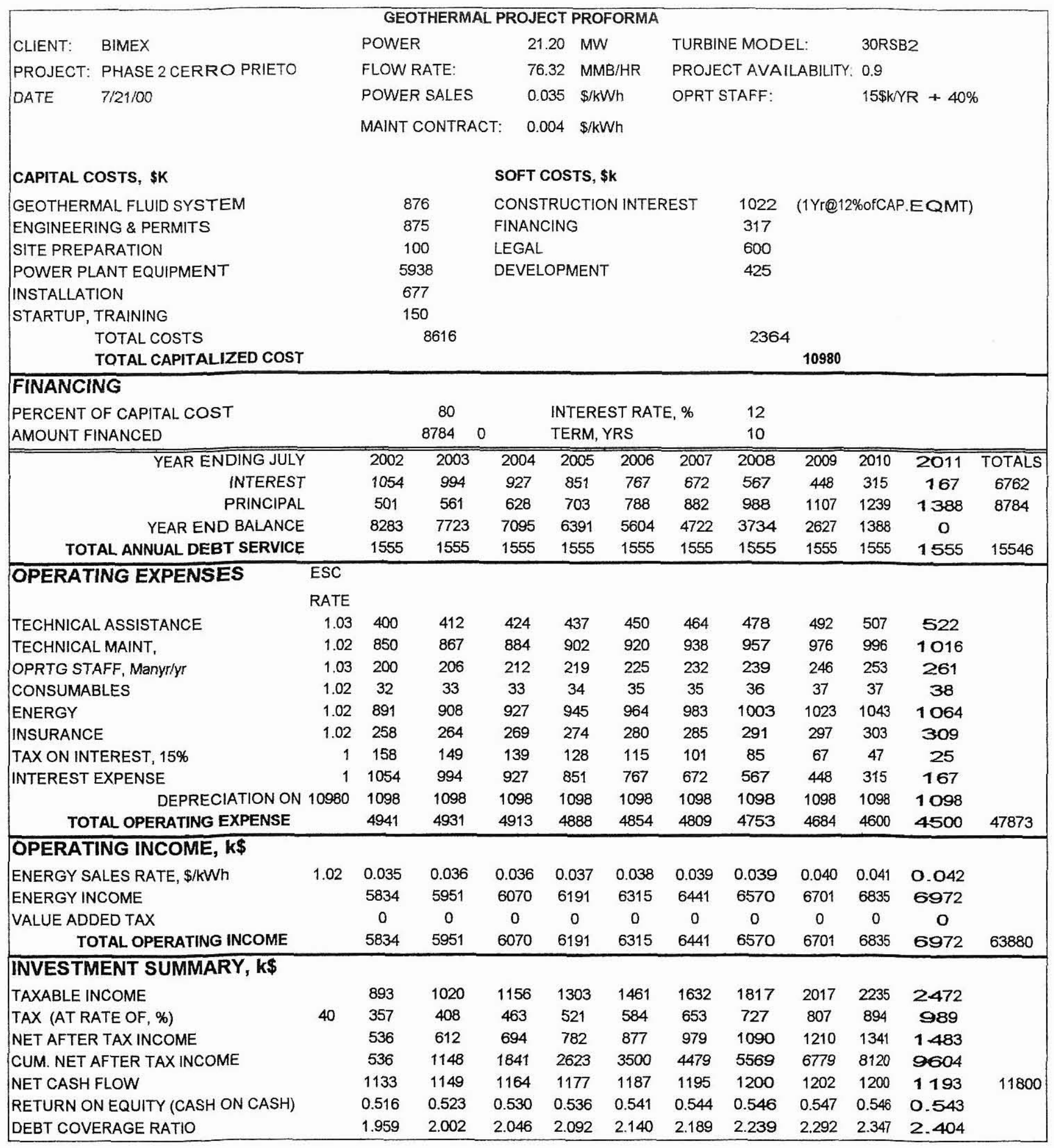


Table 16 Performance of Dual Pressure Euler Turbine For Existing Conditions at Well E-54

\author{
Nozzle Angle \\ Reaction jet Angle \\ Rotor Speed \\ Reaction jet Daimeter \\ Number of Reaction Jets \\ Inner rotor radius \\ $\mathrm{RJ}$ centerline radius \\ Nozzle Inlet Pressure \\ Nozzle Inlet Quality \\ Inlet Droplet Diameter \\ Inlet Velocity \\ Nozzle Length \\ Number of Nozzles \\ Nozzle Exit Pressure \\ Rection jet exit pressure \\ Nozzle exit velocity
}

Reaction jet velocity coeficient(liq)

Reaction jet velocity coeficient(vap)

Mass flow rate

Nozzle Inlet Ethalpy

Nozzle inlet Temperature

Nozzle Inlet Entropy

Nozzle Exit Temperature $(\mathrm{s}=\mathrm{c})$

Nozzle Exit Enthalpy $(\mathrm{s}=\mathrm{c})$

Nozzle entahlpy change $(s=c)$

Separator Velocity

Actual Noz. Enthalpy change

Nozzle Exit Enthalpy

Nozzle Exit Temperature

Nozzle exit quality

Nozzle Efficiency

Rotor Velocity

Rotor angular velocity

Reaction jet ent. Pressure

Reaction jet ent enthalpy

Reaction jet ent Temp

Reaction jet ent entropy

Reaction jet entrance quality

Reaction jet exit enthalpy $(s=c)$

Reaction jet enthalpy change $(s=c)$

RJ Exit vel (Moving frame)

\begin{tabular}{|l|r|l|}
\hline & 17 \\
\hline & 10 & \\
\hline $\mathrm{N}$ & 6250 & $\mathrm{rpm}$ \\
\hline $\mathrm{Drj}$ & 1 & in \\
\hline $\mathrm{Nrj}$ & 4 & \\
\hline $\mathrm{r} 1$ & 13 & in \\
\hline $\mathrm{r} 2$ & 16 & in \\
\hline $\mathrm{po}$ & 614 & psia \\
\hline & 0.223 & \\
\hline
\end{tabular}

\begin{tabular}{|r|r|l|}
\hline & 0.1 & in \\
\hline & 50 & $\mathrm{ft} / \mathrm{sec}$ \\
\hline & 15 & $\mathrm{in}$ \\
\hline & 8 & \\
\hline p1 & 250 & $\mathrm{psia}$ \\
\hline p3 & 200 & $\mathrm{psia}$ \\
\hline C1 & 912.19 & $\mathrm{ft} / \mathrm{sec}$ \\
\hline
\end{tabular}

\begin{tabular}{|l|r|l|}
\hline PhiRot & 0.975 & \\
\hline etav2 & 0.975 & \\
\hline $\mathrm{m}$ & 82.87 & $\mathrm{lb} / \mathrm{sec}$ \\
\hline ho & 637.13632 & $\mathrm{~b} / \mathrm{bm}$ \\
\hline To & 488.68882 & $\mathrm{~F}$ \\
\hline So & 0.8466925 & $\mathrm{~b} / \mathrm{bm}-\mathrm{R}$ \\
\hline T1 & 400.96901 & $\mathrm{~F}$ \\
\hline (h1)s=c & 616.09754 & $\mathrm{~b} / \mathrm{bm}$ \\
\hline (dhs)o-1 & 21.038773 & $\mathrm{~b} / \mathrm{lbm}$ \\
\hline Ub1 & 709.04001 \\
\hline (dh)o-1 & 18.160039 & $\mathrm{~b} / \mathrm{lbm}$ \\
\hline $\mathrm{h} 1^{\prime}$ & 618.97628 & $\mathrm{~b} / \mathrm{lbm}$ \\
\hline T1' & 400.96901 & $\mathrm{~F}$ \\
\hline $\mathrm{x} 1$ & 0.2943616 & \\
\hline (Eta)noz & -0.86317 & \\
\hline Ub1 & 709.04001 & $\mathrm{ft} / \mathrm{sec}$ \\
\hline Omega & 654.49847 & $\mathrm{rad} / \mathrm{s}$ \\
\hline p2 & & $\mathrm{psia}$ \\
\hline h2 & \multicolumn{3}{|l}{} & $\mathrm{b} / \mathrm{lbm}$ \\
\hline T2 & 412.74928 & $\mathrm{~F}$ \\
\hline $\mathrm{s} 2$ & 1.5263877 & $\mathrm{~b} / \mathrm{lbm}-\mathrm{R}$ \\
\hline $\mathrm{x} 2$ & 1 & \\
\hline (h3)s & 1182.3004 & $\mathrm{~F}$ \\
\hline (dhs)2-3 & 23.949731 & $\mathrm{~b} / \mathrm{lbm}$ \\
\hline (W3)v & 1020.8705 & $\mathrm{ft} / \mathrm{sec}$ \\
\hline
\end{tabular}


Rotor Vel

RJ Exit vel (Abs frame)

Reaction jet enthalpy change

Reaction jet exit enthalpy

Reacion jet exit quality

Reaction jet exit temperature

RJ Exit Viscosity

RJ exit Density

Nozzle Exit Liquid FlowRate

Rel. Liquid RJ exit velocity

Abs Liquid RJ Exit Velocity

Liquid Turbine Power

Nozzle Exit Vapor FlowRate

Vapor Turbine Power

Gross Power Produced

$\mathrm{RJ}$ exit enthalpy $(s=c)$

Device isentropic Enthalpy change

Isentropic Power

Overall Efficiency sans windage

Reynolds number for rotor

Windage Power

Net Power Production

Overall Efficiency with windage

Area Required to handle design flowrate

Reaction jet diameter

Noz/Sep Radius Ratio

Noz dia

Lip

\begin{tabular}{|l|r|l|}
\hline$(\mathrm{U} 3) \mathrm{V}$ & 872.66463 & $\mathrm{ft} / \mathrm{sec}$ \\
\hline (C3)v & -148.20585 & $\mathrm{ft} / \mathrm{sec}$ \\
\hline (dh)2-3 & 31.016299 & $\mathrm{~b} / \mathrm{lbm}$ \\
\hline $\mathrm{h} 3$ & 1175.2338 & $\mathrm{~b} / \mathrm{lbm}$ \\
\hline X3 & 0.9725924 & \\
\hline T3 & 381.80445 & $\mathrm{~F}$ \\
\hline MU3 & $9.252 \mathrm{E}-05$ & $\mathrm{lbm} / \mathrm{ft}-\mathrm{s}$ \\
\hline (Rhog)3 & 0.4371999 & $\mathrm{lbm} / \mathrm{ft} 3$ \\
\hline
\end{tabular}

\begin{tabular}{|l|r|l|}
\hline \multirow{2}{*}{$\begin{array}{l}\text { (ml)1 } \\
\text { (C3)I }\end{array}$} & 58.476258 & $\mathrm{lbm} / \mathrm{s}$ \\
\hline $\mathrm{PI}$ & 502.33024 & $\mathrm{ft} / \mathrm{sec}$ \\
\hline & 370.33439 & $\mathrm{ft} / \mathrm{sec}$ \\
\hline$(\mathrm{mv}) 2$ & 705.4908 & $\mathrm{~kW}$ \\
\hline $\mathrm{Pv}$ & 24.393742 & $\mathrm{lbm} / \mathrm{s}$ \\
\hline $\mathrm{P}$ & 797.83222 & $\mathrm{~kW}$ \\
\hline (h3)s=c & 1503.323 & $\mathrm{~kW}$ \\
\hline (dh)1-3 & 610.35049 & $\mathrm{~b} / \mathrm{lbm}$ \\
\hline Ps & 26.785828 & $\mathrm{~b} / \mathrm{lbm}$ \\
\hline Eff & 2124.1546 & $\mathrm{~kW}$ \\
\hline RE & 0.7077277 & \\
\hline Cm & 5498195.9 & \\
\hline Pw & 0.006551 & \\
\hline Pnet & 71.348457 & $\mathrm{kw}$ \\
\hline Eta & 1431.9746 & $\mathrm{kw}$ \\
\hline Ae & 0.67 .41386 & \\
\hline De & 0.1775591 & $\mathrm{ft} 2$ \\
\hline RR & 0.2377369 & $\mathrm{ft}$ \\
\hline Dnoz & 0.9423077 \\
hlip & 0.75 \\
\hline
\end{tabular}




\section{Table 17 Performance of Dual Pressure Euler Turbine on Flash Brine from First Stage Separator of Well E-54}

\author{
Nozzle Angle \\ Reaction jet Angle \\ Rotor Speed \\ Reaction jet Daimeter \\ Number of Reaction Jets \\ Inner rotor radius \\ $\mathrm{RJ}$ centerline radius \\ Nozzle Inlet Pressure \\ Nozzle Inlet Quality \\ Inlet Droplet Diameter \\ Inlet Velocity \\ Nozzle Length \\ Number of Nozzles \\ Nozzle Exit Pressure \\ Rection jet exit pressure \\ Nozzle exit velocity
}

Reaction jet velocity coeficient(liq)

Reaction jet velocity coeficient(vap)

Mass flow rate

Nozzle Inlet Ethalpy

Nozzle inlet Temperature

Nozzle Inlet Entropy

Nozzle Exit Temperature $(s=c)$

Nozzle Exit Enthalpy $(s=c)$

Nozzle entahlpy change $(s=c)$

Separator Velocity

Actual Noz. Enthalpy change

Nozzle Exit Enthalpy

Nozzle Exit Temperature

Nozzle exit quality

Nozzle Efficiency

Rotor Velocity

Rotor angular velocity

Reaction jet ent. Pressure

Reaction jet ent enthalpy

Reaction jet ent Temp

Reaction jet ent entropy

Reaction jet entrance quality

Reaction jet exit enthalpy $(s=c)$

Reaction jet enthalpy change $(s=c)$

\begin{tabular}{|l|r|l|}
\hline \multicolumn{1}{|l|}{ Design } \\
\hline & 20 & \\
\hline$N$ & 10 & \\
\hline$D r j$ & 1800 & $r p m$ \\
\hline$N r j$ & 1 & in \\
\hline$r 1$ & 4 & \\
\hline$r 2$ & 15 & in \\
\hline po & 17 & in \\
\hline & 200 & psia \\
\hline
\end{tabular}

\begin{tabular}{|l|r|l|}
\hline & 0.1 & in \\
\hline & 50 & $\mathrm{ft} / \mathrm{sec}$ \\
\hline & 15 & in \\
\hline & 8 & \\
\hline p1 & 100 & $\mathrm{psia}$ \\
\hline p3 & 67 & $\mathrm{psia}$ \\
\hline C1 & 269.69 & $\mathrm{ft} / \mathrm{sec}$ \\
\hline & & \\
\hline PhiRot & 0.975 & \\
\hline etav2 & 0.975 & \\
\hline $\mathrm{m}$ & 82.87 & $\mathrm{lb} / \mathrm{sec}$ \\
\hline ho & 356.34854 & $\mathrm{~b} / \mathrm{lbm}$ \\
\hline To & 381.80445 & $\mathrm{~F}$ \\
\hline So & 0.5448411 & $\mathrm{~b} / \mathrm{lbm}-\mathrm{R}$ \\
\hline T1 & 327.82283 & $\mathrm{~F}$ \\
\hline (h1)s=c & 354.09497 & $\mathrm{~b} / \mathrm{lbm}$ \\
\hline (dhs)o-1 & 2.2535627 & $\mathrm{~b} / \mathrm{lbm}$ \\
\hline Ub1 & 235.61945 \\
\hline (dh)o-1 & 1.6439934 & $\mathrm{~b} / \mathrm{lbm}$ \\
\hline h1' & 354.70454 & $\mathrm{~b} / \mathrm{lbm}$ \\
\hline T1' & 327.82283 & $\mathrm{~F}$ \\
\hline $\mathrm{x} 1$ & 0.0632055 & \\
\hline (Eta)noz & 0.7295086 & \\
\hline Ub1 & 235.61945 & $\mathrm{ft} / \mathrm{sec}$ \\
\hline Omega & 188.49556 & $\mathrm{rad} / \mathrm{s}$ \\
\hline p2 & & $\mathrm{ps} / \mathrm{b}$ \\
\hline h2 & 328.52407 & $\mathrm{~F}$ \\
\hline T2 & 1.6027372 & $\mathrm{~b} / \mathrm{lbm}-\mathrm{R}$ \\
\hline s2 & 1 & \\
\hline $\mathrm{x} 2$ & 32.34609 & $\mathrm{~b} / \mathrm{lbm}$ \\
\hline (h3)s & & \\
\hline (dhs)2-3 & & \\
\hline & & \\
\hline
\end{tabular}


RJ Exit vel (Moving frame)

Rotor Vel

RJ Exit vel (Abs frame)

Reaction jet enthalpy change

Reaction jet exit enthalpy

Reacion jet exit quality

Reaction jet exit temperature

RJ Exit Viscosity

RJ exit Density

Nozzle Exit Liquid FlowRate

Rel. Liquid RJ exit velocity

Abs Liquid RJ Exit Velocity

Liquid Turbine Power

Nozzle Exit Vapor FlowRate

Vapor Turbine Power

Gross Power Produced

RJ exit enthalpy $(s=c)$

Device isentropic Enthalpy change

Isentropic Power

Overall Efficiency sans windage

Reynolds number for rotor

\section{Windage Power}

Net Power Production

Overall Efficiency with windage

Area Required to handle design flowrate

Reaction jet diameter

Noz/Sep Radius Ratio

Noz dia

Lip

\begin{tabular}{|l|r|l|}
\hline$(\mathrm{W} 3) \mathrm{V}$ & 1165.7911 & $\mathrm{ft} / \mathrm{sec}$ \\
\hline (U3) $\mathrm{V}$ & 267.03538 & $\mathrm{ft} / \mathrm{sec}$ \\
\hline (C3)v & -898.75569 & $\mathrm{ft} / \mathrm{sec}$ \\
\hline (dh)2-3 & 12.130698 & $\mathrm{~b} / \mathrm{lbm}$ \\
\hline h3 & 1175.3504 & $\mathrm{~b} / \mathrm{lbm}$ \\
\hline X3 & 0.9951919 & \\
\hline T3 & 299.99495 & $\mathrm{~F}$ \\
\hline MU3 & 0.0001232 & $\mathrm{lbm} / \mathrm{ft}-\mathrm{s}$ \\
\hline (Rhog)3 & 0.1546495 & $\mathrm{lbm} / \mathrm{ft}$ 3 \\
\hline
\end{tabular}

\begin{tabular}{|c|c|c|}
\hline$(\mathrm{ml}) 1$ & 77.632162 & $\mathrm{Ibm} / \mathrm{s}$ \\
\hline (W3)! & 124.08297 & $\mathrm{ft} / \mathrm{sec}$ \\
\hline (C3)! & 142.95241 & $\mathrm{ft} / \mathrm{sec}$ \\
\hline $\mathrm{PI}$ & 62.213769 & $\mathrm{~kW}$ \\
\hline$(\mathrm{mv}) 2$ & 5.2378376 & $\mathrm{lbm} / \mathrm{s}$ \\
\hline $\mathrm{PV}$ & 67.000952 & $\mathrm{~kW}$ \\
\hline $\mathrm{P}$ & 129.21472 & $\mathrm{~kW}$ \\
\hline$(\mathrm{h} 3) \mathrm{s}=\mathrm{c}$ & 351.50877 & $\mathrm{~b} / \mathrm{lbm}$ \\
\hline$(\mathrm{dh}) 1-3$ & 4.8397682 & $\mathrm{~b} / \mathrm{lbm}$ \\
\hline Ps & 383.80057 & $\mathrm{~kW}$ \\
\hline Eff & 0.3366715 & \\
\hline $\mathrm{RE}$ & 474800.94 & \\
\hline $\mathrm{Cm}$ & 0.0106918 & \\
\hline $\mathrm{PW}$ & 1.3323459 & $\mathrm{kw}$ \\
\hline Pnet & 127.88238 & $\mathrm{kw}$ \\
\hline Eta & 0.3332001 & \\
\hline $\mathrm{Ae}$ & 0.4319304 & $\mathrm{ft}^{\wedge} 2$ \\
\hline $\mathrm{De}$ & 0.3707934 & $\mathrm{ft}$ \\
\hline $\mathrm{RR}$ & 0.9 & \\
\hline Dnoz & 1 & \\
\hline hlip & 1 & \\
\hline
\end{tabular}

